\title{
Recovering Borealia: \\ The Social-nature of Canada's Boreal Forest
}

\author{
by
}

William Andrew Baldwin

\begin{abstract}
A thesis submitted to
the Faculty of Graduate Studies and Research

in partial fulfillment of the requirements for the degree of

Doctor of Philosophy

Department of Geography and Environmental Studies

Carleton University
\end{abstract}

\author{
Ottawa, Ontario \\ March 2006
}

(C) copyright 2006

William Andrew Baldwin 


$\begin{array}{ll}\begin{array}{l}\text { Library and } \\ \text { Archives Canada }\end{array} & \begin{array}{l}\text { Bibliothèque et } \\ \text { Archives Canada }\end{array} \\ \begin{array}{l}\text { Published Heritage } \\ \text { Branch }\end{array} & \begin{array}{l}\text { Direction du } \\ \text { Patrimoine de l'édition }\end{array} \\ \begin{array}{l}\text { 395 Wellington Street } \\ \text { Ottawa ON K1A ON4 }\end{array} & \begin{array}{l}\text { 395, rue Wellington } \\ \text { Ottawa ON K1A ON4 } \\ \text { Canada }\end{array}\end{array}$

Your file Votre référence ISBN: 978-0-494-16663-5 Our file Notre référence ISBN: 978-0-494-16663-5

NOTICE:

The author has granted a nonexclusive license allowing Library and Archives Canada to reproduce, publish, archive, preserve, conserve, communicate to the public by telecommunication or on the Internet, loan, distribute and sell theses worldwide, for commercial or noncommercial purposes, in microform, paper, electronic and/or any other formats.

The author retains copyright ownership and moral rights in this thesis. Neither the thesis nor substantial extracts from it may be printed or otherwise reproduced without the author's permission.
AVIS:

L'auteur a accordé une licence non exclusive permettant à la Bibliothèque et Archives Canada de reproduire, publier, archiver, sauvegarder, conserver, transmettre au public par télécommunication ou par l'Internet, prêter, distribuer et vendre des thèses partout dans le monde, à des fins commerciales ou autres, sur support microforme, papier, électronique et/ou autres formats.

L'auteur conserve la propriété du droit d'auteur et des droits moraux qui protège cette thèse. $\mathrm{Ni}$ la thèse ni des extraits substantiels de celle-ci ne doivent être imprimés ou autrement reproduits sans son autorisation.
In compliance with the Canadian

Privacy Act some supporting forms may have been removed from this thesis.

While these forms may be included in the document page count, their removal does not represent any loss of content from the thesis.
Conformément à la loi canadienne sur la protection de la vie privée, quelques formulaires secondaires ont été enlevés de cette thèse.

Bien que ces formulaires aient inclus dans la pagination, il n'y aura aucun contenu manquant.

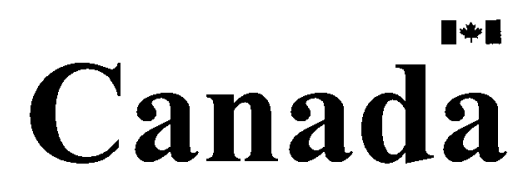




\begin{abstract}
Building on recent debates in postcolonial geography and poststructural political ecology concerning the multiple imbrications of nature and culture, this dissertation sets out to explore how the concept of nature operates as one of the dominant metaphors organizing the politics of boreal forest conservation in northern Canada. In so doing, three specific sites of nature's production in boreal forest politics are considered: forestry, the canoe expedition and forest-carbon management. In the first, it is argued that the boreal forest first attained its visibility as a contiguous space of nature within the nationalized discourse of scientific forestry in the early twentieth century. Here the nationalist rhetoric of Bernard Edward Fernow, one of North America's first professional foresters and a celebrated figure in early twentieth century conservation, is examined for the way it constitutes the northern forests of Canada as a sphere of nature with import to the Canadian imperial economy. It is subsequently argued that through Fernow's rhetoric it is possible to conceive of the boreal forest as an expression of colonial power, which is, in turn, reiterated within contemporary boreal forest conservation discourse, specific to state forestry. In the second, a media publicity campaign, which sought to draw public attention to the environmental significance of the boreal forest in 2003 , is interrogated for the way in which it constructed the boreal forest as an important site on which the narrative of national recovery could be staged. Here it is argued that through the tactical choices made by those groups politicizing the boreal forest, the canoe trip, a cherished "Canadian" pastime, becomes one of the privileged means by which such national recoveries might be experienced and lived. However, far from offering an unmediated experience with nature, it is argued that the canoe trip is predicated on an ocularcentrism
\end{abstract}


that bypasses the politics of exclusion that work to construct the boreal forest as a space of national nature. And, in the third, the discourse of forest-carbon management is examined for the way in which it constructs the boreal forest through a narrative of scarcity. It is then argued that this narrative device works as a regulatory schema governing the construction of aboriginal and Canadian national identity.

But more than simply interrogating each site for the way the boreal forest is materialized, I argue that each offers a unique vantage from which to consider the genealogical proximity of nature's production and that of Canadian national identity. By extension it is argued that recent efforts to politicize the boreal forest through a discourse of ecological modernization might also be read as a politics of Canadian nationalism. Along the way, several more arguments are advanced. First, it is argued that nature's ontological stability is neither found nor discovered in the material world, but is fabricated through the very practices that name it and is, as such, performative. Second, and closely related, it is argued that through its performativity, nature is marked by its constitutive outside, a spatial domain that must be radically foreclosed in order for nature's geography to appear. And third, it is argued that this radical exclusion, at least insofar as it works alongside representations of the boreal forest, must be considered in raced and gendered terms. 


\section{Acknowledgements}

This project was made possible by a Social Sciences and Humanities Research Council (SSHRC) Doctoral Fellowship and a SSHRC Graduate Supplement provided by the Canadian Forest Service. Additional financial assistance was provided through two Ontario Graduate Scholarships and by Carleton University.

Money aside, this project would not have been possible without the affections of so many people. At York University, I want to thank Anders Sandberg for his encouragement and support and for taking an early interest in my work, and Ilan Kapoor for challenging me to think environments in new ways. At Carleton, I want to thank Abra Adamo, Dale Armstrong, Trish Ballamingie, May Chazen, France-Lise Colin, Fiona Coyle, Andrew Dawe, Shawn Donaldson, Brian Eddy, Brian Egan, Sherrill Johnson, Tracey Lauriault, Shona Leybourne, Jamie Linton, Diego Martino, Nadine Saad, Melanie Sommerville, Paul Steenhof, Tristan Sturm, Anne Wiles, Graeme Williamson and Alette Willis for fostering such a stimulating thinking environment.

Were it not for the acuity, insight and dedication of Simon Dalby and Fiona Mackenzie, my dissertation supervisors, this project would never have happened. Both set the bar very high for me early on and for this I am most grateful. Thanks are also due to Iain Wallace and Fran Klodawsky for offering much over the years. Without the help of Hazel Anderson, Elsie Clement and Judy Donaldson, there is no doubt I would still be navigating the complex administrative geographies of Carleton University. I wish to thank each of them for their kind assistance. Thanks also to Susan Tudin for her assistance in helping me navigate McOdrum Library and to Dave Bertram and Peter Heuthorst for their technical wizardry. 
Outside academia, I gratefully acknowledge all those practitioners who took time from their busy schedules to speak to me about their work. I learned immensely from our conversations, so thank you. I also gratefully acknowledge the archival work of Louis Cardinal at the Library and Archives of Canada and Andrea Dixon at the National Gallery of Canada. To the International Institute for Sustainable Development (IISD), especially Kimo Goree, Pam Chasek and Chris Spence, I owe a special debt of gratitude for giving me the opportunity to traverse the yawning divide between theory and practice and witness multilateralism firsthand. Many thanks also to all the fantastic people with whom I have had the special fortune of globetrotting over the years with IISD. Extra special thanks are due Sylvia, Annie, James, Alex, Neel, Geoff and Sue for their friendship and support in Ottawa.

And, finally, heartfelt thanks to my family - Margaret, Patricia, Jen and Bill - for their unconditional support as I pursued what may have appeared to them an enigmatic dream and most of all to Tara, whose friendship, humour and love have contributed to this project in ways I am not sure I will ever fully comprehend.

Ottawa

January 2006 


\section{Contents}

\section{Recovering Borealia: \\ The Social-nature of Canada's Boreal Forest}

$\begin{array}{lr}\text { Abstract } & \text { ii } \\ \text { Acknowledgements } & \text { iv } \\ \text { Contents } & \text { vi } \\ \text { List of Figures } & \text { vii } \\ \text { Abbreviations } & \text { ix }\end{array}$

PART I: Nature in Question

1. Knowing Borealia 1

2. Social-naturing: Theorizing Nature, Space and Nation 36

\section{PART II: Constructing Boreal Forest Discourse}

3. Locating the Boreal Forest:

Colonial Power in the Canadian Forest Economy

4. Recovering Borealia:

Canada's Boreal Forest as Recovery Narrative

5. Settling Differences:

Canada's Boreal Forest as Scarcity Narrative

ii

vi

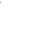




\section{List of Figures}

Figure 1.1 Canada's Boreal Region 4

Figure 2.1 Nature-Culture binary in dialectic opposition 44

Figure 2.2 1991 Canadian twenty-dollar note 67

Figure 2.3 2004 Canadian one hundred-dollar note 68

Figure 3.1 Boreal Forest Poster-Map (Front side), Canadian Forest Service Canadian Geographic $\quad 76$

Figure 3.2 Boreal Forest Poster-Map (Back side), Canadian Forest Service Canadian Geographic $\quad 77$

Figure 3.3 America, Jan van der Straet 89

Figure 3.4 Jacques Cartier rencontre les Indiens à Stadaconé, 1535, Marc-Aurièle de Foy Suzor-Coté, (1907) 92

Figure 3.5 Novae Franciae accurata delineatio, Father Bressani 99

Figure 3.6 Forest Classification of Canada, $1937 \quad 103$

Figure 4.1 Concentric filling of abstract, homogeneous nation with culturally specified space 126

Figure 4.2 Birch bark canoe on display in the National Gallery of Canada, Ottawa, surrounded by iconic images of the Canadian north 128

Figure 4.3 A Canadian Summer Boy (postcard) 156

Figure 4.4 Trudeau scouting out Figure Eight Rapids, South Nahanni River, $\begin{array}{ll}\text { Northwest Territories } & 169\end{array}$

Figure 4.5 Trudeau's companions navigating Figure Eight Rapid in a raft 170

Figure 4.6 Trudeau steering his canoe through Figure Eight Rapid, filmed from a $\begin{array}{ll}\text { canoe-mounted camera } & 171\end{array}$

$\begin{array}{lll}\text { Figure 4.7 } & \text { Suza' Tsetso offers a Dene prayer } & 174\end{array}$

Figure 4.8 Trudeau writes in his journal at day's end 175

Figure 4.9 Jim Boucher makes a speech to mark the beginning of the Athabasca $\begin{array}{ll}\text { River trip } & 178\end{array}$

Figure 4.10 Eddy Catholique enjoying a picnic lunch on the trail 183

Figure 4.11 Cinnamon buns: "Nothing beats slow food on the trail." 184

Figure 4.12 Tetlit Gwich' in elders from Fort McPherson prepare a moose carcass on willow boughs in preparation for the arrival of the Boreal Rendez-vous $\begin{array}{ll}\text { paddlers } & 186\end{array}$

Figure 4.13 Elder William Commanda at the launch of the Boreal Rendezvous in June 2003, conducting a smudge ceremony 188

Figure 4.14 Binary logic organizing visual imagery in Rendezvous with the Wild 189

Figure 4.15 Representatives of the Partnership for Public Lands and Pikangikum First Nation signing the land-use planning agreement 
Figure 5.1 Zimmermann's Meaning and Nature of Resources 210

$\begin{array}{lll}\text { Figure 5.2 } & \text { Braun's colonial rhetorics of 'wilderness' } 231\end{array}$

Figure 5.3 RTS Context Map of Northern Ontario 238

Figure 5.4 RTS Context Map depicting Road density in Northern Ontario 239

Figure 5.5 RTS Context depicting Remote Tourism Values 
Abbreviations

\begin{tabular}{ll} 
AICBF & Aboriginal Issues in Canada's Boreal Forest \\
BLC & $\begin{array}{l}\text { Boreal Leadership Council } \\
\text { CBF }\end{array}$ \\
Canadian Boreal Framework \\
Canadian Boreal Initiative \\
CFS & Canadian Boreal Trust \\
CG & Canadian Forest Service \\
CPAWS & Canadian Geographic \\
FSC & Canadian Parks and Wilderness Society \\
NRTEE & Forest Stewardship Council \\
RTS & National Roundtable on the Environment and the Economy \\
TRN & Remote Tourism Sells \\
\hline
\end{tabular}




\section{Chapter 1}

\section{Knowing Borealia ${ }^{1}$}

\section{Take One:}

The heat is on, but pockets of snow still linger in the cool shade around the edge of the cut block. The soil surface is still slightly brittle in the skidder furrows where the ice hasn't fully melted and the air is fresh. It's early May and, at seven cents a tree, I've just earned my first hundred dollar day planting black spruce in a massive clear cut one hundred and fifty kilometres northeast of Thunder Bay. A gaggle of migrating Canada Geese fly overhead and I think to myself, "man, this is wild country."

Take Two:

If I careen my neck enough, I'm pretty certain I can make out the eastern arm of Great Slave Lake. Thirty-five thousand feet below is an illimitable ocean of green. The flight path from Tokyo to Detroit passes directly overhead thousands of square kilometres of what appears to be uninhabited boreal forest.

Take Three:

Twenty some people are gathered around the boardroom table at the National

Roundtable on the Environment and the Economy in Ottawa engaged in a discussion on

\footnotetext{
${ }^{1}$ In 1864, three years prior to Canadian Confederation, the editors of The Globe, an Upper Canadian periodical, challenged its readers to name the new nation. Numerous responses were proposed, including Borealia, a derivative of Boreas, the Greek god of the north wind. For more on this history see Alan Rayburn (2001) Naming Canada: Stories About Canadian Place Names, Toronto, University of Toronto Press; and Isabelle Skelton (1921) "The Name Canada," Canadian Magazine of Politics, Art and Literature, pp.312-314.
} 
fiscal and regulatory measures for conserving Canada's boreal forest. As an observer, I sit at the side of the room, and while I find the conversation stimulating, I can't stop puzzling over what Foucault might have made of the subject.

\section{Elusive Space}

In recent years, the boreal forest of northern Canada has become an object of considerable political fascination. It has not captured the headlines in the quite the same dramatic fashion that images of tropical and temperate rainforest deforestation did in the 1980s and 1990s mind you. But, at approximately 530 million hectares (1.3 billion acres) (Lee, 2004) and home to roughly 4 million people (Henry, 2002), the stakes are certainly just as high, even more so. It has attracted the attention of a well-financed ${ }^{2}$ and tactically sophisticated environmental movement, which represents the boreal forest as a conservation opportunity with profoundly global implications that Canadians simply cannot afford to squander. The imaginations of parliamentarians and bureaucrats working at all scales of political activity have likewise been captured by the boreal's allure. So too have so many aboriginal communities located in the Canadian north, some of which have strategically anchored their hopes for a better life to the well being of the boreal forest. The science community sees in the boreal forest a wealth of veiled uncertainty. And trade interests, for well over three centuries, have identified in the boreal forest a wealth of unexploited resources and financial gain. First, it was fur. And now, more recently, the mining, forestry and energy sectors compete for the riches offered by the boreal forest.

\footnotetext{
${ }^{2}$ Between 1999-2003 Pew Charitable Trusts, a Philadelphia-based philanthropic organization, has granted slightly more than US\$16 million to boreal forest conservation projects. This information was obtained from the Pew Charitable Trust website http://www.pewtrusts.com/index.cfm on 1 September 2005.
} 
Yet, for all its apparent obviousness and its apparent Canadian-ness, the boreal forest remains for myself an incredibly elusive space (see Figure 1.1, page 4). Sitting here in my office, in the south, in Ottawa, writing this dissertation, I am at pains to experience it. Of course, with relatively little trouble I could go north to places that fall within the boreal forest region and experience it first hand. Without too much difficulty, I could get in a canoe and paddle down the South Nahanni River in the Northwest Territory. But to do so would be to experience the South Nahanni River in a canoe, not the boreal forest. Similarly, I could hike through Gros Morne Park in Newfoundland in the hope of obtaining a 'truly' boreal experience. But what could doing so possibly tell me about other 'true' aspects of the boreal forest, the experience of tree-planting in the vast clear cuts that checker the boreal forest in northern Ontario and Quebec, for instance, or life on reserve in northern Saskatchewan? I suspect very little. Ironically, I probably have a better chance of experiencing the boreal forest in its entirety from the seclusion of my cluttered office, starring, as I am, at a poster map of the boreal forest, which reminds me in no uncertain terms that the boreal forest has shaped Canada's history and economy. ${ }^{3}$

What these preliminary observations amount to is a familiar disconnect between space and place marked, on the one hand, by a desire to experience and identify with space and, on the other, by the unavoidable physical limitations imposed on us by our situatedness in place. Recognizing the Canadian boreal forest in terms of such a disconnect - between space and place, or perhaps more appropriately between space and

\footnotetext{
${ }^{3}$ I will return to discuss this image in some detail in Chapter 3 (See Figure 3.1 and Figure 3.2, page 76 and page 77 respectively). But for now it is worth noting that the cultural intelligibility of this image of the boreal forest, along with the narrative that accompanies it, trades on an innocence that is presupposed in the relation between the forested area of northern Canada and its signification in the boreal forest sign.
} 


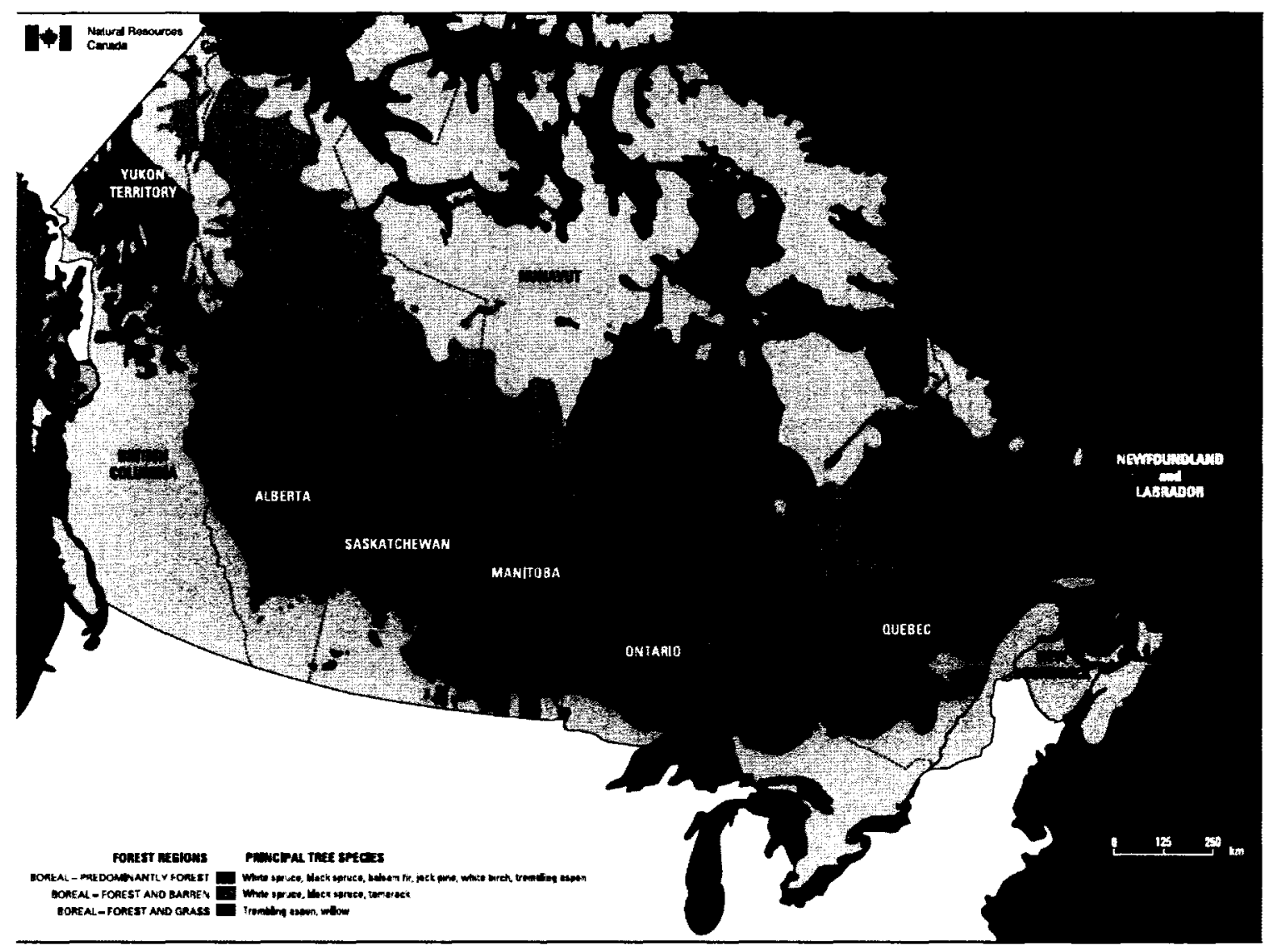

Adapted from the Fonest Regions of Canada map with permission of the Canadian Forest Service, Natural Resources Canada, 2005.

Figure 1.1 - Canada's Boreal Forest Region. Courtesy of the National Roundtable on the Environment and the Economy, Ottawa, Canada. 
places - allows for it to be understood as something more than simply a passive, bounded space or as a wall map hemmed in by a national boundary. Instead, it enables one to conceive of the boreal forest as a composite of places, movements, ethics, and histories, as opposed to simply a singular abstract ecological space with national significance. To conceive of it otherwise, borders on the impossible. The thing is just too big.

This disconnect finds a parallel in similar discussions about Canada and perhaps in debates about all forms of nationalism. To be sure, the idea of Canada might be invoked in order to confront moments of symbolic evisceration, times when the collective identity it calls up appears as though it were in jeopardy - decisions to go to war, referendums on Québec sovereignty, economic globalization, or even culturally significant hockey games. But for all the apparent certainty that Canada names a discrete space and a unique constellation of values (multiculturalism, tolerance, wilderness/north) and that people are Canadian insofar as they subscribe to those values, no single place identification whether material or semiotic comes remotely close to embodying these values in any absolute or complete sense. This sentiment is, of course, a hallmark of Canadian political culture where regional identity and province building are routinely pitted against what is often portrayed as an egregious federalism: regional cleavages said to divide neatly along the lines of western alienation, Québecois separatism, Maritime isolationism, the haves and the have nots. Similarly, no singular place identification comes remotely close to answering Northop Frye's vexing question about Canadian identity "where is here?" (Morantz, 2002). Given its national scale and boundless heterogeneity, the same might also be asked of the boreal forest. 


\section{Space and Places}

Following the French philosopher of space, Henri Lefebvre (1991), I would like to argue that this troubling disconnect between space and places provides at least some evidence that representations of space do not circulate outside the workings of ideology or power, but instead might be understood as a function of both. ${ }^{4}$ What this means in the context of Canada is that national spaces, such as aestheticized landscapes, do not prefigure their presence in national geography. Nor are they simply the stages upon which the nation's history has been and continues to be carried out. Instead, such spaces are elemental features in the exercise of power to the extent they serve as the objects of ideology and guarantee the reproduction of dominant forms of Canadian identity. Lefebvre puts a finer point on the idea when he asks, "what is an ideology without a space to which it refers, a space which it describes, whose vocabulary and links it makes use of, and whose code it embodies?" (1991:44). Ideology, in this sense, requires a direct correspondence with physical space in order to serve as its guarantor, and the guarantor of one's identity. But as Lefebvre makes clear, "ideology only achieves consistency by intervening in social space and in its production" (p.44). The internal coherence of ideology works, in other words, not because it enjoys an unproblematic correspondence with geography, but because it consists "primarily in a discourse upon social space" (p.44). Ideology makes geography. Thus, for Lefebvre, ideology maintains its

\footnotetext{
${ }^{4}$ I understand that ideology and power are clearly very different concepts and so by placing them together in this sentence and suggesting that they both have a part to play in constituting space, I do not mean to imply that their respective relationships to space are equivalent in any way. They are not. Furthermore, I understand that Lefebvre was interested in disclosing how ideology works to conceal the production of space and, in contrast, that Foucault was interested in disclosing the generative effects of productive power. These are two very different projects. I do, however, believe that Lefebvre poses an important question concerning spatial fetishism, and that this question is entirely relevant to Foucault's project. In light of this, I recognize the uneasy positioning of Lefebvre and Foucault early on in this text, but it's a creative tension that I believe to be relevant to my analysis. I shall elaborate some more on this tension in Chapter 2 .
} 
correspondence with nature, a correspondence that is actively made, the erasure of which results in what Lefebvre has famously referred to as spatial fetishism. For Lefebvre the illusion of pure space "fetishizes abstraction and imposes it as the norm. It detaches the pure form from its impure content - from lived time, everyday time, and from bodies with their opacity and solidity, their warmth, their life and their death" (p.97).

I would like, therefore, to use Lefebvre's disconnect - between the pure and impure, homogeneous and heterogeneous, bounded space and the "power geometries" that constitute place (Massey, 1999) - as an opening position from which to pose the central question that this dissertation seeks to address: how is it possible to know the boreal forest as one contiguous natural space? Or, put another way, what sort of epistemological privileging accompanies one's knowledge of the boreal forest? How does the boreal forest attain its spatial presence through such privileging? Although such questions might appear superfluous at first glance, given that the boreal forest retains such an ominous presence in the imagined geographies of the Canadian north, it is for precisely this reason I believe it is important to interrogate the boreal forest as a concept, because following what has become the stock-in-trade of poststructural analysis, it is precisely where subjects and objects appear most obviously unsullied by ideology that the productive, albeit invisible, work of power is close at hand. The boreal forest is singular and immense. The God's-eye-view from the window of an airplane bound to Detroit from Tokyo will surely attest to that. Yet somehow it gathers up an extraordinary degree of difference. The boreal forest, the signifier, is often invoked to name a collective 
biohistorical $^{5}$ experience, something that Canadians are often, if subtly, told "has shaped our history and economy" (Canadian Forest Service, 1996). But it nevertheless circumscribes a field of astonishing diversity. My question is: how?

Such a question is, for myself, however, quite daunting, for it temporarily brackets the boreal forest as a useful category for galvanizing environmental identity and political action, and forces me to ask where the concept of the boreal forest comes from, and perhaps more challenging still, how and from what cultural matrices it was fabricated. This is particularly troubling given that so much of my identity as a Canadian (however problematic such an identity might be) and someone with a predilection for environmental values (however problematic that might be) is born out of my own personal experience with the northern forest, whether tree planting ${ }^{6}$ or canoe tripping, or simply poring over maps of Canada, tracing canoe routes that I would someday like to take.

Nevertheless, answering these questions has the effect of loosening the boreal forest from its "metaphysical lodging” (Butler, 1993:30) as a natural space in Canadian environmental history, which, in turn, opens up the possibility to consider the boreal forest in other more critical ways and leads me consider a host of other questions. Who speaks when the boreal forest is spoken? And what sorts of exclusions circulate along its

\footnotetext{
${ }^{5}$ I borrow the term biohistory from Arturo Escobar (1999) “After Nature: Steps to an Anti-Essentialist Political Ecology," Current Anthropology 40(1): 1-30.

${ }^{6}$ Tree planting refers to a form of seasonal manual labour that entails the spring planting of millions of saplings, usually coniferous tree species in deforested areas throughout northern Canada. According to provincial regulations, forest concessionaires are required by law to replant previously forested areas that have been cut over. These concession holders, usually large-scale industrial producers of forest products, contract tree-planting companies who in turn hire individual planters to replant specific areas of deforested land on a piece-work basis. Given that tree planting is normally conducted in springtime, the weather conditions are often harsh. Tree planting in Canada is culturally diverse. Rural residents take part in this form of employment to supplement other forms of seasonal employment. However, a tree planting culture has also emerged over the last several decades within the Canadian university system, since the seasonal nature of the work is conducive for the employment of university students.
} 
outer edge? What is the boreal's relation to nature? To what extent, if at all, is the boreal forest implicated in the assertion of Canadian national identity? What is the boreal forest's relation to changing forms of global capital? Is it possible to understand the boreal forest as an artifact of Canadian imperial expansion? And, if so, does this artifactual-ness still resonate within the boreal forest politics of the present? How does the desperate search to re-regulate capitalism end up regulating both the self and the other? All of these questions suggest that the boreal forest is more than simply a natural space and instead gesture very strongly towards the idea that the boreal forest is as much a cultural phenomenon as it is a natural or ecological one. Following writers as diverse as Henri Lefebvre, Michel Foucault, Edward Said, Homi Bhabha and Judith Butler, it is my aim in this dissertation to suggest how this might be so.

But perhaps even more troubling, by posing these questions I am also forced into an auto-critical position, a coming to terms with my own identification as a white English-speaking male from Southern Ontario and with the colonial history from which this subject position necessarily derives, because the boreal forest, or at a minimum the figurative presence of a forested landscape dominating the Canadian north, whether I choose to realize it or not, has been elemental in the historical construction of this identity. Take, for example, a frequently cited quotation from the Canadian nationalist historian William Lewis Morton:

...this alternate penetration of the wilderness and the return to civilization is the basic rhythm of Canadian life and forms the basic elements of Canadian character. (1961:4-5)

While this certainly is a very essentialist statement on Canadian identity, it nevertheless retains at least a modicum of empirical value, for the fact that on any given Friday 
evening in the summertime the main roadways departing Toronto for the "north" are a gridlock of automobile traffic. City dwellers bound for the hinterland for their fix of "unmediated" pastoral life in the north woods, and the ex-urban "mini-van armada" (Keil \& Graham, 1998:119) returning home from a day's work. This is a movement that can be traced back to seventeenth century Jesuit cartographic representations of Huronia, to the late-nineteenth century Victorian desire for nature (Jasen, 1995), and to the Fordist movements of my grandfather, whose life as a rural physician was punctuated by routine hunting and fishing trips to the camp at Green Lake and those further afield. ${ }^{7}$ And for myself this is a movement that has played an enormous part in shaping my own identity. Growing up in Toronto in the 1970s and 1980s, the countless hours in bumper-to-bumper traffic en route to the family cottage were all too familiar. Yet it is a movement that I both embrace and resist.

In asking about how one can know the boreal forest, this play of spatial differences - south/north, here/there, civilization/wilderness, culture/nature - what for Morton constitutes the foundational experience that resides at the core of Canadian identity, must also be drawn into critical perspective. Indeed, it is not unreasonable to suggest that it is precisely these plays of difference that must be interrogated in order to gain some critical insight into one's knowledge of the boreal forest and its relationship to current forms of capitalism. I say this because knowledge takes shape around not only what it names, but also what it leaves out, or around what Foucault suggests is the difference between truth and falsity (Foucault, 1980). The production of knowledge is, in

\footnotetext{
${ }^{7}$ My grandparents lived in Brooklin, Ontario, a small agricultural community less than 30 kilometres from a large automotive assembly plant in Oshawa, Ontario. Since the mid-1990s, development interests have repackaged Brooklin as a quaint ex-urban (natural and historical) bedroom community servicing the Greater Toronto Area.
} 
this sense, a spatializing practice. Or, to put it slightly differently, knowledge is a difference producing exercise. This is not to argue that knowledge is misguided, or that knowledge-producing practices are inherently duplicitous or pathological. But it is to say that knowledge is never final or complete because its production will invariably circumscribe some but not all phenomena. It is also to argue, in line with what is by now a standard refrain in the social sciences, that knowledge is partial and 'situated' (Haraway, 1991). In the chapters that follow I will therefore direct much of my effort to sifting through the discourses of the boreal forest in order to show how they trade on such spatial differences, and put these differences into play. Equally important, I also want to consider how these differences are materialized and take effect.

Following on from this line of enquiry, another important argument I will be making throughout this dissertation is that the boreal forest is not territorial evidence of extant nature but is instead a deeply cultural space. In this regard, the argument I make is that the boreal forest does not simply materialize of its own accord into the realm of the political in the early twenty-first century, independent of modernist teleology. Nor, I argue, does it attain its status as a political unit solely at the discretion of a handful of concerned environmental groups and the scientific community that validates their claims. Instead, as I argue in Chapter 3, the moment that boreal forest entered the spatial imagination of the Canadian state in the late 1930s it became a political entity. Taking account of these relations is crucial to any understanding of the politics of the boreal forest because it is precisely these relations that give the boreal forest, along with its presence in political discourse, any kind of meaning. In other words, far from being an objective expression of nature, the boreal forest of northern Canada is a resolutely 
cultural phenomenon just as it is a biophysical one. In this dissertation I seek to draw critical attention as to how this might be so and to why it is important to think the boreal forest in this way.

\section{Normative Nature: Making the Boreal Speak}

But, if the boreal forest is a cultural phenomenon, then it is a normative one too. What I mean by this is that how the boreal forest enters into discourse matters very much when considering it in its political context because through the process of its articulation particular forms of identity attain their legitimacy as the authoritative subject positions from which the truth about the boreal forest can be spoken. This in turn normalizes not only what can be said about the boreal forest but also the very terms through which it can be legitimately spoken and, perhaps more powerful, who can legitimately speak on its behalf. A simple example illustrates the point. An ecologist can talk authoritatively about the various ecological processes that comprise the boreal forest. S/he can also talk about how the stability of such processes is threatened, and can prescribe a host of measures that might be taken to ensure such processes are not undermined. In such a scenario the ecologist retains his/her position as a legitimate spokesperson for the boreal forest. Here the language of ecology normalizes how legitimate discussions about boreal forest ecology can proceed. It is an ecological space, which must be preserved or conserved. To argue otherwise would seem almost absurd.

But such a subject position does not simply materialize out of nothing. Nor is it apolitical. Instead it must be forged, and made to appear as an unproblematic speaking entity. Its authority is established by articulating the boreal forest as an ecological space. 
But in the process other identities, what Lefebvre might have sarcastically dubbed, 'the impure', are erased from such articulations or, at a minimum, they assume a marginal status within them. To stay with the above example, ecological accounts of the boreal forest tend to say very little about the aboriginal communities that occupy so much of the boreal space. It is true that aboriginal peoples are often enlisted in political efforts to preserve or conserve wilderness space. This is especially the case when aboriginal peoples are thought of as keepers of an intimate traditional ecological knowledge that could be usefully deployed to the end of conservation. But more often than not the real presence of aboriginal peoples is overlooked when the boreal forest is rendered visible. It is the rare map, for instance, that depicts the living presence of aboriginal people in the boreal forest eco-zone. Most simply depict the boreal forest as a large green swath, emptied of any traces of human presence. Yet when they do represent aboriginal peoples, it is often done so in order to locate them as congruent extensions of the boreal forest.

Cartographic representations of the boreal forest are not the only means by which this displacement-reincorporation function occurs. All manner of representational practices from narrative writing to forestry to remote tourism and climate change policy indulge a similar oversight, or what Bruce Braun has aptly termed a "cognitive failure" (Braun, 2002:259). A less hypothetical example than the one used above can be found in a narrative appearing in a magazine published by Pew Charitable Trust, a U.S-based philanthropic organization that provides financing for environmental groups interested in conserving Canada's boreal forest. It is called Where the Wolf Stood, and was written by a cultural anthropologist named Richard Nelson. In it Nelson champions the preservation of what he calls the "near-perfect" and "immaculate" wildness of the Canadian boreal 
and along the way writes poetically about up-close encounters he has had with the wildlife that inhabit it - the woodland caribou, Dall sheep, wolves and grizzly bears (Nelson, 2005). The overall tenor of Nelson's narrative is one that celebrates boreal forest wilderness, a vast expanse of remoteness where animals range freely and the nearest road is more than three hundred kilometres in one direction, several thousand kilometres and an ocean in the other. His passion is unmistakable, perhaps even enviable. But his narrative only cursorily mentions the presence of aboriginal peoples in the boreal forest. For him, it seems that the real impulse to preserve lies with the expansiveness of the forest itself. When Nelson does draw aboriginal peoples into his account he does so only to note their dependence on caribou and to draw attention to how they are caught in a troubling conflict between their naturalized geographies and the exigencies of modern life. Aboriginal peoples it would seem feature within Nelson's account as a presence that simply lends to the boreal its distinctive wildness. That the Gwich'in and Nacho N'yak Dun First Nations have a deeply political and commercial presence in the boreal forest does not come across in his account. Such displacements are routine in boreal forest discourse.

This theme of displacement and reincorporation of aboriginal peoples in boreal forest discourse is a core theme of this dissertation, something to which I return in each chapter. I do so for a number of reasons, perhaps the most obvious being that more than one million aboriginal people, living in more than five hundred First Nation and Metis communities, are circumscribed by the boreal signifier (National Aboriginal Forestry Association, 2005). Yet, almost in spite of this very quotable fact, the lived experience of aboriginal people in the boreal forest is hardly reducible to the forest for the same reason 
that no single place identification, history, politics or ethic can be representative of the Canadian experience. The place is simply too big. The sheer heterogeneity of aboriginal experience in Canada and across the boreal forest is irreducible to either universal. The political dynamic within which the James Bay Cree struggle for recognition is markedly different than it is for Fort Mackey First Nation in northern Alberta, just as it is for Pikangikum First Nation in northern Ontario and the grandmothers and mothers of Mishkeegogamang, who live only a few hundred kilometres east. I continually return throughout this dissertation to the related themes of displacement and reincorporation, then, for one straightforward reason. In boreal forest discourse, this material heterogeneity is casually displaced by the various visual cultures that construct the boreal forest as a unified space, and is replaced by a homogenized vision of aboriginality upon reinscription. I argue that this process of displacement or exclusion is fundamental to the coherence of discourse, but also, and perhaps more important, the moment that aboriginality is reinscribed back into the boreal narrative marks the moment that aboriginality is excluded from the discourse. Something is lost from aboriginality the moment it is represented through the language of alterity. Just as for Judith Butler for whom, "the economy that claims to include the feminine as the subordinate term in a binary opposition of masculine/feminine excludes the feminine, produces the feminine as that which must be excluded for that economy to operate," (Butler, 1993:36) so too aboriginality is precisely that which is excluded for boreal forest discourse to retain its internal coherence.

Another reason I pay so close attention to the displacement-reincorporation device is that it features as a signature move in national discourse. National discourse by 
definition seeks to unify across a vast field of difference. But to produce the effect of uniformity, some radical exterior must be constituted for its interior to cohere. In boreal forest politics, this is crucially relevant because for all the apparent objectivity that accompanies the term 'boreal forest', its cultural significance trades heavily on discourses of the Canadian nation and national subject. The boreal forest signifier, in other words, conjures up images of the pristine and the pure, images like the 'north' and 'wilderness', images that have figured so importantly in the construction of Canadian identity (Grace, 2002; Hulan, 2002). In many cases this invocation is a direct appeal to national identity. In others, such appeal is not as explicit, but it is no less present. Yet such appeals to the nation and national identity are also appeals to the radical exteriority of race. Thus, following Renée Hulan, who argues that, "because Canadian national identity follows the dispossession of aboriginal people, both physically and symbolically, thinking about Canadian nationalism means thinking about race," (2002) I argue that to the extent the boreal forest conjures up a lexicon of national imagery, thinking about the boreal forest in specific discursive contexts must also involve thinking about race. Conversely, to speak about the boreal forest and not speak about race would be to overlook entirely one of the dominant cultural dynamics at play in boreal forest politics.

A third reason for my interest in displacement-reincorporation, very closely related to this, is that it suggests that environmental political discourse also enacts a similar mode of racial inscription. To say this, however, is very different from saying that environmental politics are racist or that one of the primary objectives of environmentalism is the subjugation and denigration of alterity. It is, however, to say that, insofar as spaces like the boreal forest are politicized and environmentalized through 
discourses of the nation, certain modes of environmental politics can and should be read for their implicit racialism. In other words, the categories of race and racial difference work implicitly through national identity and are subsequently maintained when such nationally focused identifications are articulated through discourses of environmental conservation. Furthermore, what this amounts to is recognition that conservation politics cannot be so easily detached from the processes of identity production.

Taken together, these twin processes of identity production, or subjectification the production of the legitimate speaking subject and the production of the marginalized abject subject - work to govern not only what these identities might become in the future but, and perhaps more importantly, how. In other words, if identity is not a stable thing, but something that it is always contested, always in state of transformation, always in a state of unfolding, as I believe it is, then how this unfolding/becoming occurs, the very terms that make being and becoming possible are crucial for understanding what is at stake in the politics of identity. Identity politics are therefore not just about who one thinks one really is. They are also about the conditions of possibility that regulate how one becomes.

My analysis, therefore, is not simply a deconstruction of the boreal forest, the object signifier. It is also very much a deconstruction of the modes of subjectivity that particular representations of the boreal forest produce. In this regard, both object and subject deconstruction must occur hand-in-hand if either is to have any political resonance. Indeed, we can engage with Haraway's method of "reflexive artefactualism" (Haraway, 1992:295) but in doing so we also need to attend to the normative effects of subject shifting that necessarily accompany reflexive artefactualism. 
One last point concerning what this dissertation is about. It recognizes that in recent years many commentators working within the field of human geography have used Judith Butler's idea of performativity to elaborate the social-ness of nature (Braun \& Castree, 1998b). It also recognizes that the use of Butler's notion of performativity in the construction of space is somewhat less theorized (Gregson \& Rose, 2000). This dissertation therefore seeks to draw these two geographical metaphors - nature and space - together into a mutual performative in order to challenge the practices of spatial fetishism.

\section{Boreal Forest in Geopolitical Context: Contours of a Movement}

In conventional geographic terms, the Canadian boreal forest biome is said to traverse the entirety of the Canadian sub-arctic, occupying a contiguous zone from Newfoundland in the east to the Mackenzie River delta in the Northwest Territories (see Figure 1.1 on page 4 ). Often included within this general formulation are three subclassifications: the taiga, the thin canopied area that lies between the boreal forest proper and the tundra to the north; the boreal forest, a predominantly coniferous forest consisting mainly of fir, black spruce, tamarack but also trembling aspen, poplar and peat; and the aspen parkland, a much smaller zone relative to the other two, also thinly canopied, interspersed with grasslands and situated between the Canadian prairie and the boreal forest to the north. Given its sheer magnitude, roughly two thirds of the Canadian landmass according to some accounts (Burton et al, 2003), it is not difficult to accept the notion that the boreal forest is ecologically significant. It is, after all, rich in biological diversity, home to thousands of woodland caribou and billions of migratory birds 
(Blancher, 2003; Savage, 2004), and is said to retain 25\% of the globe's terrestrial carbon pool (approximately 700 petagrams) ${ }^{8}$ in the form of both trees and peat (Apps et al, 1993; Intergovernmental Panel on Climate Change, 2000).

Yet, the boreal forest is not simply an ecological space. As I have already mentioned, it is also very much a human space, circumscribing as it does, several large urban centres, including Edmonton and Winnipeg, as well as hundreds of smaller resource centres, including Rouyn-Noranda, Fort McMurray and Yellowknife, in addition to well over 500 First Nation and Métis aboriginal communities (National Aboriginal Forestry Association, 2005). It is, furthermore, estimated that approximately 3.9 million people, or 14 percent of the Canada's population, live within the boreal forest (Henry, 2002:5), suggesting once again that the boreal forest is not simply an "immaculate" wild space, but also a composite of human places and movements. This human presence is reinforced by accounts that emphasize the economic importance of the boreal forest to the Canadian economy. For instance, according to the Canadian Council of Forest Ministers, forest production in the boreal forest comprises up to 60 percent of Canada's forest sector, with an export value of $\$ 26.6$ billion and $\$ 1.38$ billion in government revenue (Burton et al, 2003:2). This is in addition to the oil and gas sector in northern Alberta, the numerous hydroelectric dams, mostly in northern Quebec, a well-established metals industry, and a burgeoning diamond sector.

Needless to say given the scale of capital investment located both materially and symbolically in the boreal forest, it is perhaps not surprising that it has become a centre of political concern for so many. In what follows, I would like to offer a chronological

\footnotetext{
${ }^{8} 1$ petagram $=1$ billion metric tonnes.
} 
sketch of the boreal forest as it has emerged in political discourse over roughly the last decade. In doing so, however, I should say up front that it is difficult, perhaps even misguided, to pinpoint the precise origin of any particular social movement. Origins, like nature, are, after all, neither specific places nor objective events, but rather fictionalized sites through which cultures and identities are continuously asserted and remade. Locating the origins of the environmentalization of the boreal is, therefore, really no different.

With this in mind, I would nevertheless like to suspend this concern, if only momentarily, in order to characterize the environmentalization of the boreal forest as a relatively recent phenomenon. I say this because prior to the mid-1990s, from what I can tell, no attempt had been made to represent the boreal forest for mass political consumption in explicitly political terms. To be sure, the boreal forest has featured prominently on generic physical maps of Canada - as a scientific concept - from as early as the late 1930s. However, as a political project and as an explicit means of mobilizing environmental political identity, it is very much caught up in the politics of the present, articulated through a number of related discourses that characterize contemporary environmental politics - sustainable forest management, ecosystem management and climate change to name only a few. This is not to say that prior to the mid-1990s people did not identify with the boreal forest, nor that they were uninspired by its presence on the map. Indeed, the Canadian north, of which the boreal forest constitutes a major part, has occupied an important symbolic location in the Canadian imagination since at least Confederation. What I am saying, however, is that such inspiration was not articulated in recognizably environmental political terms until the mid-1990s when a profusion of 
boreal forest imagery entered into wide public circulation, starting with the publication of a thematic poster map of the boreal by the Canadian Forest Service and Canadian Geographic magazine.

After the mid-1990s, however, there has been a veritable profusion of political representations of the boreal forest. ${ }^{9}$ In 1996 Canadian Geographic magazine in conjunction with the Canadian Forest Service published a poster-sized map of the boreal, which is still in wide circulation (see Figure 3.1 and Figure 3.2 on page 76 and page 77 repsectively). The following year, in 1997 the World Resources Institute, an environmental non-profit group based in Washington D.C., published the findings of a preliminary research project in The Last Frontier Forests: Economies and Ecosystems on the Edge in which the boreal forest (of both Canada and the Russian Federation) was represented as the world's largest, relatively unthreatened frontier forest. This report made the further claim that due to its relatively intact status, the boreal forest represented a "great" conservation opportunity, meaning that with the right mix of planning and stewardship, boreal countries "have a real chance to keep most of their original frontier forests" (Bryant et al, 1997:49). Not long after, in the spring of 1999, the Government of Canada Senate Standing Committee on Agriculture and Forestry issued a report called Competing Realities: The Boreal Forest at Risk, based on these earlier findings. This text has subsequently become a standard point of reference for Canadian boreal forest conservation. In it, Senators Nicolas Taylor and Mira Spivak documented the importance

\footnotetext{
${ }^{9}$ By identifying a profusion of political representations of the boreal forest following the publication of the Canadian Forest Service-Canadian Geographic (CFS-CG) thematic poster map in 1996, I do not mean to imply that the CFS-CG map was the direct cause of this proliferation. If anything, this dissertation seeks to write against the cause-effect relation that characterizes conventional history. My emphasis on the significance of the mid-1990s is simply to underscore that the boreal forest is very much caught in a politics of the present.
} 
of the Canadian boreal forest to the Canadian economy, characterized it as a threatened ecosystem, and proposed a number of recommendations to safeguard it, including a conservation formula, specifying that 20 percent of the boreal should be set aside for intensive timber management, 60 percent should be less intensively managed for a number of forest values, and the remaining 20 percent should be protected for ecological and cultural purposes (Taylor \& Spivak, 1999:41). In that same year Richard Desjardins, a popular Québécois folk musician, released a documentary film entitled L'Erreur Boreale (translation: Forest Alert) in which he represented the forests of northern Québec as severely threatened by industrial capital, and made a case that the boreal forest of northern Québec is an important aspect of French-Canadian identity (Desjardins \& Monderie, 1999). ${ }^{10}$ In the summer of 2000, Laura Shaw, Ben O'Hara, Graham Nichols, and Sarah Henderson, four avid canoeing enthusiasts from Toronto, set out in their canoes on an extended expedition through northern Canada to raise public awareness about the boreal forest. Armed with a satellite phone, a laptop computer, a solar battery recharger and all their provisions for the 4500 kilometre canoe trip from Saskatchewan to the Canadian parliament buildings in Ottawa, the paddlers sent digital images and text back to the Canadian Parks and Wilderness Society (CPAWS) office in Toronto, which were subsequently uploaded onto a website from which interested observers from all over the world could track their progress. Their efforts would serve as a campaign template for a much larger media publicity campaign about the boreal forest that CPAWS would orchestrate three years later. I will address this campaign in more detail in Chapter 4.

\footnotetext{
${ }^{10}$ For more on the film $L$ 'Erreur Boreale and its effects on Québécois national identity see Anders Sandberg, Nicholas Houde and Patrick Lavoie, 2004, "Beyond L'Erreur boréale: The forest industry, environmentalism and image production in Québec, Canada," in A. Lehtinen, B. Sæter, and J. DonnerAmnell, eds., The Politics of Forests: Northern Forest Industry Regimes in the Age of Globalization. Aldershot: Ashgate.
} 
Also in 2000, Global Forest Watch Canada, an affiliate of the World Resources Institute, published a Canada-specific sequel to the Last Frontier Forests entitled Canada's Forests at a Crossroads: An Assessment in the Year 2000 in which the arguments from the first were refined and abetted with more up-to-date information specific to Canada, including detailed information about tenure allocations and a series of maps depicting Canadian forests in terms of their degrees of use and conversion. At the World Summit on Sustainable Development in Johannesburg in 2002, the same group, this time in conjunction with several other environmental and conservation organizations, ${ }^{11}$ presented to the international community a draft map entitled Remaining Wildlands in the Northern Forests, which depicted the Eurasian and North American boreal forest in terms of its degrees of intactness, and, in so doing, rearticulated the boreal forest as an explicitly global political issue (Global Forest Watch, 2002). And in the summer of 2003, the Canadian Parks and Wilderness Society staged a high-profile media campaign that represented the boreal forest as a space of Canadian national significance, linking the boreal's environmental significance to one of Canada's most sacred, yet unchallenged, cultural symbols: the canoe.

Amidst these political awakenings, several institutional developments pertaining to the boreal forest were also underway. In 2001 the Canadian Boreal Trust (CBT) was established with the aid of a US\$2.1 million grant from Pew Charitable Trust, a large philanthropic foundation based in Philadelphia, with the purpose of informing debate about the boreal forest through scientific research and support of traditional knowledge,

\footnotetext{
${ }^{11}$ These include: Finnish Nature League (Helsinki), Biodiversity Conservation Centre (Moscow), Greenpeace (Moscow), International Socio-Ecological Union (Moscow), Swedish University of Agricultural Sciences (Umeå), Conservation Biology Institute (Corvallis) and the World Resources Institute (Washington).
} 
raising public awareness about Canadian boreal ecosystems, acting as a focal point for building a common vision and understanding of the boreal, building partnerships with other organizations and groups, and providing financial support to groups and communities working on conservation issues (Taiga Rescue Network, 2002). It has also been said that part of the motivation behind establishing a national organization on boreal conservation issues derived from the fact that several provincial and regional initiatives were underway at the time and that a national group was required to consolidate the vision of these various projects into a single national vision.

Not long after it was formed, however, CBT wound down its affairs, and was reconstituted as the Canadian Boreal Initiative (CBI), which assumed CBT's mandate in 2002 with the help of another Pew grant this time valued at US\$4.5 million. In 2003 CBI received another Pew grant worth the same amount and in that same year published a 'report card' on the extent to which the Canadian federal government had followed up on the recommendations that had been spelled out five years earlier in Taylor and Spivak's Senate report. ${ }^{12}$ The report card noted that, while some progress had been made in implementing the Senate recommendations, overall much still remained to be done to conserve the boreal forest. In so doing, $\mathrm{CBI}$ carved out for itself the additional mandate of holding the Government of Canada accountable to these recommendations.

Five months later in December 2003, on the very same day that the federal government's National Roundtable on the Environment and the Economy convened the

\footnotetext{
${ }^{12}$ Data relating to Pew Charitable Trust grants issued to the CBI was accessed from the Pew Charitable Trust website on 9 December 2005. http://www.pewtrusts.com/index.cfm.
} 
first meeting of its Boreal Task Force, ${ }^{13}$ the $\mathrm{CBI}$ raised the bar on boreal conservation by publicly announcing that it had entered into a strategic partnership, called the Boreal Leadership Council (BLC), with an eclectic assortment of environmental groups, First Nations and forestry and energy firms. ${ }^{14}$ At the same time, the CBI also established what it and the members of the BLC had termed the Canadian Boreal Framework (CBF), which basically amounted to a shared vision among the members of the BLC to protect at least 50 percent of the boreal region in a network of large interconnected protected areas, and, in the remaining land base, to support sustainable communities by implementing ecosystem-based resource management practices and stewardship (Canadian Boreal Initiative, 2003). Precisely how this vision was to be implemented was never specified. But regardless, these were not inconsequential statements, particularly given that the boreal forest occupies such a sizable portion of the Canadian land mass.

Many working in the public sector at the time immediately recognized the significance of the CBF, a function perhaps of the state's complete absence in the coalition. Probably the most outspoken opposition to the CBF came, ironically, from Charles Caccia, then Canadian Member of Parliament from Toronto, Chair of the House of Commons Environment Committee, and a committed environmentalist, who argued that the CBF had no legal basis given that the land-base in question was virtually all

\footnotetext{
${ }^{13}$ The National Roundtable on the Environment and the Economy (NRTEE) is an arm's length advisory body to the Office of the Prime Minister of Canada. The NRTEE Boreal Task Force was struck to recommend to the federal government a set of fiscal and regulatory measures that could be employed to improve conservation in the Canadian boreal forest. It was established to follow-up on a series of national scale consultations on conservation, which culminated in the National Roundtable on the Environment and the Economy (2003) Securing Canada's National Capital: A Vision for Nature Conservation in the 21st Century, Ottawa: National Roundtable on the Environment and the Economy.

${ }^{14}$ The organizations involved in the Boreal Leadership Council are: the Canadian Boreal Initiative, which acts as secretariat to the BLC; Canadian Parks and Wilderness Society; Forest Ethics; World Wildlife Fund Canada; Ducks Unlimited; Deh Cho First Nations; Innu Nation; Popular River First Nation; Alberta-Pacific Forest Industries Inc.; Domtar Inc.; Suncor Energy Inc.; and Tembec Inc.
} 
Crown land (Jaimet, 2003). ${ }^{15}$ According to Caccia, the BLC had no right to pre-determine how public lands should be used. Echoing the views of some civil servants, Caccia argued that these were matters of public policy, and should not be left up to the private sector and civil society to arbitrate. Furthermore, Caccia argued that 50 percent protection was too low and that at least 80 percent of the boreal forest should be protected (Caccia, 2003).

What I find most intriguing about the CBF/BLC, however, is not so much the range of responses it has provoked, although these are very important developments, but rather that it is so difficult to categorize. Unlike other more homogeneous political coalitions, like environmental coalitions or trade associations, which often advocate a fairly uniform set of interests, the $\mathrm{CBF} / \mathrm{BLC}$ is composed of a curiously diverse set of groups, and is, in this sense, hard to make sense of. At one extreme sits Forest Ethics, an organization that deploys market tactics to encourage large-scale producers (forest companies and tenure holders) to alter their production practices and large-scale consumers (big-box retail chains) to alter their product procurement policies. At the other extreme sit Domtar, Tembec and Al-Pac, three of Canada's largest forest products producers with combined gross annual revenues of well over CDN $\$ 8$ billion. ${ }^{16}$ Needless to say, Forest Ethics wields a great deal of market clout and represents a considerable threat to the revenues of any forest company, not least those that have endorsed the CBF. Also included is the Canadian Parks and Wilderness Society, a well-established conservation group that advocates wilderness protection throughout Canada, as well as

\footnotetext{
15 'Crown land' refers to land owned by the state under either federal or provincial jurisdiction.

16 This figure is a rough estimate taken from company reports as reported by http://www.globeinvestor.com on 4 January 2005. It does not include Alberta-Pacific's revenues as Alberta Pacific is not a publicly traded company and this information was not readily available. It is jointly owned by Tokyo-based firms Mitsubishi Corporation and Oji Paper Company Ltd. and is the largest pulp producer in North America.
} 
three aboriginal communities - Poplar River First Nation, Deh Cho First Nations, and Innu Nation - located in three very different parts of the boreal forest region. The inclusion of these First Nations is important because it reflects a global trend in conservation politics, albeit a controversial one, whereby conservation groups are realizing the importance of involving aboriginal and indigenous peoples in conservation initiatives, particularly in efforts to set aside large protected areas (Chapin, 2004). Yet the involvement of these three First Nations also exposes one of the weaknesses of the CBF/BLC, since there are so many more First Nations not included in the CBF/BLC that have a stake in, not only how the boreal forest is managed, but also how it and they are represented. Needless to say this is not the sort of coalition that one would expect to have much in common. Yet, almost miraculously, it does.

Another crucial development in the emergence of the boreal forest as an object of environmental political concern was the development of a Forest Stewardship Council (FSC) forestry standard for the boreal forest region, which was finalized by the FSC Canadian Working Group in December 2003 (von Mirbach, 2004). The FSC is a forestry certification standard formed in 1993 by a coalition of nongovernmental organizations in response to the unwillingness of the International Tropical Timber Organization to establish an internationally recognized certification system that would differentiate between forest products derived from sustainably managed sources and those from unsustainably managed sources (Elliot, 1999). The FSC standard setting process operates on a consensual basis by bringing together interested stakeholder groups - environment, community, aboriginal and industry - to negotiate how sustainable forest management should be conducted in forest-ecosystems around the globe. It consists of a set of 
voluntary, global principles, but also requires that sub-regional standards be developed to take better account of the unique socio-political and ecological conditions that constitute particular regions (Forest Stewardship Council, 2000). ${ }^{17}$ Forest product producers conforming to the FSC standards earn the right to attach the FSC logo to their products. As such, the FSC concept trades on the twin premise that consumers are motivated to mobilize their purchasing power to some apparently ethical end and that they garner sufficient market demand to achieve that end. ${ }^{18}$

In the context of Canadian forestry and forest conservation, the development of the FSC boreal standard has been critical to the geopolitics of the boreal forest because, not only has it represented the possibility of stronger forestry standards and practices, it has benefited from at least partial industry support from the outset of its development. What this meant was that with some forest companies putting their support behind the standard setting process, ${ }^{19}$ there was a strong likelihood that some would actually use it in their operations. And indeed, they did. The same forest companies that have endorsed the Canadian Boreal Framework have also adopted the FSC forestry standard to varying degrees.

\footnotetext{
${ }^{17}$ For those unfamiliar with the FSC, there does exist an FSC governance structure and a corresponding set of rules, including a dispute settlement mechanism, which prescribes how stakeholders must negotiate forestry standards for particular regional ecosystems.

${ }^{18}$ Among the many pitfalls with the FSC idea is that the ethical priority to which the FSC regime is directed differs from region to region. For example, in Canada, the socio-ecological issues addressed through FSC certification might be deforestation and distribution rights to aboriginal communities. In another region of the globe, however, FSC certification may be used to address illegal logging and the trade of high conservation-value species. What this means is that the comparability of FSC wood products is very difficult. Read differently, though, this may also be the FSC's strength. The model, in effect, globalizes sustainable forest management, but leaves open for whom and to what purpose the regime may be directed. In other words, it is not exclusively an instrument for corporate green washing or cooptation. Instead, the credibility of the FSC model hinges on regional and sub-regional difference, a move that can also legitimize regional discursive power formations in the exercise of postcolonial identity.

${ }^{19}$ It should be noted, however, that by putting their support behind the standard setting process, these companies were not endorsing the standard per se but were simply expressing an interest in how the standard was set.
} 
Another institutional development concerning the boreal forest, one to which I have already alluded, was the establishment of the Boreal Task Force convened under the auspices of the National Roundtable on the Environment and the Economy (NRTEE). The Boreal Task Force met several times from December 2003 to May 2005 to formulate a series of recommendations on fiscal and regulatory measures that could be implemented to improve the conservation of the boreal forest. At the time of writing this dissertation, the Boreal Task Force's recommendations had only just been published, ${ }^{20}$ so it would be premature to comment on the task force in much detail. Nevertheless, I raise the issue of the task force at this point to signal that it represents at least one effort by the federal government to secure for itself a position within the burgeoning political discourse on the boreal forest.

A last institutional development, one that may yet prove to be the most significant in terms of the boreal forest, concerns the arrangements under the Kyoto Protocol that specify the conditions under which its signatories can include forest carbon for national carbon accounting purposes. At present, no definitive policies have been set by the federal Government of Canada that deal with the issue of forest carbon. However, given the sheer estimated volume of carbon stored in the Canadian boreal forest, it is not difficult to imagine that the environmental and economic stakes will be very high in whatever policy arrangement the government decides upon. I will say more about the boreal forest, climate change and performative identity in Chapter 5.

\footnotetext{
${ }^{20}$ The recommendations of the NRTEE Boreal Task Force can be found in National Roundtable on the Environment and the Economy (2005), Boreal Futures: Governance, Conservation and Development in Canada's Boreal, Ottawa: National Roundtable on the Environment and the Economy.
} 
In outlining these recent policy developments, it is not my intention to adjudicate which stands the best chance of conserving the boreal forest to the greatest effect. In most cases, it is simply too soon to draw any conclusions of this sort. Similarly, in drawing attention to the recent proliferation of political representations of the boreal, it is not my intention to adjudicate which of these comes closest to the truth about the nature of the boreal forest. Instead, my interest in these representational and institutional developments has to do with the very simple fact that in each it is taken as axiomatic that it is possible to speak about the boreal forest as a singular whole. Is the boreal forest one of the world's last remaining frontier forests? Has the boreal forest shaped Canada's history and economy? Does it reveal something essential about what it means to be Canadian? Is it an ecosystem under siege? Is it a global phenomenon that demands a global response? In one sense, the boreal forest $i$ all of these things. But my interest lies not in the veracity of these statements, for to pursue their veracity would be to assume that there is a singular truth about the boreal forest to which all statements about it can be reduced. I am not convinced that any such a priori truth exists. Instead, my interest is on its presence, its being, and the process by which it becomes possible to refer to the boreal forest as a singular, natural entity. This is why I have italicized the active verb in the foregoing rhetorical questions: to emphasize that my interest is on the making of the boreal's being, the making of its is, rather than the evaluation of its ought. Each of the representations and institutions pertaining to the politics of the boreal forest mentioned above gives presence to the boreal forest and has, in this sense, a part to play in its making.

Related to this is another of my concerns, one to which I have already alluded, namely a concern for the specific environmental narratives, or scripts, that make the 
boreal forest comprehensible. In this sense, my interest lies not in identifying the various discourses that contextualize the boreal forest and give it meaning, but rather in understanding how the boreal forest as a concept obtains its metaphysical presence through specific environmental narratives. There is a subtle yet important difference here. In the former, the act of identifying the pertinent discourses that enable one to comprehend the boreal forest as something - a wilderness, a national symbol, a carbon reservoir - assumes that the boreal forest has an a priori existence and that it is simply discourse that animates it as a pre-existing object. In slight contrast, however, I argue that the boreal forest's a priori-ness only takes effect through specific discursive practices. In other words, rather than accept the assumption that the boreal forest has a verifiable ontological presence, my central aim in this dissertation is to challenge this assumption by arguing instead that the boreal forest is foremost an effect of the language that circumscribes it.

In drawing attention to some of the central developments in the politics that surround the boreal forest, I also want to emphasize that the politics of the boreal forest exist in a state of unfolding. This is to say that after almost eight years following the publication of the World Resources Institute's declaration that the boreal was the world's largest, intact frontier forest and a "great" candidate for resource conservation, matters are still very much uncertain for the boreal forest. The problem of the boreal has not been solved, and the case has certainly not been closed. By this I do not mean to suggest that those who advocate conserving the boreal forest have failed. Such a view would occlude the very difficult, very time consuming, and very important work required to raise public awareness about environmental issues, particularly in a political culture that seems to 
have all but abandoned environmental matters. Instead, I wish to emphasize that, while the case of the boreal forest has only just been opened, the assumption that it can be closed - that the problems facing the boreal forest can be solved - obscures a much more fruitful, if protean, notion that political activity is an inherently open exercise. This is to say that there are no definitive ends to political activity. There are only becomings. Political victories are never final. They can only ever be fleeting. It follows that being and becoming are linked, whereby the boreal's being, the means by which it attains its presence, regulates and conditions what the boreal can become.

But, in drawing attention to these institutional developments, I also wish to emphasize that no matter how innocently or convincingly its environmental proponents might portray the boreal forest - as the last 'frontier forest' on earth, as a national icon, as an immaculate wilderness, or as a continentally-sized lung - the boreal forest always seems to bear an unmistakably cozy relation to global capitalism. In other words, each of these representations of the boreal forest implies an underlying set of problems like deforestation, metropolitan consumption and climate mitigation, and in each, the solution is an unapologetically capitalist one. Although glaringly obvious, this is nevertheless an important observation and one that needs to be clearly articulated because it suggests that the boreal forest has a part to play in resolving capitalism's ecological crisis. But perhaps even more troubling, it suggests that modern environmentalism also plays an important part in remaking capitalism and opening up new terrains of nature to capitalist accumulation and control. This brings me back to one of my original points about spatial fetishism: space, and in this dissertation, natural-space, is deeply implicated in the 
exercise of power and it plays an important function in maintaining relations of

difference under capitalism.

\section{Outline of the Argument ${ }^{21}$}

These arguments are fleshed out more fully in three empirical investigations

appearing in Part II. However, before turning to those discussions, I first outline in

Chapter 2 the methodological approach I use to structure my overall argument. The aim

21 Before I continue any further a few caveats are in order. First, and most significantly, one of the foremost problems I faced in writing this dissertation concerns the overall scale of analysis of the project itself. The boreal forest is a massive space, one that is routinely made to appear uniform. What this dissertation therefore seeks to do is disarticulate this uniformity by drawing critical attention to how the boreal forest is made to appear as such. However, in discourse analysis, where it is customary to evaluate specific discourses in order to disclose their exclusions, it is almost de rigueur to provide detailed case studies of micro-scale political struggles in order to demonstrate just how egregiously homogenizing metanarrative can be. In other words, one reads micro-level political struggles in order to explain how bodies caught up in such struggles are marked, made, constituted and so on, through meta-narrative. Such tracings are the hallmark of the analytics of capillary power.

In light of the popularity and strength of this approach, deploying it would seem a most appropriate means of critically evaluating the discursive construction of the Canadian boreal forest. Indeed to observe how the meta-narratives of boreal forest conservation condition the political possibilities at specific micro-level sites would no doubt reveal much about the identities at stake in boreal forest politics. However, I have chosen not to undertake this type of analysis for this particular project since what I really wanted to do above all else was look at the various ways in which the boreal forest itself is constructed as an object of national and environmental concern. This is not to say that I believe local-scale political struggles to be unimportant or unworthy of careful consideration in this regard. Nor is to say that nationalscale environmentalism does not generate material effects that are locally situated. Not at all. To be sure, I feel strongly that both types of analysis are crucially important to disarticulating the politics of identity production in conservationism, especially considering the overwhelming cultural heterogeneity that constitutes a 'natural' space as enormous as the boreal forest. This cultural heterogeneity needs to be heard and I can think of numerous projects of this type that I would very much like to undertake that would render more audible what are current very localized, marginalized and unheard voices. However, my interest in writing this dissertation was motivated by a different concern, namely a desire to contemplate what decolonizing the Canadian geographic imagination might entail. Thus, I have been more concerned with exposing the cultural visuality and tracing the "cognitive failures" (Braun, 2002:259) that enable the boreal forest to attain its legibility than with exploring the specific material effects of such failings. In this sense, I am inspired by a set of concerns similar to those underwriting Joel Wainwright's plea "that political ecologists should reject a realist approach that assumes that regions and spaces exist in a Cartesian world and are simply there for us to examine. As soon as we define a space or region as our object (North America'; 'the West'), we stand to lose sight of its becoming. We can forget that the very objectivity of a space is a problem to be explained, and not a scale of analysis to be embraced." (Wainwright, 2005) In this dissertation, I seek to make a space for contemplating how the objectivity of naturalized space is a "problem to be explained" and do so from the conviction that it is incumbent on those who identify as Canadian to disarticulate the implicit naturalism and objectivism that guarantee this sort of national identification. 
of this chapter is to show how the idea of nature is integral to the formation of the idea of the nation and how this conjunctural moment between nation and nature is reiterated within contemporary discourses of the boreal forest. The chapter opens with a brief rendering of current debate in cultural geography concerning the social construction of nature. I then turn to Michel Foucault to consider how representations of nature are genealogical. I will explain this in more detail, but for now what I mean by a genealogy of nature is that nature's visibility is not singular, but is instead rendered in multiple ways, through all manner of epistemological investments. Each representation of nature thus carries with it a unique genealogy, or lineage, that can be traced through previously articulated citations. Each can change over time and each can move from one context to the next. Following this brief discussion on genealogy, I then explore how the social-ness of nature can be traced through two specific analytic modes: postcolonial geography and poststructural political ecology. The remainder of the chapter explores the imbrication of nature and Canadian identity and how both are conjoined in environmental discourse.

Chapter 3 is the first of three empirical investigations. In this chapter, I use a thematic map of the boreal forest, published in 1996 by the Canadian Forest Service and Canadian Geographic Magazine, to consider the how the boreal forest is constructed through a discourse of state forestry. The aim of this chapter is to show not only how nature becomes an object of state concern, but also how the ambivalence of nature, as something to be both desired and feared, consolidates the authority of the state forester. In examining these ideas, I evaluate the discursive context of an emergent national forestry in early twentieth-century Canada through the rhetoric of Bernard Edward Fernow, an early proponent of Canadian forestry and a national forest policy. 
Chapter 4 examines a very different site of nature's production in boreal forest discourse: recreational canoeing. Here my aim is to show how what I have termed the 'national recovery narrative' works to secure the space of the boreal forest as a natural site of environmental political concern within a discourse of English Canadian nationalism. In doing so I examine one aspect of a political campaign organized by a number of Canadian conservation and environmental organizations in which several Canadian celebrities participated in a series of extended canoe expeditions throughout the Canadian boreal forest as a means of drawing public attention to the forest and to the issues it faces. This is the campaign orchestrated in part by the Canadian Parks and Wilderness Society I mentioned briefly in the previous section. In this chapter I also show how representing the boreal forest through the narrative of national recovery might be understood in racialized terms. To explore these themes I focus my attention on two media productions that represent these canoeing expeditions and that served as important awareness raising devices in the boreal forest media campaign: a made-for-television documentary film and a coffee table book of photography and text.

In the penultimate chapter, I then examine how the related discourses of wilderness and climate change construct the boreal forest through a narrative of resource scarcity and how these discourses might also be read for their implicit racialism. I conclude the dissertation by considering the implications of the argument for postcolonial geography, political ecology and nature studies. 


\section{Chapter 2}

\section{Social-Nature: \\ Theorizing Nature, Space And Nation}

Nothing is more artificial than naturalness; nothing less natural than throwing oneself at the mercy of the laws of nature.

- Zygmunt Bauman, Modernity and Ambivalence

Social nature is the nexus I have called artifactual nature.

- Donna Haraway, The Promise of Monsters

The north is not in a form. It is shorthand for the suburb's antithesis.

- Glenn Gould, The Idea of North ${ }^{22}$

The names of things were lodged in the things they designated, just as strength is written in the body of the lion, regality in the eye of the eagle, just as the influence of planets is marked upon the brows of men: by the form of similitude.

- Michel Foucault, The Order of Things

\section{Geographies of Nature}

One of the central questions I raise in this dissertation asks after the conditions that enable one to comprehend the boreal forest as a singular entity. Another equally important question asks: How is this geography? Answering both, however, begins with another question (but not one I intend to dwell on): What is geography? For myself, for better or for worse, geography comes down to this: it is the practice of putting down lines, on land, on bodies and in the mind, lines that invariably seek to create order out of chaos by delineating the field of difference from the domain of the same. These are lines that chart the limits of the known and unknown worlds, whether microscopic or

\footnotetext{
${ }^{22}$ As quoted in Peter Davidson (2004) The Idea of North, London: Reaktion.
} 
terrestrial, and the lines that, once laid down, lend a degree of predictability to human movement. In this sense, they are navigational tools that enable one to sift through the multiple intertwinings of complex political, emotional, historical and cultural landscapes. And even more, geography is about ascertaining the historical circumstances from which those lines attain their currency and become culturally meaningful. It asks about who put them there? And why? Why those lines and not others? Why do they appear where they do, when they do? Why do they change and why do they endure? So, if geography is about lines and the spaces they create, then it is, perhaps, not too difficult to accept that the act of inscribing lines has always been a deeply political undertaking. Indeed, the power to draw lines represents the power to set oneself apart from others, to secure the boundaries of the self, home and nation. But it is also, following Lefebvre, about understanding how the drawing of lines assists in the appropriation, regulation and control not only of certain spatial environments but, more poignantly, the human movements that occur within and across the fictional divides they create.

With these general comments about geography in mind, I seek to do three things in this chapter. First, I want to sketch the various analytic modes used in the dissertation: social-nature, Foucauldian genealogy, political ecology and postcolonialism. Second, I want to pay close attention to how the lines circumscribing the idea of national-nature are drawn. By national-nature, I am referring to those images of nature that are so closely associated with national identity. In Canada, such images revolve more or less within a lexicon of 'wilderness' and 'north'. This is an important undertaking because in the three central discourses I examine in this dissertation (forestry, recreational canoeing and climate change) the boreal forest is made to occupy the semiotic space opened up by national-nature such that the boreal forest is effectively reified as a national wilderness, a 
material expression of the Canadian north and, in turn, an extension of Canadian identity. As I argue in the empirical investigations in Chapters 3 and 4, the end of the nineteenth century and the beginning of the twentieth marked an important moment in the emergence of national-nature in Canada. In both chapters, I will examine the emergence of national-nature at that time in order to draw some insights about what is at stake in the contemporary politics of the boreal forest.

My third aim in this chapter, closely related to the second, is to focus attention on the role played by the boreal forest in sustaining the national subject. Here the main thrust of my argument is that the national subject, the Canadian national subject, cannot be conceived of in the absence of a set of created landscapes that seek to represent a nature that all Canadians have in common. In other words, landscapes such as 'north' and 'wilderness' are not simply symbols of Canadian identity, but assume a much more formative function in the actual making of the national subject. Again, in Chapters 3 and 4 I examine two different historical sites - the discourses of national forestry and recreational canoeing - where the national subject was constituted alongside the making of a national-nature. But in addition to the formative role that national-nature plays in making the Canadian subject and contributing to its internal consistency, I also wish to draw attention to the normative function that it plays in regulating and governing the national subject. What I mean by this is that national-nature is not simply an aesthetic image, a cognitive space, a decorative art style, or a view from the cottage window, but it also assumes a decidedly disciplinary function, albeit a very subtle one, by normalizing the visual practices by which nature becomes a recognizable entity and in turn normalizing those expressions of nature within a cognitive frame that might be construed as distinctly Canadian. 
Investigating the conditions of emergence for national-nature and the subsequent national identity to which it gives rise is important for understanding contemporary boreal forest politics because, as I have already mentioned, in each of the discourses I examine in this dissertation - forestry, canoeing and climate change - the boreal forest is constructed in no uncertain terms as a national space. However, to borrow again from Renée Hulan, a very important corollary here is that thinking about the boreal forest in national terms demands that it also be thought of in terms of race and, in light of the arguments I present in Chapter 3, gender.

But this dissertation is not exclusively concerned with deconstructing the idea of nature along raced and gendered lines. It is also very much a discussion about space or, perhaps more appropriately, it is a discussion concerning the imbrication of nature and space, since these two concepts routinely work in conjunction. At the outset, then, I should offer a reminder that at work in this dissertation is a concern for what Henri Lefebvre has called spatial fetishism or, perhaps more appropriately, the fetishism of natural space - the absence of historical explanation concerning the emergence of specific spaces as means for organizing and regulating human activity (Lefebvre, 1991). Lefebvre laments discourse theory and science for their mutual avoidance in qualifying how spatialization actually works to secure the physical spaces that give order to the material word. For him, the "structural connection" (1991:1) assumed to exist between signified and signifier is never explained in either methodology, which leads him to ask "what intervenes, what occupies the interstices between representations of space and representational space?" (1991:43) Lefebvre subsequently answers his own question by drawing together a distinctly historical materialist account of the dialectics of space. My interest, however, is somewhat different. Whereas I share Lefebvre's interest in 
identifying something called spatial fetishism, I am less interested in explaining how history and ideology work together to create space. Instead, I wish to begin with the assumption of spatial fetishism, that is to say, the recognition that "the very objectivity of space is a problem that needs to be explained" (Wainwright, 2005). But rather than staying with Lefebvre's analysis of space, I wish instead to draw from Judith Butler's notions of performativity and citationality to articulate the role played by Foucauldian power in constituting space. In moving away from Lefebvre though, I am not trying to suggest that Lefebvre's approach to space and spatialization is misguided or incorrect. Nor is it to say that performativity offers a much more accurate reading of spatialization. I am not convinced that accuracy and precision should be the central objectives of critical thinking. But it is to say that I think Butler offers a much clearer way of bringing together signs and signifieds, material and symbols, physical bodies and discourses and does so in a way that recognizes the complex, yet subtle, intertwinings of power, vision, hegemony and control. Furthermore, in my view, Butler's approach allows for a less rigid understanding of the idea of nature, whereas Lefebvre seems to invoke all too easily and unproblematically a depiction of nature that is pre-ontological, if slightly nostalgic. Take for example his ruminations on nature found in The Production of Space

Why do I say that nature does not produce? The original meaning of the word suggests the contrary: to lead out and forward, to bring forth from the depths. And yet, nature does not labour: it is even one of its defining characteristics that it creates. What it creates, namely individual 'beings', simply surges forth, simply appears. Nature knows nothing of these creations - unless one is prepared to postulate the existence within it of a calculating god or providence. A tree, a flower or a fruit is a 'product' - even if it is in a garden. A rose has no why or wherefore; it blooms because it blooms. In the words of Angelus Silesius, it 'cares not whether it is seen'. It does not know that it is beautiful, that it smells good, that it embodies a symmetry of the $n$th order. It is surely almost impossible not to 
pursue further or to return to such questions. 'Nature' cannot operate according to the same teleology as human beings. The 'beings' it creates are works; and each has 'something' unique about it even if it belongs to a genus and species: a tree is a particular tree, a rose a particular rose, a horse a particular horse. Nature appears in the vast territory of births. 'Things' are born, grow and ripen, then wither and die. The reality behind these words is infinite. As it deploys its forces, nature is violent, generous, niggardly, bountiful, and above all open. Nature's space is not staged. To ask why this is so is a strictly meaningless question: a flower does not know that it is a flower any more than death knows upon whom it is visited. If we are to believe the word 'nature', with its ancient metaphysical and theological credentials, what is essential occurs in the depths. To say 'natural' is to say spontaneous. But today nature is drawing away from us, to the very least. It is becoming impossible to escape the notion that nature is being murdered by 'anti-nature' - by abstraction, by signs and images, by discourse, as also by labour and its products. Along with God, nature is dying. 'Humanity' is killing them both - and perhaps committing suicide into the bargain. (1991:70-71)

Lefebvre's lament for the passing of a pre-ontological nature is unmistakable in this otherwise very eloquently written passage. It is for precisely this reason that I want to bracket Lefebvre's response to his own question on the grounds that I think a concern for spatial fetishism must take into account a more nuanced, socialized and genealogized understanding of nature, a nature that is continuously made and remade in specific discursive contexts, not one that sits unassumingly at the genesis of history. Before elaborating on what I take to be the most important aspects of Butler's notion of performativity as it relates to the spatial formation of the boreal forest, I would first like to consider briefly the importance of understanding nature as social and historical. 


\section{Social-naturing}

In drawing together how nature and space work together to produce nationalnature, I have found the concept of social-nature invaluable (Braun \& Castree, 2001). It is not necessary to go into any detail concerning the numerous debates and methodologies that comprise this general approach to nature studies as so many accounts of it are already in wide circulation (Braun \& Castree, 1998a; Braun \& Castree, 2001; Castree, 2005; Cronon, 1996b; Demeritt, 2002). But if I can offer a crude rendering of the core theme running through the debate, it is that nature is not a pre-social phenomenon, but instead attains its spatial presence through all manner of human involvements. It denotes the impossibility that a pre-discursive or pre-cultural nature might be said to exist outside human experience, regardless of whether such experience is characterized in historical materialist terms or through language, image and sign. In this sense, social-nature is what you get when you take seriously the idea that nature names both a constructed space and a socially infused biophysical process. Understood materially, social-nature recognizes that industrial production has held an active role in conditioning the production and biophysical reproduction of the so-called natural order. Understood discursively, socialnature gives us that an ontologically discrete nature is rendered intelligible only within the discursive regimes that make such natures possible in the first place. Such a simple schematic of the social-nature debate very clearly elides far more than it reveals, but the point I wish to emphasize here is that knowledge of nature, produced through any epistemological investment (science, religion, capitalism and so on) is not a purely objective knowledge, but is one that is always, and can only ever be, a social phenomenon. As will become clearer as I proceed, my analysis is more concerned with 
discursive formations of nature than it is with material history. Yet, as a cautionary note, this should not be taken to mean that I reject material history as an appropriate method for studying the social content of nature. It is merely to suggest, following Arturo Escobar, and consistent with Butler's notion of performativity, that any discussion of nature's materiality must also be a discursive analysis (Escobar, 1996).

The point I wish to make in this section, then, is that nature, both the idea and the material space it seeks to name, does not exist apart from the exercise of power. Instead, nature is both integral to and constructed through the activity of meaning making, whereby culturally meaningful objects, events, practices or spaces, become so by virtue of their relation to nature, while, conversely, the cultural recognizability of nature is attained and maintained through such objects, events, practices and spaces. In this sense, by fetishizing nature, by masking its material history and construction from its representation, one risks overlooking the power relations that set it in motion along with the social interests that it works to stabilize.

At this point it is worth illustrating what $I$ have in mind with the use of a simple schematic diagram. In Figure 2.1 (page 44), nature and culture are made to appear as realms that stand independent of one another. The arrows, however, indicate, albeit in a highly simplified form, the relationship that exists between the two. The top arrow indicates the path of nature's construction, while the bottom arrow is meant to draw attention to how nature is appropriated in the articulation of culture. In this sense, it is not difficult to see how both realms stand in a machine-like relation of dialectical production. But for the purpose of my overall argument, it is very important to emphasize that this is not a pre-given dialectical relation. Rather, it is an effect of and, therefore, constituted by power. This qualification is critical, because it is the construction of the nature-culture 


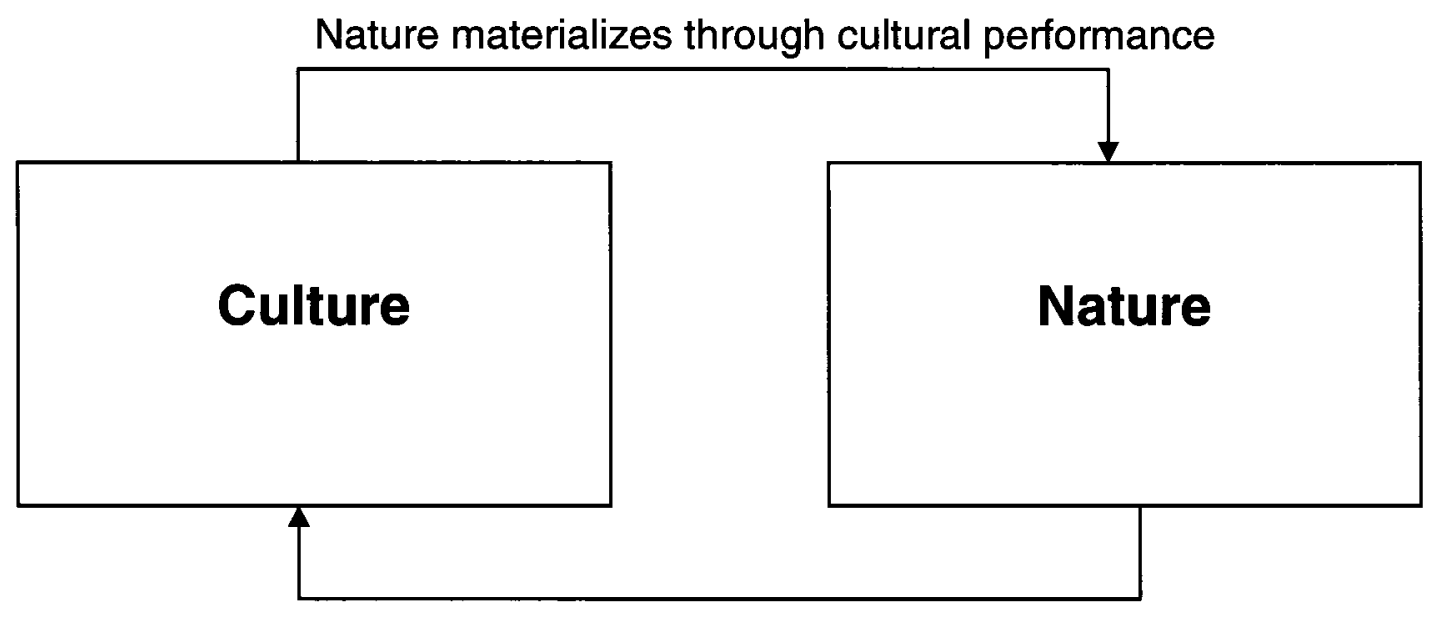

Culture appropriates referents and images of nature

Figure 2.1 - Nature-Culture binary in dialectic opposition. ${ }^{23}$

\footnotetext{
${ }^{23}$ This diagram is a slightly altered version of a similar one used by Derek Gregory (2001).
} 
dialectic that gives both nature and culture their visibility. In this sense, the world comes into view through this cultural matrix such that things attain their visibility through these opposing categories.

However, in exposing the power relations that set various forms of nature in motion, it is not so much that nature is a social construction that should come as a shocking realization, except perhaps to those who remain committed to an unmediated biocentrism. Rather, the power of a critique of nature resides in interrogating the specific social practices through which nature is constructed, practices such as the bureaucratic control of natural resources, the cultural regulation of nature through discourses of nationalism, leisure and forest policy and the economic regulation of nature through ethical consumption to name only a few. What this means is that interrogating the concept of nature in the abstract does little to expose the social relations that are sustained by it. Instead, it is only by looking critically at the various social practices by which nature is made to appear that it becomes possible to get a sense of how the concept of nature works to secure dominant social identities. This is important for several reasons.

First, nature is used routinely to signify the presence of some underlying essence, something innate about a particular object or subject. In this sense, nature is central to the process of identity formation, since so much of the act of identification is about distilling from the complex field of signs and subjective experiences the basic characteristics that define one's true self, that is to say, who one thinks one really is above all else. In this sense, the act of perceiving one's true self, one's true nature, is not just about identity, but it is also to obtain some cultural purchase within the otherwise hyper-real that marks contemporary, urban life. Amidst the chaotic, swirling imagery of the hyper-real, locating how the social is expressed through the natural therefore enables one to see more clearly 
the identities that nature works to ground. To use a simple example, appeals to authenticity in the discourse of modern nationalism are illustrative of how nature, or some variation on the theme of original experience, works to secure a particularly national form of cultural identification. In such appeals, the nation (and the 'people' it is said to represent) is rendered synonymous with authentic national experience, such that the national subject grounds his/her identity by expressing the self through particular mores characteristic of and easily recognized as national tradition. In this simple example, nature is codified as tradition and underwrites the experience of cultural (national) authenticity. The authentic experience associated with tradition, in turn, stabilizes identity by providing it with a secure set of boundaries in the otherwise hyperreal of modernity. The subject of national tradition is grounded in the experience of authenticity and, in doing so, attains for his or herself an embodied sense of the real.

Closely related to this is that, while identity is frequently articulated as who one really is, this practice of identification implicitly, but necessarily, requires the construction of some form of 'other' onto which are projected the characteristics of who one really is not. Here nature is used as a boundary marker, demarcating the space of the self and the space of the other. In the national register, the sign of nature marks a similar demarcation between national identity and an identity that exceeds the nation and cannot be circumscribed by it easily. The central argument here is that only some natures count in the production of culturally meaningful national identity, whereas other natures, those that exceed the boundaries of familiar nature, are actively repudiated. Thus, as mentioned earlier, nature and culture limit one another.

Third, by tracing genealogies of nature across a range of sites and discursive practices, it can be shown that nature is context specific, contingent on all manner of 
events, cultures, places and times. Such tracings, in turn, allow for the recognition that nature is particular to the specific culture it animates, thus challenging the universalizing logic that so frequently accompanies the idea of nature. In this way, it is more appropriate to speak of multiple, situated natures, as opposed to simply one, grand unifying nature to which all of humanity is equally subject.

And last, perhaps the most important rationale for asking after nature's social-ness is that by examining nature as a function of social practice we can locate specific historical forms of nature and, in turn, attempt to come to terms with how nature might be implicated in the continuous spatial unfoldings of capitalism. This is crucial because all too characteristic of capitalism is a contradictory tendency towards both fragmentation and unity (Gregory, 1994) - capitalism destroys nature, but it also promises to restore nature to its original form. As Harvey insists, through time-space compression capitalism accelerates the experience of modern life and in so doing collapses the institutions of modern capitalism and gives way to conditions of hyper-modernity and social fragmentation (Harvey, 1990). Yet, capitalist discourse also holds out the promise of redemption and unity. Ecological and reflexive modernity provide good examples of this redemption narrative insofar as both promise to salvage capitalism from its propensity for crisis. In both, capitalism is routinely represented as the means by which nature can be saved and ecological prosperity restored throughout the world. In matters of policy, the discourse of sustainable development offers many of the same promises. A critical question that emerges from this, therefore, is that if capitalist discourse promises to ameliorate its own contradictions by 'saving nature', whose nature does capitalism seek to save? Where does this nature come from? Whose history does it name? Whose sense 
of fragmentation and loss is being recuperated through its restoration? And what forms of value are being created and valorized through the process of nature's recuperation?

These are complex questions and, as I have already strongly alluded, ones that are impossible to answer using the same general terms by which they have been posed. The idea of nature is simply far too slippery and unwieldy for it to be reducible to any singular formulation. Moreover, capitalism itself is geographically far too diffuse, dispersed and contradictory for its relation to nature to be reducible to any singular history. Instead one needs to consider very carefully the specific discourses of capitalism through which nature is made to appear in order to gain an appreciation for the specific identities to which it gives rise. Such an approach to critiquing nature points to the utility of Foucault's idea of genealogy for tracing the emergence of such discourses. In what follows I offer a brief explanation of Foucault's idea of genealogy and how genealogy can be used to illuminate the social-ness of nature.

\section{Genealogy}

For Foucault, genealogy is a method of critique used to illuminate the contingencies constitutive of the present. In using genealogy, Foucault sought to show that the present is not an objective experience or event, but is fully crossed over by relations of power. In carrying out his genealogical surveys, however, Foucault was not at all interested in privileging conventional history or historical narrative as the exclusive means for drawing meaning from present day events. Instead, he was more concerned with demonstrating the contingent nature of the present and with showing how the present is something that emerges out of continuously shifting fields of discourse, as opposed to it being a singular moment in the fluid unfolding of time. To do so, he sought 
to show how the subjects and objects of contemporary discourse are not the fully autonomous agents of reality they are often assumed to be, but are themselves constituted by the discursive fields within which they circulate.

For Foucault, historical analysis and genealogy are radically different methodologies each serving radically different ends. He argued that conventional history, in its preoccupation with excavating the past to reveal origins - origins of knowledge, morality, identity, space, nature and so on - produces identifications of self that unproblematically correspond with these origins. Drawing from Nietzsche, Foucault argued that conventional history "always encourages subjective recognitions and attributes a form of reconciliation to all the displacements of the past" and was primarily about "dissolving the singular event into an ideal continuity - as a teleological movement or a natural process" (1984:88). As such, the practice of conventional history takes on the quality of collating highly differentiated events, disparately situated across both space and time, into a singular historical trajectory and subjectivity that presupposes its own internal logic. According to this reasoning, it is precisely the job of the historian to objectify this internal logic by letting the events (and subjects) of history speak for themselves, while rendering invisible his own interpretive positionality. For Foucault, then, "the historian's history finds its support outside of time and pretends to base its judgements on an apocalyptic objectivity" (1984:87).

Marxian and nationalist histories both provide good examples of how this sort of historical narration, one that "encourages subjective recognitions," works to objectify the past. The fundaments of Marxist history are the histories of class formation and class conflict, which are underwritten by a dialectical process driven by the labour process and mediated through the logics of capital. The spatial expression of this dialectical relation is 
an uneven pattern of development and accumulation (Smith, 1984). According to this sort of Marxist narrative, the historian could rationally account for the occurrence of past events by observing how the capitalist and labouring classes have interacted historically, either through conflict (general strike or revolution) or consensus (the Fordist compromise), and by reducing these interactions to the ways in which capital organizes the production process and in turn affects the social process (exchange, distribution, quotidian life). In Marxism, then, history assumes the quality of an object to be studied and, as such, can be used to approximate the historical truth underlining collective forms of subjective experience. By this logic, the Marxist historian may speak about the working class as a singular entity by arguing that the experience common to the working class has been the commodification of its labour into the abstract labour form by the historical circulation of global capital. Similarly, a nationalist variation on the objectivity of history would have it that history universalizes experience and organizes collective identity by narrating the triumphs and catastrophes, victories and sacrifices, of the past. In either case, the present, understood in this case as an objective event - globalization for example - obtains its legitimacy as a universal context and unified field of experience because it is expressed and subsequently understood as the culmination of past events (Poster, 1989), where the past collapses seamlessly into the present.

In using genealogy, however, Foucault was less concerned with verifying the causality of events that comprise conventional histories, than he was with tracing the conditions that made possible particular, and even universal, knowledges, about the world. For him, knowledge is neither an absolute, nor a direct, reflection of some underlying truth about the world, but is instead highly contingent on power. In this sense, knowledge and power, while distinct, are functionally related. This view is captured quite 
succinctly in a frequently quoted paragraph from Discipline and Punish in which

Foucault suggests that:

Perhaps, too, we should abandon a whole tradition that allows us to imagine that knowledge can exist only where power relations are suspended and that knowledge can develop only outside its injunctions, its demands and its interests. Perhaps we should abandon the belief that power makes mad and that, by the same token, the renunciation of power is one of the conditions of knowledge. We should admit rather that power produces knowledge (and not simply by encouraging it because it serves power or by applying it because it is useful); that power and knowledge directly imply one another; that there is no power relation without the correlative constitution of a field of knowledge, nor any knowledge that does not presuppose and constitute at the same time power relations. These "powerknowledge relations' are to be analysed, therefore, not on the basis of a subject of knowledge who is or is not free in relation to the power system, but, on the contrary, the subject who knows, the objects to be known and the modalities of knowledge must be regarded as so many effects of these fundamental implications of power-knowledge and their historical transformations. In short, it is not the activity of the subject of knowledge that produces a corpus of knowledge, useful or resistant to power, but powerknowledge, the processes and struggles that traverse it and of which it is made up, that determines the forms and possible domains of knowledge. (1977:27-28)

In this passage - and this is perhaps the most crucial point I draw from Foucault Foucault makes the case, in no uncertain terms, for the imbrication of power and knowledge, and that knowledge, and the subjects and objects that knowledges illuminate, are the effects of power. What this means is that things, for Foucault, do not possess an objective existence outside of the relations of power and discourses that constitute them. The same holds for subjectivity. Genealogy suggests that specific forms of subjectivity cultural, sexual, national and so on - are to be understood as the effects of power, not as ontologically pre-given forms of identification. By doing genealogy Foucault, therefore, 
deliberately challenges the idea that things, whether objects or subjects, have inherent or innate essences that exist outside the realm of power.

But how exactly does power work to stabilize subjectivity? Answering this question was among Foucault's main preoccupations. But at no point did he offer an explicit theory of power. Doing so, he thought, would presuppose a historical objectivity to power, which is precisely the sort of analysis that he was trying to avoid. Instead, he proposed an "analytics of power: that is: toward a definition of the specific domain formed by relations of power, and toward a determination of the instruments that will make possible its analysis" (1977:82). One of the instruments, then, that makes possible an analysis of power is the idea of political technology, since it is through political technology that power is exercised and truths come into effect. Here, knowledge and truth making are political technologies complicit in the exercise of power.

The two following passages from The History of Sexuality capture very cleanly what Foucault had in mind when he spoke of knowledge and truth as integral to the exercise of power.

Truth is a thing in this world: it is produced only by virtue of multiple forms of constraint. (Foucault, 1980:131)

The intellectual can operate and struggle at the general level of that regime of truth which is so essential to the structure and functioning of our society. There is a battle 'for truth, or at least 'around truth' - it being understood once again that by truth I do not mean 'the ensemble of truths which are to be discovered and accepted', but rather 'the ensemble of rules according to which the true and the false are separated and specific effects of power attached to the true', it being understood also that its not a matter of a battle 'on behalf ' of the truth, but of a battle about the status of truth and the economic and political role it plays. (Foucault, 1980:132) 
In the first passage, Foucault is clearly not denying the existence or possibility of truth, as some of his critics seem to contend (Taylor, 1984). Instead, Foucault is alluding to the idea that truth making is a mechanical activity made possible by constraint; truths are made by virtue of what they exclude. In the second, he specifies that the rules governing constraint, namely those permitting or disallowing the delimitations between truth and falsity, constitute the domain of the political. Taken together, both statements suggest that the mechanics of truth making are political. Through mechanical truth making devices, such as constraint, some forms of knowledge are permitted entry into the realm of truth and deemed to be legitimate, whereas others are denied such entry. In this sense, truths, and the discourses authorized by truth and truth making activities, are contingent on the moment of the outside, the relegation of things to the realm of falsity, the making of the other. Understanding the act of constraint as technological is, therefore, crucial for Foucault's analytics of power, not only because it locates in the modalities of construction, distinction, differentiation and dissemination the exercise of power through the discursive circumscription of objects and subjects, but also because, as a technology, constraint is mobile (Dreyfus \& Rabinow, 1982), can be made to do work in the realm of meaning making and, as such, can be applied strategically from one context to the next.

One of the core presuppositions underwriting the arguments I make in this dissertation, then, is that, while entities, truths, natures, spaces, essences - those elements that constitute our existence and that impel our identities into being - may have the appearance of being pre-ontological and, therefore, absolute, they are made to appear, as such, not by virtue of their inherent-ness, but through and as a result of the exercise of power. Internal to the exercise of sovereign power, according to this mode of analysis, therefore, is the constitution of some outside, some external realm, made available to us 
(the subjects of our experiences) through the act of representation, representations that derive not from the objective thing in itself, but through the construction and recognition of difference.

Genealogy is therefore a methodology concerned with exposing the discursive legacies that organize subjectivities, intersubjectivities and subject-object relations, as these are exercised through present-day contexts. For Foucault, the practice of genealogy is twofold; it elaborates the emergence of the modern subject as an object to which the methods of reason - science, logic - can be applied, and about which contingent truths can be drawn and ethics formed; and it traces the emergence of objects themselves into the realm of knowledge. Such a critique, however, is not motivated by a nihilistic desire to dispose of those epistemological practices that forcibly delimit the inside and outside of knowledge. Rather, it is motivated from an ethical position that takes the opposite view, which is that signs and the 'objects' they name do not necessarily correspond to what is universally true, and that because of this non-correspondence it is incumbent that we assume a reflexivity vis-à-vis the conceptual apparatuses we invoke when positioning ourselves in certain discursive contexts.

Bringing Foucauldian genealogy to bear on the concept of nature means that specific socio-natures are constructed through triangulations of space, nature and self. What I mean by this is that not only are the concepts of nature and space co-productive, but also that their mutual articulation is integrally related to the construction of subjectivity. In effect, specific cultural narratives of nature constitute the self. But here I should also add that there is no one definitive means of tracing these triangulations; they could conceivably be pursued through any number of methodologies. In this sense, the idea of social-nature has no real methodological home. In fact, to assign it a home would 
seem counterintuitive to the social-nature project itself, since the act of social-naturing is a boundary confusing exercise that seeks to disrupt the rigid demarcations that homing implies. Instead, by using virtually any combination of critical methodologies the socialness of nature can be exposed. By extension it might be argued that the subject produced through nature's construction does not have a definitive 'home' either, which is to say that the subject is not an entity existing outside the field of generative power, nor that it occupies a purely stable space.

Tracing genealogies of the nature-space-subject formation has important consequences for understanding the idea of national-nature because through such tracings it becomes possible to locate the moment when various discursive practices converged and produced specific national spaces and its corresponding subjects. The importance of genealogy in this sense is to demonstrate how the national subject and the nation itself are immediately linked to the enumeration of nature in specific discursive settings that occurred in the past. In tracing such a genealogy of the boreal forest, I have chosen to trace the boreal's sociality through two related fields of inquiry: poststructural political ecology and postcoloniality. The reason I have chosen to do this is because central to both ideas is the idea of nature. Yet, both invoke the idea of nature very differently.

\section{Poststructural Political Ecology}

As a methodology, poststructural political ecology is important not only because it recognizes the constructed-ness of nature, but also because it gives us that environmental politics can be understood less as political struggles over the protection and control over environmentalized space than as struggles over the discursive strategies by which spaces themselves are environmentalized, by whom and to what semiotic and 
material end (Escobar, 1996; Peet \& Watts, 1996a; Peet \& Watts, 1996b; Peet \& Watts, 2004). There are several implications that follow from this.

First, through the lens of poststructuralism, environmental politics are understood less as struggles over the institutionalization of environmental ethics - the creation of environmental legislation and regulation or re-embedding markets towards a socioecological end, for instance - and more as struggles over how environmental ethics are made in the first place. For Arturo Escobar, the emphasis here is on anti-essentializing nature, demonstrating how nature does not, cannot, assume an objective form outside the historico-discursive contexts within which it emerges. By showing how biophysical processes are related both to material history and to discursive investments into smooth space, Escobar's aim is to show how natures are not timeless essences but biohistorical (1999:4). His interest here, however, is not simply in showing how nature is cultural; this sort of analysis now figures as a standard hallmark for virtually anything that might be labelled poststructural. Rather, Escobar's interest is in articulating how certain logics of capital mediate "between natural and social systems" (1996:48). For Escobar, there are two dominant means by which capital mediates society's relation with nature and contributes to capitalist production and social reproduction. The first is what he called a modern view of capital whereby nature is coded as a resource available to exploitation. The second is a postmodern resignification of nature, whereby nature is codified as an essential ingredient to capitalism itself, and where ecological managerialism and sustainable development become core values in overcoming the second contradiction of capital (O'Connor, 1994:154). ${ }^{24}$ In either case, the point that Escobar is making here is

\footnotetext{
${ }^{24}$ James O'Connor's 'second contradiction of capital' refers to the tendency for capital to erode the ecological conditions of its own production and reproduction. For instance, under the second contradiction,
} 
that natures are constructed through specific moments in the historical unfolding of capitalism and that it is through these moments that specific naturalist ethics are formed.

A second implication follows from this. If poststructural political ecology is in part about recognizing the discursive contexts through which nature is produced, then clearly this discursive context will change from setting to setting and from historical period to historical period. This is what Peet and Watts mean when they deploy the term "regional discursive formations." (Peet \& Watts, 1996b:15). For them regional discursive formations are the specific historical-geographical contexts within which nature is fabricated, contested and negotiated. Thus, nature's construction in one discursive setting is not universally applicable to all settings.

Third, recognizing nature's construction does not simply amount to a critique of nature for the sake of critique. Nor does it propose that environmental politics be dispensed with on the simplified grounds that because nature is a construction or an effect of power it retains little political utility. On the contrary, poststructural political ecology never gives up on the need to secure liveable and habitable futures; $;^{25}$ such futures are very much a part of the poststructural modus operandi. Poststructural political ecology deliberately seeks out these futures, and does so by redirecting the terms of environmental debate away from the use of rigid, universalizing notions like culture, nature and nation, and towards new articulations of biohistorical nature that are "conducive to more just and sustainable social and ecological relations" (Escobar, 1999:4). In this sense, when examined from the vantage of poststructuralism, environmental politics become less concerned with safeguarding space-bound natures

productive soil is degraded, forests are converted and the environmental services they provide are lost, and rivers and aquifers are drained.

${ }^{25}$ I borrow the term "liveable future" from Bruce Braun (2000). 
(material and semiotic) from industrial intrusion than with negotiating sustainable outcomes that are pluralistic and just. This is critical because it suggests that poststructuralism is not 'anti-environmental' but is instead unwilling to accept that environments are ahistorical and not crossed over by power. This points to a recurring theme in deconstruction best captured by Gayatri Chakravorty Spivak, who argues, "the most serious critique in deconstruction, is the critique of something that is extremely useful, something without which we cannot do anything" (Spivak, 1993 as quoted in Butler, 1993). Donna Haraway has brought this idea to nature, arguing, "nature is for me...one of those impossible things... which we cannot not desire" (Haraway, 1992). What both Spivak and Haraway seem to be saying here is that, for all its imperfections and all its social inflections, nature remains a crucial category for understanding the present yet one that is impossible to come to terms with in any complete sense. Instead, the idea of nature must be constantly grappled with in order to prevent its reification as a singular, universal, ahistorical point of reference; their point being that as a point of reference, nature is continuously shifting and must never be made to rest.

The central theme I would like to emphasize coming out of this brief discussion of poststructural political ecology is that the field places great import on the discursive constitution of the natures that are deployed in ordering the world. In this sense, following Jacques Derrida, it is my goal in writing this dissertation to put the idea of nature sous rature (English translation: "under erasure") by which I mean to challenge its metaphysical presence as singular and knowable in any objective sense (Derrida, 1974 as quoted in Spivak, 1974). More specifically though it is the boreal forest, nature's signifier, that I will hold under erasure in this dissertation. Instead, by disclosing the boreal forest's traces, drawing attention to the always present absences that make its 
identification possible, I want to disrupt those invocations of the boreal forest that assume its unproblematic (k)no(wa)bility as a space of nature.

\section{Performativity of natural space}

Aiding me in disclosing the boreal forest's human traces, Judith Butler's notion of performativity has been invaluable. Although Butler developed her notion of performativity with an explicit emphasis on gender performativity (Butler, 1990) and subsequently refined her work to address body materiality in terms of performative gender inscription (Butler, 1993), her work on the body has been taken up by some scholars working on questions of the social construction of nature (Braun \& Castree, 1998b). I will come back to this usage of the performative momentarily, but before I do let me offer a cursory sketch of Butler's notion of performativity.

For Butler, "performativity must be understood not as a singular or deliberate 'act,' but, rather, as the reiterative and citational practice by which discourse produces the effects that it names" (1993:2). By this she means that an entity, in her case gender, does not assume its coherence, as such, outside the discourses that construct it. In other words, gender is not an innocent field situated outside the messy intertwinings of power upon which discourses merely come to settle, but instead gender difference comes into being, is given ontological form, through discourses that invoke gender. However, in response to her critics who argued that her theorization of gender performativity fell short of accounting for the materiality of the body, Butler pressed her argument further, suggesting that the body's materiality, or more specifically the materiality of the sexed body, is impelled through a similar iterative process where discourses on sex play a decidedly regulatory function over the materiality of sex by reiterating and citing 
previously established norms that qualify what counts as a legitimately materialized sexed body. In this respect, a regulatory schema, not the body itself, governs the materialization of the body. Critical for Butler in this regard, therefore, is the idea that a legitimately sexed body must also imply an illegitimately sexed body; the subject of sex must also imply a corresponding abject such that the subject and abject are not functionally distinct, but necessary correlates. Thus the regulatory schema of the body works through inscription but its coherence as an inscription device is sustained through the violent repudiation of the abject, what Butler has termed the constitutive outside. However, the persistent presence of the constitutive outside along the perimeter of the subject renders the materialization of the subject an always incomplete task such that the subject itself is a paradoxically unstable entity. In other words, by seeking to stabilize itself through performative identificatory acts, the subject creates the conditions of its own instability by giving rise to an abject body that haunts the limits of the subject thus necessitating further rounds of performative practice. Thus a fully secure subject is an impossibility held together, however precariously, by a series of continuously repeated acts.

I draw three arguments from Butler's idea of performativity and apply these in my theorization of nature. First, natural space is materialized through a regulatory schema of nature. Second, this regulatory schema attains its coherence through the iteration of previously established norms that qualify what counts as nature. Third, the schema of normative representations of nature is accompanied by a violent repudiation of other, less desirable forms of nature. But far from being completely set apart from nature, this abject nature is nevertheless always inside nature as its "founding repudiation" (Butler, 1993:3). And fourth, to the extent that nature assumes its ontological presence through the 
repetitive citation of nature's regulatory schema, nature might be thought of as an effect of power, where power is exercised through the act of delimiting nature from its abject.

As I will be arguing throughout this dissertation the idea of a Canadian nationalnature attains its legibility through a similar exercise of power, where the lines of national-nature are put down, to borrow from Butler, "through a set of violations, ones which are unwittingly repeated in the contemporary invocation." Critical in this regard, however, is that such violations cannot be thought outside the racializing logic that set them in motion.

\section{Postcolonialism}

There is no clean way into a discussion on postcolonialism. Aside from its concern with the epistemological investments of colonialism and their repetition in the post-colonial present, few generalizations can be made about postcolonial theory as a whole. Its lineage can be traced through literary and cultural studies, but in recent years it has become immensely popular across a range of traditional academic fields: geographers, historians, environmental scholars, sociologists and anthropologists have all made important contributions to the field of postcolonial studies. My interest in postcolonialism centres on a recurring theme in postcolonial studies, one captured well by Edward Said, who wrote that:

the main idea is that even as we must fully comprehend the pastness of the past, there is no just way that the past can be quarantined from the present. Past and present inform each other, each implies the other and...each co-exists with the other" (1994:4).

In recent years, perhaps echoing Said's conviction that "none of us is outside or beyond geography" (Said, 1994:7), this theme has found a firm footing in geography, leading to 
what has been termed in recent years "postcolonial geography". Within the field, Bruce Braun has registered a similar observation. For, while "“postcoloniality' is often taken to refer to a condition 'after colonialism'" such a view overlooks the ways that colonial pasts continue to organize experience in the present" (Willems-Braun, 1997:4). It is the latter aspect of Braun's postcolonialism that I would like to focus on in this section, an emphasis not simply on how the past infuses the present but also on the invisible epistemological habits, or "buried epistemologies" (Willems-Braun, 1997), that make the present available to us and that enable us to comprehend and identify with it in very specific ways.

One such epistemological habit, perhaps the dominant habit theorized under the sign of postcolonial studies, concerns the articulation and apprehension of colonial space. The main thrust of such theorizing is that colonial space - those spaces that were drawn into imperial purview and made the subjects of colonial rule - did not pre-exist their entry into knowledge as discrete entities. Rather, colonized spaces, like nature, attained their legibility through various forms of knowledge that were assembled about them. Edward Said's Orientalism provides an excellent example of how knowledge about the Orient produced the Orient as Europe's other and, in so doing, produced what he called Europe's 'imaginative geography' (1979). In other words, Europe's pursuit of knowledge concerning the Orient was crucially important not only for how it produced the Orient as an internally coherent whole, but also for the way it rendered Europe as distinct from the Orient. Following this seminal work by Said, much postcolonial scholarship has gone on to apply Said's notion of 'imaginative geography' to other colonized spaces. The persistent emphasis in this literature has been on articulating the emergence of a distinctly colonial spatiality between the colonized and colonizer and on how this spatiality ordered 
not only past colonial relations, but continues to resonate within contemporary settings as well. Derek Gregory summarizes quite eloquently what is meant by a colonial spatiality:

If we remain within the usual transactions of French philosophy then one side of that coin will display the face of modernity as (for example) an optical, geometric, and phallocentric space; a partitioned, hierarchical, and disciplined space; or a measured, standardized, and striated space. And the reverse side will exhibit modernity's other as (for example) primitive, wild and corporeal; as mysterious, capricious and excessive; or as irregular, multiple and labyrinthine. Although the coin is double sided, however, the two are not of equal value. For this is an economy of representation in which the modern is prized over - and placed over the non-modern. (2004:4).

Gregory's coin metaphor is an apt means of describing the double-sidedness that characterizes the idea of a colonial spatiality, perhaps even more so than he realizes. It captures the idea that the spaces of modernity - the liberal rule of law, social progress, development, humanism, and civility, for example - are profoundly marked by the coexistence of the spaces of the non-modern other - arbitrary law, fundamentalism, underdevelopment, antihumanism, and barbarity, for example. This is to say that no matter how successful the project of Enlightenment emancipation might appear, the project itself cannot shed these so-called non-modern identifications for they crucially demarcate the temporal movements of modernity and spatial form it assumes. Strictly speaking, the ideology of modernism needs this dualist identification, if the coin is going to retain any cultural purchase whatsoever. Pushing the coin metaphor a bit further, if the so-called modern is going make any investments into the so-called non-modern world, then their spatial differentiation must be denominated in advance. The important point here, however, is that it is the modern that sets such hierarchical spatial differentiations in motion. 
This notion of prior denomination points to an important set of questions in postcolonialism. What are the cognitive mechanics/failings that produce colonial spatialities? ${ }^{26}$ Which individuals or social groups have access to these mechanics? When are these invoked? And across what material fields are they applied? Bodies? Continental geographies? The sub-molecular/genetic universe? It also points to the very important role that articulation and representation play in the construction of difference. Here, the inequality that marks the two sides of the modern coin is more than just a convenient metaphor, because it is precisely through this perceived inequality that colonial space is produced. For Gregory, this spatiality "is an economy of representation in which the modern is prized over - and placed over - the non-modern" (2004:4). If I could reinterpret Gregory on this, what I think he means here is that the mechanics (or technologies) of colonial spatialization are financed by an unequal economy of selfrepresentation in which the modern constructs an image of itself through the denigration and devaluation of the non-modern other.

Critical to this discussion of colonial spatiality, then, are the specific discursive regimes through which the spaces of other-ness and spaces of the same come into view. As such, postcolonialism seeks to draw attention to how colonial space might be understood as an effect of power by elucidating how these spaces enter into the field of politics through the articulation of difference. In this regard, what concerns me are the various ways in which the idea of nature is invoked in the practices and discourses of colonialism, the construction of colonial spatiality and the exercise of colonial power. Here again, I draw from the important work of Bruce Braun, whose critical attention to the various discourses (environmental, scientific, aesthetic, and recreational and so on)

\footnotetext{
${ }^{26}$ I take the notion of cognitive failing from (Braun, 2002).
} 
that have produced the recognizable natures of Canada's west coast, particularly

Clayoquot Sound, has opened up an important cognitive space for thinking about how nature and colonial power interact in settler colonies, and perhaps even more importantly, for understanding, or at least beginning to understand, how this nature-colonial relation might contribute important insights to debates concerning and the practice of environmental politics. I will say more about the implications of Braun's "space-clearing gesture" momentarily (Sandilands, 2003:141). But for now the general point I am making can be sharpened somewhat by staying with Gregory's coin metaphor.

Although probably just a semiotic coincidence, the images that adorn most pieces of Canadian coin and paper currency exemplify, almost uncannily, what I am getting it. Take, for example, the 1991 Canadian twenty-dollar note (see Figure 2.2, page 67 ). ${ }^{27}$ On one side of the bill is an etching of Queen Elizabeth $\Pi$. On the reverse appears a typical Canadian wilderness scene in which two common loons (Gavia immer) are shown swimming on a lake against a human-less backdrop of black spruce and rolling hills typical of the Precambrian shield. Taking both images together, the monarch can easily be read as Canadian sovereignty personified, the embodiment of civility and benevolence watching over and caring for a vulnerable Canadian nature. Here, nature stands opposed to, but has no value independent from, some form of sovereign rule, in this case, the monarch. Indeed, the cultural value of both images (and of the twenty-dollar bill itself!) trades on their mutual presence so much so that it is only through their co-presence that either might be said to have any cultural significance.

\footnotetext{
${ }^{27}$ Although this twenty-dollar note was officially replaced in 2005 with a new note, it remains in wide circulation. Incidentally, the new note features a revised image of the Queen on one side and an image of a sculpture depicting the Haida Gwai origin myth on the other. One could easily read the same colonial narrative through the new note, since First Nations in Canada are so frequently characterized as naturalized objects in Canadian iconography.
} 
Another example of the same can be found in the 2004 Canadian one hundred-dollar note (see Figure 2.3, page 68). In this example, an image of Sir Robert Borden, Prime Minister of Canada from 1911 to 1920 , adorns the front of the bill, while a map of Canada depicting very clearly the Canadian boreal forest and a birch bark canoe appear on the reverse. Canadian sovereignty and Canadian sovereign-nature work together in an internally coherent, mutual relationship. Sovereign nature underwrites the legitimate exercise of sovereign power, while sovereign authority nurtures the very (divine) nature that underwrites it legitimacy.

If postcolonial geographic scholarship has been concerned primarily with the construction of colonial space, then it has been to specific colonial texts that these scholars have turned in order to show how colonial spaces attain their visibility. It has also been concerned with asking after how such texts continue to organize the colonial present. At the same time, poststructural political ecology has been concerned with constructions of nature and the implications that such an analytics might have for environmental subjectivity. Bruce Braun's work is extremely important, in my view, precisely because it draws these two projects into dialogue by tracing the emergence of natural space through the colonial register in order to show how colonial visualities and practices continue to organize environmental politics (Braun, 2002; Willems-Braun, 1997) in the so-called 'colonial present' (Gregory, 2004). What Braun is suggesting is that the politics of 'liveable futures', as a matter of both politics and policy, has something to learn from a postcolonial analytics of space, identity and ethics, while at the same time suggesting that the practice of postcolonial theorizing could profit from a closer reading of poststructural political ecology. 

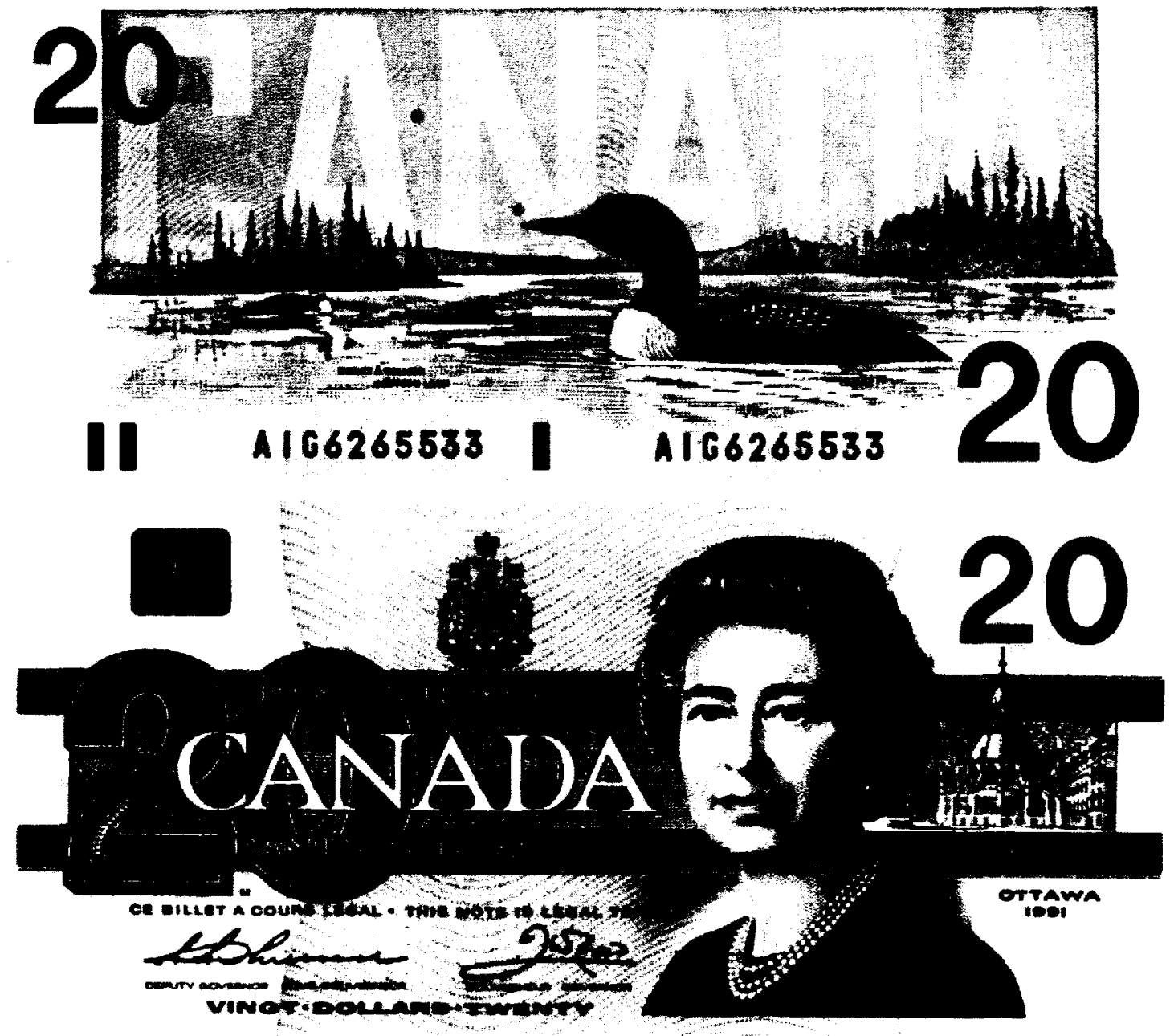

Figure 2.2. - 1991 Canadian twenty-dollar note. 

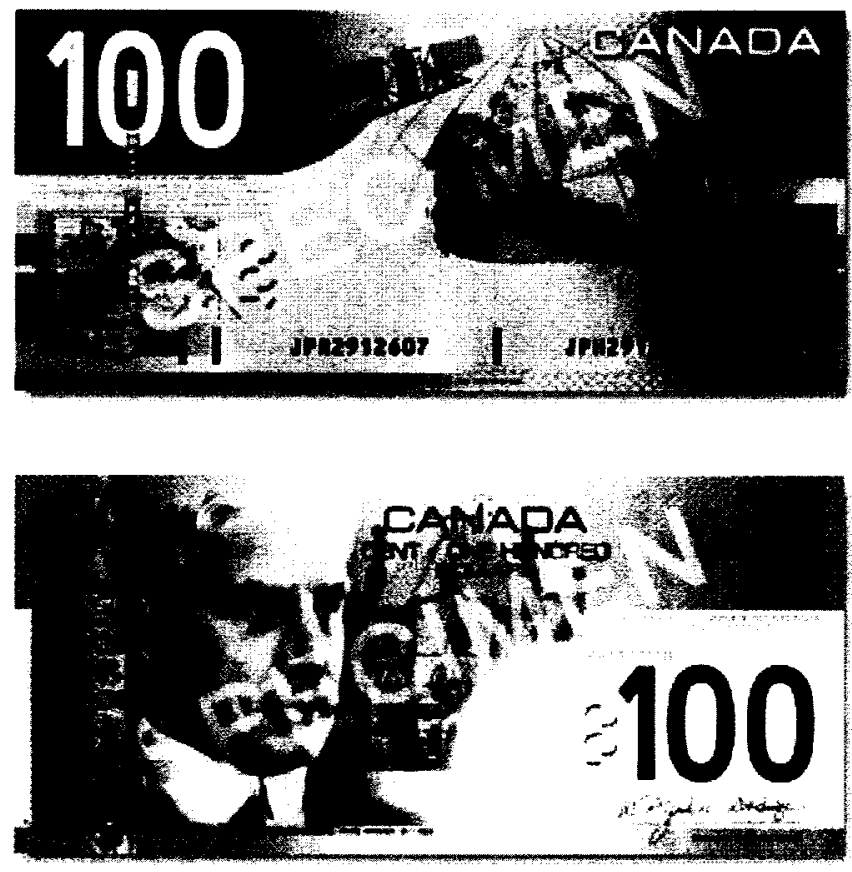

Figure 2.3 - 2004 Canadian one hundred-dollar note. 
Between poststructural political ecology and postcolonial studies, and building on Braun, the theoretical argument I am making is that the presences of specific natural spaces bear a direct relation to the histories of colonialism where they are born out of and materialize through historically contingent discourses and practices of colonialism. Such natures are real insofar they occupy biophysical space. But to assume that the sign of nature space is always a direct reflection of nature's essence or signals the presence of an underlying order to the material, overlooks some of the valuable insights concerning space and geography that come from postcolonial literary theory. Here, Edward Said and other postcolonial theorists recognize that the period of colonialism and empire and imperialism more generally have been about the drawing of sharp distinctions between internal-external, here-there, us-them, self-other and that such distinctions are highly contingent on a colonial mentality and visuality that locates sovereign authority in the viewing subject. Indeed some have argued that the value of postcolonial theory lies in the recognition that space and spatiality are the privileged means through which differences are constructed, and that the apparatus of time is merely instrumental in constituting the spatial organization of the colonial encounter (Agnew, 1998).

I draw one last argument from postcolonialism: the idea of ambivalence and its relation to colonial authority. Here the point I wish to make is that colonial space always comes into view through an ambivalent moment that is characteristic of the colonial gaze. This idea of ambivalence is probably best articulated by Homi Bhabha, who uses it to elucidate the perpetually precarious position of colonial authority (Bhabha, 2004), not unlike that marking the idea of performative subjectivity I discussed earlier. For Bhabha, the metaphor of the nation serves as a productive site for considering what is at stake in 
colonial ambivalence because it is through the concept of 'the people', and 'the nation' to which they are made to belong, that this ambivalence comes into view. Indeed, for Bhabha, the nation-space "provides the most apt analogue for imagining the structure of ambivalence that constitutes modern authority" (2004:209).

What, then, is the source of this national (modern) ambivalence? It is the insecurity born out of the difference produced through the subject's articulation of national belonging. Thus, for Bhabha, "the performative intervenes in the sovereignty of the nation's self-generation by casting a shadow between the people as 'image' and signification as a differentiating sign of Self, distinct from the Other of the Outside" (Bhabha, 2004:211-212, Bhabha's emphasis). But for Bhabha,

The problem is not simply the 'self-hood' of the nation as opposed to the otherness of other nations. We are confronted with the nation split within itself, articulating the heterogeneity of its population. The barred Nation It/Self, alienated from its eternal self-generation, becomes a liminal signifying space that is internally marked by the discourses of minorities, the heterogeneous histories of contending peoples, antagonistic authorities and tense locations of cultural difference. (2004:212)

In other words, to self identify with the nation is to inscribe one's self within the sign of the national space. But such an identification, while rendering a space outside the orbit of the nation, also calls attention to those circumscribed by the national sign, yet who nevertheless exceed its limits, in particular those unwilling to submit to colonial rule. Bhabha's notion of the "nation split within itself" is therefore fundamental to understanding the legitimacy of colonial authority because it is precisely this ambivalent split that colonial rule seeks to ameliorate through the repeated assertion and reassertion of colonial rule. 


\section{Nature and Canadian National Identity}

This brings me to what I consider to be an absolutely necessary site for interrogating nature's sociality: the nation. In nationalist discourse there is a pervasive sense in which the fate of the nation is tightly bound to the fate of the natures that constitute it. Perhaps no other culture bears the mark of such naturalized national destiny more so than that manifest in the dominant cultural logic found in the United States. Marked by a narrative of innocence lost and innocence regained, American culture is often represented and lived as a journey through a corrupted or merciless wilderness, followed by some form of salvation and a recovery of one's innocence (Merchant, 1996). Whether pushing back the wilderness frontier in Frederick Jackson Turner's imperial imagination, or installing liberal democracy through violent military campaigns, the myth of heroic return in American culture is always closely linked to a taming of 'wild places' and their transformations into places of salvation or gardens of plenty.

This proximity of nature and nation is perhaps not surprising, particularly since the word nature derives from the Latin word nascere, meaning 'to be born' (Olwig, 1993). Indeed, a familiar logic organizing the enterprise of wilderness travel is that, under carefully controlled conditions, one can be rejuvenated and thus reborn in nature. Similarly, through nature entire cultures are reborn, cultures that locate their origin in some primordial past. Wildernesses, in this sense, can also be reborn. Transformed, wildernesses are purged of their wantonness and allowed to enter fully into their destiny. So transformed, nature becomes a garden pressed into the service of some higher moral unity. Yet what is always so striking about the wildernesses in these myths of national 
recovery is that they summon not from some absolute place called "wilderness", but from the historically located trepidations and ambivalences of those who stand before them.

Locating these myths of origin in national culture is important because doing so allows us to understand how myth can be used to mobilize collective national identity. This is a familiar argument. National cultures are by definition expressions of same-ness held together by some common or originary experience, usually fictitious, usually located somewhere in a naturalized past. But locating myths of origin in national culture can also provide us with some useful insights into how constructions of nature and space interact in the construction of abstract national space. This is to say that by examining myths of national origin, particularly those suffused with representations of nature, we can disclose the often complex, imaginative geographies that underwrite national culture. In reference to the imposition of the modern state system onto North America and the culture of displacement it implies, Michael Shapiro has called these imaginative geographies the "cartographies of violence," since some form of violence almost always accompanies the practice of territorializing national identity in the land. Indeed, as is so frequently the case, such 'militant geographies' are routinely disregarded in the 'triumphant geographies' celebrated in nationalism. Instead, geographic militarism is often recast "as heroism and self-sacrifice" in the national register (Shapiro, 1999:164). ${ }^{28}$

This is no less the case in Canada, than for other nations. In the discourse of Canadian nationalism, nature and wilderness are dominant cultural forms. The landscape images of the Group of Seven, Tom Thomson, Emily Carr and their contemporaries routinely invoked as aesthetic expressions of something uniquely Canadian - a still, quiet

\footnotetext{
${ }^{28}$ Neil Smith takes this idea one step further, arguing that the imaginative geography of twentieth century American triumphalism has not only erased its geographic militarism, but it has completely erased its geography! (Smith, 2003).
} 
and timeless presence that nurtures the national soul and that must, in return, be nurtured. These forms are frequently given expression in the idea of north (Grace, 2002; West, 1991) and have ordered not only a hegemonic cultural sensibility in Canada, but at various times have underwritten a Canadian economic sensibility as well. As I hope to demonstrate in the next chapter, such an economic sensibility underwrote Bernard Edward Fernow's vision to rationalize Canadian forests in the economic interest of the nation, just as it did early Cold War articulations of the Canadian north (Grant, 1988). The economic gaze was among the dominant themes with which Justice Thomas Berger grappled in his famed inquiry into Mackenzie Valley Pipeline (Berger, 1977). And it ordered the triumphant geographies of Québecois nationalism and the development of hydro-electric power in northern Québec in the 1970s and 1980s (Desbiens, 2001). But, as Roderick Neumann offers, such wildernesses are also imposed (Neumann, 1998). In other words, while frequently represented in triumphalist terms, the territorialization of nature onto the space of Canada was accompanied, at various moments in its history, by its own cartography of violence. In the chapters that follow it is my aim to peel back the nature fetish and reveal the 'militant geographies' that accompanied the construction of Canadian national-nature. But more than this I am interested in how, through various discursive practices, the boreal forest has been made to occupy the semiotic space opened up by the idea of national-nature. Furthermore, I am interested in how discourses about the boreal forest work to secure dominant forms of national identity, how the visibility of the boreal forest as a national environment is marked by the production of an abject subject, and how these nationalizing discourses position boreal forest politics firmly within the ambit of race and gender politics. In the chapters that follow, I elucidate these themes more fully by looking specifically at three empirical sites - forestry, the canoe 
expedition and forest-carbon management - as they relate to the ontological production of the boreal forest of northern Canada. 


\section{Chapter 3}

\section{Locating The Boreal Forest: Colonial Power In The Canadian Forest Economy}

Canada in 1871 was, however, a nation projected rather than a nation formed. William Lewis Morton, The Canadian Identity

Nay, the celebrated Linnaeus has even ventured to assert, that the knowledge of plants is the very foundation of the whole public economy; since it is that which feeds and clothes a nation.

Anonymous review of Hasselquist's Voyages and Travels in the Levent ${ }^{29}$

The forester is needed to direct the work of Nature.

Bernard E. Fernow, Canada's Interest in Forestry

\section{This Forest Has Shaped Our History and Economy}

In 1996 cartographers at the Canadian Forest Service (CFS) teamed up with the editors of Canadian Geographic (CG) magazine to co-publish a thematic, poster-sized map of the boreal forest of northern Canada $(1: 10,750,000)$ (Figure 3.1 and Figure 3.2, page 76 and on page 77 respectively). In total over two hundred and fifty thousand copies of the poster were produced for public consumption, most of which were distributed as inserts in the May/June 1996 issue of Canadian Geographic magazine. ${ }^{30}$ In its most general form, the map plays an important pedagogic role for the Canadian Forest Service and the Government of Canada, since it was developed with the aim of educating the readership of Canadian Geographic magazine on the value of the boreal forest and forestry to the Canadian economy and on the responsibility a forested nation has in

\footnotetext{
${ }^{29}$ As quoted in Mary Louis Pratt's Imperial Eyes: Travel Writing and Transculturation, London: Routledge (1992).

${ }^{30}$ This information was obtained through email correspondence directly from Canadian Geographic magazine.
} 


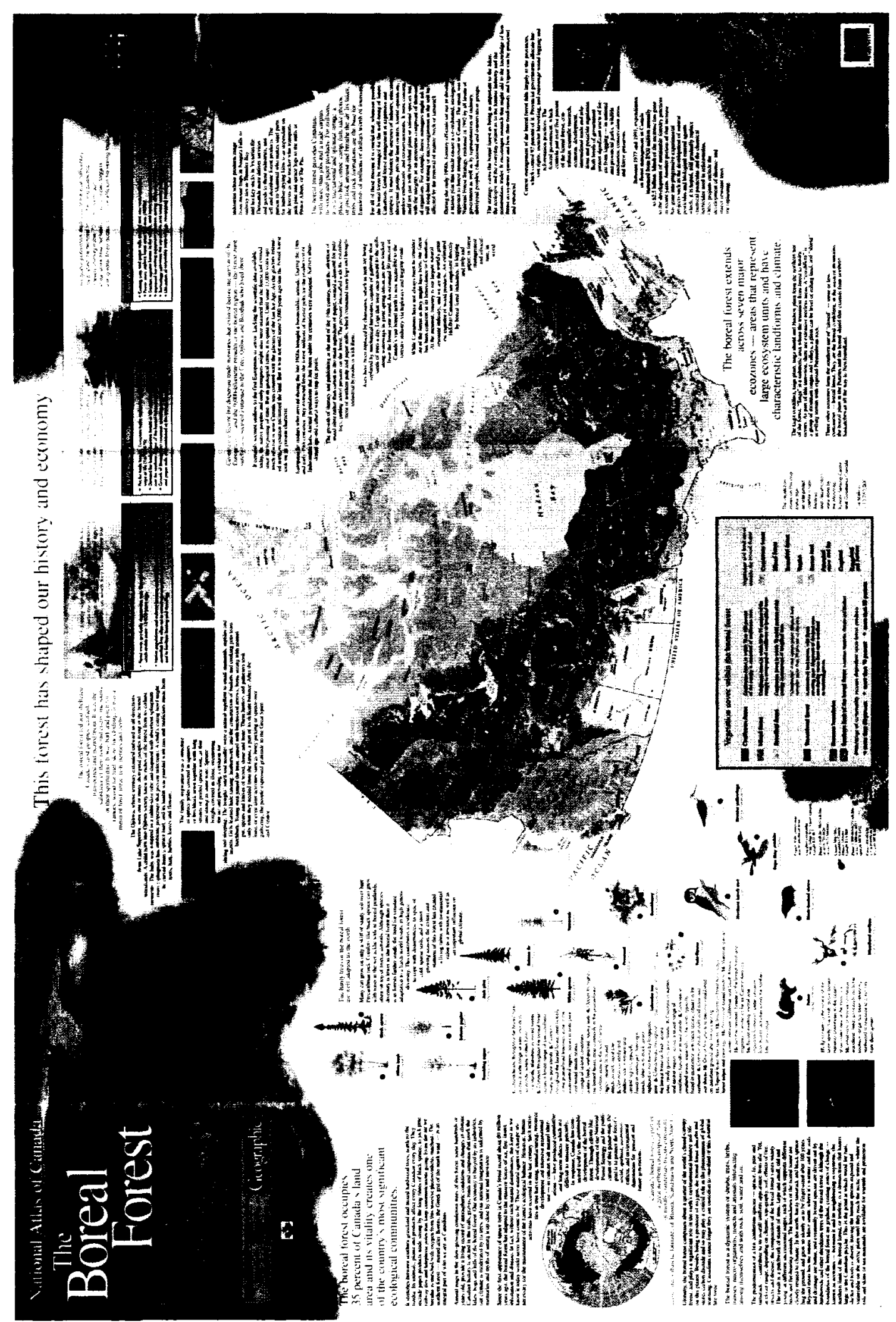

Figure 3.1 Boreal Forest Poster-Map (Front side), Canadian Forest Service - Canadian Geographic, 1996 


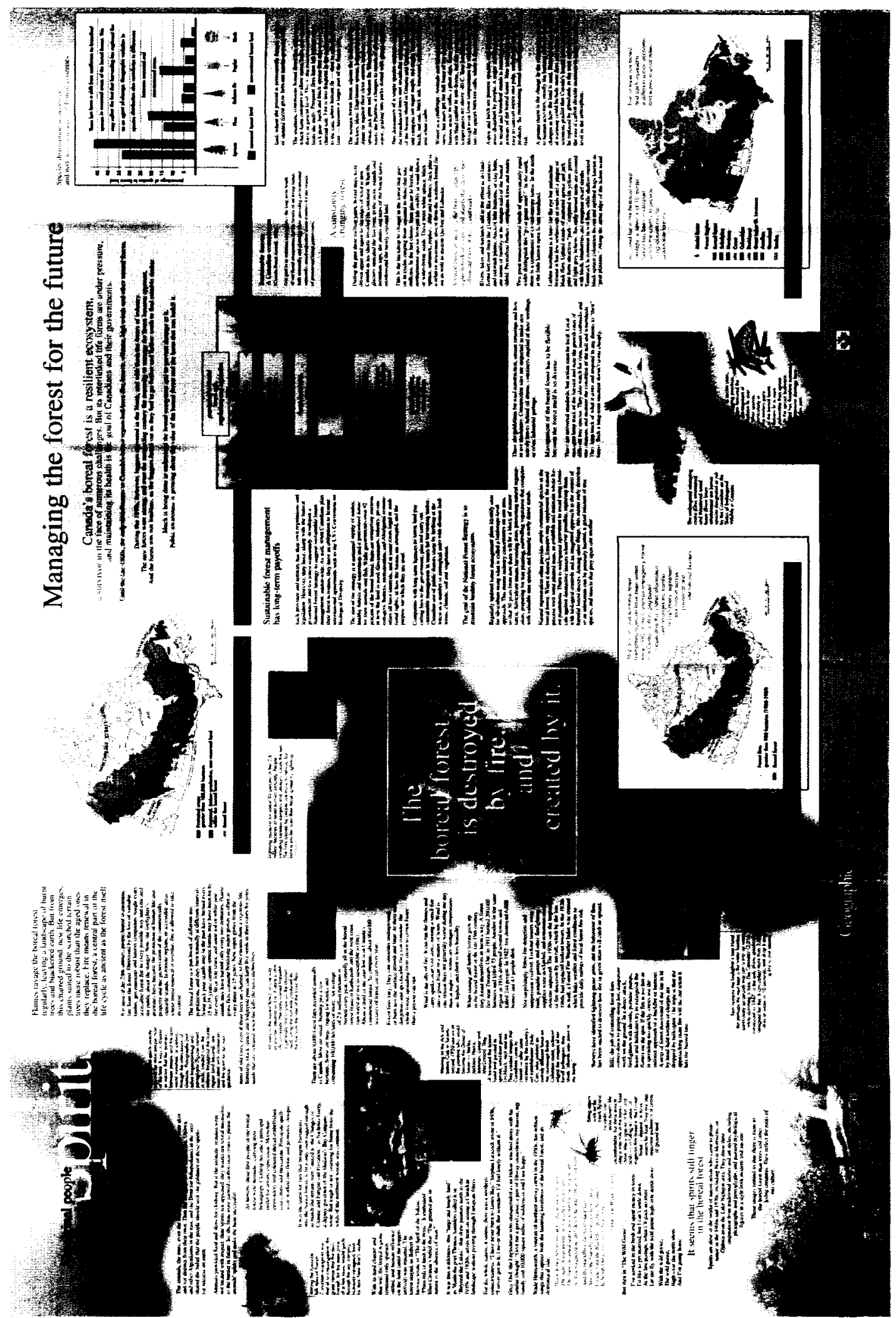

Figure 3.2 Boreal Forest Poster-Map (Back side), Canadian Forest Service - Canadian Geographic 
balancing its national forest consciousness with the realities that befall a forest-based economy. ${ }^{31}$ In this regard, the poster-map renders the boreal forest as absolutely indispensable to the Canadian forest economy and in so doing constructs the boreal forest in no uncertain terms through a national discourse of forestry and silviculture. Indeed, there can be no mistaking the overall argument made on the poster-map, which is that only the Canadian government wields the capacity to manage the boreal for its multiple values. To be sure, the poster-map duly acknowledges provincial jurisdiction over resource management in Canada, but the overwhelming tenor of the poster-map is that the boreal forest is a national asset, something in which the entire Canadian nation has a stake. Closely related to this is another striking feature of the poster-map: the indelible linkage it seeks to draw between the boreal forest and Canadian national identity, a sentiment captured very clearly where the map reads, "the northern forest ...is an integral part of who we are as Canadians."

At the centre of the poster sits a map of Canada on which each of the various ecozones falling within the Canadian boundary are delimited. The most prominent of these, the boreal forest, appears as a green swath running west from Newfoundland and Labrador, wrapping around the southern latitudes of Hudson's Bay and James Bay and extending north and west through the northern reaches of the prairie provinces and the Northwest and Yukon territories before coming to rest at the Mackenzie River delta on the shores of the Beaufort Sea. ${ }^{32}$ This image of the boreal forest wields an enormous amount of cultural appeal, since it resonates with an overly simplified, but nevertheless potent, stereotype that Canada is a massive "environment," which must inevitably have

\footnotetext{
${ }^{31}$ It must be noted that since its publication in 1996, the text on the poster-map has been translated into German, suggesting that its target audience extends beyond the Canadian reading public.

${ }^{32}$ Significant portions of boreal forest also extend into central Alaska. But given that my concern has to do with the boreal forest and Canada, I will not attend to this aspect of the boreal forest. As such, this omission must not be taken as a sign of disrespect, but rather as a matter of convenience.
} 
some bearing on how Canadians think of themselves. Much of Canadian social theory and geography, characterized by the field of Canadian studies and writers like Harold Innis, as well as Canadian nationalist sentiment, has focused on precisely this relation, how something called Canadian identity might be directly or indirectly related to the expansiveness of the Canadian land mass (Angus, 1997; Berger, 1966; Drache, 1995; Grace, 2002; Haliburton, 1869; Hulan, 2002; Morton, 1961). It was exactly this sort of idealized aesthetic that was popularized by Tom Thomson, the Group of Seven and their contemporaries in their early twentieth century landscape painting and that has since become emblematic of 'official' Canadian culture and identity. It is also an aesthetic on full display on the CFS-CG map. That the poster-map depicts the boreal forest in the colour green drives home the message that northern Canada is a fecund, natural space and that such fecundity plays an important part in maintaining the well being of Canada and the overall quality of life enjoyed by all Canadians. After all, to be 'green' is to approximate nature.

This sense of national commonality is reinforced with the help of a textual representation of the boreal around the perimeter of the map, as well as on the back, which provides an historical and taxonomic tour through the boreal forest. Here the text identifies several species of flora and fauna that are characteristic of the boreal and offers some passing remarks on the significance of these species for the overall well being of the forest ecosystem and its dependent economies. It also includes a brief paragraph or two on the historical presence of the Cree, Ojibwa, Innu, Dene and Beothuk, the first human inhabitants in the boreal. Little mention is made on the map concerning the current presence of aboriginal peoples in the boreal forest. I will elaborate on this in more detail towards the end of the chapter. But for now it is enough to say that their presence is 
simply recorded in the past tense as though to suggest that aboriginal presence in the boreal was and continues to be temporally distinct from the rest of Canada. The map text ends with a lengthy description of the Canadian government's effort to safeguard the boreal against fire and pestilence and to manage the boreal for its multiple values: forest products, recreation, employment, cultural importance, and so on. Perhaps more than any other, it is the last of these storylines that constitutes the dominant set of meanings to be drawn from this map because, as the mapmakers would have us believe, managing the boreal is as much about managing Canada and Canadian identity as it is anything else.

This nationalizing storyline, and the space of nature that structures it, however, is important for more than just its effect on cultural identity and for the exclusions that constitute it. It is crucially important for the way in which it locates the authority to manage nature in a bureaucratic expertise that places national public welfare above all else. The CG-CFS map of the boreal forest provides a vivid example of how this national-nature narrative works to locate authority in the expertise of the state forester. Specifically, the narrative that accompanies the poster-map makes clear the importance of the Canadian boreal forest to Canada's history and economy. It also suggests that stateled sustainable forest management represents the most suitable body of knowledge for curtailing threats to the boreal forest and efficiently managing its productivity, since, according to its proponents, such knowledge purports to have only the national interest in mind.

Yet, however natural and disinterested the boreal forest space might appear on this map, and countless other representations of the boreal forest like it, to understand the boreal exclusively in terms of its bounded objectivity, would be to overlook the discursive context through which the boreal space enters the field of political discourse as 
a knowable thing. Such an oversight has profoundly ethical consequences insofar as the context out of which the boreal forest emerges as a fully naturalized, objective spatial form is not innocent, but instead bears traces of a colonial and expansionist past that have become inscribed in the boreal forest as a result of Canadian imperial development. This is important because it is this colonial legacy that continues to order, not only the cultural (national) meaning ascribed to the boreal forest in the present, but also, and perhaps more importantly, the very terms by which contemporary articulations of the boreal forest are carried out.

The first thing I wish to do in this chapter, therefore, is attend to this absent context. Specifically, I want to locate the discursive context within which the boreal forest emerges as a concept and assumes a place in the official geographic imagination of the Canadian-nation. In effect, what I seek to do here is trace a genealogy of the boreal forest that brings early imperial relations to bear on its contemporary representation as a space of economic significance to the Canadian forest economy. In doing so, I argue that the boreal forest attains its legibility as a forested space with import to the Canadian forest economy through a narrative of colonialism. Furthermore, I argue that understanding the boreal forest through such a narrative device is important because it draws critical attention to the racialized exclusions that mark it. In tracing the emergence of this narrative pattern, I will examine the rhetoric of Bernard Edward Fernow, who in the early part of the twentieth century was among the first voices in Canadian conservation history to advocate a national forest policy and draw the link between forest management and Canadian identity. My second aim in this chapter is to draw attention to the inherently unstable and ambivalent position of the national forester. Third, I want to re-read the CFS-CG poster-map through this ambivalence. 


\section{Locating natural and cultural space}

If anything, what the CFS-CG representation of the boreal forest provides is a naturalized image of the Canadian north the cultural intelligibility of which trades on a conventional interpretation of Canadian history in which the history of Canada is narrated as the progressive transcendence of physical space. This is the familiar 'railroads and wheat' narrative that usually begins with Sir John A. MacDonald's now mythic vision to forge a nation from coast to coast to coast, and is, along the way, punctuated by other important historic events such as the construction of the Canadian Pacific Railroad, the settlement of the agricultural frontier and even the establishment of the Canadian Broadcasting Corporation. According to such a narrative, one that locates its geographic epicentre in south central Canada, the north and the northwest are defining spaces for the Canadian identity. To argue otherwise would be attenuate an important dimension of this identity. In a similar spirit, representations of the boreal forest come to stand for Canada and Canadian identity, since they symbolize the triumph of northwest expansionism in the form of a fully reified ecosystem. In so doing the boreal forest lends credence to the nationalist project since the geographical contiguity of the Canadian jurisdiction can be seen to mimic an already existing natural form, an expanse of forest running from east to west and north. In short, the boreal forest mimics the expansionist narrative of Canadian history and can be invoked to naturalize the Canadian state boundary.

But, more than this, the CFS-CG boreal forest map presumes that history and geography, as disciplinary undertakings, can be studied in very particular ways. It assumes for instance that Canadian experience is punctuated by an originary moment. It also assumes that, with the careful application of historical method and objective 
analysis, the events of history can be peeled back to reveal these origins as pure antecedents. In this sense, MacDonald's vision embodies an aesthetic purity that needs no explanation. In geographical terms, the CFS-CG poster-map assumes the boreal forest is pre-historic and thus pre-human and original, and that its very presence has influenced the unfolding of human history, a determinist gesture captured very succinctly where at the top of the map it reads: 'This forest has shaped our history and economy.' Thus embedded within the CFS-CG representation of the boreal forest is a conventional notion of geography that works alongside, and indeed complements, the historiographic assumption, the idea that geography can be understood as the formal study of bounded space and that such space is a necessary precondition for the more rigorous pursuit of historical analysis. Geography is history's predicate; it provides a spatial reference for historical details and, in so doing, lends meaning to historical events. Such assumptions, however, are exemplary of Lefebvre's spatial fetishism, the idea that space is routinely portrayed as objective and ahistorical. Against this purported objectivity, Lefebvre and other critical geographers have been calling for a means of critically articulating how space is made, how it abets capitalist production, and how space is ideological to the extent its production is masked.

In light of this critique of conceptualizing history and geography, I would like to propose that the boreal forest is not an ahistorical space of nature, but is, in fact, a space deeply implicated in the territorial expansion of the Canadian colonial state, and is, accordingly, better understood as an artefact of colonial governmental power, than simply a defenceless object of environmental concern. What I am suggesting here is that the boreal forest is not an innocent, timeless space, as the CFS-CG mapmakers might have us believe. Instead, it is a political space that, along with a host of other spaces constitutive 
of the "official" Canadian geographic imagination, was actively constructed by a burgeoning centralized state apparatus in the latter years of the nineteenth century and first half of the twentieth century. In this sense, the boreal forest becomes a space with ecological significance to the Canadian state and a bourgeois elite by virtue of its relation to capitalist production and the colonial visuality engendered by resource capitalism.

\section{Colonial Narrative}

In making this claim I want to draw from what Anne McClintock (1995) has referred to as a colonial narrative, which, regardless of the context it orders, follows the same basic storyline: dangerous marginality, segregation and reintegration. What she means by this is that, insofar as the colonial experience might be organized around an encounter with difference and, as such, might be marked by a fear of the other, the colonial observer deploys the colonial narrative in order to stabilize the encounter, in a sense, to render the encounter intelligible. Here the colonizer registers the other as dangerously marginal to the colonial settlement project, segregates the 'dangerous' other either physically (through some form of internment) or semiotically through language inscription, and finally seeks to reincorporate the other into the development teleology that underwrites the settlement experience. This accounts for colonial policies such as assimilation in which aboriginal peoples are first admonished for their startling difference (savage, primitive, animist and so on) and are then forcibly made to adopt colonial norms and behaviours.

The argument I seek to make is that the colonial narrative works as a very powerful political technology insofar as it draws a sharp distinction between nature and society. On the one hand, nature is synonymous with those spaces outside European 
civility thought to harbour 'man's' basest instincts, and, on the other, national culture came to represent the sovereign spaces of civility and salvation. Accordingly, the colonial frontier served to demarcate these two epistemological domains: on the one hand, the space of nature, which provided the colonial observer with bountiful evidence of nature's objective existence; and, on the other, the spaces inhabited by the colonial explorer - his ship, his crew, his logbooks, port of embarkation and so on, all retained their positions within the privileged domain of European civility and order. This dualist spatiality represents a crucial 'grounding' in the dynamic unfolding of the colonial experience and, as I try to show, underwrites the practices of colonial representation and government. It is, however, a highly unstable grounding given that the terms used to mediate the colonial experience - nature and culture - are themselves highly constructed notions that have much less to do with the world of 'facts' than they do with a desire to observe the world in very particular ways.

The central idea here, one that shows up repeatedly in postcolonial geography, is that within the colonial gaze lies the power to mediate and represent difference, a move that not only constructs natural space as something other than cultured space, but, perhaps more importantly, one that fixes the power to represent in the authoritative figure of sovereign rule. The power to represent difference through the colonial gaze was made possible by the concept of nature. Through the cultured lens of the colonial observer, nature came to represent pure difference. The importance of nature to the legitimation of colonial authority cannot be overstated. Indeed, the power to represent nature as a realm that stands in opposition to culture is the signature manoeuvre in the exercise of colonial power. But more than this, it was the power to represent, or characterize, nature as something, that underwrote this power. Derek Gregory has observed that not only was 
colonial nature something to be domesticated and appropriated by colonial culture, it was also a means of representing space as either one of excess or as a norm (Gregory, 2001). Thus feminized spaces of colonial nature were shown to be pathological spaces that harboured irrationality, impulsiveness and sexual excess. Such naturalized spaces, however, stood in stark contrast to the much more subdued natures of Europe, which were heralded for their normalcy. Purging feminized colonial nature of it excess and making it work for, rather than against, the colonial enterprise was, therefore, among the central tasks that colonial authorities assigned themselves.

In what follows, I would like to build on this idea of the gendered spatial practices of colonial governmentality and link these to the colonial experience in Canada by arguing four things. First, I want to suggest that the political technology separating nature and society has been, and continues to be, an important device in the exercise of state biopower, where it concerns a biopolitics of land and nation. Second, such a technology is marked by a gendered visuality that can be traced to the masculinist heroics of colonial 'discovery.' Third, I want to suggest that a national vision of Canadian forests, of which the boreal forest constitutes by far its most expansive form, was accompanied by the governmentalization of something that might be called forest-nature - that ubiquitous image of the forest that is routinely used to signify nature's essence and underwrite the biopolitical claims of Canadian nationalism. And fourth, I would like to argue that the governmentalization of forest-nature was fundamental to the consolidation of state power in early Canadian history, insofar as the imperative to conserve forest-nature led to the establishment of a national forestry. 


\section{The Cartographic Anxiety of Colonial Mapping}

Derek Gregory's notion of the "cartographic anxiety" is an appropriate metaphor for interpreting the colonial impulse to map (Gregory, 1994:70). For Gregory, the cartographic anxiety hints at a "profound un-certainty" that silently co-exists alongside knowledge claims said to be grounded within fixed geographic grids of reference, claims about space that purport to truth (Gregory, 1994:72). In other words, the impulse to map derives, on one level, from the exigencies of practical experience and the need to position oneself vis-à-vis the other objects that comprise one's immediate environment. For obvious reasons, doing so enables us to navigate whatever worlds we happen to inhabit, whether these are the material worlds of cities or remote watersheds, or the worlds of language, image and sign. On another level, however, the impulse to map is driven by a distressing fear that a timeless, a priori grid of reference simply does not exist outside subjective experience, a fear that works to remind us that there is really nothing available to be mapped other than a partial reflection of our own selves and desires. In what follows I would like to build on Gregory's metaphor by suggesting that the cartographic anxiety provides an important analytical device for coming to terms with how the boreal forest has come to occupy a space in the geographic imagination of official Canadian identity.

To do so I will begin with the idea that a gendered visuality, or what Anne McClintock has called a colonial technology of conversion, mediated colonial encounters with difference and converted these from the unintelligible to the intelligible, or from the monstrous to the meaningful (McClintock, 1995). For a number postcolonial theorists concerned with the colonial appropriation of space, including McClintock, the image of 
Jan van der Straet's America provides a vivid portrayal of how the mythical contact experience is converted through the visual field of the colonial explorer into the distinguishable spheres of nature and culture (see Figure 3.3, page 89)(Gregory, 1994; McClintock, 1995; Merchant, 2004; Sawyer \& Agrawal, 2000). On the left side of the painting stands Vespucci, the iconic explorer, clutching his tools of imperial mastery, an astrolabe and cruciform staff, while before him the eroticised figure of America. For both McClintock and Gregory, such 'contact' moments, typified by images like America, can be read for the ways in which they produce a gendered, naturalized colonial landscape that authorizes masculine inscription.

McClintock has taken this idea of colonial spatiality further, suggesting that such colonialist orderings of space are marked by a profound ambivalence "animated not only by an imperial geography of power but also a gendered erotics of knowledge" by which the spaces of colonial otherness, terra incognita, are constructed as feminine spaces, the spaces of irrationality, chaos and excess, and the spaces of nature (McClintock, 1995:230). On the one hand, the female figure, sitting in the hammock, can be read allegorically as a symbol of Vespucci's "fantasy of conquest" and masculine desire. On the other hand, the background scene, depicting two severed limbs, one lying on the ground, the other being roasted over a fire by several other naked female figures, comes to stand for the terrifying sense of loss and disfigurement that accompanies the male figure on the threshold of liminality.

For McClintock, "the inaugural scene of discovery becomes a scene of ambivalence between an imperial megalomania, with its fantasy of unstoppable rapine - 


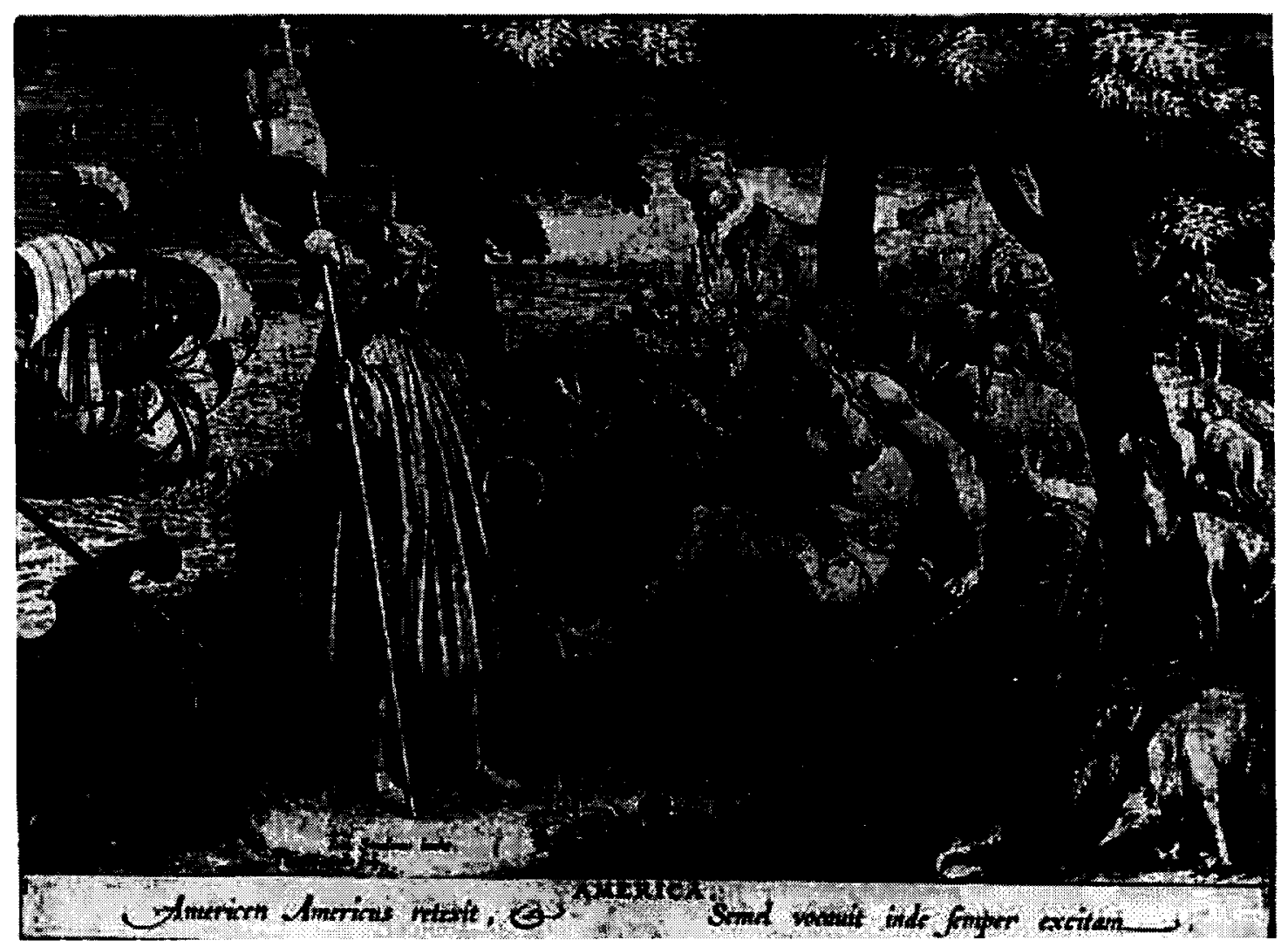

Figure 3.3 - America, Jan van der Straet. 
and a contradictory fear of engulfment, with its fantasy of dismemberment and emasculation" (McClintock, 1995:26-27). For the male colonial conqueror, liminal spaces, marked by the colonial frontier, are inherently unstable and elicit a visceral fear, since liminality, by definition, eludes "the network of classifications that normally located states and positions in cultural space" (Turner, 1969:95 as quoted in McClintock 1995). McClintock goes on to suggest that it is precisely this masculinist ambivalence that converts the frightening moment of colonial encounter into a more familiar set of codes. She argues that in order for liminal space to be properly apprehended and made to fulfill the colonial objective, it first had to be distinguished from the cultured domain of imperial knowledge. Only then could it be reclassified according to imperial taxonomy and put to work in fulfilling the obligations of the colonial enterprise. For McClintock, “colonial discourse repeatedly rehearses this pattern - dangerous marginality, segregation, reintegration"(McClintock, 1995:25).

This same pattern of spatial intelligibility can be seen operating through a similar conversion moment marking the Canadian experience, or perhaps more properly the French Canadian experience, found in Marc-Aurièle de Foy Suzor-Coté's 1906 iconic painting entitled Jacques Cartier rencontre les Indiens à Stadaconé, 1535 (see Figure 3.4, page 92). The painting hangs prominently in le Musée national des beaux-arts du Québec in Quebec City where it memorializes (and in so doing mythologizes) the original moment of contact between Cartier, who was then on his second 'voyage of discovery,' and the Huron. In this image, Jacques Cartier is shown posturing before a group of aboriginal people as though making some sort of appeal, or offering to his newly "discovered" people the promise of salvation. Behind Cartier lies his claim to authority, an army of fellow seafarers brandishing weapons of all kinds - guns, swords, battle-axes 
and pikes. But, perhaps more importantly, Suzor-Coté's use of light signals Cartier's true source of authority, the rising sun, a symbol of Godly omnipotence, located in the east and Europe from whence Cartier's crew had just arrived. Opposite Cartier is a band of crouching, half-naked aboriginal people, four of whom are pictured approaching Cartier and his army with what seems like an equal degree of timidity, curiosity, and genuflection, each partially illuminated by the light emanating from the sunrise on the eastern horizon. ${ }^{33}$ In behind this group of four are several more naked, androgynous, indigenous bodies whose presence blends almost seamlessly with the dark foreboding forest that makes up the left side of the painting. In this image the ambivalent geography of imperial conquest is on full display. Here, the excess of imperial military power can be read as underscoring the fear of engulfment and emasculation that marks Cartier's landing on the north shore of the Saint Lawrence River (somewhere near Quebec City). Indeed, what occasion, other than one in which the fear of engulfment is foremost, could possibly warrant such military excess?

Yet, at the same time, the naked bodies of the gesturing aboriginal people point to another excess, that of nature's excess in the form of savagery and cannibalism. In much the same way that van der Straet's image of America articulates a specific ontological distinction between the gendered spheres of the active, masculine realm of the known (the social) and the passive, feminine realm of the unknown (the natural), so too SuzorCoté offers a similarly gendered differentiation of space in which the forest, along with its docile inhabitants, awaits the paternalistic touch of colonial managerialism.

\footnotetext{
${ }^{33}$ One should note the deep paradox in this painting. The luminescence of European thought is emanating from the east. Most critiques of European logocentrism, such as Said's Orientalism, position Europe in the West, not the East. In this respect, it is also worth noting Suzor-Coté's choice in picturing Cartier's movement as from right to left (east to west) across the canvas. This spatial movement bears an uncanny resemblance to the spatial teleology that constitutes the much more familiar "railroads and wheat" narrative found in "official" representations of Canadian history and geography.
} 


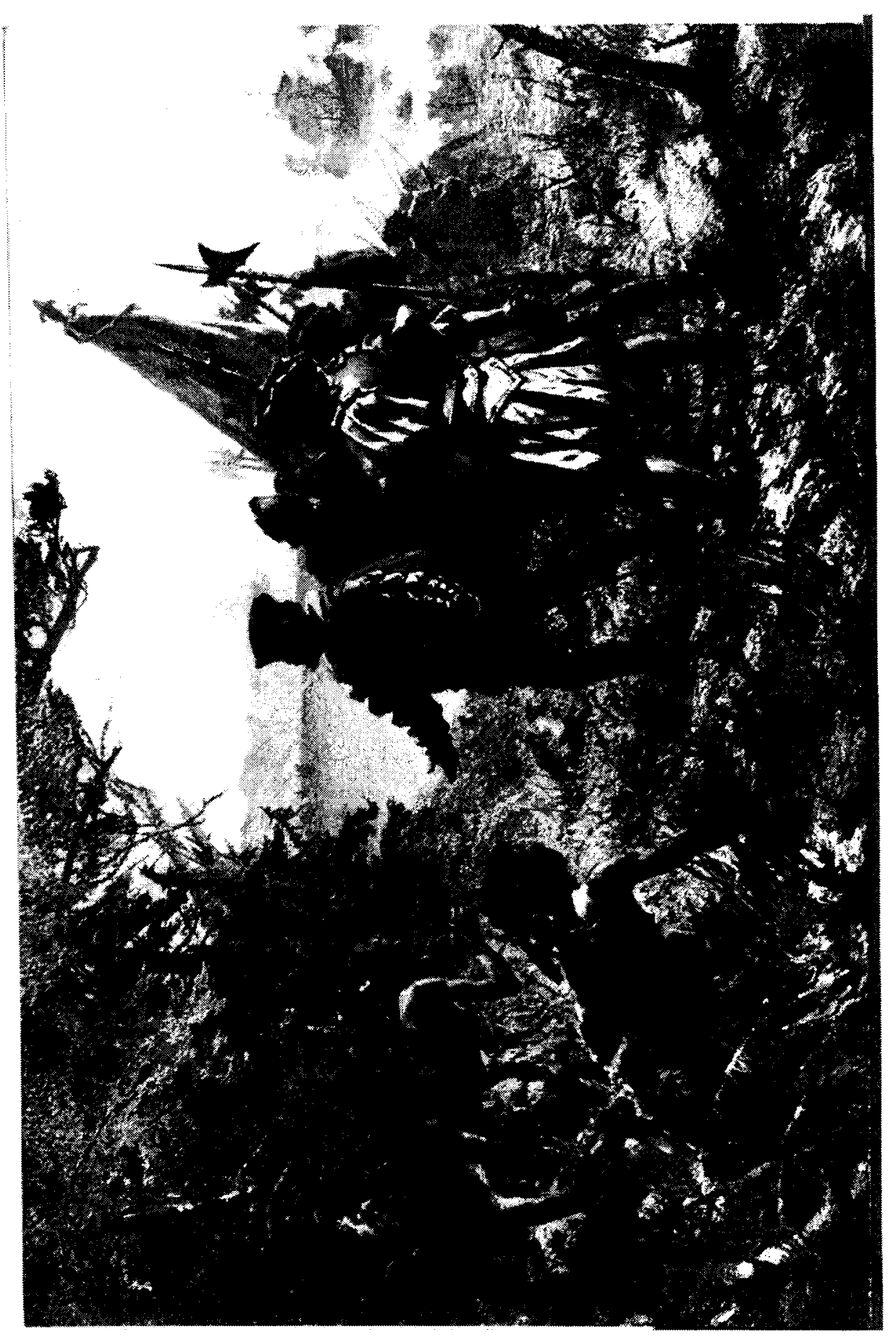

Figure 3.4 - Jacques Cartier Meeting the Indians at Stadacona, 1535, (1907) MarcAurèle de Foy Suzor-Coté. Oil on canvas, 266 x $401 \mathrm{~cm}$. Permission: Musée National des Beaux Arts du Québec, accession number 34.12. Photographer Patrick Altman. 
Also at work in Jacques Cartier is another crucial element in the exercise of imperial power, namely the "figuring of geographical difference across space as historical difference across time," or what McClintock has called the construction of anachronistic space (McClintock, 1995:40). Indeed, it was precisely this imperial masculinist ambivalence that made possible the redefinition of the colony as a temporal phenomenon. By constituting space and its inhabitants as somehow ill-formed and incomplete and positioning this space within, quite literally, a different temporal context, colonial administrators could argue that the colonies and their occupants were badly in need of technological and institutional betterment. In this sense, anachronistic space operates as a political technology insofar as the people and their surrounds were presumed to "exist in a permanently anterior time within the geographic space of the modern empire as anachronistic humans, atavistic, irrational, bereft of human agency - the living embodiment of the archaic "primitive"" (McClintock, 1995:40). Such a view of space legitimated colonial authority and ushered in a paternalistic colonialism that sought to improve upon the excesses of "nature" by drawing nature, along with its inhabitants, first into the truth regimes of Christian pedagogy and subsequently into the logocentric folds of rationality and colonial development. In the context of Canadian imperial expansion, such paternalism was expressed in the doctrine of assimilation by which state administrative authorities sought to improve the livelihoods of aboriginal people by, first, segregating aboriginal people onto reserves, and subsequently trying to reincorporate them into colonial society through their forcible compliance with European standards of social conduct (Harris, 1997; Harris, 2002). 
Other aspects of expansionist Canadian frontier policy also bear the marks of this archetypal colonial narrative. As John Sandlos argues, the 1930s bore witness to a conservationist elite, who, through an aesthetic view of the Canadian north, marginalized the Plains Cree and Dene on the grounds that their hunting practices were "wantonly destructive" (Sandlos, 2001:12). The result was a bureaucratic conservationism that segregated aboriginal people from their traditional hunting relations and attempted to reincorporate aboriginal hunting access through a regulatory apparatus prescribed by the centralized state (Sandlos, 2001). Here again McClintock's threefold pattern of colonial narration - marginalization, segregation and reincorporation of difference - seems to have played an important part in aestheticizing (and materializing) the liminal experience during the formative nation-building phase of the first half of twentieth century Canada. Both of these images, America and Jacques Cartier, are illustrative of how the colonial narration of difference constructs anachronistic space and works to produce a spatiality in which the spheres of nature and culture are circumscribed and rendered both spatially and temporally distinct. The result is a twofold representation in which an ill-formed, ahistorical and inertia-bound nature is made to stand in contradistinction to the cultured, teleological domain of European life and thus begs to be ruled over and civilized.

What is important to take from this analysis, however, is not simply the idea that the ontological existence of nature and culture, and the identifications they elicit, are highly contingent on both one another and their exclusions, nor that such contingent ontologies are born out of and reinforced through colonial encounters with difference. Rather, what is of crucial importance here is that liminal experiences, those that eschew textual or cognitive familiarity, along with the concomitant impulse to map these experiences onto the nature-culture binary, are marked by an anxiety and fear of the 
unknown, a fear that finds its resolution in the cocksure act of rendering the unknown known through a system of representation, or narration of difference. The act of knowing space, in this sense, is to foreclose one's fear of the non-space of terra incognita, to identify in fear an irrational impulse that can only be overcome by forcibly relegating it to the epistemological scrap heap. The fear of "un-certainty," according to such logic, has no place in the rigorous pursuit of knowledge, or in the materialization of one's moral certitude.

What this points to is the very important relationship between the processes of subject formation - the very idea of the subject - and the construction of space and spatiality (Duncan, 1996; Thrift \& Pile, 1995). Here, the dialectic tradition of subjectobject relations seems almost self-evident insofar as subjective identity depends on the negative recognition of an external other different from one's self. The resultant spatiality of the subject experience is a dialectical ordering of here-there, not unlike the natureculture spatiality that is re-produced through the colonial narration of difference. However, what this dialectic tradition seems to overlook in the determination of subjective experience is this fear-relation with the non-space of the unknown other, and more importantly, the abjection of fear and the objects of fear (otherness) in the practices of knowledge formation and subjectification. In other words, through the radical exteriorization of fear, a dialectic spatiality operating through what appear to be the fully autonomous spheres of subject and object comes into existence. What this suggests is that dialectical relations are not so much reflections of any real or immediate experience as they are contingent on a cultural hegemony that seeks to exteriorize or displace fear (Butler, 1992). 
This sort of critique of dialectics marks an important intervention in debates concerning the purity of knowledge and, by extension, the ontological claims that make "pure" knowledge possible. For Jacques Derrida, any claim to knowledge, insofar as this knowledge is expressed through the use of the sign (language, image, text), is always already marked by a trace, which, according to Gayatri Chakravorty Spivak, "is the mark of the absence of a presence, an always already absent present, of the lack at the origin that is the condition of thought and experience" (Spivak, 1974) ${ }^{34}$ What Spivak is getting at here, I think, is that for Derrida all signs bear the trace of whatever has been excluded from their signification. In other words, to formulate a sign and to self-identify with that sign is to circumscribe a set of relations, an act that necessarily forecloses some other corresponding or co-existent set of relations. The act of foreclosure, then, is characteristic of all signs. Moreover, to the extent that identity is constituted by sign-relations, the traces of foreclosure and absence are the pre-conditions of identity formation. What this means in terms of space is that territorially defined space, far from denoting a fully independent, segregated sphere, regardless of how objective it may be made to appear, is always marked by the traces of its absences, indeed, can only exist by virtue of these absences.

This formulation has the appearance of a negative dialect. It suggests that inside (self) is only possible alongside a "constitutive outside" (excluded other); the self is made possible by a co-existent, yet external, non-self. But the point I am trying to make here is slightly different, and can hopefully be clarified with the help of Judith Butler's notion of contingency. For Butler, in working out what it means to be political, it is not enough to simply define the political as the realm comprised of a clash between inside and outside,

\footnotetext{
${ }^{34}$ This quote was taken from the Gayatri Chakravorty Spivak's "Translator's Preface" to Jacques Derrida (1974) On Grammatology, Baltimore: The Johns Hopkins University Press.
} 
thesis and antithesis, self and other, or industrial modernity (resource extraction) versus an unassuming nature (boreal forest). It is, rather, the prerogative of any radical political project to come to terms with how the positions occupied (spaces) in a dialectic relation (nature-culture, self-other, inside-outside) are made and, more specifically, with how the contours of the "constitutive outside" are formulated (Butler, 1992:20). This is what Butler means when she invokes the notion of contingency. Constitutive outsides are not pre-given, or natural, but are contingent on how they are made. She is referring here to an explicit recognition that the constitutive outside is not pre-political or pre-cultural, but that the constitutive outside of any dialectic is both political and cultural, not pre-given, or ontologically a priori. In other words, how the constitutive outside "comes to matter" (Braun \& Castree, 1998a: 22), how it attains its cultural intelligibility, depends on the active erasure of the power relations that make it possible.

To further illustrate the point I am trying to make, the Jesuit experience in Nouvelle France is instructive. In 1657 Father Bressani produced Novae Franciae accurata delineatio, a cartographic representation of encounter with the aboriginal inhabitants of Nouvelle France (see Figure 3.5, page 99). In the bottom right-hand corner of the image, Bressani has illustrated the torture of two Jesuit priests, Father Jean de Brébeuf and Father Lalemant. In the centre of the image lies the purified space of Nouvelle France, a space made available to cultivation and civilization by virtue of the resources and the naturalized life of the native inhabitants. However, around the perimeter of the map, a liminal zone coinciding sharply with the metaphoric edge of colonial empire, Brébeuf and Lalemant are being martyred; the Jesuits' flesh being pierced, torn and burned as they suffer the indignity of death by torture at the hands of 
their Iroquois masters. ${ }^{35}$ Fear, and its close ally (dis)possession, are inscribed onto the space of Nouvelle France from its early beginning. In this image Nouvelle France is constituted simultaneously as a deeply threatened space but also one of potential salvation. Indeed, it is precisely the pervasive threat of such tortuous encounters that fuelled the Jesuit mission in Nouvelle France, such that threat and potential as two separate moments in the colonial narrative represent two sides of the same coin. They must be thought together. At the risk of universalizing the "contact experience," I use this image because it offers a vivid example of how the colonial construction of anachronistic space is ordered through a binary logic that contains its own internal teleology: archaic, threatening spaces can be civilized by harnessing the unrealized potential of the new world and mobilizing this potential to the end of social betterment in the service of God's will. This map also provides an excellent illustration of Derek Gregory's (1994) notion of the cartographic anxiety; fear underwriting the impulse to map.

This approach to theorizing the so-called 'contact' experience, those mythical moments when colonial explorers first encountered the inhabitants of far flung places, also accords well with those environmental historians concerned with tracing the origins of conservation and environmentalism through imperial power (Barton, 2002; Grove, 1995). Granted, these historians do not explicitly invoke the psychoanalytic tradition. Nor do they read the colonial experience contrapuntally in order to argue that a reading of colonial space is at the same time a reading of imperial subjectivity. Grove nevertheless alludes, to a greater or lesser extent, to an ambivalent moment underwriting the practice of colonial resource control not unlike McClintock's geographies of imperial power and erotics of knowledge. On one hand, Grove identifies that early colonial administrators

\footnotetext{
${ }^{35}$ Although difficult to make out in this reproduction, the original clearly shows the Jesuits' skin being cut open by an Iroquois man with what appear to be crustacean shells of some sort.
} 


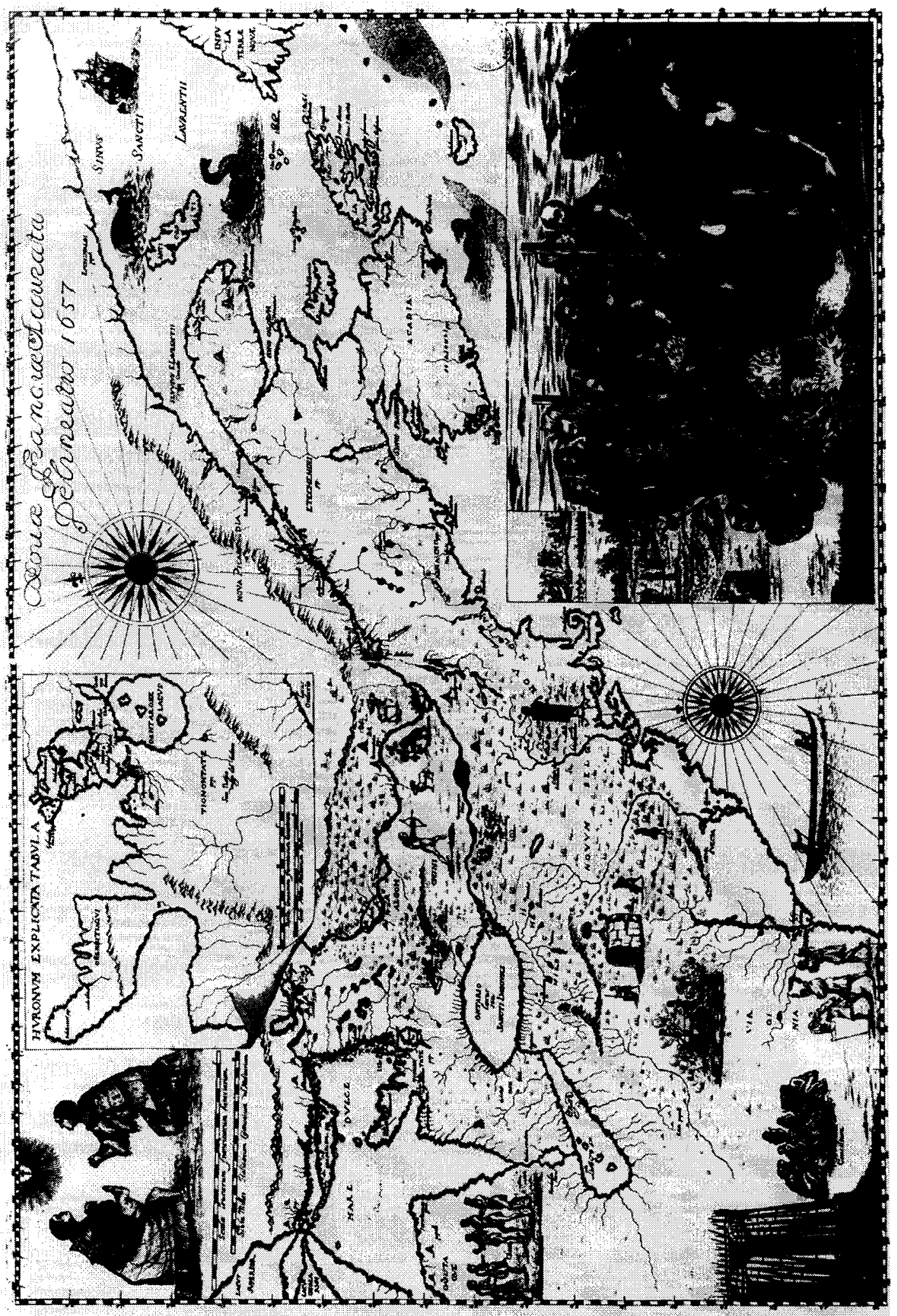

Figure 3.5 - Novae Franciae accurata delineatio, 1657, Father Bressani. Library and Archives Canada/Bibliotheque et Archives Canada. NMC 6339. 
had to confront an anxiety about the security of their possessions given that the practice of colonial resource extraction could imperil the terrestrial ecologies and climates that sustained them. Yet he also acknowledges that this fear was instrumental in the political strategies deployed by the colonials to secure their tenure.

According to Grove, it was out of this tension - between fear and possession - that a specific notion of conservation emerged (Grove, 1995:14). In other words, conservation came to embody a twofold constitution. It articulated a concern for the destruction of an artifactual nature actively constructed by the conservationist, while at the same time promised to curtail, or at a minimum, manage this destruction. Here, the application of a scientific forestry sensitive to both terrestrial ecology and the exigencies of mercantilism had the effect of recasting colonial ambivalence as both socially productive and morally imperative.

Rather than situate the origin of conservation exclusively within the American frontier narrative, as so many brands of North American environmentalism seem to do, such genealogies locate the antecedent of environmentalism within the colonial imagination. For Grove:

the available evidence shows that the seeds of modern conservationism developed as an integral part of the European encounter with the tropics and local classifications and interpretations of the natural world and its symbolism. (Grove, 1995:3)

Such evidence positions the advent of environmentalism within the colonial encounter and perhaps even more so within an elusive Europeanized search for Eden. But if the metaphor of encountering tropical paradise serves to historicize one half of the conservationist ideology, namely an encounter with a purified natural space, then the effects of colonial trade and metropolitan consumerism constitute conservation's other 
half in the form of degradation and despoliation in these same imaginary, purified and originary spaces.

\section{Locating the Boreal Sign}

But how does such ambivalence organize a particularly Canadian geographic imagination, one that constructs the Canadian hinterland as a vacant, natural space available to resource exploitation? In the Canadian colonial context, the state authority absolutely required the nature-society dualism in order to formulate its own sovereign position and legitimize state resource control, an authority that rested, and continues to rest, on an ambivalent moment not unlike that proposed by McClintock. Here the discourse of forest conservation in Canada has relied on the fictionalized image of pristine forested natural space, one borrowed from the colonial ontology, which rendered the aboriginal person abject. At the same time, the state used this image of the pristine to legitimize an aggressive assault on the very same "natural space" in the name of social progress and development. In this sense, the state sought to consecrate the pristine, while simultaneously seeking to improve upon it by rationalizing its productivity. In the Canadian context, this ambivalence comes into view in the rhetoric of the early forest conservation movement in Canada promulgated by figures like Bernard Edward Fernow and through institutions like the Dominion Forestry Service. I will attend to Fernow's rhetoric momentarily. But before I do, let me first locate the ontological production of the boreal forest in the first half of the twentieth century.

The boreal forest first entered the 'official' Canadian geographic imagination in 1937 with the publication of a map entitled A Forest Classification of Canada and Coast 
of Labrador (see Figure 3.6, page 103). ${ }^{36} \mathrm{~W}$. E. Halliday produced the map under the auspices of Roy Cameron, Dominion Forester for the Canadian Forest Service, then housed within the Lands, Parks and Forests Branch of the Canadian Department of Mines and Resources (Halliday, 1937). However, long before the publication of A Forest Classification of Canada and Coast of Labrador, the colonial and imperial authorities had routinely naturalized northern Canada as a space with enormous potential for natural resource development and for achieving the ideals of the Canadian imperial project (Shields, 1991).

Building on Gregory's notion of the cartographic anxiety, I would like to suggest that it is through the colonial narrative, one that locates the exercise of power through the colonial gaze, that the boreal forest is made to appear as an objective representation of nature. To the uncritical observer, the boreal forest of northern Canada enters the imagination as an aestheticized, natural space dominating the northernmost reaches of the Canadian map. But such an aesthetic view of the Canadian north was not at all a reflection of nature. Instead, as John Sandlos points out, such a view was intimately tied to a "civilizing ideology" espoused by a Canadian conservation elite in the early twentieth century (Sandlos, 2001:7). According to Sandlos, the conservationist ethic that framed the Canadian north was located almost exclusively in the south among a conservationist elite that actively erased the north of its aboriginal presence, an ethic expressed through all manner of state-led initiatives, most notably wildlife management (Sandlos, 2001 see also Loo, 2001).

Unlike the highly celebrated and well-documented story of forest conservation in

\footnotetext{
${ }^{36}$ This reproduction does not clearly show where the boreal forest appears on the map, but the original does. The top line of the legend on the right side of the image reads "boreal forest region." Next to it is a rectangle with a " $\mathrm{B}$ " inside it. All spaces on the map outlined by a dark black line with a " $\mathrm{B}$ " inscribed in it indicate the boreal forest.
} 


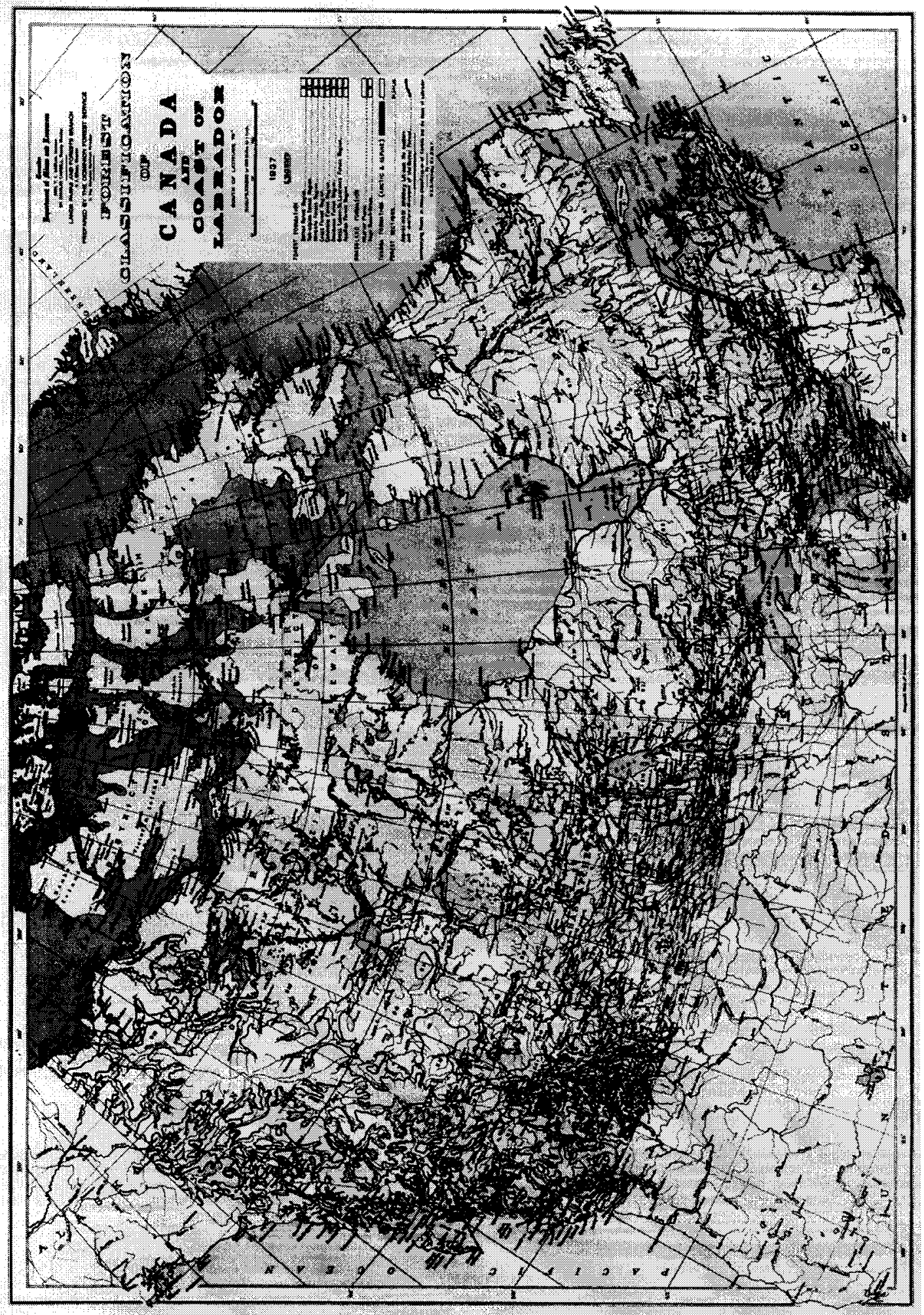

Figure 3.6 - Forest Classification of Canada and Coast of Labrador, 1937, Canadian Forest Service. Library and Archives Canada/Bibliotheque et Archives Canada, NMC 25049. 
the United States during the Progressive era, forest conservation in Canada might be read as a somewhat thwarted ambition. Numerous efforts to foment public discussion concerning forest conservation in Canada did emerge in the early twentieth century, particularly by Bernard Edward Fernow, the first Dean of Forestry at the University of Toronto, and later through the work of the Commission on Conservation. However, it is doubtful whether forest conservation ever really captured the imagination and degree of public debate in Canada to the extent it did in the United States. Nevertheless, forest conservation was a powerful development in early Canadian public policy. It also provides a very fruitful discursive site through which to observe the ordering of colonial space in early Canada along the nature-culture binary and, perhaps most importantly for my argument, supplies the context out of which the boreal forest first emerged in Canada as an object of nature.

To better appreciate how the Canadian discourse of forest conservation orders colonial space, I would first like to introduce the term forest-nature. Forest-nature is a projection, which when cast outwards from a centre serves to "dramatize the distance" (Said, 1979:55) between the centre and the treed spaces on the periphery by calling up the differences between these domains.

In this sense, it is a double-sided assumption. It represents the preconceived, taken-for-granted idea that nature can be found in the forest, while at the same time foreclosing the possibility that nature can be found in urban centres. Suzor-Coté's image of Jacques Cartier rencontre les Indiens à Stadaconé, 1535 (see Figure 3.4) is illustrative. In the image, Cartier can be read as casting his imperial gaze onto the Huron and their surroundings and projecting onto them the embodiment of forest-nature, while carving out for himself and his crew the privileged position of civility and order. 
Early cartographic representations of the Canadian north, such as those found in Tackabury's Atlas of the Dominion of Canada (Walling, 1875) and in both the 1906 and 1915 editions of the Atlas of Canada (Canadian Department of the Interior, 1906; Canadian Department of the Interior, 1915) are exemplary of how forest-nature was cast onto the space of post-Confederate Canada. In each case, forest-nature enframes; it abstracts and deterritorializes space and reterritorializes these abstractions within the teleology of the imperial observer. For Cartier, forest-nature was reterritorialized into the Christian teleology of social betterment, whereas for the Atlas of Canada cartographers, the Canadian north, represented as a green, and by implication forested, space spanning more or less the area of what has subsequently been dubbed the "boreal forest," was reterritorialized within the teleology of the burgeoning nation-state of Canada. In these examples, the colonial gaze puts the idea of forest-nature to work by circumscribing and segregating the dangerous marginality of spatial and temporal difference, and subsequently reincorporates these into the universal project of Canadian imperialism.

The practice of forest conservation in Canada, however, involved more than simply the projection of forest-nature. To paraphrase Braun, the cultural meaning assigned to forest-nature also relied on a very "potent political fiction," that of the public (Willems-Braun, 1997). This is to say that forest conservationists have always recognized that forests should serve the public interest. In the United States, Theodore Roosevelt's Progressive era conservationism was, in part, about rendering natural resources within the public domain and, more importantly, locating the authority to manage these within the federal bureaucracy (Hays, 1959). ${ }^{37}$ Doing so, it was argued, would ultimately benefit the American public, since state-led scientific management was said to guarantee the

\footnotetext{
${ }^{37}$ According to Samuel Hays, another dominant aim in Progressive-era conservationism was the installation of science as the dominant body of knowledge to be used in managing public natural resources.
} 
efficient use of the resource (Demeritt, 2001; Hays, 1959). Similarly in Canada, the discourse of forest conservation has always been concerned with managing forest-natures in the public interest. The late nineteenth and early twentieth centuries in Canada saw the emergence of forest conservation as a means, if not a rhetorical strategy, for improving Canadian forest-nature in order to secure a steady supply of timber with which to furnish two distinct, but related publics: the Canadian national economy (Gillis \& Roach, 1986; Nelles, 1974); and the British Empire. Forest-nature and some notion of the public were, therefore, integral components of the discourse of forest conservation in imperial Canada and together had the effect of locating at least partial authority to manage the public benefits of the national-natural forest in the centralized bureaucracy. Of course, much of Canadian forestry can be read as a jurisdictional rivalry between the provincial and the federal forest authorities. But the point here is that forestry in Canada is a centralizing discourse. It is centralized in a state bureaucracy, which in the Canadian context can be either provincial or federal, or both.

We can look to the figure of Bernhard Edward Fernow to see how this vision of a national forestry was organized and, in much the same way as in United States, how the idea of a "national forest" enabled a nineteenth century Canadian biopolitics of resource control. In using Fernow this way, however, I am not suggesting that he was the most important figure in the establishment of a Canadian forestry or that other prominent figures in the Canadian conservation movement, such as Elihu Stewart, Clifford Sifton Gordon Hewitt, or Ernest Finlayson, paled in comparative significance (Gillis and Roach, 1986). Not at all. These individuals were all crucially important to the development of conservation in Canada. Nor am I arguing that the politics of forest conservation can be reduced to discourse alone. Discourse is extremely important for an understanding of the 
process of capitalist territorializations of nature, particularly in light of the critique that capital codifies nature in all sorts of different ways. But discourse can never materialize outside the political economies within which it circulates. What I am suggesting, however, is that Fernow's rhetoric captures very succinctly the moral argumentation that was used in support of a Canadian state forestry authority, and is therefore exemplary of the kind of representation that linked forest-nature with national health and imperial hegemony.

\section{Bernard Edward Fernow}

Bernard Edward Fernow first came to North America in 1876 from Germany, where he had trained for many years as a professional forester. ${ }^{38}$ In 1886 he became Chief of the Forestry Division in the United States Department of Agriculture, and spent the next twelve years navigating messy bureaucratic and Congressional politics to establish a national forestry (Miller, 1992). In 1898, he resigned the Forestry Division, and became the founding head of the short-lived School of Forestry at Cornell University. In 1903, his position at Cornell was terminated when the school's funding was rescinded by the New York State authorities following a "crippling" lawsuit filed against Cornell for failing to fulfill a lumber cutting contract (Miller, 1992). In 1907 Fernow founded Canada's first forestry school at the University of Toronto. ${ }^{39}$

Aside from his institutional legacy, Fernow left behind a political philosophy in the form of numerous texts, speeches, lecture notes and reports that reveal not only his

\footnotetext{
${ }^{38}$ Gregory Barton has chronicled the history of British Empire Forestry and argues that modern professional forestry originated in Germany in the mid-nineteenth century. For more on this history see Gregory Barton (2002) Empire Forestry and the Rise of Environmentalism, Cambridge, University of Cambridge Press.

${ }^{39}$ For a detailed biography of Bernard Edward Fernow and the history of North American forestry see Andrew Denny Rodgers (1951) Bernard Edward Fernow: The Story of North American Forestry, Durham: Forest History Society.
} 
deep personal commitment to the practice of forestry, but also that his commitment was about considerably more than simply trees and forests. The ontopological ${ }^{40}$ trick of territorializing national identity in the soil is a hallmark of Fernow's rhetorical strategy, one that implies that through the rational management of trees and forests national identities could be enhanced, preserved and stabilized. Take for example, Fernow's 1908 speech before the Canadian Club of Montreal in which he advocated before Montreal's English-speaking elite the need for a national forestry. Fernow opened his address suggesting that, while societal concerns, such as

whether to extend suffrage to women, whether to abolish or reform the Senate, whether to have a high tariff, or no tariff, an income tax or a head tax, direct or indirect taxation (p.4)

were important considerations for Dominion administrators, none were more pressing for the advancement of the national interest, nor for the "power and happiness of a nation" than "two factors: man and soil" (1908:4). He went on to argue that

there are ill-advised procedures, which, without causing immediate trouble, or injuring present interests, insidiously undermine the very foundations of your national structure, and which, if not stopped in time, cause irreparable loss - and these we must attack first. (p.4)

Fernow then added that

the permanent prosperity of your nation depends on the moral character of its people and on the wisdom with which your natural resources, the soil in particular, are used, (p.4)

\footnotetext{
${ }^{40}$ I borrow the term ontopology from Erin Manning, who in turn has borrowed the term from Jacques Derrida. According to Manning, ontopology refers to "the implicit connection, in the language of the nation, between ontology (being) and topos (territory, native soil, city, or body)." See Erin Manning (2003) Ephemeral Territories: Representing Nation, Home and Identity in Canada, Minneapolis, University of Minnesota Press.
} 
and warned his audience that

if you have any conception that Canada is capable of enduring as a nation for a thousand years, do not be in a hurry to dispose of your resources wastefully. (p.4)

At work in Fernow's speech is a very familiar biopolitical technique that sought to connect the morality of Canadian man (sic) to the essence of the nation, namely its healthy soil. He suggests that if these two things, the moral character of the population or the health of the soil, waver from their purity, or are sullied by poor judgement or carelessness, the greatness of the Dominion of Canada could be jeopardized. It is not surprising that Fernow's speech assumed a strongly nationalistic tenor given that he was speaking before a group of devout Canadian nationals. But Fernow's other writing contains similar sentiments, suggesting that forest conservation and nationalism, at least for Fernow, were natural allies.

Not surprisingly, Fernow's prescription for the potentially disastrous effects of an eroding moral culture and soil base in Canada was the application of scientific forestry. The quotation at the beginning of this chapter captures this sentiment perfectly in which Fernow claims that the forester is needed to direct the work of nature. Implicit in this sentiment is the belief that, if its dangerous marginality is left unchecked, the unbounded excesses of Canadian nature might undermine the project of Canadian imperial development. According to Fernow's argument, only the forester, by virtue of his disinterest and impartiality, would be in a position to curtail the potentially devastating consequences of an unmanaged frontier. Only the forester would possess knowledge sophisticated enough to emancipate the backwoods from disorder by drawing it into the folds of civility. 
Fernow, however, was speaking not simply of the unbounded excesses of a precolonial nature inhabited by what he called "the nomads of today...the Scythians of ancient times" (Fernow, 1902:21) in reference to aboriginal people whose presence often serves to mark the threshold of the natural. Rather, his moral forestry was more strongly influenced by a frontier culture of timber extraction in Canada that failed to see the forest beyond the trees. This was a mode of extraction that favoured present over future values and preferred the individualized short-term profits of trees and timber over long-term "socially" distributed benefits of forests and forest management. In most instances agriculturalists and settlers were responsible for this form of timber extraction, since they foresaw greater economic value in converting forests into agricultural space (Gillis \& Roach, 1986). In their place, Fernow offered Canadians a vision of the forest that he considered to be far more sophisticated as it promised not only to advance the national interest, but to civilize the wilderness as well.

There is one factor of national importance resulting from the industries concerned in the conversion of our virgin forests, which does not at all, or not to the same extent, attach to them in other countries, and which, in the end, is of more moment than estimates of stumpage or land values or values of products can express. Not only does the lumberman with the systematic development of his business, which has enabled him to supply a superior article as cheaply as the inferior one is sold in Europe, give rise to many manufactories and industries, and render possible the development of distant agricultural regions, which renders profitable the building of railroads and the employment of labor, but he has been the pioneer in bringing the wilderness itself within reach of civilized influences; and which has often been done at an unnecessarily extravagant sacrifice of much of our natural forest resources, the opening up of these back woods must nevertheless be considered a potent influence for good, resulting from his business.

Per aspera ad astra, through rough work to civilization, is the history of settling of the backwoods, which the logger has accomplished. (1903:13-14) 
In civilizing the wilderness through forestry, Fernow was proposing an instrumentalism that sought to put nature to work in the interest of satisfying human desire. But it was not just any nature that was put to work in fulfilling the imperial ambition. It was an unequivocally nationalized forest-nature that was called into service. Although similar in many ways, Fernow's nature was unlike the natures employed by agriculturalists to perform more or less the same nationalizing function of feeding the nation and supplying the British Empire with calories. Rather, Fernow's conservation discourse was about managing in perpetuity the nation's natural forest according to the precepts of rational scientific production in order to guarantee a steady supply of timber products for metropolitan consumption. Although, as epistemological claims, agriculture and forestry were both about circumscribing wilderness, the two represented competing discursive modes of colonial power: both sought to regulate their encounters with colonial nature through entirely different sets of knowledge. Both visualized the same space, but to different ends. Agriculture, bound up in Lockean visions of land and property, placed sovereign authority in the knowledge wielded through the work of the colonial agriculturalist (Kuehls, 1996). Such visuality capitalized colonial nature through a specific agricultural mode of working the land, and underwrote the liberal discourse of private property. On the other hand, Fernow capitalized forest-nature through a biopolitics of public access to the forest, while granting sovereign authority to the forester who was then permitted to regulate forest-nature in the national interest.

It is at this point in Fernow's discourse on forestry that it is possible to see how the state featured as the agent best equipped to deliver the promise of forest conservation. According to Fernow, unlike the self-interested lumberman or agriculturalist, the morally 
grounded state and the impartial forester had the public interest at heart and were, therefore, best suited to deliver this system of scientific rationality.

Forestry is the business of the State or Municipality - The long time element makes it incumbent on the guardians of the future to undertake the business of forest cropping. Moreover, forestry, as far as it is concerned in the reproduction of a crop for a distant future, means financially "foregoing present revenue or making present expenditure or investments for the sake of future revenues." It is profitable only in the long run, and hence again, although there are ways in which the forester can be of financial value to the present day lumberman, only governments can finally engage in providing for the future. (Fernow, 1908:11)

The question of which level of government - provincial or federal - was best suited to manage the public forest resource, however, was an entirely different question, and was a recurring political issue between the provinces and the Dominion government. The fight for jurisdictional control over the forest resource is by now a well-known story, so need not be recounted here (Gillis \& Roach, 1986; Nelles, 1974). Suffice it to say that in Canada control over forest resources, along with the right to tax the resource, was steadily granted to the provinces from the time of Confederation in 1867 to 1930 , when the provinces of Manitoba, Saskatchewan and Alberta were finally granted these rights (Howlett \& Rayner, 2001).

However, notwithstanding almost three decades of institutional squabbling between the provincial and federal forest authorities in Canada over the place of a national forest policy and a national forest inventory (Gillis \& Roach, 1986), the point I want to emphasize here is that Fernow's rhetoric concerning the national importance of the Canadian forest authorized an imperial visuality. It permitted politicians, nationalists, professional foresters and bureaucrats to observe the space of Canada as though it were available to the imperial project uncontested. Through the language of national 
improvement, Fernow gathered up distant space and the trees that fell within that space and reterritorialized these within the teleology of the Canadian state. Yet, in doing so, there was no mention of the indigenous and frontier communities inhabiting what, from the privileged vantage of south central Canada, had been represented as liminal space. Fernow's rhetoric proceeded as though such inhabitants did not exist, or that if they did exist their lives were so poorly advanced that they resembled "the Scythians of ancient times."

Here, Fernow's biopolitical rhetoric of resource control deploys the rules of constraint that make knowledge possible and reveal its contingency. First, the space of national forest-nature is made to appear through the discourse of forest conservation precisely at the moment it forecloses the possibility that any other person or group might have been said to inhabit that space. In other words, indigenous and frontier communities are constrained from view. By this stage in the exercise of Canadian imperial development, aboriginal peoples had been removed for many years from the land, living on reserves after having been assured by the Dominion government that living on reserve would not impede their access to the land or the livelihoods they had derived from them. Others were taken from their families and deposited into residential schools where they were subject to acculturation, forced assimilation and a host of other unconscionable sexual and psychological abuses. Needless to say, the promise of access to resources never materialized, an issue that continues to infuse present-day aboriginal-state relations. In light of this sort of treatment, which some have likened to cultural-genocide (Robinson \& Quinney, 1985), it is no surprise that technocrats, like Halliday, who drew the forest regions of Canada into the imperial taxonomy with the publication of the Forest 
Classification of Canada and Coast of Labrador in 1937, overlooked aboriginal presence on the land.

Second, in Fernow's discourse where aboriginal peoples and agricultural settlers are present, they resemble nothing more than Scythians of ancient times and, therefore, according to Fernow, could not be expected to possess the technological sophistication required to manage the resource in the imperial interest.

But, as I mentioned earlier, at work in these foreclosures is not simply an innocent colonial myopia, or accident of thought that can be excused with the aid of hindsight. Instead, foreclosure marks the condition of being present and bears the mark of fear. What I have tried to show in this chapter, particularly with the aid of iconic images of Vespucci, Cartier and Brébeuf and Lalemant, is that, in the colonial register, the foreclosures that make presences possible are accompanied by fear, a fear of the Other that necessitates its abjection. I argue that the abjection of fear, in this case dangerous aboriginality and careless settlement, works to produce these images of forest purity.

The place of fear in the construction of forest-related scientific knowledge in the form of the forest regions of Canada shows up very clearly in a 1939 article written by W.E.D Halliday appearing in the Canadian Geographic Journal, the precursor to Canadian Geographic magazine. The article was published two years after the publication of the Forest Classification of Canada and Coast of Labrador in 1937, and was entitled simply "Forest Regions of Canada." Halliday begins the article with a gendered narration of the pre-colonial forest in Canada by citing a passage from Baron de Lahontan's New Voyages to North America. According to de Lahontan:

The whole Country being a continued Forrest of lofty Trees, the stumps of which must be grub'd up, before they can make use of Plough. 'Tis true, this is a troublesome and chargeable task at 
first; but in short time after they made up the Losses; for when the Virgin is capable of receiving seed, it yields an increase to the rate of an hundred fold. (de Lahontan, 1684 as quoted Halliday, 1939:229).

Through this passage, Halliday uses a gendered insemination narrative to celebrate the arrival of the colonial settler in the liminal forest. However, a few paragraphs later, he offers his reader a curious and somewhat $u n$-settling account of the same colonial encounter. He writes, "the forest dominated early settlement in a far from friendly guise. It was the enemy at the door, the check to the plough, ever present to the traveller, and often the harbourer of unfriendly native peoples." (Halliday, 1939:230) To emphasize his point, Halliday goes on to say that

This fear is strikingly illustrated in the following extract from the Jesuit Relations. As translated by Thwaites it reads: "Father Gabriel having been given to them, eight shallops and several canoes, all filled with savages, bore him away from us on the $22^{\text {nd }}$ of September of last year, 1647 , to take him eighty or one hundred leagues from Kebec, into the land of shades, so to speak, that is to say, amid frightful mountains and forests, where the sun never looks upon the earth except by stealth." (Halliday, 1939:230)

Taken together, the foregoing passages suggest that Canadian forest-nature, far from a fully essentialized space, is instead marked by a profound patriarchal ambivalence. On one hand, it is the Virgin, which if forcibly brought under control, is capable of receiving seed and producing bountiful yields (the fantasy of unstoppable rapine). On the other, it is representative of the enemy at the door (the fear of engulfment and emasculation). Halliday goes on to say that, "it is true that the forest provided valuable building material and most necessary firewood, but the urge was to get rid of it" (p.230). Against this ambivalence and in support of the "urge...to get rid of it," the rest of his account rationalizes Canadian forest-nature; Halliday assigns each section of the 
Canadian hinterland a place in the imperial forest taxonomy. Here, it is possible to read the rationalization of the Canadian hinterland as an attempt to fantasize away an irrational space and thus make room for a superior, objective and ordered forest-nature that can be put to more productive use in fulfilling nationalist ambitions.

It is in this sense that Fernow's nationalist rhetoric authorized the production of the Forest Classification of Canada and Coast of Labrador map in 1937 and inadvertently helped draw the boreal forest into the realm of the political. His discourse constructed the sign of a national forest-nature and released this sign into the institutional apparatus of the Dominion administration.

It would be misplaced, however, to assume that Fernow's discourse on forest conservation was the direct reason that the Forest Classification for Canada and Coast of Labrador was produced. His was simply one form of nationalist rhetoric that emphasized the importance of forestry as a body of knowledge that could fulfill the imperial ambition. Nevertheless, Fernow's dialogue is important for, unlike any other, his was the first in Canada that gathered together forested space on a national scale, and constructed forestry foremost as a nationally focused enterprise.

\section{Representing Exclusion: Rereading the CFS-CG Boreal Map}

My aim in this last section is to reread the Canadian Forest Service-Canadian Geographic poster-map of the boreal forest that was presented at the beginning of this chapter. In particular, I want to draw attention to how the construction of the boreal forest appearing on the poster-map exteriorizes aboriginality. With the use of a pictorial narrative, I want to show how aboriginal exclusion marks the teleological narrative of progress in which the forest moves from being locked in a state of nature to being put to 
full productive use in the present. In this, I want to consider how the boreal forest attains its legibility as a productive national asset.

There are two separate places on the CFS-CG map where the boreal forest origin story begins with its aboriginal inhabitants, once on the front and once on the back. In both, aboriginality is represented as a fixture of the past, something displaced by time. I will examine both.

On the front of the poster-map, in the upper right corner, is a short narrative that captures very simply how aboriginality is marginalized in national forest discourse and becomes synonymous with the original state of the boreal forest. The narrative appears as a series of three images arranged in what is meant to be chronological order.

Accompanying each is a short descriptive sentence or two. Immediately beneath each image is a set of bullet points that provide some additional information about the corresponding temporal period. The first image is a black and white photograph of a group of aboriginal people engaged in what is meant to represent a typical, traditional scene of aboriginality. In the foreground is a birch bark canoe, a symbol of aboriginal traditionalism. Behind the canoe are several aboriginal people. Two men stand to one side wielding steel axes and smoking pipes and behind them stands a woman, who is also shown smoking a pipe. Next to them is a wigwam, a few more aboriginal people and behind the wigwam there is what appears to be a canvas tent. What is striking about the image is that the accompanying text bears no apparent relationship to the content of the image aside from the fact that aboriginal people seem to be the common theme. Here the text mentions that, "for early northern natives the boreal forest was not so much a landscape or resource, as a world, a complex natural support system on which they founded their lives". What this statement suggests is that, unlike European settlers and 
dominion expansionists, aboriginal people lacked the capacity to see the boreal forest as an aesthetic landscape or resource. Instead they are simply made to occupy a distant past contiguous with the naturalized forest. This is reinforced in a textbox header, appearing immediately beneath the photograph, which reads " $7,000-8,000$ years ago," suggesting a time period that long preceded the arrival of Europeans. The text in the textbox informs the reader that after the last ice age receded thirteen thousand years ago the boreal forest appeared and was soon followed by the in migration of its $a b$-original inhabitants. Yet, in the photograph, there is really nothing to suggest that the people in the scene are part of a distant past any more than early colonial settlers were. For instance, everyone in the image wears clothing far more typical of what might have been worn by European settlers up until World War One. The men wear pants and shirts and the women wear long dresses. The axes, the pipes and canvas tent also suggest the same. Indeed, it would not be difficult to find an archival image of a group of Europeans engaged in much the same sort of scene. Instead, the image and the accompanying text together construct an anachronistic space that naturalizes aboriginality and displaces aboriginal people onto a past that co-exists, albeit contradictorily, alongside the forces of modernity.

This image is followed in the chronology by two subsequent images, one depicting an old industrial sawmill, presumably in operation around the turn of the century, and the other a much more modern pulp and paper plant, which appears far more sophisticated technologically than its predecessor. Overall, this small set of images exemplifies the modern teleology of the boreal forest by telling how the boreal forest was once a space of aboriginality (not so much a landscape or resource, as an aboriginal cosmos) and, as history progressed, has come to assume its rightful place at the centre of a productive economy, fuelling twentieth century, global demand for wood and pulp 
products. Indeed, its development follows very closely the development of the Canadian nation. Once a relatively minor colony in the Commonwealth, Canada is now a fully recognized participant in the global economy. Accordingly, aboriginal people simply fade into the past, disappear into the ledgers of history and become human artefacts of a culture that demands to be recovered.

On the reverse side of the map a similar displacement narrative is at work. In the upper left corner of the poster, the text continues, "Aboriginal people who made the boreal forest their home saw themselves as part of a world imbued with spirits." This text is overlaid onto a photograph of an aboriginal pictograph and the word "Spirits" written in large, bold, white lettering. ${ }^{41}$ This is followed by three short paragraphs explaining that in the past aboriginal people sought guidance from these spirits as they drew their livelihoods from the boreal forest. This is then followed by a short history explaining how the first Europeans to arrive in the boreal forest were drawn there by a quest for furs and that the boreal forest has played an important part in Canadian aestheticism. Later, however, the CFS-CG map calls attention to the unsaid presence of aboriginal people in the boreal forest where it says, "that spirits still linger in the boreal forest." According to the Oxford English Dictionary (1989), to linger is "to stay behind, tarry, loiter on one's way; to stay on or hang about in a place beyond the proper or usual time, especially from reluctance to leave it." By this definition it seems that, despite being displaced, despite modernity's ongoing crusade to expel them from the forest, the spirits persist. The postermap text offers this notion of lingering spirits in a celebratory manner, suggesting that they "remind us that there is more to the boreal forest than trees and other living creatures. They reflect the roots of our culture." Yet what the poster-map does not specify

\footnotetext{
${ }^{41}$ The pictograph shown is from an important pictograph site in Lake Superior Provincial Park in Ontario, and is located on rock shelf on the east shoreline of Lake Superior. Ironically, Lake Superior Provincial Park does not fall within the boundaries of most conventional representations of the boreal forest.
} 
is to whose culture these spiritual roots belong. Given the nationalist tenor of the CFSCG poster-map, one is left to believe that they are the roots of Canadian culture, a national culture, which, as the remaining text makes very clear, rationalizes the forest. The rest of the poster-map subsequently discusses the role of the state in managing the forest fires that are pervasive throughout the boreal forest and in operationalizing sustainable forest management throughout the boreal.

For the purposes of my argument, the details of the ensuing discussion on the role of the state in managing the forest are not as important as the general narrative pattern of the story itself. The textual representation of the boreal that accompanies the map is full of inconsistencies and elides many important historical details and for this reason has no pretence to being a complete representation of the boreal's place in Canadian environmental history. To read the poster-map for its inconsistencies, thus, might suggest that what I am offering is a more accurate reading, or that I am challenging the veracity of the claims it makes by exposing its falseness. To challenge the truthfulness of the poster-map on the grounds that it does not accurately represent the boreal forest is to assume that the boreal has a physical presence that can be represented more objectively. Instead I want to draw attention to how the boreal forest is constituted by a specific national narrative that displaces aboriginal people into the past and in so doing cleanses the boreal forest of its human inhabitants and makes the forest available to all manner of national investments - symbolic, capital, national, poetic, political and so on.

In this respect, three more images on the poster-map bear mentioning. Each appears on the far right side of the front face of the poster-map. And each suggests that with the advent of modernity, following the displacement of aboriginal people, the boreal forest has finally achieved its full purpose since it is now being put to proper use. 
Whereas it was once a space were spirits dwelt, a space inhabited by aboriginal people, with the arrival of modernity the boreal forest can now fulfill a much more socially useful function of furnishing and nurturing the Canadian nation. In the first image, three construction workers are shown framing a new home under construction, one commonly found in suburban housing developments all across North America. The San Fernando Valley, perhaps? Or maybe one of the numerous subdivision developments that sprang to life on the outskirts of the Greater Toronto Area during the mid to late 1990s (Keil \& Graham, 1998). It also creates the distinct and uneasy impression that for this largely white, suburban culture the boreal forest is nothing more than a source of inexpensive timber. The second image shows a white man, presumably a scientist or resource manager of some sort, with a clipboard and pen, closely examining the quality of a tree sampling. His presence suggests that the boreal forest is being carefully managed through an objective, disinterested science that has only the national interest in mind. The third image depicts three white people paddling in canoes on a lake somewhere in northern Canada. In all three images, the boreal forest appears entirely devoid of political content and is repositioned within the respective narratives of national economic growth, public management of the national forest, and leisure. No mention is made in these images that throughout the boreal forest aboriginal peoples have been marginalized from the land and in so many instances contest the exclusive state ownership of these lands. Instead, it is simply assumed that the boreal forest is a Canadian asset, whose rational management will enhance the lives of all Canadians. These are all very powerful images and are worthy of far more careful consideration than what I have given them here. In the next chapter, however, I will consider in much finer detail the ramifications of the third image 
- the act of canoeing in northern Canada - particularly as it pertains to the politicization of the boreal forest of northern Canada, racialization and performative identity. 


\section{Chapter 4}

\section{Recovering Borealia: \\ Canada's Boreal Forest As Recovery Narrative}

The recurrent metaphor of landscape as the inscape of national identity emphasizes the quality of light, the question of social visibility, the power of the eye to naturalize the rhetoric of national affiliation and its forms of collective expression.

- Homi Bhabha, The Location of Culture

[The] canoe is a symbol of and for Canada...This frail craft, originally made of the bark of the birch tree, thin cedar slats, spruce roots, and pine gum, carries a heavy symbolic and metaphorical load.

- C.E.S Franks, book review of The Canoe in Canadian Cultures

When we enter the 'Canoeable Canadian Landscape,' we believe we are rediscovering and reinforcing our national virtues.

- Daniel Francis, National Dreams

\section{Boreal Nation}

"Canadians divide into two groups: those who use and love canoes, and the rest" (Franks, 2000:393). This is the opening sentence of C.E.S. Franks' review of a book entitled The Canoe in Canadian Cultures. And whether Franks realized it or not, it captures exceedingly well what is at stake in the mapping of national experience. Very simply, Franks' remark suggests that some experiences are constitutive of the national imagination whereas others are simply not. Embedded within the quotation is the idea that whatever sorts of things "the rest" use and love are of marginal significance, whereas the use and love of canoes unproblematically gives rise to a category of Canadian-ness that is made to exist apart from anything else. What intrigues me about Franks' statement 
is that the cultural passion he seeks to represent hinges so unambiguously and unapologetically on its closure. But perhaps even more compelling is that such closure finds unwitting resonance within the contemporary field of Canadian conservation politics.

I open this chapter with this quotation because it also illustrates that the articulation of national identity is frequently concerned with qualifying what counts as national activity and that so much of qualifying what counts as national activity involves exclusion and closure. This is not a new idea. Elucidating the exclusionary habits that produce the nation and the national subject is a theme that runs through postcolonial studies, where according to Homi Bhabha, "the political unity of the nation consists in a continual displacement of the anxiety of irredeemably plural modern space" (Bhabha, 2004:213). A corollary to this is that the subject of national activity is also marked by these exclusions and by the displacement of a modern anxiety. In this sense, the abject is not made to stand apart from the national subject, but rather is fully constitutive of the national subject. This is to say that, while a perceptible distance may physically segregate the subject and abject, this distance, and the autonomous subject this distance is said to guarantee, is much more difficult to sustain metaphysically, since an ontologically discrete subject can always be shown to be marked by its outside. For Judith Butler:

...the subject is constituted through the force of exclusion and abjection, one which produces a constitutive outside to the subject, an abjected subject, and abjected outside, which is, after all, "inside" the subject as its founding repudiation. (1993:3)

I raise these issues - identity, nation, exclusion, culture and the canoe - here because so central to the articulation of the Canadian boreal forest as a natural object of 
environmental concern in recent years has been its articulation as a national phenomenon of political concern.

As a national site in the language of contemporary environmental politics, the boreal forest is made to stand as a liminal space synonymous with the abstract nation, not unlike the myth of the north. And to the extent that this is so, the environmentalization of the boreal forest can easily be read as the next evolution in the development of Canadian myth. This is important because through its articulation in recent years as a political concern of national importance, the boreal forest has become emblematic of the northern myth of Canadian culture, and is being reconfigured as yet another site in the ongoing struggle to secure and stabilize a national imagination and with it a privileged national subject. The politics of the boreal forest can thus be thought of as a national politics of double fulfillment, where the abstract space and the 'homogeneous empty time' (Bhabha, 2004:226) of the sign of the Canadian nation is filled in by the myth of the north and where the boreal forest is, in turn, made to occupy this mythical space (Figure 4.1, page 126). Here, the boreal forest is invoked to provide greater definition to the space of the north and to the abstract nation. Whereas the mythic north is often construed as an expanse that exceeds the imagination (Davidson, 2004), the boreal forest delimits the imaginative geography of north by giving it a definitive presence. Consequently, through the environmentalization of the boreal forest and its articulating language of Canadian canoe culture, Canadian national identity and environmental identity are thus asserted as a singular frame of political reference (see Figure 4.1, page 126). Important to bear in mind, however, is that these founding myths of the nation - the north and the boreal forest - are fully constituted by their founding repudiations, abject bodies and abject 


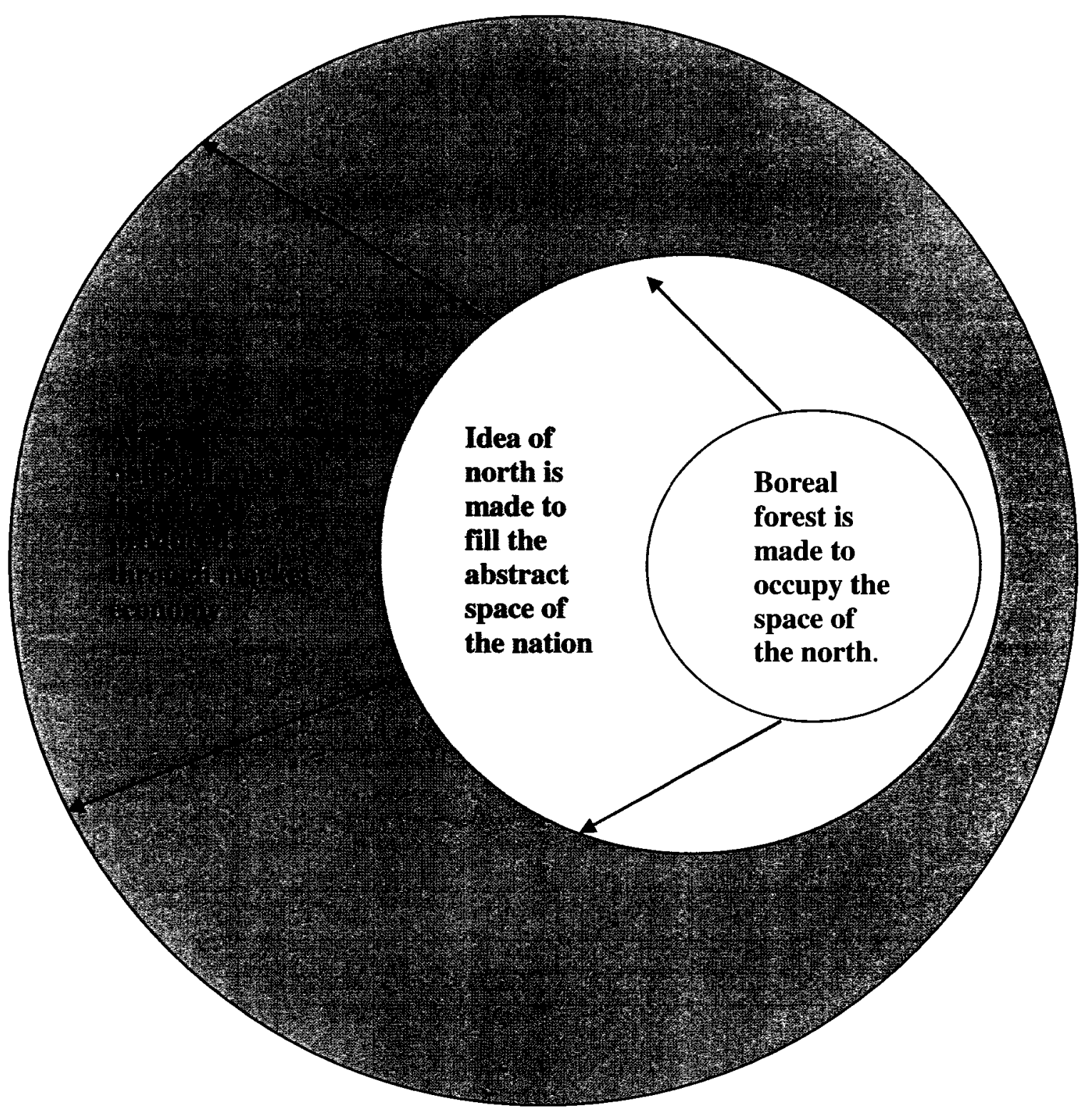

Figure 4.1 - Concentric filling of abstract, homogeneous nation with culturally specified space. 
domains that may not be visibly present in the mythology of dominant Canadian culture, but which are nevertheless apparent, appearing almost like apparitions, in the scenes of the nation.

Building on recent work in critical geography and anthropology, I would like to argue that these forms of abjection should be read as racialized exclusions (Moore et al, 2003). As I have already mentioned, the idea of the Canadian north stands as an abstract universal sign of Canada, and is routinely populated by representations that depict it in pure, ahistorical and aestheticized terms. But, if the fundaments of poststructuralism are taken seriously, neither the myth of the north, nor the abstract national space it is made to occupy, can take objective form outside the exercise of power: power renders visible and in the same move it constrains. As such, the myth of a pure, icy cold, windswept Canadian north is frequently used to depict official Canadian culture. This is immediately obvious in the image appearing in Figure 4.2 (page 128), which depicts a birch bark canoe sitting prominently in the National Gallery of Canada amidst a host of iconic images of the Canadian north. But constrained from view in the formation of the Canadian north are the racialized bodies that mark its limits, aboriginal bodies that haunt the liminal experience and ethnic bodies that occupy zones of alterity in the urban landscape. Such a reading of the Canadian north is important for as Moore, Kosek and Pandian argue not only does "landscape [articulate] both culture and nature, seer and scene" (Moore et al, 2003:11), "race and nature are constitutive features of modern power" and "integral to the rule of modernity rather than an exception" (Moore et al, 2003:15). 


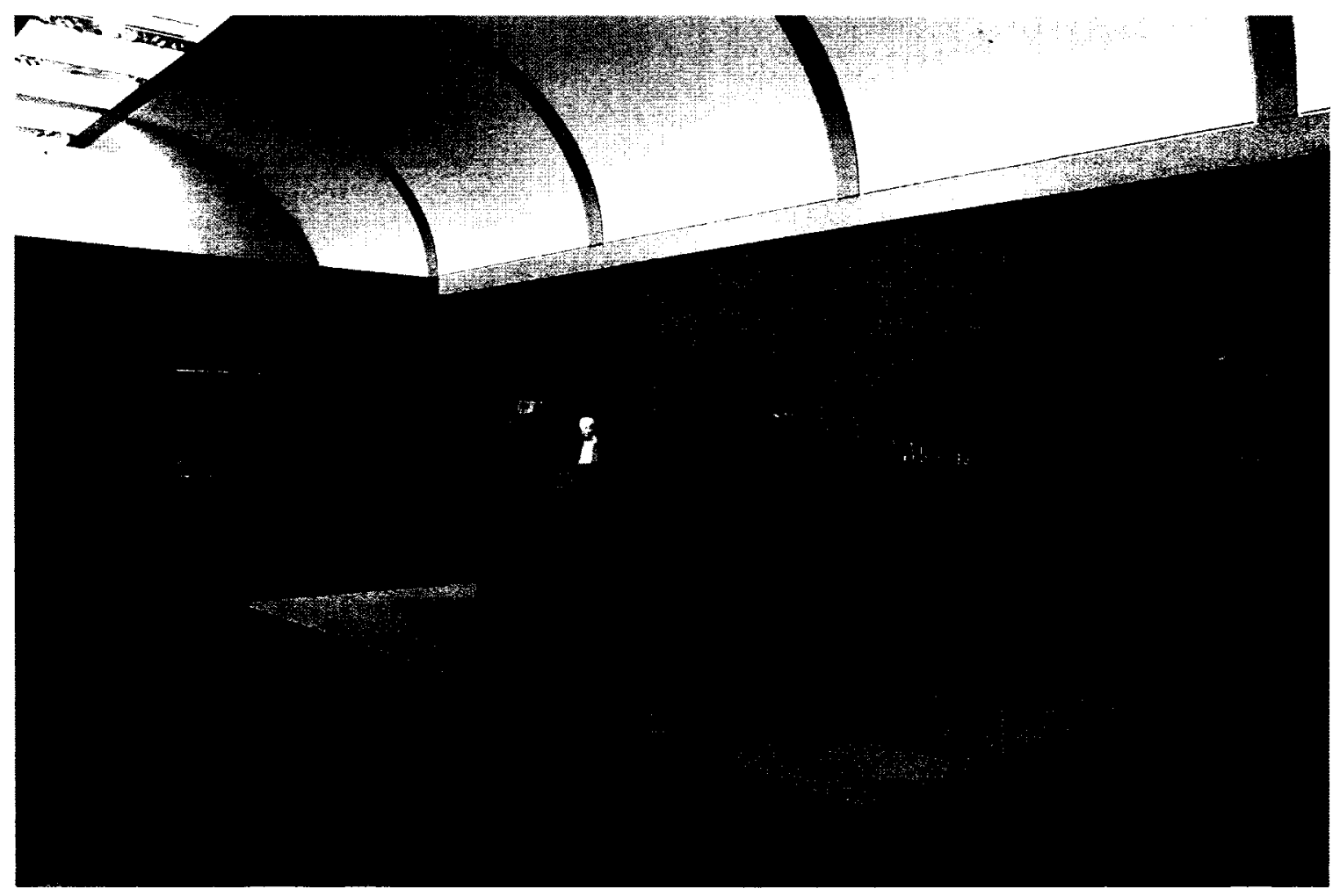

Figure 4.2 - Birch bark canoe on display in the National Gallery of Canada, Ottawa, surrounded by iconic images of the Canadian north. Noteworthy in this regard is Lawren Harris' North Shore, Lake Superior (1923) to the left. Permission: National Gallery of Canada, Ottawa. 
These are all very broad themes so let me contextualize them. As I have already mentioned in Chapter 1 the boreal forest has emerged in recent years as a site of national political significance. In this chapter, however, I aim to show that one of the ways this political significance has been achieved has been by articulating the boreal forest within the discursive formation that binds together the canoe and Canadian culture. What I mean by this is that there exists a hegemonic cultural logic in Canada that organizes how the canoe features within Canadian culture, both as something to use and revere, and this cultural logic has been used to politicize the boreal forest (Benidickson, 1997; Hodgins \& Hobbs, 1985; Jennings et al, 1999; Raffan \& Horwood, 1988). Through such readings of Canadian canoe culture, the canoe is aestheticized and has come to symbolize the abstract space of the Canadian nation, since, as the argument goes, it is one of the only means by which the Canadian landscape can be experienced. This argument also embodies a profound normativity for as Raffan and Horwood assert, "a portent of the canoe's place in Canadian culture is the fact that it remains the most appropriate vehicle for travelling the greater part of this boreal country" (Raffan \& Horwood, 1988:1, my emphasis). To the extent this might be the case, ${ }^{42}$ following McClintock, I argue that the canoe emerges as a "threshold object" (McClintock, 1995:24), meaning that its very presence and use mark some threshold of the imagination where the space of the same gives way to difference, an embodied structure of feeling that organizes space into two distinguishable, albeit gendered, hierarchical realms - familiar/strange, masculine/feminine,

\footnotetext{
42 There can be no doubt that the canoe is an elegant watercraft. However, I want to insist that the canoe may not be "the most appropriate vehicle for travelling" the Canadian hinterland, on the grounds that the snowmobile, snowshoe, dogsled, float plane and bicycle also represent modes of transportation that have been and can be adapted to remote travel in the Canadian north. At the core of this assertion, therefore, are critical questions concerning what qualifies as "appropriate" and "travel." If for example "appropriate" is read in commercial terms, then perhaps the snowmobile is more appropriate given that snowmobile travel contributes enormously to the winter economy in the north.
} 
rational/irrational. Building on this idea of the canoe as a threshold object, I argue that the recent emergence of the boreal forest as a nationally significant (and politically important) ecosystem is organized through a similar structure of feeling. In short, the boreal forest attains its legibility as a political site in environmental discourse through the familiar signifier (the nation), signified (the canoe) and embodied referents (bodily normativity) that pervade an already existing Canadian national culture.

In this chapter, then, what I would like to do is pay close attention to the ideas of nature and race in the culture of Canadian nationalism by examining a recent effort to politicize the boreal forest of northern Canada. I will argue that this effort routinely articulated the Canadian boreal forest as both a national and natural space and that, as such, the boreal forest is an important site on which the narrative of national recovery is staged. It is furthermore argued, however, that through the tactical choices made by those groups politicizing the boreal forest, the canoe trip, a cherished "Canadian" pastime, becomes one of the privileged means by which such national recoveries might be experienced and lived. Yet, far from offering an unmediated experience with nature, the canoe trip is predicated on an ocularcentrism that looks past the politics of exclusion that work to construct the boreal forest as a space of national nature. ${ }^{43}$ Instead, the structure of feeling organizing the canoe trip experience produces the very effect it seeks out, namely unmediated nature, which is also of an invisibly racializing kind.

I will say more about the performativity of national-nature and its regulation of the national subject later. But for now, let me say that what makes this conjuncture between Canadian canoe culture and the boreal forest - even more compelling is that, far

\footnotetext{
${ }^{43}$ I borrow the term ocularcentrism from Sasha Davis who uses it to describe the curious visual logic that celebrates Bikini Atoll, one of the atolls in the Mauritius archipelago, as a wilderness zone. This in spite of the fact that Bikini Atoll was used for several decades by the US military as a nuclear testing site and has been bombed well over 25 times (Davis, 2005).
} 
from naming a culture-nature relation that operates outside the field of power, it reiterates a nineteenth century biopolitical discourse that drew together the categories of nature, race, class, nation and bodily practice in the production, regulation and stabilization of national subjects. This is important because once again it challenges the taken-for-granted assumption that underlies the epistemological claim that the boreal forest is an ecological fact of nature the ontological status of which is guaranteed by its very presence. Rather, it proposes that the boreal forest is actively constituted by its own founding repudiations of class and race. By calling into question the metaphysical fixity of the boreal forest, we can begin to recognize that the environmentalization of the boreal forest is rendered visible through the spectacle of national recovery. Seen through such an optic, the boreal forest becomes as much a space of ecological importance as it is a stage of national importance. It emerges as a scene of national recovery, one in which the geographic particularities of Canadian experience are subsumed under the universal sign of Canada. And perhaps of even greater consequence, the environmentalization of the boreal forest can also be read as a raced and classed politics.

\section{Geographies of Whiteness}

It is important to situate this discussion of nature, race and Canadian identity within on going debates in geography concerned with race and racialization. As critical geography scholars now point out, through its implication in the imperial project, the practice of geography was founded, at least in part, on the mapping of racial hierarchy. It is also argued that, while the invocation of race as a biological fact of nature no longer has any epistemological credibility, geographers inadvertently continue to "reinscribe[s] many of the racialized metaphors upon which it [geography] was established" 
(Kobayashi \& Peake, 2000). Landscapes, for example, continue to bear racialized inscription (DeLuca \& Demo, 2001; Kosek, 2004) and through such inscriptions work to normalize particular modes of subjectivity. Moreover these critical interventions serve as a reminder that race and racialization mark the practice of geography in profound ways and that geographers should attend more closely to how this is so.

Important in these discussions, then, is critical attention paid to the geographies of whiteness where it has been argued that the normative power of whiteness operates precisely through its invisibility as a racialized form. This is to say that in certain contexts, whiteness simply does not need to be explained as a social phenomenon. To take Canadian multiculturalism as an example, such a view suggests that whiteness as an invisible marker of identity works to normalize Canadian identity as white by representing Canadian society through a discourse of racial diversity. There is an explicit recognition, for instance, that Canada, through its economic dependence on immigrant labour, is becoming increasingly multicultural (read: increasingly racialized). Hence, the argument is often made that the fabric of Canadian society is changing and that Canada has become a very diverse place. The City of Toronto for example is often celebrated as one of the most diverse municipalities on the planet. However, embedded within the casual observation that Canada is becoming more multicultural is the implicit assumption that at one point Canada was less multicultural (read: less racialized). The subject position that enables the recognition of Canada's 'increasing' multicultural-ness occupies a vantage that allows for the recognition of change to occur in precisely these (raced/cultured) terms. The recognition of Canada's changing 'face' suggests that Canada (i.e.: Canadian identity) is no longer what it used to be, that is, white. Accordingly, or so the implicit logic goes, original Canadians were white, Anglo-Saxon or Protestant, 
whereas new Canadians have a tendency not to be. Effaced from the discourse of 'increasing diversity', however, is the fact that racial and ethnic diversity has always been an aspect of Canadian culture. Diversity, in other words, is not a recent phenomenon. Yet the invisible whiteness behind the claim that diversity is increasing in the present suggests that it is.

These observations have important consequences for the politics of Canadian identity because, as I have already mentioned, national identity is very closely linked to national activity, where one's claims to Canadian nationhood are often predicated on and articulated as what one does. Official Canadian culture teaches that true Canadians endure cold weather without complaint, play hockey, consume copious amounts of beer, go camping, paddle around and have (hetero)sex in canoes, celebrate indigeneity and have an enduring respect for public debate and cleverly written legislation. Thus true Canadian culture, as opposed to new Canadian culture, obtains its place in the official Canadian imagination because it can trace its lineage within the historical geographical trajectory of Canada. The important point here, however, is that these activities, which are meant to articulate a singular Canadian culture, are heavily racialized. In other words, white Canadians will likely experience these activities differently than would non-white Canadians.

With this in mind, what this chapter aims to do is draw attention to the racialized dynamics that are at play in the politics of the boreal forest. Here when I refer to racialized dynamics, I mean this in two senses, but will only focus in this chapter on the second. In the first sense, the politics of the boreal forest are articulated almost exclusively as a white, urban, middle- and upper-class set of concerns that have to do with either the preservation of the boreal forest, or its conservation. Here, the imagined 
geography of the boreal forest as a national domain features as the common denominator in both sets of related concerns. As such, boreal forest preservation and conservation are not articulated as something that might be of concern to newly arrived immigrants, or well-established ethnic groups residing throughout Canada, but are instead, simply articulated as matters that should concern all Canadians. After all, as the logic goes, environmental despoliation knows no boundaries, whether national, ethnic, regional and so on. But the critical point here is twofold: environmental despoliation is experienced differently across race and class boundaries; and the boreal forest is only represented to a specific group of privileged urban Canadians.

The second racial dynamic at play in boreal forest politics is the one that concerns me in this chapter. Here, my specific concern has to do with the representation of aboriginal people as aboriginal people in various texts that have been used to politicize the boreal forest. How this is significant will become more clear as I proceed with my argument.

\section{Boreal Rendezvous}

In making these claims about race, nature, Canadian canoe culture and the boreal forest, I will be drawing from a recent publicity (political) campaign orchestrated by the Canadian Parks and Wilderness Society (CPAWS), a Canadian non-profit conservation organization, alongside several other of their partner organizations - environmental groups and organizations, foundations, a retailer outlet, a university and an internet travel website to name just a few- in which the boreal forest was cast as a political object. ${ }^{44}$ The

\footnotetext{
${ }^{44}$ The complete list of organizations involved in one way or another in the Boreal Rendezvous and the True North Wild and Free campaigns are: Adventure Nouvell; Boréale; Canadian Boreal Initiative; CBC RadioCanada; Canadian North; Canadian Parks and Wilderness Society; David Suzuki Foundation; Domtar Inc.;
} 
campaign, dubbed by its organizers the Boreal Rendezvous: True North Wild and Free, was carried out in two phases over the course of the summer and fall of 2003, and had the intended purpose of elevating the political profile of the boreal forest in the minds of the Canadian public. It was a publicity campaign that sought to educate Canadians about their own natural history by demonstrating to Canadians that the boreal forest bears an enormous responsibility in mitigating global climate change through its retention and sequestration of carbon, preserving biological diversity and providing for the health and well-being of all Canadians.

The Boreal Rendezvous is linked directly to a broader North American environmental/conservation movement, which has been drawing political attention to the boreal forest for several years. The Boreal Rendezvous is, therefore, probably better thought of as one component of a much larger, heterogeneous political network that is seeking to alter how and under what conditions capital accumulation in the boreal forest is conducted. For its part, the Boreal Rendezvous represents a public education campaign targeting a specific segment of the Canadian population, namely those who identify in the broadest sense with Canadian canoe culture, such as outdoor enthusiasts, birders, professional and amateur naturalists and landscape artists. ${ }^{45}$ Other organizations, on the

\footnotetext{
Expedia.ca; George Cedric Metcalf Foundation; GPS Central.ca; Giles W. and Elise G. Mead Foundation; Horizon's Unlimited; Marquardt Printing; Mountain Equipment Co-op; Nahanni River Adventures; Patagonia Inc.; Queen's University; Royal Geographic Society of Canada; Sila Sojourns; Stikine River Song; The EJLB Foundation; The McLean Foundation; The Richard Ivey Foundation; The Tragically Hip; The Walter and Duncan Gordon Charitable Foundation; The Wilburforce Foundation; The William and Flora Hewlett Foundation; Tides Canada Foundation; VIA Rail Canada; Walden's Guiding and Outfitting; WWF Conservation Science and Solutions Fund.

${ }^{45} \mathrm{~A}$ few more issues relating to CPAWS and its role in boreal forest conservation bear mentioning. First, while CPAWS operates a national office and organizes national campaigns, it is, for all intents and purposes, a decentralized institution. It consists of several regional and provincial chapters. I mention this because not of all of the work that CPAWS does is oriented towards the boreal forest. I do not want to cast CPAWS as a single-issue organization. Second, the Boreal Rendezvous represents just one aspect of CPAWS' boreal forest work. Outside their public education campaign, CPAWS has been involved for several years with a number of First Nations, including Pikangikum First Nation in northern Ontario, on issues of land rights and forest tenures.
} 
other hand, fulfilled very different functions, such as producing cartographic information, seeking to reshape industry structure by directly influencing markets through consumer education, and engaging in policy development. I have chosen to focus my attention on the CPAWS campaign given that it was so highly visible. Other efforts to politicize the Canadian boreal forest in recent years have not, at least to my knowledge, sustained a media presence to quite the same extent.

The first phase of the campaign, staged over the summer of 2003, was organized as a series of ten, multi-day canoe expeditions along ten different rivers in Canada. Probably one of the more interesting aspects of this political campaign is that many of the canoe trip participants were notable Canadian celebrities. ${ }^{46}$ The canoe trip staged on the South Nahanni River in the Northwest Territories, for example, included Justin Trudeau, the first son of the former Prime Minister of Canada, Pierre Elliot Trudeau. This is significant because it was in 1976, during Trudeau's tenure as Prime Minister, that the Canadian federal government established the Nahanni National Park Reserve as a means of safeguarding the river against hydroelectric development. This trip was thus represented as Justin retracing his father's footsteps. In 1970, the elder Trudeau had paddled the South Nahanni River on a well-publicized canoe trip. Now, almost 35 years later, Justin is shown returning to the very same place to voice his conservationist appeal.

\footnotetext{
${ }^{46}$ Those celebrities on the Boreal Rendezvous canoe trips included: Laurel Archer (outdoor educator, writer); Douglas Cardinal (architect); Tom Cochrane (rock musician); Wade Davis (ethnobotanist, photographer); Brian Deines (author); Marc Déry (singer-songwriter); Gord Downie (rock musician, poet); Ken Dryden (Member of Parliament, former hockey star); Franklin the Turtle (cartoon character); Margie Gillis (dancer); Sarah Harmer (musician, songwriter); Tomson Highway (playwright, author, musician); Cathy Jones (broadcast comedian); Thomas King (writer, broadcaster); Silken Laumann (Olympic medallist); Rebecca Mason (landscape artist, daughter of celebrated Canadian canoeist, Bill Mason); Rick Mercer (broadcast comedian); Derek Miller (musician); Courtney Milne (photographer); Seamus O'Regan (broadcaster); James Raffan (author, educator); Jimmy Rankin (singer-songwriter); The Rheostatics (rock band); Serena Ryder (singer and songwriter); Candace Savage (cultural historian); David Schindler (scientist and ecologist); Ed Struzik (journalist, author); David Suzuki (broadcaster, scientist); Veronica Tennant (ballet dancer, writer, director); Three Rivers Artists (visual artists); Justin Trudeau; and Florent Vollant (singer, songwriter).
} 
Another example was the trip staged on the Athabasca River in northern Alberta, which featured Ken Dryden, a former professional hockey player and now a Member of Parliament and Minister for Social Development, David Suzuki, a popular television broadcaster and environmental activist, and David Schindler, a world renowned ecologist. Very obviously, the intended purpose of including celebrities on these trips was to bolster the overall recognizability and legitimacy of the campaign.

The rivers on which the canoe trips were staged are significant for a number reasons not least that some feature prominently in Canadian history as sites of the fur trade and early European exploration. They are also significant because they have the appearance of being geographically representative of the Canadian boreal, which is an important point to bear in mind because so much about the experience of Canadian identity has to do with locating oneself regionally under the universal sign of Canada. This first phase of the Boreal Rendezvous campaign was also punctuated by a number of quasi-public $^{47}$ celebrations and fund raising events in major cities across Canada, and culminated in a large quasi-public celebration, called the True North Wild and Free, held at the Museum of Civilization in Ottawa in September 2003. Another interesting aspect of this first phase of the campaign is that a television documentary film about two of the canoe trips was produced and subsequently aired on the Canadian Broadcasting Corporation's popular television show, The Nature of Things, hosted by David Suzuki, a well known broadcaster, geneticist and environmental activist, and as I mentioned above also a celebrity paddler on the Athabasca River canoe trip.

\footnotetext{
${ }^{47}$ By quasi-public, I mean that these were fundraising events open to anyone willing to pay the entrance fee. I am hesitant to call them private events insofar as they were intended to be civic celebrations of public culture.
} 
The second phase of the Boreal Rendezvous involved the publication of a book, entitled Rendezvous with the Wild: The Boreal Forest, which celebrates the Canadian boreal forest through a compilation of written text, illustrations, poems, and photographs all based on the experiences of those who participated in one way or another on the Boreal Rendezvous canoe trips. This second phase of the Boreal Rendezvous also involved a cross-Canada, 10-city book tour during which the editor of the book alongside several of the various celebrities staged a series of quasi-public celebrations featuring slide shows, live music and spoken word all having to do with the boreal forest and the experiences many of the canoe trip participants had while canoeing in the boreal forest.

I will elaborate in more detail on the Boreal Rendezvous towards the end of this chapter, but for now I would like to make a few preliminary observations about the Boreal Rendezvous campaign, the most obvious being that throughout the campaign the boreal forest was represented as an unmistakably national space. This is not surprising given that the boreal forest fits so neatly within the contours of Canada's political boundary. It does, after all, pass through most Canadian provinces and territories. Related to this is another observation. The Boreal Rendezvous, in spite of its name, fit quite squarely within the contours of English Canada's linguistic boundary, which is to say that it was almost entirely an English-Canadian phenomenon. To be sure, one of the canoe trips was conducted predominantly in French. It followed the Moisie River from its headwater in northern Québec to the north shore of the Saint Lawrence River. But the other canoe trips were English-speaking and the Rendezvous with the Wild was, plupart, written in English. I raise here the issue of language not as a point of criticism, but to point out that the Boreal Rendezvous, while very obviously a conservation politics aimed at securing an ecologically benign future, can also be read as an iterative expression of 
English Canadian identity. What I mean by this is that central to the project of English Canadian nationalism has been the construction of a largely Anglophone public space into which the national ideals of multiculturalism and wilderness have been placed and through which English Canadian nationalism is routinely exercised (Angus, 1997; Mackey, 2002; Sandilands, 1999a). The irony that marks this public space, however, is that no matter how celebrated liberal pluralism might be within the public domain, liberal pluralism has its limits, limits that are set and enforced by "a white Anglophone majority" (Mackey, 2002:3). It seems that the Boreal Rendezvous sought at once to constitute and occupy this public space.

Related to this is another observation, which is that the Boreal Rendezvous was a highly racialized campaign. In saying this, however, I do not mean to imply that it was a racist campaign. The connotations of hate and violence that accompany the terms racism and racist are, in my view, far too powerful to be used casually in characterizing something as non-threatening as a group of people celebrating the act of canoe trip and the spaces within which the canoe trip is possible. The campaign was nevertheless a predominantly white, middle and upper class movement, which is to say that those attending the quasi-public celebrations were overwhelmingly white and that the canoe trips were peopled almost entirely by white urbanites. Of course there were exceptions to this, but for the most part the campaign was a racialized reflection of the individuals to whom it was trying to appeal. Again this is a casual observation, which doesn't mean anything definitive, but it does suggest that constructions of race, nature and difference are very much in play in contemporary Canadian conservation politics.

One last observation should be made concerning the Boreal Rendezvous and that is that through the campaign the canoe trip is represented as one of the dominant 
metaphors organizing boreal forest politics and boreal forest political identity. The canoe trip and the structure of feeling it embodies work as a form of cultural hegemony that make landscape and the experience of landscape possible in immensely cultural ways. The canoe trip authorizes a visual logic that temporalizes the nature within which it occurs as belonging to a national past. The canoe trip enables its participants to regard this nature as the scene of the nation's origin and identify in it the true home of the nation and the true home of the national self. At the same time, however, this visual logic secures the subject in relation to the contemporary time of the modern nation. Thus the subject is split in a diachronic space: the primordial time of national origin and the contemporary time of modernity. The split subject attempts to synchronize its diachronicity by incorporating the natural into the modern, by remaking the modern home and the modern self in the likeness of the naturalized past. Understanding the canoe trip as an organizing metaphor for identity politics, thus, has uncanny resonance with Bhabha's claim that metaphor "transfers the meaning of home and belonging across the 'middle passage'... across distances, and cultural differences, that span the imagined community of the nation-people" (Bhabha, 2004:200). Recognizing the possibility of canoe trip in the naturalized spaces of the nation, thus projects onto that middle passage (the boreal forest) the possibility for a synchronic national experience. Moreover, the boreal forest is a mezzo-zone of Canadian north; it is not the high arctic, but a middle passage, a forgotten zone in the imaginative geography of the Canadian nation. Reoccupying the middle passage through the act of canoe trip is to recreate the nation's home and to reconstitute the imagined community of the nation by flattening cultural difference. 
I will return to this discussion of the Boreal Rendezvous later. But before I do let me turn my attention to the narrative of national recovery and the place of nature within it. This is important because the Boreal Rendezvous was carefully constructed using this narrative structure of national recovery. In this sense, recovering the boreal forest from industrial modernity was also to recover Canada and the national subject. The canoe trip provided the perfect metaphor for reterritorializing this recovery project in the public domain.

\section{The architecture of recovery}

The narrative of national recovery is organized through a complex arrangement of signs in which nature animates the nation. I do not assume, however, that the nature that dramatizes the nation pre-exists the national identity it is meant to articulate. Instead, I would like to restate that nature is performative, which is to say that it takes form through the exercise of power. In this sense, engagements with external nature are to be understood less as unmediated engagements with the real, than as highly mediated, historicized utterances that produce the effects they name. In other words, the nature one assumes can be found in the forest is an effect produced through the very act of going to the forest in search of nature. A similar onto-logic marks the exercise of nationalism where the act of national recovery gives rise to the very same nation that makes its recovery possible.

Explicit in the notion of recovery is the sense that something lost can be regained and that, once reunited with the stuff of loss, the injured self can finally enjoy the sensation that comes with completion and fulfillment. This is the signature narrative of all nationalisms and, perhaps, also of modern subjectivity and it follows a familiar Judeo- 
Christian storyline. The threats posed by temporal progress can be reversed, or at least temporarily abated, by rediscovering the essential moment(s) of original (national) experience and inscribing these into daily life. In this sense, the modern (national) subject can be recuperated through the reinscription of a priori truth onto the present experience of fragmentation and rupture. Hence, subjective experience can be lived as not only loss, but simultaneously hope and the promise of completion.

Carolyn Merchant reminds us that narratives of recovery lived as temporal progress or decline feature prominently in Western culture. For her, they "form our reality" (Merchant, 2004:3) and furnish Western culture with the scripts required in order to navigate a complex world of multifarious and often contradictory signs. Extending Merchant's thesis, we might say that the recovery narrative is an important marker of political identity, since it tells the story of original innocence in nature, marks the fall and promises a return to innocence. As a temporal logic, the recovery narrative trades on a causal relation between past and present that enables identity to be understood as having proceeded smoothly along a singular trajectory of time. In short, it provides an architecture of identity by signalling where identity originates (nature), how it is ruptured (knowledge/otherness) and how the wounds inflicted in the fall will be sutured (reconnecting with nature). Through reinscribing the past onto the present, past-present are recreated as an immutable whole that can carry forward unproblematically into the future. Here, the diachronic gives way to the synchronic.

My interest, however, is not to essentialize the recovery narrative as a core feature of Western culture as, I believe, Merchant does (Merchant, 2004). Nor is it to argue that the architecture of recovery is a universal human archetype. Doing so would presuppose a timeless subject of recovery to which all of Western experience is reducible. This, I fear, 
would occlude, or perhaps even preclude, critical discussions about the practices of constraint that work to produce relations of inside/outside, which are so central to identity production and subjectification in the first place. Rather, what I would like to do is argue that the recovery narrative, along with its architecture, is performative. In other words, the recovery narrative does not pre-exist the subject of loss and recuperation, but instead materializes through the reiteration of cultural norms of recovery. The subjective experience of recovery (innocence, loss, recuperation) thus attains its coherence by citing these previously established and culturally permissible norms.

For Butler, however, the performativity and citationality (the implicit citing of norms) that render the subject of recovery visible do not equate to acts of construction. They are, to be more precise, identificatory acts whereby the identifying subject comes into effect through exclusion. Performativity and citationality actively materialize the boundaries that stabilize the subject of experience. But these materializations are compelled into being through previously established norms, norms that function as regulatory limits. In this sense, the reiterated normative acts that secure and stabilize subjective experience actively produce the subject's own constitutive outside. Hence, some abject form is always present inside the subject as its own founding repudiation. The crucial point of performativity, however, rests not so much on how the subject is demarcated by its excess, but rather in the possibility that this excess might return to destabilize the subject. The constitutive outside therefore represents a persistent threat to the subject's stable recovery thus requiring the continuous repetition of the norms governing subject formation. For Butler, what this means is that the subject is never fully 
stabilized, can never be fully stabilized, and that complete and final recovery will always remain elusive. $^{48}$

This is important for several reasons. First, it shows how the sites marking either end of the recovery narrative, the space of original rupture on one hand, and the space of recuperation on the other, are produced through normative acts of demarcation that say as much about the identifications secured through the articulation of these spaces as they do of the spaces themselves. This is what Moore, Kosek and Pandian mean when they say "landscape articulates culture and nature, seer and scene" (Moore et al, 2003:11). Landscapes are normative expressions of culturally desirable nature that constrain from view the undesirable. They also shield from view the exercise of power and constraint that renders them visible in the first place, not unlike the idea that the normativity of whiteness is concealed in racialization.

Second, recovery is a contingent process. It is never fully completed, but is always being reiterated through the historical norms that make it possible. What this means is that the continuous, repetitive making of the self, is also a continuous remaking of the normative spaces of innocence (nature), rupture (unnatural nature) and recuperation (national salvation). Through the staging of the national self, national nature is continuously produced and reproduced.

A third implication, related to the idea of contingent recovery, is that the spaces of exclusion produced through such acts of national recovery draw attention to the very instabilities of the national recovery narrative. This means that not only is recovery a continuously repeated act of securing identity. It is also always subject to potential

\footnotetext{
${ }^{48} \mathrm{Homi}$ Bhabha makes a similar set of arguments concerning the production and regulation of the colonizing subject and colonized abject subject. Accordingly, one could argue that this perpetually unstable condition is a characteristic marker of postcolonial geographies.
} 
disruption by the abject others that haunt the limits of the always recovering subject, hence, the requirement that the subject be continuously secured through performative acts of norm reiteration. Therefore, far from being a completable experience, national recovery and a stable national subject belies the possibility of suture, because to occupy the subjective experience of possible national recovery is to always remake the abject experience, to always remake the conditions that could potentially destabilize the nation.

\section{National-nature}

As already mentioned, nature plays an important part in organizing the architecture of national recovery for it is through some form of original experience, like nature, that the nation is dramatized. Another look at Morton's familiar characterization of the 'Canadian psyche' illustrates the point very clearly:

...this alternate penetration of the wilderness and the return to civilization is the basic rhythm of Canadian life and forms the basic elements of Canadian character. (1961:4-5)

Here, Morton's "wilderness" is meant to exemplify the essential qualities of the nation and signifies the potential embodiment of national unity, where 'official' Canadian experience becomes synonymous with the heroic return from national-nature. What I would emphasize, however, is that in the culture of Canadian nationalism, this nationalnature has always been north, ${ }^{49}$ since the north was and is a direction to which all could relate, common as it is to both the east and the west.

\footnotetext{
${ }^{49}$ When I refer to the cultures of nationalism in Canada, as opposed to the culture of Canadian nationalism, I am making explicit reference to both English- and French-Canadian nationalisms. This is an important distinction to make in discussions of Canadian nationalism because calling on a singular form of Canadian nationalism to describe the Canadian national experience overlooks the important linguistic differences that mark Canadian political culture. Moreover, the invocation of the idea of the north in Québécois nationalist discourse emerges out of a distinctly French Canadian literary and cultural genealogy. For more on these
} 
This fantasy of Canadian nordicity was first given rhetorical force in the 1860s when the Canada First Movement, a group of Canadian imperialists, loyal to the English empire and hostile to liberal continentalism, began celebrating the idea of an essential Canadian identity rooted in the Canadian north. In his now infamous lecture at the Montreal Literary Club in 1869, Robert Grant Haliburton, one of the group's associates, celebrated Canada as a northern climate and for being "a congenial home for the growth of a free and dominant race" (as quoted in Grace, 2002:58). Haliburton then went on to praise the Canadian "stock" and celebrated Canadians as the "apostles of a new, of a Northern, of a Christian civilization" (Grace, 2002:58) in what was clearly an effort to stabilize a racial hierarchy that placed people of Northern European descent at the pinnacle of Western civilization and on the threshold of the aspiring Christian nation of the Dominion of Canada. For Haliburton the Canadian nation was a northern, white nation characterized by strength, resilience and resolve, which stood in contrast to the effeminate degeneracy of the south. ${ }^{50}$

My point, however, is not to forgive such an insidious conflation of race and nation, but to emphasize that, in Canadian colonial discourse, signifiers of nature - the north in this case - played an important part in stabilizing the architecture of national identity in post-Confederation Canada and that from early on in Canadian historiography the north has been inscribed by a racializing logic. To the extent that the idea of north is

themes see Caroline Desbiens 2001 'Power from the North: The Poetics and Politics of Energy in Québec's Geography' Ph.D. Dissertation, University of British Columbia and Caroline Desbiens 2004 'Producing North and South: A Political Geography of Hydro Development in Québec', The Canadian Geographer, 48(2):101-11. This genealogy stands in contrast to (but not necessarily conflict with) a genealogy of English Canadian nationalism that tends to identify the north as a nation-wide phenomenon, perhaps even a north-western phenomenon, not one confined to simply any one province. This is not the place to go into detail about the power relations that constitute Canadian multiculturalism, but these are nevertheless important.

${ }^{50}$ It bears mentioning that Haliburton's reference to the south was of a generic south, not the United States. The main thrust of his argument was that Northern European enjoy a natural superiority to those from the south. Haliburton explores these ideas through a reading of Greek and Roman history. 
embodied in official Canadian identity, the racialization of the north works silently in the constitution of the Canadian national subject. What we see, then, in Haliburton's nationalistic language is the governmentalization of nature - the north - that was used to normalize Canada as a northern nation but also the national subject as a northern people.

I now want to look more closely at how Canada's northern nature might be understood as performative and how its performativity features within the biopolitics of national- and self-recovery. The image of a northern nature is perhaps the most important master signifier found in Canadian nationalism. The space of Canada is, after all, according to this sort of nationalist logic, often imagined and represented as one big, vast space of nature. The landscape paintings produced by Tom Thomson, the Group of Seven and their contemporaries provide perhaps the best examples of how the "Canadian" experience is essentialized in very specific scenes of nature. Rising to prominence in the second decade of the twentieth century, during and immediately following the first world war, Tom Thomson and the Group of Seven were celebrated for their refusal to adopt European styles of landscape painting in favour of a style that was more 'true' to the wild space of the Canadian northern frontier (Fulford, 1992). ${ }^{51}$ Their stylized renditions of the raw Canadian wilderness - the snow, the rock, the windswept pines and autumnal hues were thought to be far more representative of the rugged enduring nature that marked the Canadian experience than the effeminate natures that composed the landscape paintings of European impressionism. But these images were not only symbolic of the Canadian

\footnotetext{
${ }^{51}$ Important to note here is that, while Tom Thomson and the Group of Seven were and continue to be celebrated figures in Canadian culture, their rise to national prominence was not without controversy. In an editorial in the Globe and Mail, Robert Fulford, a well known Canadian columnist now writing for the National Post (a devoutly conservative national daily) reminds us that, from the outset, built into the myth of the Group was a sense of their departure from the norms of artistic taste which were sure to offend the sensibilities of Canada's small, but elite 'cultured' class. Fulford goes on to say that this controversy was actively cultivated by certain members of the Group, who were fully aware that it would bolster their appeal. See Robert Fulford, "Robert Fulford looks at the making of a great Canadian myth," The Globe and Mail, November 25, 1992, p. C1.
} 
myth of national origin. They also became the stylized and aestheticized scenes of official national recovery.

The conflation of these images of the "wild" with national recovery was given national prominence in a recent 2002 exhibition of Tom Thomson's landscape painting, which opened at the National Gallery of Canada in Ottawa and which was subsequently exhibited in galleries across Canada. Here, the figure of Tom Thomson and his paintings were reread through a lens of double recovery, ${ }^{52}$ the premise of the exhibition being that, while Thomson and his landscapes have always been synonymous with Canada and emblematic of Canadian art, the actual persona of Thomson has been largely effaced from his work. Thus the dominant theme around which the exhibition was organized was the theme of recovery - Thomson's recovery. But here Thomson's recovery was not only a recounting of the events of his short life alongside an invitation to reread his artistic legacy against his life history. To be sure, the exhibition was certainly intended to provide an intellectual space for such a rereading of Thomson's work. But that was not all it was. More important was that, through Thomson's recovery, exhibition goers were invited to consider Tom Thomson as embodying a pervasive nineteenth century cultural logic of national recovery.

\footnotetext{
${ }^{52}$ It is worth pointing out as well that part of the exhibition was a rereading of Tom Thomson and his paintings against the now common critique set against Thomson and the Group of Seven for rarely depicting people in their paintings in spite of the fact that the spaces they painted were heavily populated or at least bore traces of human presence. A good example of this sort of critique can be found in Jonathan Bordo 1992-1993 'Jack Pine - Wilderness Sublime or the Erasure of Aboriginal Presence from the Landscape', Journal of Canadian Studies, 27(4): 99-128. In the case of Tom Thomson, for example, his oeuvre is replete with images depicting forestry operations and logging in Algonquin Provincial Park, which had been set aside by the Province of Ontario to provide, among other things, for a steady supply of pine timber for markets in the Ottawa Valley and along north shore of Lake Ontario. Indeed, at the time, Algonquin was very much a site of labour, particularly that related to the pine timber and pulp and paper industry. Many of Thomson's paintings are in fact representations, albeit highly aestheticized, of second growth deciduous forests, logging chutes, waterfall dams and logging drives.
} 
This is evident in the opening chapter of the book that accompanied the Thomson exhibition, in which Andrew Hunter positions Tom Thomson's arrival on the Toronto art scene in the early twentieth century, right around the time that "going north" was the fashion of the day (Hunter, 2002). Going north, which at the time meant going to those parts of Ontario - Algonquin, Muskoka, Temagami and Georgian Bay - that lay within two or three hundred kilometres of Toronto, was widely considered to be a therapeutic remedy to the hardships experienced in daily life in the city, an antidote against pollution, urban chaos and the degenerate classes (i.e.: non-white immigrants), and a preventive measure against stress and neurasthenia (Jasen, 1995). But 'going north' was not simply an innocent, individualized care of the self or a patriarchal caring of family. It embodied strong nationalizing undertones as well, undertones that were at the same time deeply racializing. Of course direct appeals to national and racial purity were never explicitly foregrounded in the discourse of bodily purification represented by the so-called wilderness experience. However, as Patricia Jansen makes clear in her work on fin-desiècle nature tourism in Ontario, acts of personal recovery in the 'wild' spaces of the north were of a directly nationalizing and racializing kind (Jasen, 1995). Retreating to the northern wilderness, to the metaphoric and physical places that Thomson painted, was a means of recuperating one's self and rejuvenating one's body. In the national register, these were acts carried out with a view to improving one's overall fitness and state of mind, both of which were required to better perform the tasks associated with daily work. It followed that if a healthy workforce could be guaranteed, then a productive Canadian economy and a healthy Canadian nation would most likely ensue. According to Jasen, underwriting the prescriptions for personal recovery in the 'wild' was an abiding concern 
for the health of the nation. These sorts of biopolitical claims pervade the late nineteenthcentury recovery narrative.

For his part, Thomson is routinely represented as embodying this biopolitical movement from city to wilderness and back again. Indeed, the last five years of his short life were spent living and working in Toronto as a commercial artist, moving up to Canoe Lake in Algonquin Provincial Park in springtime to paint and fish, and returning to Toronto each fall. Moreover, Thomson's paintings captured all the drama one might expect to encounter in the landscapes of "northern" Ontario while recovering from neurasthenia, or "brain fag" as it had come to be known. In a sense, his entire collection of work presents as though one's personal recovery from brain fag could be experienced through Thomson's work. The landscapes of Algonquin and Georgian Bay thus became zones of filtration, the very spaces through which bodily purification could be achieved.

Yet the sanctioned (racialized) spaces in which such recoveries became permissible did not simply pre-exist the act of personal/national recovery. Rather, such spaces were constructed through a number of colonial practices that actively marginalized aboriginal presence from the landscape and reincorporated this displaced aboriginality into the teleology of the Canadian nation. Jonathan Bordo, who argues that the modern landscape painting of Tom Thomson and the Group of Seven is a useful site for interrogating how the modern wilderness was made, gives one side of this equation. In Bordo's work, the figurative presence of the Laurentian wilderness - a pictorial representation of wilderness attributed to Thomson - is located precisely in the erasure of aboriginal presence (Bordo, 1992-1993). This is of course very closely related to what Foucault had in mind when he argued that "truth is a thing in this world: it is produced only by virtue of multiple forms of constraint" (Foucault, 1980:131). In this sense, the 
truth of wilderness, at least as it appears through Thomson's and the Group of Seven's portrayals of the Laurentian wilderness of Algonquin and elsewhere, is produced through constraint - constraining aboriginal presence from view. However, from the point of view of postcolonial critique Bordo's insightful analysis falls short, since it fails to account for the corollary argument, namely that displaced aboriginality is reincorporated into the colonial narrative through the calculating language of modernization and improvement.

Late nineteenth century Canadian tourism and recreation provides a more potent set of colonial discourses for thinking about how the sanctioned, national space of recovery emerged as both a naturalized and racialized space. During the mid-nineteenth century, a good deal of the Canadian tourist industry was predicated on the romantic, fetishistic desire to consume aboriginality in its 'natural' and 'historical' state. As such, the industry catered to this cultural desire through its self-professed ability to bring the tourist into face-to-face encounters with the 'forest primeval' itself and render aboriginal bodies visible to the adventurous colonial (Jasen, 1995). This is important because it was through the desiring gaze of the tourist, and the 'civilizing' discourse that accompanied it, that aboriginal peoples were temporalized and thus spatially displaced from the land. According to this sort of logic, the forested landscape, within which aboriginality could be witnessed, was assigned a place outside the time trajectory of modernity. Indeed to experience the forest unmediated by the contaminating forces of civilization was, for the tourist, to go back in time, or to experience "anachronistic space" through the fantasy of return (McClintock, 1995). Thus, formulating and witnessing the primordial forest was also to erase the aboriginal from view.

Yet, once erased, aboriginality could then be carefully reintroduced into the tourist narrative as a historicized way of life simply by virtue of its physical location in 
pre-historic forested space. In this sense, the discourse of wilderness tourism follows very closely Anne McClintock's colonial narrative pattern of "dangerous marginality, segregation and reintegration" (McClintock, 1995). In contradistinction to the modern life of the tourist, the lived experience of aboriginality was therefore also thought to occur in a different historical time. The tourist lived within a civilized (and civilizing) time trajectory in which wilderness (national-nature) played an important part in regulating the experience of personal and national recovery, whereas the aboriginal had not been so fortunate and lived an anterior time. Jansen provides numerous accounts of how nineteenth century tourists deliberately sought out the so-called native in his or her "natural" habitat in order to witness the native way of life first hand before it inevitably gave way to the civilizing forces of modernity. The irony that the tourist gaze was, in many ways, complicit in the "demise" of the native way of life did not seem to enter into the considerations of the tourist. To do so would have invited criticism of the Canadian imperial project and the processes of civilization and subjectification that underwrote it, something that few were willing to indulge. Instead, the decline of the aboriginal way of life was considered a pity, but, in the much more serious pursuit of Canadian imperialism, a small price to pay for progress. Some tourist accounts of the native even registered a sense of disappointment insofar as the observed native, bearing some (but not all) of the accoutrements of modernity, did not accord with their prior convictions of what the stereotypical native should look like. In this sense, the native appeared to have changed so dramatically from his/her 'natural' state, a change expressed as the perceived inability to adapt to the exigencies of modern life, that extinction seemed inevitable. The aboriginal figure, through the optic of white geography, thus became an ambivalent object of white resentment and fascination insofar as aboriginality had come to represent 
a diachronic existence. To be aboriginal was to retain unmediated access to the experience of nature, yet, at the same time, it was to navigate, albeit laggardly and unsuccessfully, the trajectory of modern national time.

Returning to the performativity of national-nature, the tourist gaze actively materialized the northern wilderness by repeating the racialized norms that pre-figured within Canadian imperial discourse. This materialization was carried out by displacing aboriginality into the anterior time of pre-historic nature and then reintegrating aboriginality into the modern time of the Canadian nation by representing it as being entirely devoid of history and as lacking the proper agency to adapt to the exigencies of modernity. The important point in all of this is that through the displacement of the aboriginal other, the Canadian national subject was secured as an unmarked (i.e.: white) subject in the scene of national recovery. However, this subject position could never be fully secured, since the displaced aboriginal represented to the national subject the everpresent possibility that the order and stability so carefully created and maintained through the scene of national recovery might be disrupted by the return of the aboriginal.

\section{Masculine Biopolitics of National Recovery}

At the turn of the last century, the performative utterance of national nature also worked to secure the national masculine white subject in the scene of national recovery. By the late nineteenth century and early twentieth century, such biopolitical prescriptions had become synonymous with the Progressive movement in the United States, championed by the likes of Theodore "Teddy" Roosevelt, Gifford Pinchot and Ernest Thompson Seton. These men - all of whom were representatives of cultural and political elites - were notably concerned about the prospects of social and national decay, or what 
Mark Seltzer has called the "depletion of agency and virility" in the male (urban) body, that might arise from too much consumerism, too much domesticity and too little physical exertion by way of manly pursuits in the urban setting (1992:149). Seton's concerns were perhaps even more emphatically expressed in the handbook for the Boy Scouts of America in which he wrote that the Woodcraft movement had been founded "to combat the system that has turned such a large proportion of our robust, manly, selfreliant boyhood into a lot of flat-chested cigarette smokers, with shaky nerves and doubtful vitality" (as quoted in Seltzer, 1992:149). Responding to their own anxieties about social decay and the depletion of virility, these men issued a cultural prescription that sought to reinvigorate boyhood and nation by setting American boyhood loose, albeit in a highly rationalized and hierarchical manner, on the spaces of an already domesticated national-nature.

One of the principal means by which bodily and national recovery could be enacted and practiced was through the mimicking of so-called primitive man. By the turn of the century, the iconic image of primitive man, the 'Red Indian' in Seton's words (Seton, 1921), had become a celebrated figure in modern culture at a time when the crisis of masculinity had become socially pervasive. Here, the figure of the primitive served as a symbolic reminder as to the 'natural' mode of life that pre-existed modern culture. It also supplied the elemental traits of natural manhood and suggested the possibility that natural manhood could be reclaimed and lived through mimicking the ways of the 'Indian'. Here, it was assumed that the conflicted self (flat-chested, cigarette smokers) could be recuperated (made manly) through a reenactment of the ways of being that had been associated with primitive (natural, non-conflicted) man. Attending one of the many youth camps that had been set up to ameliorate the fears of youth degeneracy was thought 
to be an effective means of instilling in young men the attributes necessary for success in the modern world. According to one account, "self reliance, resource and independence are brought out as much as possible so that the boy may become a true white Indian" (as quoted in Benidickson, 1997:66) (see Figure 4.3, page 156). Return to the wilderness thus became a fashionable way of reconnecting with one's 'inner primitive' and remaking modern, national man - another remedy against the defiling temptations of urban culture. The Woodcraft movement, synonymous with the figure of Ernest Thompson Seton, provided one form of subjective experience that could be enacted to help restore manhood to its 'original' form and in so doing restore modern culture to its true purpose.

In contrast, although to a similar end, another important figure appropriated for the remaking of modern national man was found in the iconic image of the frontiersman. These were men who were said to represent the height of manly endeavours by virtue of their successful conquests at the limits of Empire. They were endowed with the qualities of self-reliance, personal strength and resolve and were said to possess so intimate a knowledge of their frontier surroundings that they could live for weeks and months at a time impervious to adversity. In Canada these were the men of the North West Mounted Police who policed the northwest frontier and quelled Riel's rebellion. These men were also the surveyors who mapped Canada along resourcist, racial and temporal lines and they were the voyageurs and couriers de bois who 'innocently' traded guns, germs and alcohol with their native counterparts.

In both cases, the masculine celebration of the primitive and the frontiersman was enacted in the spaces of national-nature. Thus the practice of 'going north' in Canada was, for many at the time, about getting back to one's masculine roots and reliving what masculinity really meant: hunting, fishing, making camp, cooking over an open fire, and 


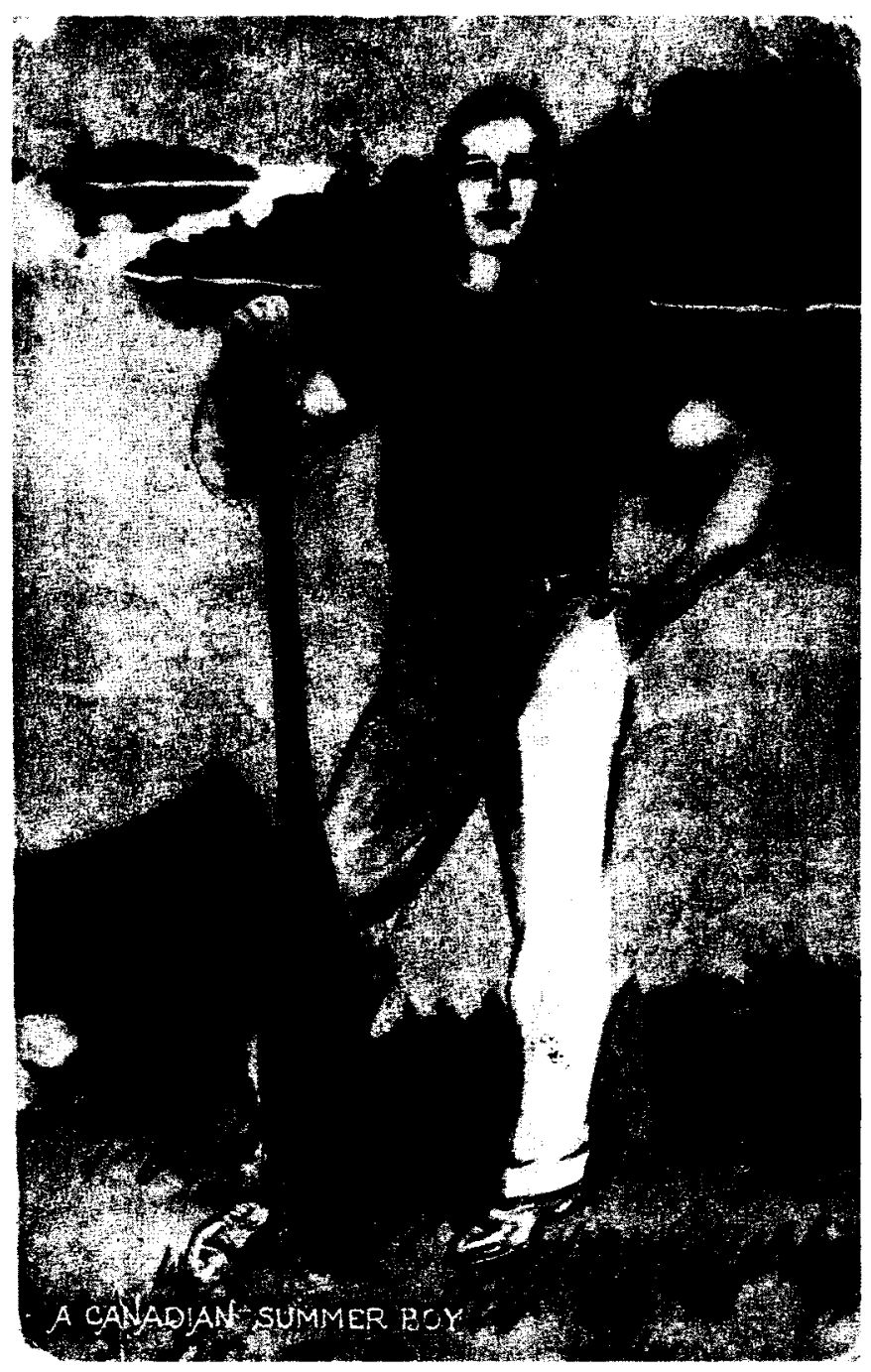

Figure 4.3 - A Canadian Summer Boy; (postcard) ${ }^{\mathbf{5 3}}$

\footnotetext{
${ }^{53}$ I owe a debt of gratitude to Jamie Benidickson for supplying me with this image. The image is a postcard. But there is no information on the reverse, giving any indication as to who was responsible for its production.
} 
re-enacting what it might have been like to have lived on the edge of Empire. Not surprisingly given its versatility, the canoe featured prominently as an aesthetically pleasing form of transportation that allowed people to venture off into the wilderness for several days at a time, to have intimate encounters with nature in its most pristine form and to live a temporarily rugged existence.

Thus, late nineteenth and earlier twentieth century wilderness tourism, or 'going north', was not simply a remedy prescribed by mental health experts and doctors to patients exhibiting symptoms of nervousness and stress. It can also be read as part of a much broader ideological prescription administered by political and cultural elites against potential national and racial decline that might have been the result had the excesses of urban life overtaken the rational (white) mind. What this suggests is that central to an emerging form of late nineteenth and early twentieth century governmental rationality that sought to discipline a 'soft' population was the governmentalization of nationalnature. This national-nature in turn played an important part in racializing the biopolitics of Canadian national recovery, since race and nature worked to organize the purification of both individualized bodies and the social body of the nation.

As mentioned earlier, however, the biopolitics of recovery was not exclusively a politics of racial exclusion at the limits of civilization 'up north.' The purification of the national white subject was contingent on urban racial exclusion as well. Ernest Thompson Seton illustrates in rather stark terms that the scouting movement was not simply an innocent attempt at purging sloth from young men by turning them into an elite class that placed great value on "being prepared." Seton's project was underwritten by a profound moralism that set itself against urban culture. 
History shows us, that with scarcely an exception, every great nation, after climbing laboriously to the zenith of its power, has then apparently become exhausted by the effort, and has settled down in a state of repose, relapsing into idleness and into indifference to the fact that other nations were pushing up to destroy it, whether by force of arms or by the more peaceful but equally fatal method of commercial strangulation. In every case the want of some of that energetic patriotism which made the country has caused its ruin; in every case the verdict of history has been, Death through bad citizenship....

One sign of the disease (which was also one of the signs of decay in Rome before the fall) is the horde of unemployed leading miserable, wasted lives in all parts of the country - the great many drones in our hive.

It is no longer a mere temporary excrescence, but is a growing tumor pregnant with evil for the nation.

These people, having never been taught to look after themselves, or to think of the future of their country's good, allow themselves to become slaves by the persuasive power of a few professional agitators whose living depends on agitating (whether it is needed or not); and blinded by the talk of these men they spurn the hand which provides the money, till they force employers to send fortunes either in divesting machinery that will take their place and will not then go on strike, or in getting in foreign labor, or in removing their business to other countries, leaving the agitators fat, but the mass of their deluded followers unemployed and starving and unable to provide for the crowds of children which they still continue improvidently to bring into the world. (as quoted in Nash, 1970:24)

Much can be said about this quote. It speaks quite clearly to Seton's contempt for labour organization and trade unionism. It also suggests that the Boy Scout movement and the youth camping movement it spawned was, at least in part, about ensuring that white boys did not fall victim to the rhetoric perpetrated by the racial and ethic groups associated with labour organization. But the point I would emphasize is the implicit spatialization of urban experience built into this passage in which the elite spaces of privilege, citizenship and responsibility are made to stand apart from the raced and classed spaces of degeneracy, crime, sloth and promiscuity. This spatialization is also 
replicated in those journeys taken by juvenile elites to racialized northern landscapes to learn responsibility, leadership and citizenship and, perhaps more insidiously, to escape from the spaces of urban degeneracy so closely associated with national decline.

National nature is performative insofar as it is a space constituted by the exclusionary forces that make it. Following Butler, this means that the white national subject secured through the national recovery narrative is actually never fully secure, since the abject outside always stands as a potential disruption to the perceived order of stability created through national recovery. Furthermore, neither is the racialized landscape of national nature fully secure, since the abject can always potentially reoccupy that space. From Seton's quote above, the national project is, by extension, never complete even when, or perhaps especially when, it has reached the "zenith of its power." The persistent threats of military invasion or commercial strangulation demand that energetic patriotism always remain on hand to reproduce the nation and guarantee national survival. For Seton, outdoor pursuits represented the promise of personal discipline, but they also furnished the nation with a disciplinary language that could be enlisted in managing the unruly urban mob - "the great many drones in our hive" - that threatened national cohesion with commercial strangulation, bad citizenship and improvident reproduction.

\section{Canoe trip as a means to national recovery}

I would like now to return my attention to the Boreal Rendezvous in order to clarify in more detail how, through the performative act of the canoe trip, the boreal forest is rendered simultaneously a political space of national concern and an environmentalized space of ecological concern and how such a rendering privileges the 
white subject in the politics of national recovery. This is critically important, in my view, because understanding the canoe trip as a means of personal recovery and as an iterative repetition of the norms regulating nineteenth century national recovery situates the act of canoe trip within the field of productive power and in a sense decentres it from the position of privileged innocence that it occupies in popular Canadian culture. As I mentioned earlier, the canoe trip is one of the privileged means by which national recovery can be experienced as (a raced, gendered and classed) personal recovery. This is only slightly different today than it was a century ago.

At the outset, however, I need to stress very strongly that what follows is not an indictment of the canoe trip. Nor should it be read as an indictment of those who profess the merits of the canoe trip as a legitimate recreational or pedagogical pursuit. As a metaphor for experience, I feel strongly that the canoe trip is an excellent medium for practicing companionship, contemplation and cooperation. But I am considerably less convinced that modern canoe travel should be used as a means of teaching good citizenship, or as an antidote to bad citizenship, especially where the embodiment of citizenship is so closely related to raced and classed identity. I am also sceptical about the merits of using the canoe trip as a venue for historical rediscovery for to do so assumes that there is a history to be rediscovered. Historical rediscovery is more often than not a celebration of history (usually white and male), rather than a means for being selfreflexive. ${ }^{54}$ In a similar vein, I am also sceptical that modern canoe travel guarantees an

\footnotetext{
${ }^{54}$ In saying this, however, I do not want to convey the idea that self-reflexivity is also an innocent activity. It is not. Self-reflection, particularly the kind that the canoe trip often engenders, is also marked by class and race exclusions. This is to say that it is culturally acceptable for someone, usually a white someone, to contemplate the crisis of modernity and their place in it from the vantage of liminality i.e.: the wilderness. This act secures the white subject in modernity and legitimates that subject's experience of crisis. But it is altogether something different for an aboriginal woman to cast the tourist gaze onto the cityscape and use this experience as a means for being self-reflexive and decrying modernity. This aboriginal woman, while
} 
unmediated experience with nature. That said there is no reason why modern canoe travel cannot be used to facilitate a questioning of gender, class, race and the space of nature. In fact, this is precisely the point of deconstruction. It is to disarticulate the metaphysical form, to reveal the exclusions that are generated through its philosophical presuppositions. But it is also to reoccupy those presuppositions in such a way as to bring these exclusions to light. It is, to borrow from Butler, a miming of mimesis, "an insubordination that appears to take place within the very terms of the original, and which calls into question the power of the original" (1993:45).

What follows, therefore, is, in one sense, an invitation to reconsider the perceived innocence of the canoe trip as a Canadian pastime and resituate the popular practice of canoe trip within the field of productive power. This is to say that the canoe trip and the subjectification it sanctions, like any other form of discourse, is shaped by power.

Therefore, to characterize the canoe trip as a pure or innocent act that operates outside the scope of conventional political activity is to make several assumptions about both the canoe trip and the political. These assumptions need to be challenged. But this challenge should not be read as political nihilism. Rather, it should be read as an attempt to decentre one of the dominant discursive means through which the boreal forest attains its cultural legibility as a natural space, namely Canadian canoe culture and the hegemonic visuality that authorizes the canoe trip as an innocent pastime.

The canoe trip performs the recovery narrative. It is a staging of identity and is a means of recuperating from modern fragmentation and rupture by reconnecting with the lost innocence of a supposedly pre-ontological nature. It is also represented as a means of

she might receive some sympathies, would be written off as hopelessly unaware of the sheer complexity of modern life and the moral imperatives that underwrite it. 
washing away the 'grime' of the city and of purging the mind of the excessive tele-visual and digital banter that inhibits the subject from living a fully content, unsullied life. The appeal of the canoe trip experience lies, in this sense, in the promise that one might have an authentic engagement with the real. It is a reminder that real experience is attainable outside the less real routines of urban living. In others words, the canoe trip is performative; the subject and the real experience it produces both come into effect through the act itself and in the same move generate an un-real space, a realm of the unmarked and un-thought that will always circulate along the perimeter of the real.

The point that I am making can be made a little more forcefully with the idea of ocularcentrism. Ocularcentrism refers to a visual logic through which the subject is shored up by denying everything that falls outside its vision-scape. The canoe trip in this sense is organized through an ocularcentric logic to the extent it forcibly marginalizes the social relations that make it possible in the first place. Following Lefebvre, "the work in its concrete reality, its products, and the productive activity involved are all thus obscured and indeed consigned to oblivion" (Lefebvre, 1991:189). The means by which the canoe trip is attained are often erased from the experience itself. For instance, the van ride up to the headwater is quite easily forgotten and erased. So too are the social relations that make these trips possible: highway construction, the politics of traffic congestion, of road food, and of exurban development. The plastics and synthetic resins that constitute modern canoe travel are also forgotten. Similarly, the ocularcentrism of canoe trip demands a space that is devoid of human congestion. Motorboat traffic on the lake and river is frowned upon. So too are excessively large groups of other paddlers. Moreover, canoeists are very often suspicious of other paddlers, since their presence works to disrupt the scenes of nature that the modern canoe traveller works so hard to create. 
Braun has made similar observations regarding kayak travel on British Columbia's West Coast (Braun, 2002).

Thus modern canoe travel, to the extent that it is constructed as an explicitly Canadian pastime, which very often it is, is analogous to Bhabha's idea of bypassing. In the performative act of recovery through modern canoe travel, in this sense, national recovery, the very terms that are sought to be recovered - the nation, nature, the national subject - come into effect. But the important point here is that through the act of recovery, the heterogeneity of modern space is bypassed and the "anxiety of plural modern space" is displaced (Bhabha, 2004:213). Thus through the canoe trip, the Canadian national subject is marked by that which it bypasses, namely the messiness of the present. According to Neil Smith, "in most people's minds, a four-lane highway has been built in the last two decades connecting environmental awareness with "saving' nature" (Smith, 1998:279). Yet, all too easily, it is precisely this four-lane highway - the very infrastructure that governs Morton's Canadian psyche - that is erased in the formulation of national environmental identity.

All of these observations are very important to my overall argument (nature is performative) because through the Boreal Rendezvous campaign, the boreal forest is represented as simultaneously a space of personal rejuvenation and a space of nationalnature. Implicit in this formulation is that the boreal forest must be conserved in order to safeguard the nation from the excesses of modernity. However, to the extent that the boreal forest names a racialized and racializing geography, we might also read the biopolitical project of personal/national recovery operating through the boreal forest discourse as a raced recovery, a purification of race. 
Again, this is not to say that anyone who gets in a canoe and goes for a four-day canoe trip in Algonquin Park or Temagami is racist, or that the political projects prosecuted by CPAWS and English left nationalists in Canada are explicitly racist projects. Not at all. What I am saying, however, is that the experience of those landscapes in the terms privileged by the Boreal Rendezvous - the true north wild and free - is highly racialized, a racialization that works in two directions - in the direction away from the racialized urban and in the racializing direction of the north. To experience those landscapes as evidence of nature repeats the norms of purity and the exclusions that emerged as the founding repudiations of the nation. The foundational myth of the north works on raced urban bodies very differently than it does non-raced bodies. Similarly, the foundational myth of the north works on aboriginality in very different ways, because for the myth of the north to work, for it to have any meaning as a pure and purifying landscape or as an open universal space through which the national subject can articulate his hopes, fears and desires requires its own founding repudiations. It needs to displace aboriginality and assimilate aboriginality through a logic of "almost, but not quite" (Bhabha, 2004:129). In this sense, the founding repudiations that make the myth of the north work are the abject bodies that occupy racialized urban space and, in the north, the abject bodies that populate the margins of the purified and purifying space of north.

I now want to explore these themes further by looking specifically at how the boreal forest was constructed through the Boreal Rendezvous campaign and how this construction worked to reproduce and secure a white (i.e: non-raced) national subject. In doing so, I would like to focus my attention on two cultural representations that gave the Boreal Rendezvous campaign such a strong visible presence in the Canadian media over a two-year period from 2003 to 2004 . The first is a made-for-television documentary film 
and the second is a glossy coffee table book that celebrates the Boreal Rendezvous canoe trips and the boreal forest space more generally.

In both narratives the overall focus is on the white subject. To be sure, the theme of (a gendered) aboriginality does appear in each, and is often given a strong presence. But the role of aboriginality in each representation is secondary to the dominant agency of the white environmental protagonist. In this sense, aboriginality abets the white project by giving it sanction. At no point, however, does aboriginal agency appear outside the visual field of environmentalism, nor does it stand in contrast to, or in conflict with, white agency. Instead, these two agencies are represented as complementary projects but in an implicit hierarchy of race relations that gives predominance to the white, masculine, national subject over the dark skinned, feminine, aboriginal subject.

\section{Canada's Amazon: A Boreal Forest Journey}

This notion of hierarchal complementarity is evident in the made-for-television documentary film, entitled Canada's Amazon: A Boreal Forest Journey (2003). The film is about two of the Boreal Rendezvous canoe trips, one taken by Justin Trudeau on the South Nahanni River in the Northwest Territories and one along the Athabasca River in northern Alberta, which included two national celebrities, Ken Dryden, a former professional hockey player, and David Suzuki, a famous Canadian geneticist, environmental activist and well-known television personality. Both canoe trips, however, provide the setting for a much more serious set of related stories concerning the destruction of Canada's boreal forest. Through Trudeau's trip, we learn that the two greatest threats facing the South Nahanni River are the Prairie Creek mine, an abandoned silver mine that sits on one of the tributaries to the South Nahanni and that the Canadian 
Zinc Corporation seeks to reopen, and the nearby Cantung mine, which, according to Harvey Locke, CPAWS' Vice-President of Conservation, is nearing the end of its productive life and must therefore be properly decommissioned. Through the Athabasca trip we learn that the greatest threat to the boreal forest in northern Alberta are the tar sands developments and oil and gas exploration. I have chosen to examine this film because it gave the boreal forest campaign a strong visual presence in the Canadian media, airing several times over the course of 2003 on the Canadian Broadcasting Corporation's weekly science and nature program, The Nature of Things.

The film is also important because its two main storylines trade squarely on the masculine performative where the film's dominant subject is a white male national agential subject, embodied in the figures of both the risk taking subject and the environmental subject. In the film, these modes of white male agency stand in contrast to the equally gendered, albeit considerably less agential, feminine aboriginal subject.

Briefly, the film seeks to narrate the experiences of Justin Trudeau and David Suzuki on their respective canoe trips. Both trips are represented using very different sets of visual imagery. To affect a sense of simultaneity, the filmmakers toggle the viewer from one trip to the other. Here, the viewer is shuttled from the ranging waterfalls and rapids of the mountain-flanked South Nahanni River in the Northwest Territories to the much less dramatic, but no less sublime, landscape of the Athabasca River watershed in northern Alberta, from a canoe trip culture that emphasizes danger and risk to one that values tranquility and repose. In the first, Trudeau performs the risk character, where his on-screen persona is about personal triumph in the face of physical adversity represented by his capacity to conquer the unruly, wild river in northern Canada. In the second, David Suzuki plays a central role as environmental scientist whose presence in the film offers 
the possibility that the environmental problems faced by the boreal forest are solvable. In both stories of masculine subjectivity, however, the white masculine subject stands in a position of hierarchical complementarity to a trope of feminine aboriginality in which the feminine speaks in order to sanction masculine white practice. The feminine, in this sense, can be understood as working to support masculine agency. Let me clarify how this works.

Following a few introductory remarks by Trudeau and Locke, the first storyline opens against a backdrop of fast moving river and dramatic music, while Justin Trudeau and his paddling partner set out in their canoe. As they do so, Trudeau's voice narrates his impending canoe trip experience:

Any river is challenging. Rivers have their own personality, and there's always surprises around the bend...It's a good river to paddle. I think it should be within the realm of what I can do, I mean the rock in the middle of Virginia Falls is named after one of the guys who taught me to canoe, Bill Mason. And now I sort of have the feeling that if I do good over the next few days, I owe it all to Bill and my father. If I do poorly, its my fault, or Jerry's fault. [laughing] We'll see how that works.

It is clear that Trudeau's narrative contains a mildly humourous tone and that he does not appear to be taking himself too seriously. But there is nevertheless a strong tone of masculinism at play in his speech, evident in the themes of challenge and surprise that appear in the above narration. This sense is bolstered by his resolve to overcome these adversities.

A few scenes later, the danger plot continues. Suspenseful music is set against a picturesque view from a mountaintop, looking down to a set of white water rapids on the South Nahanni River below. This time the voice of Neil Hartling, a local outfitter and tour operator, narrates the image. In an assertive masculine voice, he says: 
This is Figure Eight rapid. Raymond Patterson, in his book The

Dangerous River, called this the meanest piece of water he'd ever seen. It's a very challenging piece of water, large standing waves, and massive boils that create great instability for your canoe.

The image then gives way to one of Trudeau, who is shown standing shirtless in a life preserver on the edge of a cliff several hundred feet above the river, tracing out the path he will take down the river (Figure 4.4, page 169). With a quick change of scene one now watches Trudeau's travel companions in an inflatable raft make their way through Figure Eight rapid (see Figure 4.5, page 170). The image is accompanied by a rhythmic drumbeat meant to evoke a sense of danger but also a sense of primitive tribalism. Next comes Trudeau and his paddling partner in their canoe. Taken from a camera mounted on the stern thwart of his canoe, an image of Trudeau's body and face captures the intensity of being jostled around in the rapid and brings the viewer into the canoe, to experience the thrill virtually (see Figure 4.6, page 171). This camera angle also gives the viewer a close encounter with the embodiment of control and mastery so clearly needed to successfully undertake such calculated risks. The danger passes. The rapid is safely navigated. Trudeau and his partner are shown paddling out of peril into an eddy and in a gesture of masculine bravado Trudeau lets out a vigorous "Whaohoo!," raising his arm in triumph. Crisis averted. Justin's father and Bill Mason would, no doubt, approve. In this short scene, it is possible to read the masculine pursuit of danger as evidence of an innate quality of manhood that has been eviscerated by modern culture. Accordingly, reconnecting with one's 'inner primitive' can thus rejuvenate one's manhood. Several sequences later, we are returned to the South Nahanni trip, 


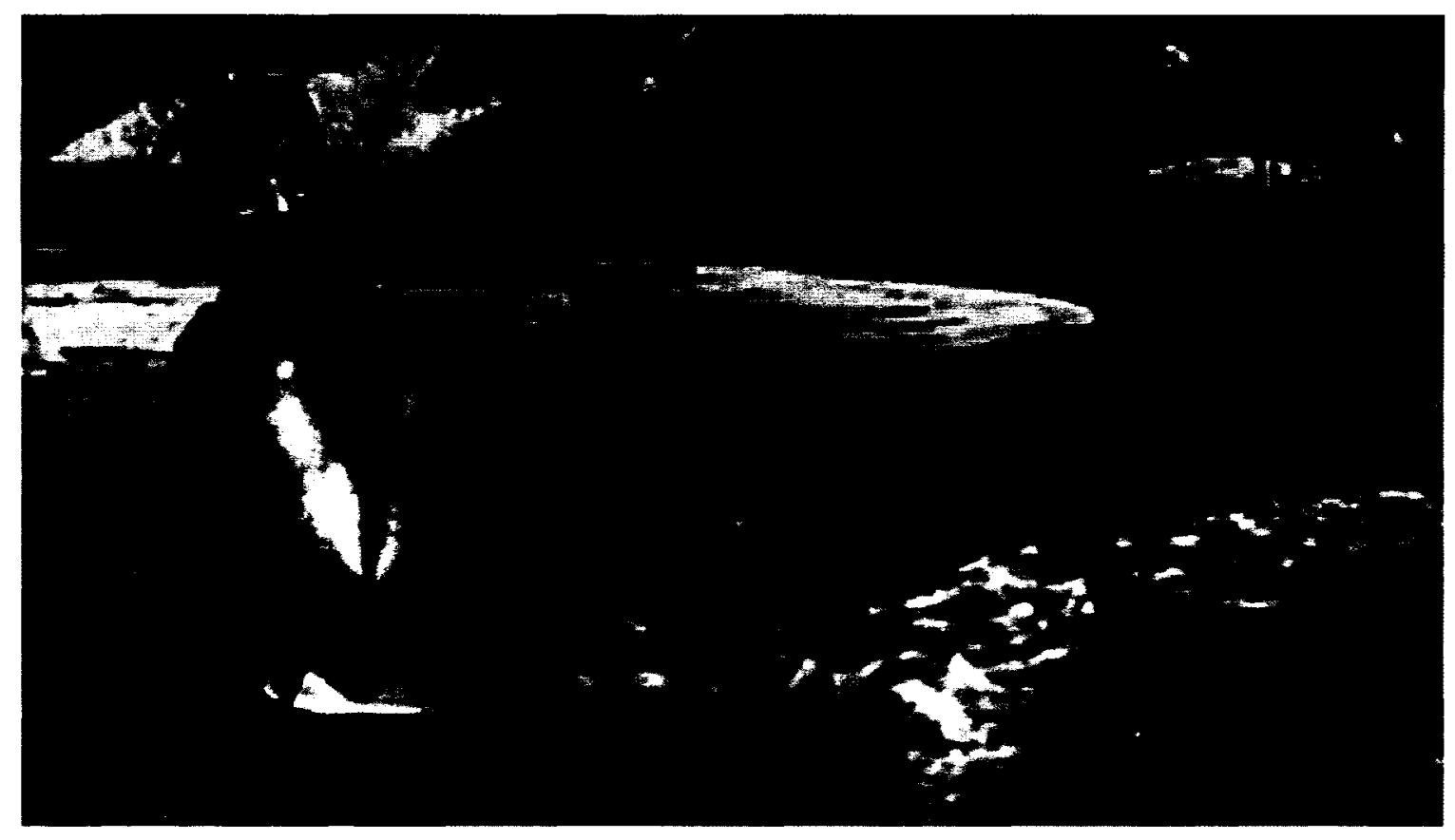

Figure 4.4 - Trudeau scouting out Figure Eight Rapids, South Nahanni River, Northwest Territories. Source: Canada's Amazon: A Boreal Forest Journey. Permission: Canadian Broadcasting Corporation. 


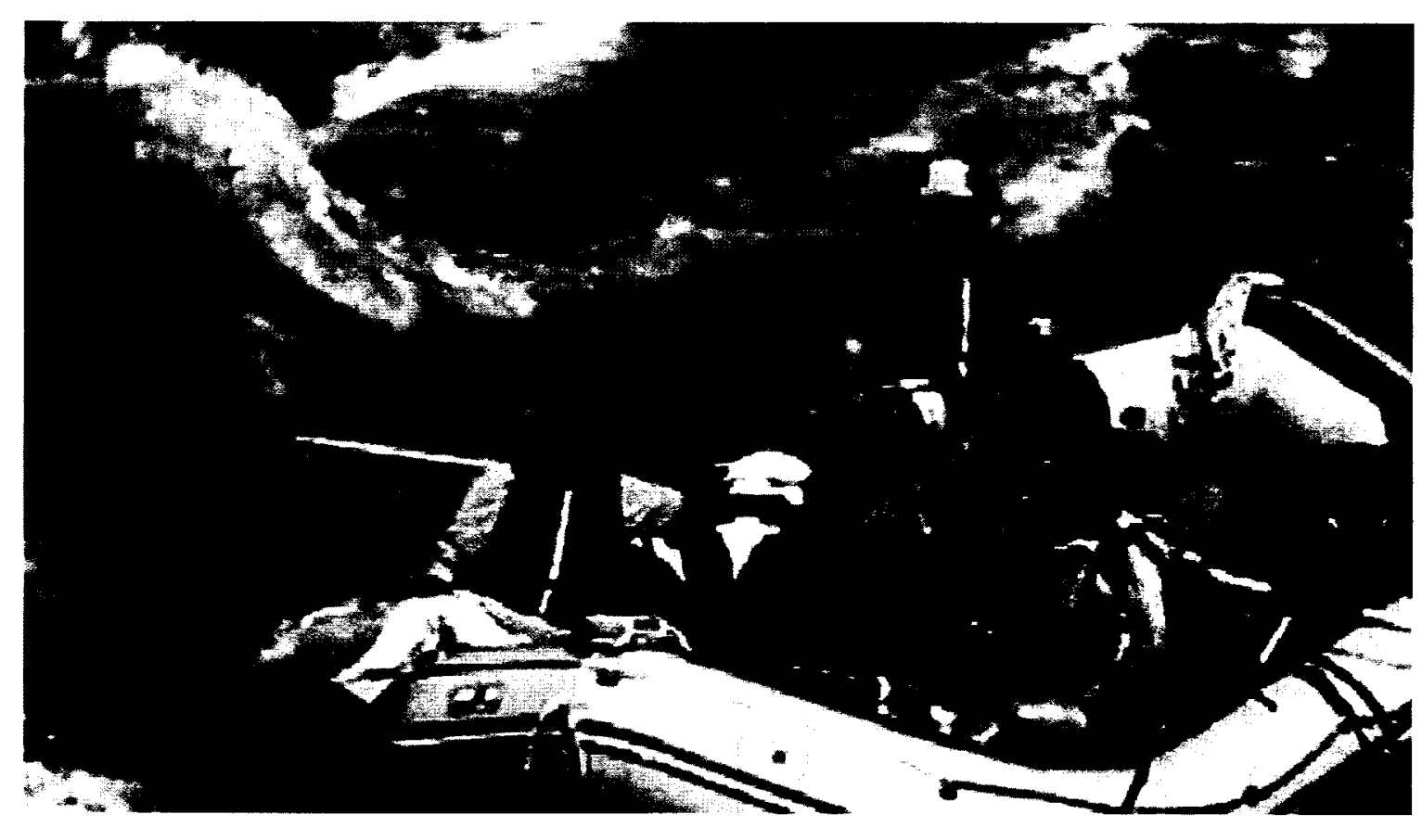

Figure 4.5 - Trudeau's companions navigating Figure Eight Rapid. Source: Canada's Amazon: A Boreal Forest Journey. Permission: Canadian Broadcasting Corporation. 


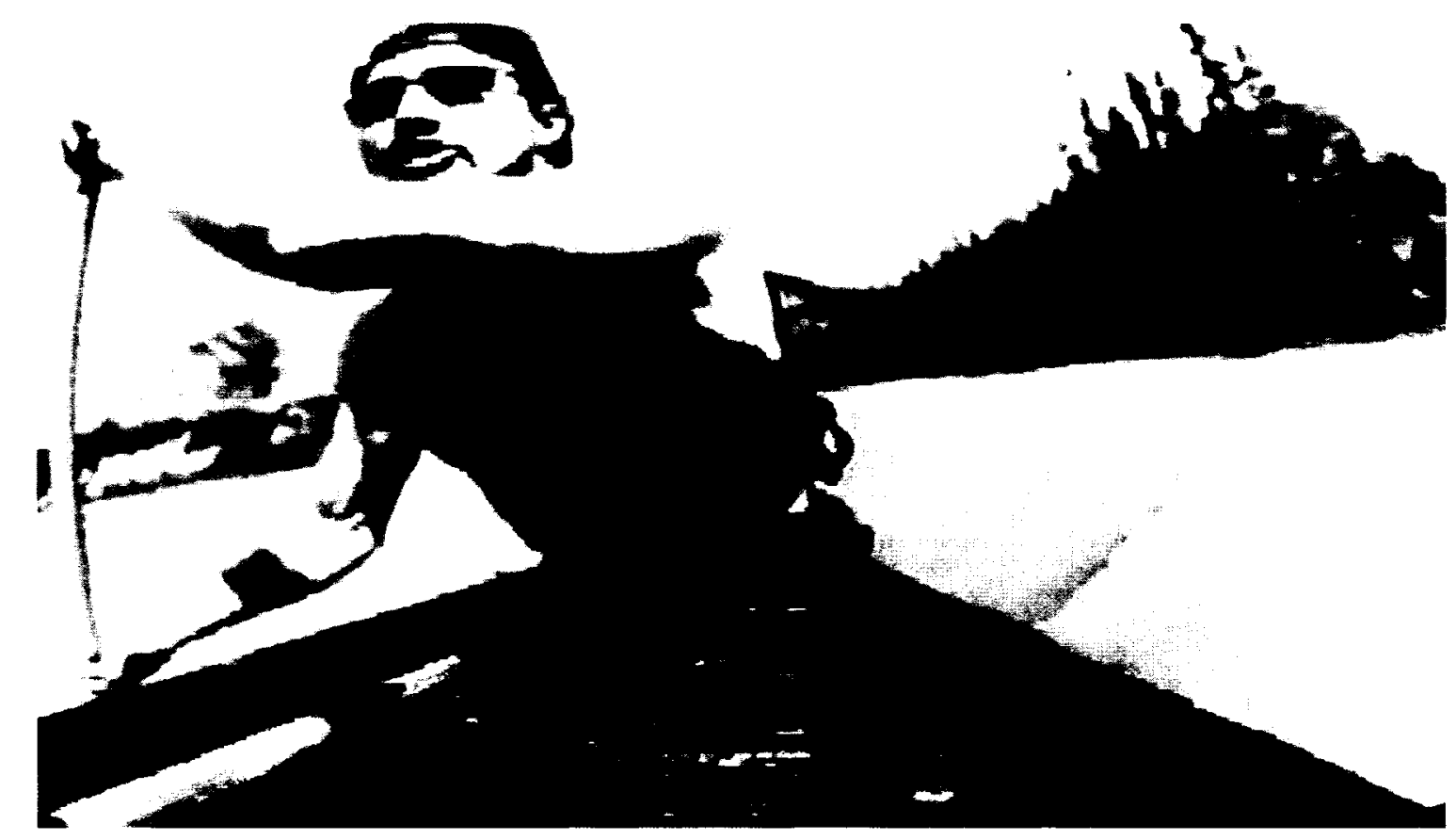

Figure 4.6 - Trudeau steering his canoe through Figure Eight Rapid, filmed from a canoe-mounted camera. Source: Canada's Amazon: A Boreal Forest Journey. Permission: Canadian Broadcasting Corporation. 
where the storyline of danger continues with one of the male canoe trip participants, Greg Yeoman, the CPAWS Conservation Director for the Northwest Territories, recounting to Suza' Tsetso, a Dene woman and one of the trip's participants, a harrowing experience he had had on the river that day. The scene then immediately cuts to Suza' Tsetso, who reflects on what the river canyon means to her:

It means history to me. It means power. It means a lot of strength and power and energy being in this sacred place.

As she speaks, the image of her face gives way to an image of a rushing rapid followed by one of her crouched down in what appears to be a prayer position, speaking Dene. The camera then pans the group, most of whom are white men, including Trudeau (left), who stand above her, looking down, and watching intensely the scene of aboriginal prayer (see Figure 4.7, page 174). Some stand with their eyes closed, honouring the prayer. Others simply observe the scene, casually drinking coffee from thermal mugs. Immediately following, an image of Tsetso reappears in a much less ceremonial capacity where she reflects on the experience of canoeing down the Nahanni River.

And what this journey means to me is that, it means that there is hope for the wildlife that lives in this area. There's hope for people to come here in the future and enjoy this beautiful sacred place, enjoy the mountains, the water, the land. It's, this is heaven.

Following Tseto's intervention, the film sequence cuts to a final image of a contemplative Trudeau, sitting at the river's edge, pondering, one assumes, his day of risk, or perhaps, one of the canoe trips he took as a child with his father (see Figure 4.8, page 175).

I want now to suggest that this series of related images - the movement from the risk subject to the praying aboriginal subject and then back to contemplative risk subject can be read as Tsetso giving sanction to the white male experience of risk and danger. 
Aboriginal spirituality sanctions white activity, where aboriginal agency, which equates to prayer and spiritual knowledge, stands in contrast to white agency, which is virile and active. Entirely absent from this series of images, however, is any mention of Dene political agency. Indeed, any mention of Dene political agency and the challenge these claims represent to conservation politics in this performative staging of national-nature would disrupt one of the core messages the film seeks to convey, which is that the boreal forest is a Canadian phenomenon, something that all Canadians have a stake in securing. Instead, the film repeats a norm of governmentalized national-nature whereby the canoe trip and its predominantly white subjects are shown to embody the qualities that are synonymous with the masculinized Canadian subject - a desire to pursue calculated risk, an ability to skilfully manage surprise, mastery of the outdoors and grace. Conversely, the raced aboriginal subject is made to fit within this narrative of national recovery by blessing it with symbolic sanction. The political agency of the Dene is erased and has no meaning, except where its cosmology underwrites white nationalized action.

A similar move is found in a short exchange occurring earlier in the film between Yeoman and Tsetso concerning the power of place. Four canoe trip participants are seated at a campsite on the river's edge, discussing the power of place. Tsetso speaks:

That's the message that needs to get out there. People need to know the special uniqueness of this area, because it hasn't, that message hasn't been passed on to people yet.

This image is immediately followed by one of Yeoman, who speaks about the importance of Dene culture to modern environmentalism. He says: 


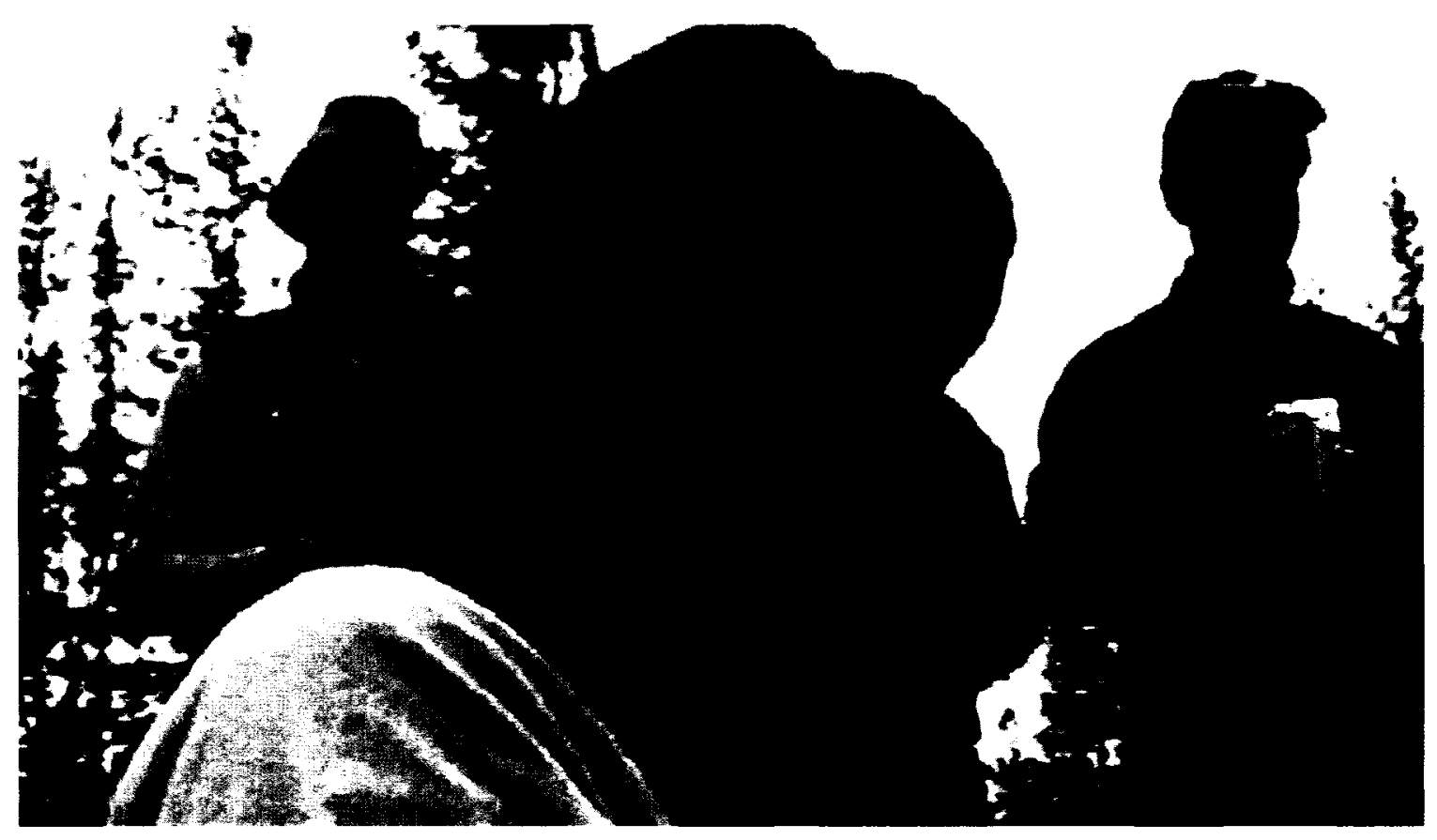

Figure 4.7 - Suza' Tsetso offers a Dene prayer. Source: Canada's Amazon: A Boreal Forest Journey. Permission: Canadian Broadcasting Corporation. 


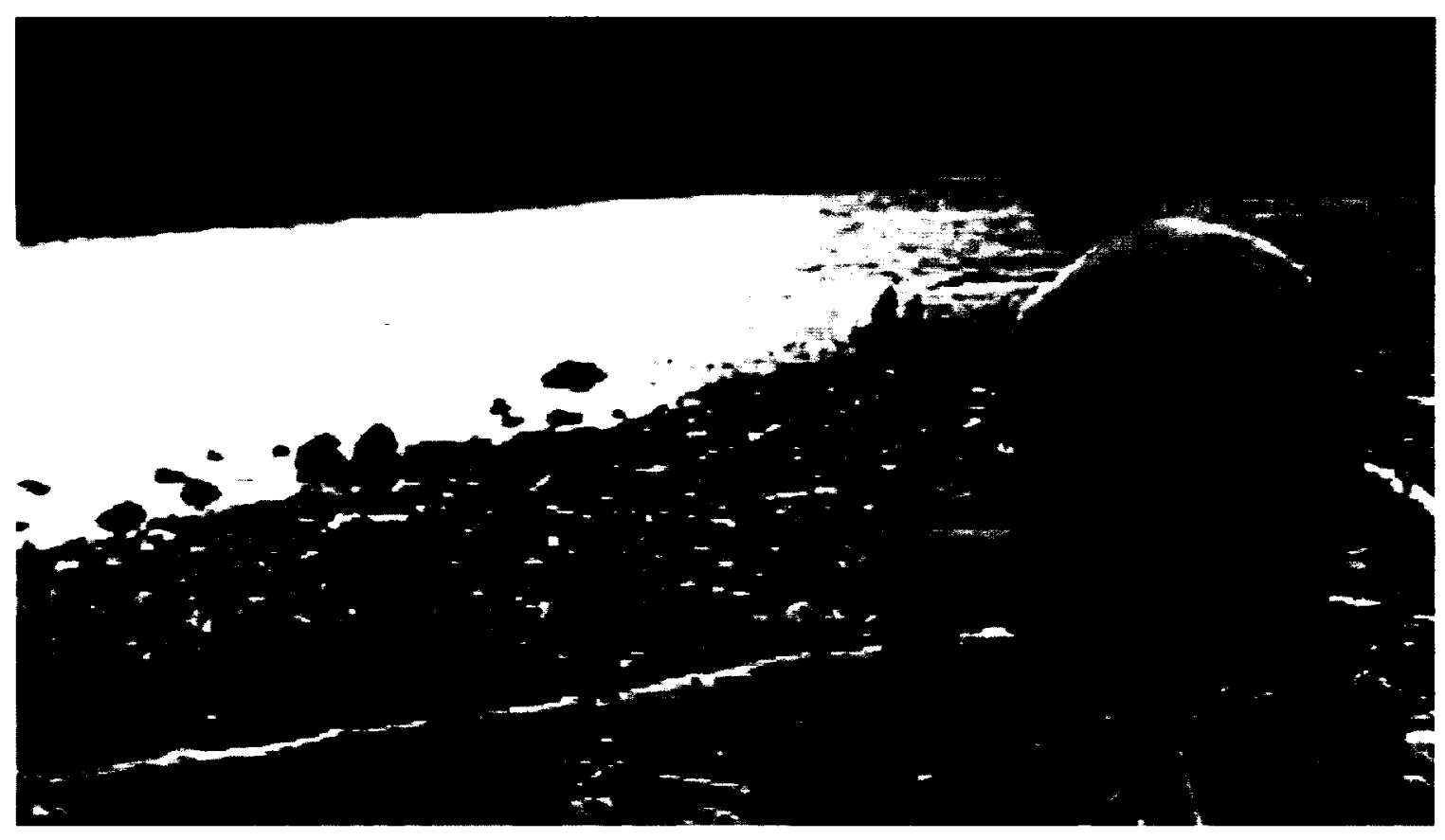

Figure 4.8 - Trudeau writes in his journal at day's end. Source: Canada's Amazon: A Boreal Forest Journey. Permission: Canadian Broadcasting Corporation. 
The Dene say that if we take care of the land, the land will take care of us. And they talk about the northern boreal forest as a green halo across the northern part of the globe. And so I think of it a little bit as an ecological guardian angel. You take care of the boreal and the boreal will take care of us. With all the filtering of water, storing of carbon, regulating the climate. I mean this is a major ecosystem in the world.

In this exchange Dene culture is appropriated by the national subject and made to work in support of a universalizing project of global environmentalism. No mention is made of exactly how either the land or the boreal forest takes care of the Dene. Nor is there scope in Yeoman's remarks to consider Dene land-use outside the constraints of naturalism. Instead, the Dene axiom, which is an expressed concern for the land, is extrapolated and made to fit the parameters of concern that constitute modern western vision - global climate and biodiversity and a concern for water scarcity.

A similar position of hierarchical complementarity between the masculine white subject and feminine aboriginal subject is seen working through the second of the film's storylines. This storyline opens at the launch site of the Athabasca River canoe trip, where we witness to a similar ceremonial gesture of aboriginal sanction. Here, Jim Boucher, Chief of the Fort McKay First Nation, in a pre-trip speech reflects on the importance of the trip that is about to take place (see Figure 4.9, page 178).

I think there is a good reason in terms of why this event is occurring. It's to demonstrate and to show the world that this river we have, which is a heritage river, is a beautiful place to be. It used to be the food basket of our people here. The elders in the community have noticed a deterioration in the quality of the river. The population of the fish has dramatically declined. The quality of the fish itself is no longer of any value to the people. So, I think there's still some beauty and there's still hope that someday this river will become what it used to be. 
Not unlike Tsetso's ceremonial prayer on the Nahanni, Boucher's speech contains a ceremonial quality, since it gives a symbolic blessing to the canoe trippers and sanctions what they are about to do. Yet as Boucher's words are spoken, the white geographies of modern canoe travel comes into stark view against the raced geography of aboriginality as the camera pans the expectant crowd of paddlers revealing them to be predominantly white. In behind Boucher sits his pickup truck. No doubt, as the white paddlers get into their canoes and paddle gaily down the river, Boucher will get into his pick-up truck and drive away; two very different racialized geographies momentarily converge in a symbolic gesture of compatibility before diverging and disappearing into their respective horizons. ${ }^{55}$

\section{Rendezvous with the Wild: The Boreal Forest}

Another important cultural production to have emerged from the Boreal Rendezvous was a coffee table book entitled Rendezvous with the Wild: The Boreal Forest (Raffan, 2004). Perhaps not surprisingly, the book is comprised of numerous photographic images of the boreal forest, images one might expect to find in a book of realist nature photography -

\footnotetext{
${ }^{55}$ Here it should be noted that in the summer of 2005 under the leadership of Jim Boucher, Fort McKay First Nation announced its intention to develop a $\$ 25$ million oil resource that it received as part of a recent treaty settlement. A Canadian Broadcasting Corporation news report made the point that Fort McKay First Nation elders say that the oil and gas industry has destroyed trap lines and the forests surrounding their homes. In the report, Zachery Powder, one such elder, said that the traditional way of life is slipping away, and sees developing the oilsands as the best way to guarantee a good future for his family. "For moose, it's not that good. For air, it's not that good. For water, it's not that good," Powder said. "But if we owned one oil outfit, it would be good for living, for McKay here" (Canadian Broadcasting Corporation, 2005). Powder's vision of aboriginality thoroughly disrupts the image of aboriginality as spiritual and close to nature that the filmmakers were trying to convey. After all, environmental groups argue that oil sands development is the most destructive land-use in the boreal forest in northern Alberta, accounting for the greatest degree of fragmentation. Yet for Powder, Boucher and others in Fort McKay First Nation long term survival of the community in the boreal forest is not reducible to traditionalism or a way of life symbolic of a naturalized past. Instead it is about developing a resource considered not only destructive of the boreal forest but one directly implicated in anthropogenic climate change and the current geopolitical configuration of the international state system.
} 


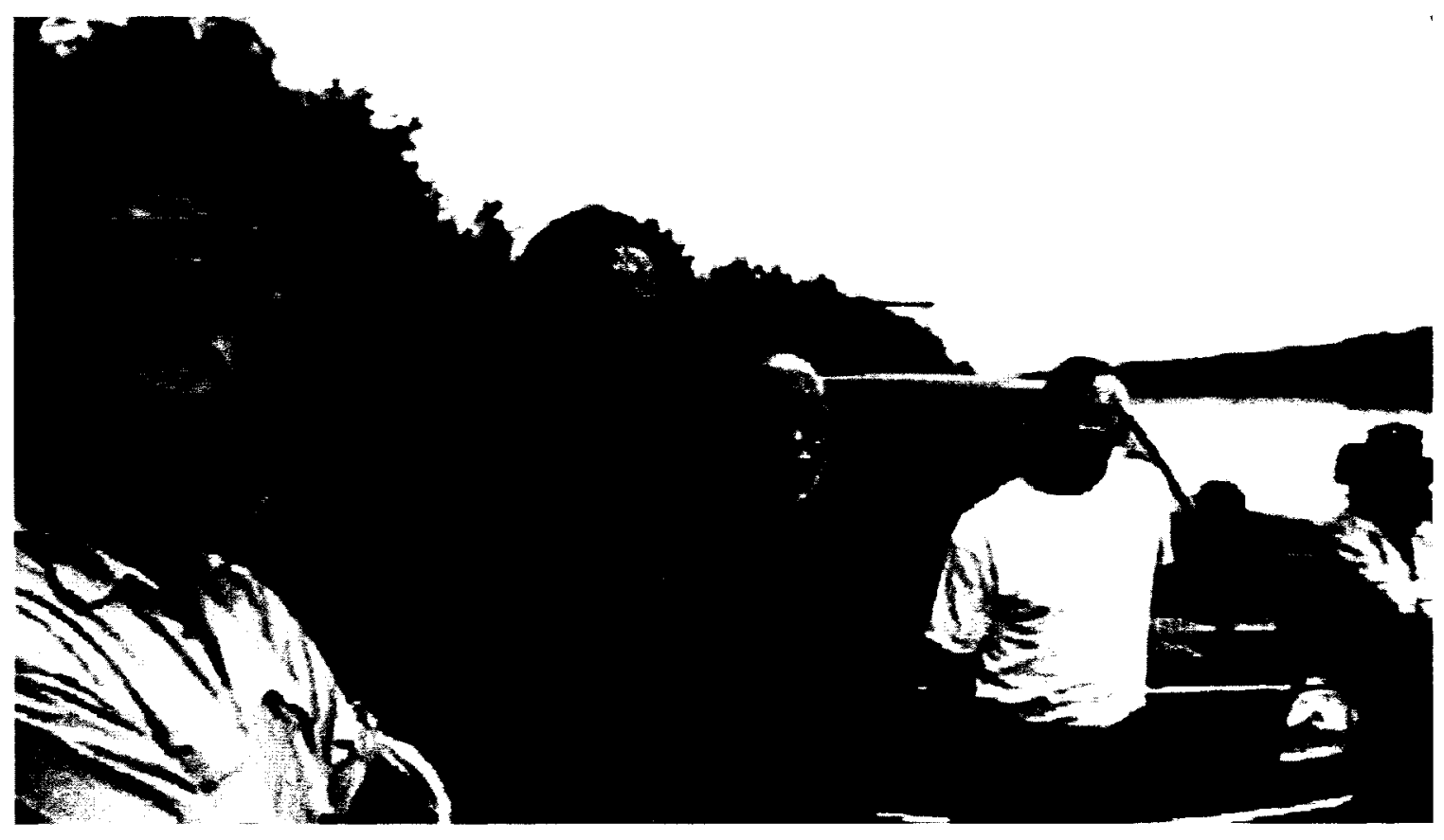

Figure 4.9 - Jim Boucher (second from the left) makes a speech to mark the beginning of the Athabasca River trip. From left to right: David Suzuki, Jim Boucher, unknown, David Schindler, Suzanne Bayley. Source: Canada's Amazon: A Boreal Forest Journey. Permission: Canadian Broadcasting Corporation. 
dramatic waterfalls, mountain vistas, landscapes that disappear into infinite horizons, inspiring sunsets and all manner of flora and fauna. What is so unique about this book, however, is that these representations of nature are combined with a host of complementary representations depicting various aspects of the actual Boreal Rendezvous canoe trips and images of the campaign more broadly - photographic images of people engaged in the act of paddling canoes, rafting down rivers and sitting around the campsite being jocular, pensive and the like, but also ceremonial images depicting the launch of the Boreal Rendezvous campaign and many of the individual trips. Moreover, these photographs are not simply narrated by a single, detached voice, but instead take a more diverse quality, since they are narrated through an eclectic collection of written text and artistic expressions - short essays, poems, anecdotes, quotations, journal entries, field sketches, even an amber cast of a wolf print - provided by many of the canoe trip participants and others who feature prominently in both Canadian conservation and canoe culture. There are far too many written entrees to go into any detail about them all, but together they appear in the book like a mosaic of experience and strongly suggest the irreducibility of the boreal forest to any one single story. In this sense, through the book, the boreal forest takes on the quality of a palimpsest given spatial form through a layering of stories. It also reads like an expression of Canadian multiculturalism, since it seems to exemplify the principle of inclusion that organizes the project of liberal pluralism. Not one voice, but many. Not one narrator, but several. There is a multiplicity of voices working through this text that seek to shape the meaning of the boreal forest, or at least that is the impression created when reading through it. Furthermore, the book's numerous entries are organized regionally - western boreal, central boreal and eastern boreal - again reinforcing the boreal's polyvalent nature, but also the deep regional cleavages that cut 
across Canadian political culture. In this text, then, boreal forest politics, thus, appear like a postmodern environmentalism, a more enlightened approach to political identity that is at once irreducible, celebrated and diverse. Here, the book also represents a departure from many other books of its kind, which routinely seek to aestheticize nature as a pure, pre-human form. ${ }^{56}$ Instead, by foregrounding the human experience in the boreal forest, such objectivist, aestheticized forms of nature appear to be challenged and the textured, social nature of boreal forest nature appears to be given full expression. Indeed this is a book that seeks to tell more about the boreal forest than a conventional book of photographs might wish to tell. Instead, it tells a human story, one that inspires, celebrates companionship and offers much hope.

Yet, in spite of its polyvalence, the book is unequivocally organized around the trope of national recovery in which the boreal's heterogeneity is flattened through a politics of national guardianship. In this sense, the plurality of stories becomes subsumed within a logic of the empty homogenous time of national sameness. It is, after all, the idea of Canada and the identifications it conjures that sets the parameters within which the boreal forest's polyvocality is permitted to flourish, that regulates what types of identities are permitted to speak within a nationally-infused environmentalism. This collapsing of experience into and the regulation of identity by the abstract space of the nation can be read by examining the types of activities in which the book's racialized characters engage. Here, as in Canada's Amazon, white agency stands in stark contrast to aboriginal agency.

\footnotetext{
${ }^{56}$ Examples of books of this kind include Wayne Lynch's The Great Northern Kingdom: Life in the Boreal Forest; Roberta Bondar's Passionate Vision: Discovering Canada's National Parks; Lori Labatt and Bruce Littlejohn's Islands of Hope; and Adrian Dorst and Cameron Young's Clayoquot: On the Wild Side.
} 
In the book there is a preponderance of images depicting the canoe trip participants, most of whom are white, engaged in acts that are representative of what one might expect to do while on a canoe trip in the Canadian wilderness. Not only are there numerous images of manly adventure on the rushing river, but there are also images of people relaxing in their canoes and paddling through fog and through tall grass. There are images of people who have climbed up a mountainside for that perfect panoramic view of the river below. There are images of hardy, brave souls enduring the bugs. And there are images of people, lounging around the campsite, playing guitar. Yet there is one overriding binary visual logic that organizes so many of the images appearing in the book: the image of the agential white canoeist and his/her position in relation to the remote, spatially fixed aboriginal, whose presence in the book, much like in the film, often works to sanction white agency. Several examples of this visual logic stand out.

In one striking example, Eddy Catholique, a Chipewyan elder, is shown roasting the heads of two caribou over an open fire in what might be early fall or late spring (see Figure 4.10, page 183). Catholique's clothes are tattered and dirty. His teeth are stained. And his equipment is outmoded by the standards of contemporary outdoor fashion. Catholique is pictured sitting on the ground atop a bed of spruce boughs, grimacing. His hands are clasped together as though having just been burned, or very cold. The image appears as a photographic inset for a short piece of text entitled "Food on the Trail," which is an excerpt from James Raffan's travelogue, Summer North of Sixty, on the social cohesion that meal preparation and mealtime engender on the wilderness canoe trip. In viewing Catholique's image against the others appearing in the book, it is difficult not to recall the frequently occurring images of clean, white canoeists, paddling in colourful synthetic canoes, wearing colourful synthetic clothes. Catholique's image in the text 
stands out against such a familiar backdrop. In contrast to the predominantly white paddlers, his image comes very close to representing aboriginal subsistence and has an almost barbaric, uncivilized quality to it. The two caribou heads appear to be freshly severed from their bodies and sit helplessly on the burning logs. From this image one gets the sense that Eddy Catholique is a real Indian, engaged in the sort of activity for which real Indians are noted and celebrated. Read this way, the picture is also meant to celebrate cultural diversity and the sacred relationship aboriginal people have with the caribou herds that migrate throughout the boreal forest. It also provides an interesting juxtaposition to the experience of canoe trip cuisine depicted in Raffan's piece of text. In this sense, Catholique appears to embody the difference so celebrated in Canadian multiculturalism. But it can also be read for the way in which it constructs aboriginality as the antithesis of civilized white culture. I say this because on the very page opposite is a montage of photographs depicting the various steps required to make bannock cinnamon buns in a campfire oven (see Figure 4.11, page 184). Although not explicitly stated in the text, in viewing these images in juxtaposition, one is left with the distinct impression that the cinnamon buns are being prepared by a seasoned canoe tripper from urban white culture, someone for whom the cinnamon buns are taste of civility, or a reminder of home. Curiously, however, no effort is made to draw the parallel between these two very different images. The reader is simply left to ponder the difference the two sets of opposing images - Raffan's civility, symbolized by the cinnamon bun, and Catholique's primitive barbarism, symbolized by the caribou's severed head.

Earlier in the book there is a similar image of two Tetlit Gwich'in elders carving up a moose carcass on a bed of willow boughs (see Figure 4.12, page 186). Their 


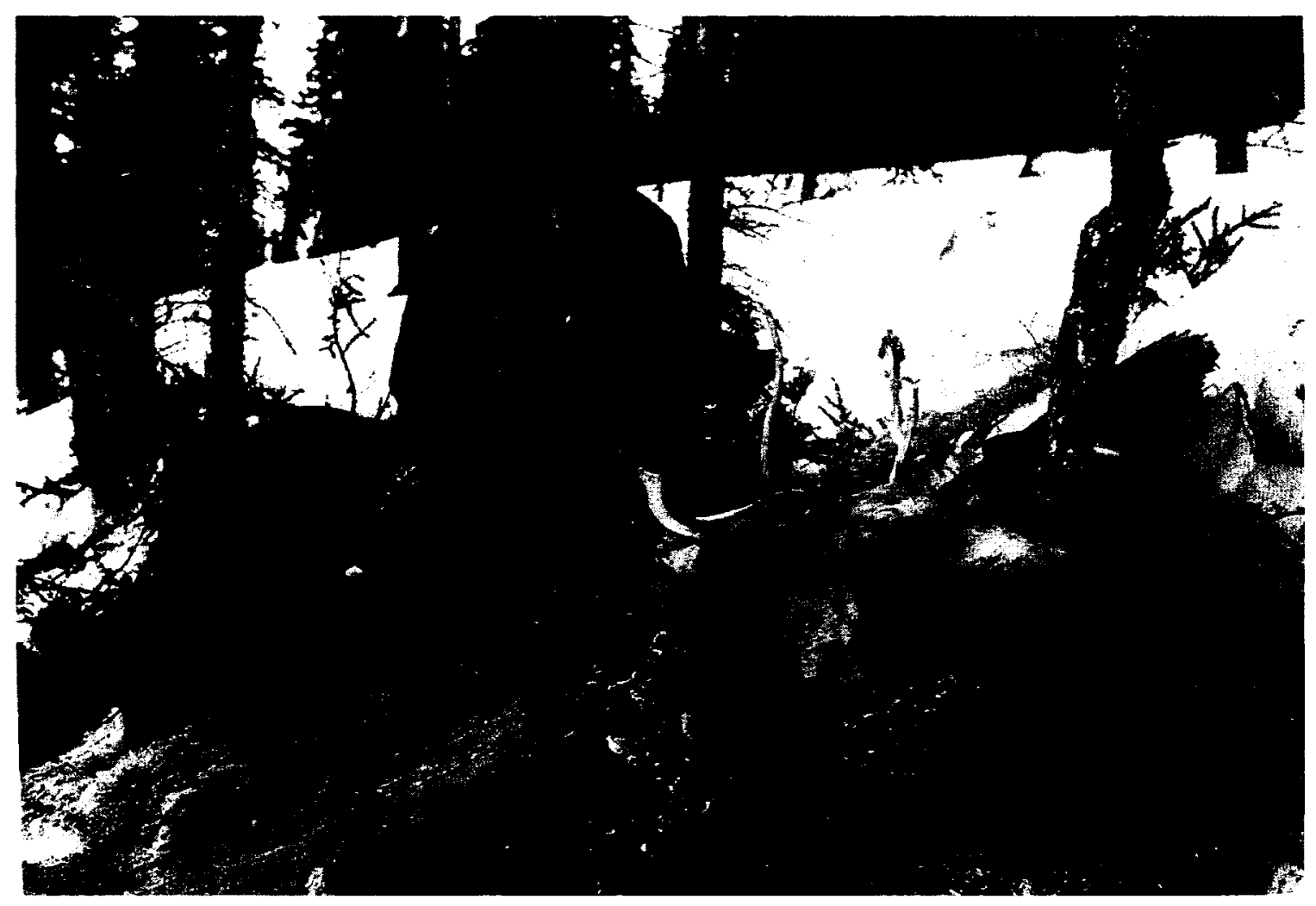

Figure 4.10 - Eddy Catholique enjoying a picnic lunch on the trail. Source: Rendezvous with the Wild. 


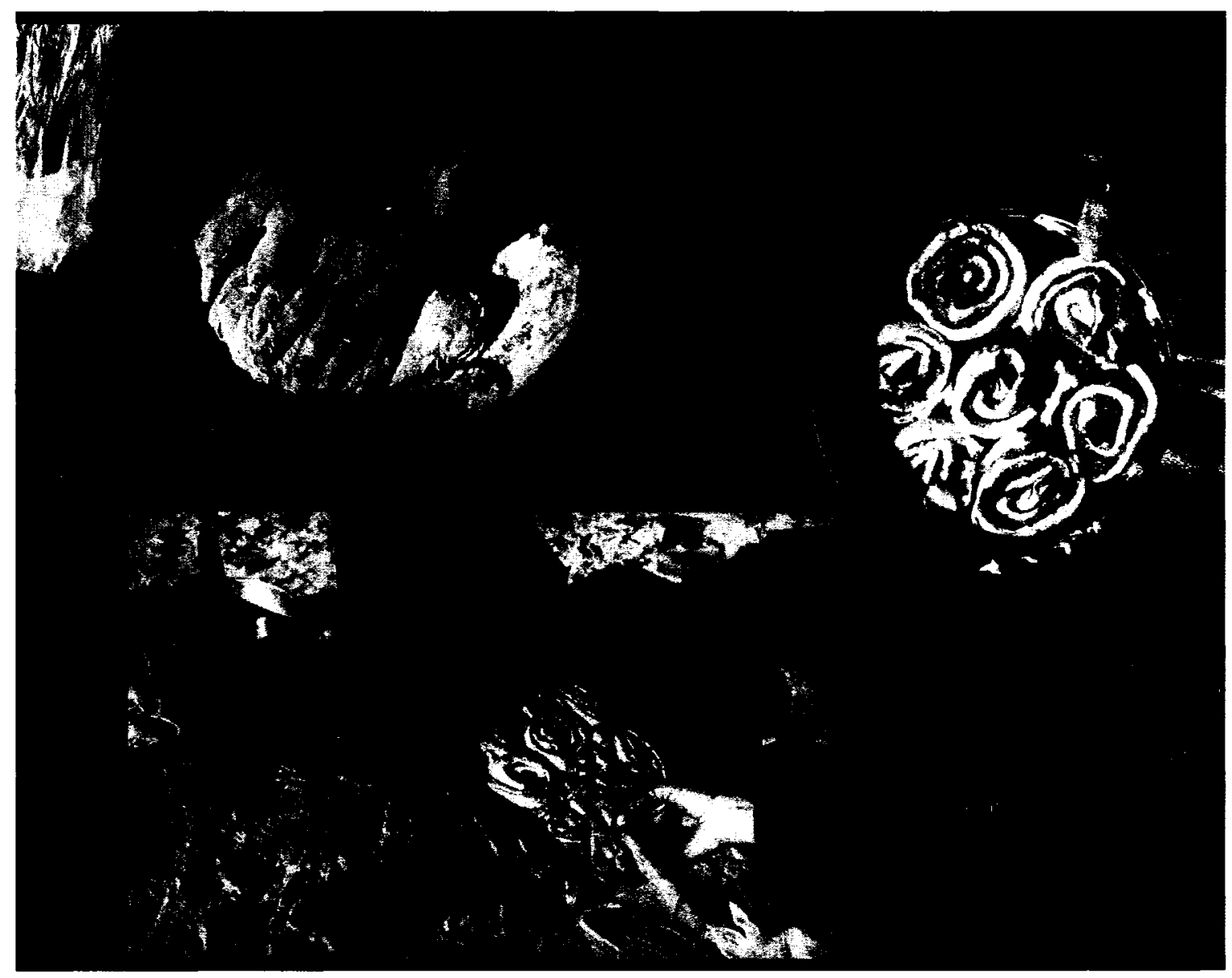

Figure 4.11 - Cinnamon buns: "Nothing beats slow food on the trail." Source: Rendezvous with the Wild. 
hands are stained by moose blood, the red flesh of the carcass contrasting sharply with the deep green willow. The image is a supplement to Teresa Earl's journal entry from the Wind River trip, in which we learn that the moose carcass is being prepared for a feast hosted by the Gwich'in in celebration of the arrival of the Wind River paddlers and those from some of the other Boreal Rendezvous canoe trips. Yet, like the image of Eddy Catholique, it too is caught within an ambivalent frame. In one sense, this is a celebratory image. It marks the moment when the white Boreal Rendezvous paddlers are reconciled with the boreal forest's aboriginal inhabitants, a moment of syncretic rapprochement when the message of boreal forest conservation dovetails so cleanly with aboriginal experience. In the context of the Boreal Rendezvous celebration, this image is thus easily construed in humanist terms - aboriginal people are by nature generous and willing to embrace any wayward, haggard travellers. Yet, at the same time, it can be read for its explicit romanticism, evidence of aboriginal naturalism and tradition, one that bears the mark of a remote, perhaps almost barbaric, primitivism.

In the book, half a dozen or so other images depict aboriginal people, most of whom are men, in similar positions of rapprochement relative to the white paddlers. There are images in which aboriginal people occupy the iconographic image of the wilderness guide, escorting white canoeists through their traditional territory. There is an image of a native man showing a white environmentalist how to harvest long grain wild rice. And there are numerous images that show aboriginal people engaged in some sort of spiritual ceremonial blessing of the Boreal Rendezvous (see Figure 4.13, page 188). In each of these images, the modern urban dweller's desire for nature synchronizes with the native's lived experience. 


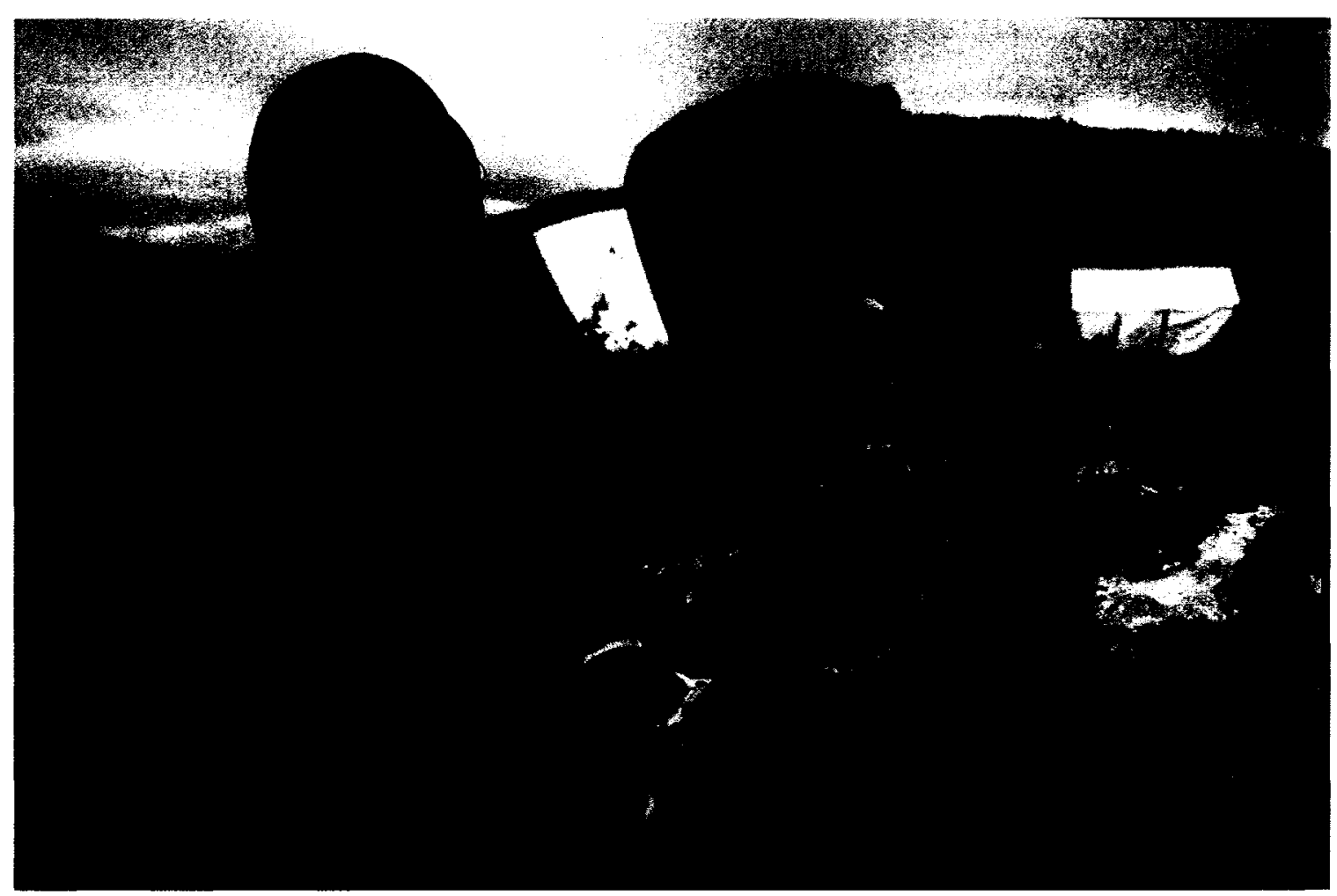

Figure 4.12 - Tetlit Gwich'in elders from Fort McPherson prepare a moose carcass on willow boughs in preparation for the arrival of the Boreal Rendez-vous paddlers. Source: Rendezvous with the Wild. 
The dominant logic organizing the visual imagery of Rendezvous with the Wild trades on a distinction between the aboriginal person as traditional, cultural, spatially situated, spiritual, natural, unclean and remote, on the one hand, and the white canoeist as urban, acultural, spatially mobile, political, scientific/environmental, clean and caring, on the other (see Figure 4.14, page 189). These are two highly racialized sets of contrasting, yet complementary, identities. Of course, there are some minor exceptions to this. But it is the overwhelming binary logic of these images that needs to be emphasized because it is a binary of unequal proportions that retains a tremendous amount of regulatory power and durability. It is the (universal) trope of white nationalism that sits invisibly behind this cultural diversity and that positions aboriginality within the narrative trajectory of Canadian national and environmental recovery. Moreover, by reducing aboriginal presence in the boreal forest to one of primitive naturalism, this binary forecloses other forms of aboriginal political presence in the boreal forest. By displacing aboriginality into an historically a priori space-time and reincorporating this displaced 'primitive' aboriginal presence into national teleology through a discourse of conservationism, the book disavows the contemporary struggles of resource control in which so many of the aboriginal peoples living in the boreal forest are caught up.

Ironically, however, at the end of Rendezvous with the Wild there is considerable attention paid to precisely this issue: aboriginal resource control. Here, we learn that in the summer of 2003 a consortium of environmental groups entered a landmark partnership with Pikangikum First Nation in Northern Ontario in which both parties - 


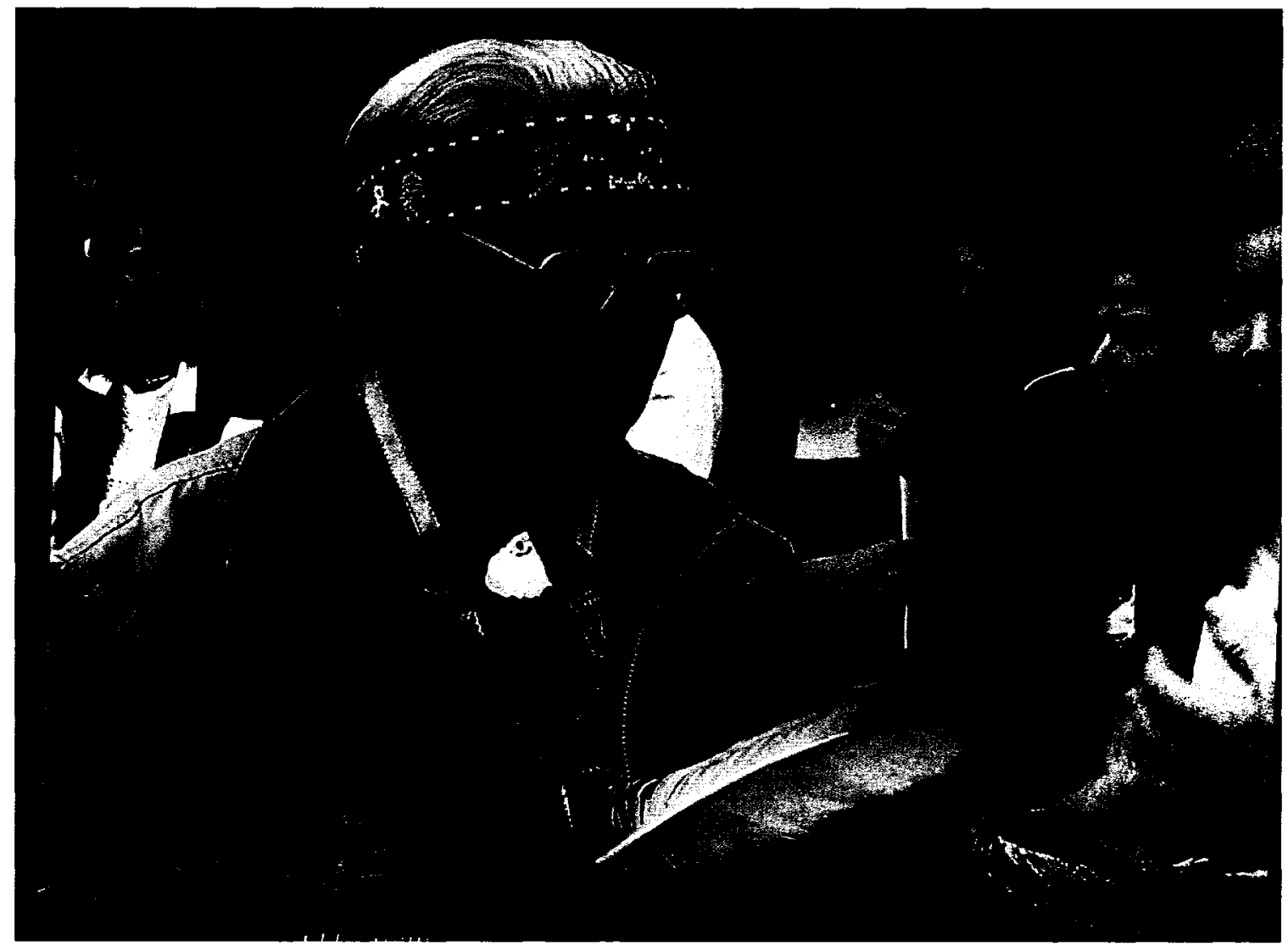

Figure 4.13 - Elder William Commanda at the launch of the Boreal Rendezvous in June 2003, conducting a smudge ceremony. Source: Rendezvous with the Wild. 


White Canoeist
Urban (modern)
Acultural
Mobile
Political
Scientific/Environmental
Clean
Caring

\author{
Aboriginal \\ Traditional \\ Cultural \\ Spatially situated \\ Spiritual \\ Ceremonial/Natural \\ Unclean \\ Requiring care
}

Figure 4.14 - Binary logic organizing visual imagery in Rendezvous with the Wild.

Pikangikum First Nation and the Partnership for Public Lands ${ }^{57}$ - agreed to a host of principles, which if properly implemented, will ensure that Pikangikum First Nation would manage a section of the boreal forest to the highest environmental standard. In an accompanying photograph, a white woman representing the environmental consortium is shown signing the agreement at a table amongst a large gathering of what appears to be mostly men from Pikangikum First Nation, who are also about to sign the agreement (Figure 4.15, page 191). This is a landmark agreement, especially important since it represents a rapprochement between aboriginal groups from northern Ontario and the largely urban-based conservation organizations who were caught up in an embittered struggle during the controversial Lands for Life land-use planning process initiated in 1997 by the Government of Ontario (Cartwright, 2003). ${ }^{58}$ It also represents a progressive form of economic development, insofar as it seeks to place control over resources within the purview of Pikangikum First Nation and direct resource revenues to the people of

\footnotetext{
${ }^{57}$ It should be noted that the Partnership for Public Lands is a consortium of three environmental preservation/conservation groups - Canadian Parks and Wilderness Society, World Wildlife Fund Canada, and the Federation of Ontario Naturalists- and was formed in 1997 during the embittered Lands for Life process orchestrated by the Progressive Conservative Government of Ontario under the Premiership of Mike Harris.

${ }^{58}$ It should be noted, however, that the controversy surrounding the Lands For Life process did not directly involve Pikangikum First Nation.
} 
Pikangikum. ${ }^{59}$ In this respect, this is a very important agreement, one that I certainly do not intend to decry. But, even here, to assume that these sorts of developments occur in the absence of productive, racialized relations of power would be careless. These are not innocent political projects but instead are rendered culturally meaningful within highly complex fields of previously articulated signs (Braun, 2003).

In making this argument, I turn to Braun's use of citationality. For Braun, citationality suggests that "meanings do not come into the world fully formed, nor can they be explained solely through reference to the intention of the subject who speaks or acts. Rather, they operate through repetition" (2003:187). That is, meaning attaches to specific events, images or acts to the extent that these things are themselves repetitions of past events, images or acts that were previously articulated as culturally significant. I argue that it is precisely the work of citationality that makes the signing of this historic agreement culturally significant. This is so because the cultural significance of the partnership agreement trades on the same binary logic that organizes the visual imagery in the book: aboriginal-traditional-situated-spiritual-natural-dirty-helpless versus white canoeist-urban-mobile-rational-environmental-clean-caring. Here, aboriginal political agency and access to modernity are contingent on white agency, meaning that the former is largely silent unless officially sanctioned by the latter.

But what is critical here is that this view trades on another familiar economy of signs whereby aboriginal people are often portrayed in popular discourse as in need of

\footnotetext{
${ }^{59}$ Anticipating that forestry and other forms of industrial development would eventually reach and potentially compromise their traditional territory, starting in 1996 Pikangikum First Nation began discussing with the Ontario Ministry of Natural Resources the possibility of establishing an aboriginal forestry on its territory. Out of these discussions was spawned the Whitefeather Forest Initiative, an economic development initiative in Pikangikum First Nation that uses indigenous knowledge to guide the process of land-use planning. For details see Chapeski et.al., forthcoming. Thanks are due to Andrew Chapeski for making this document available to me.
} 


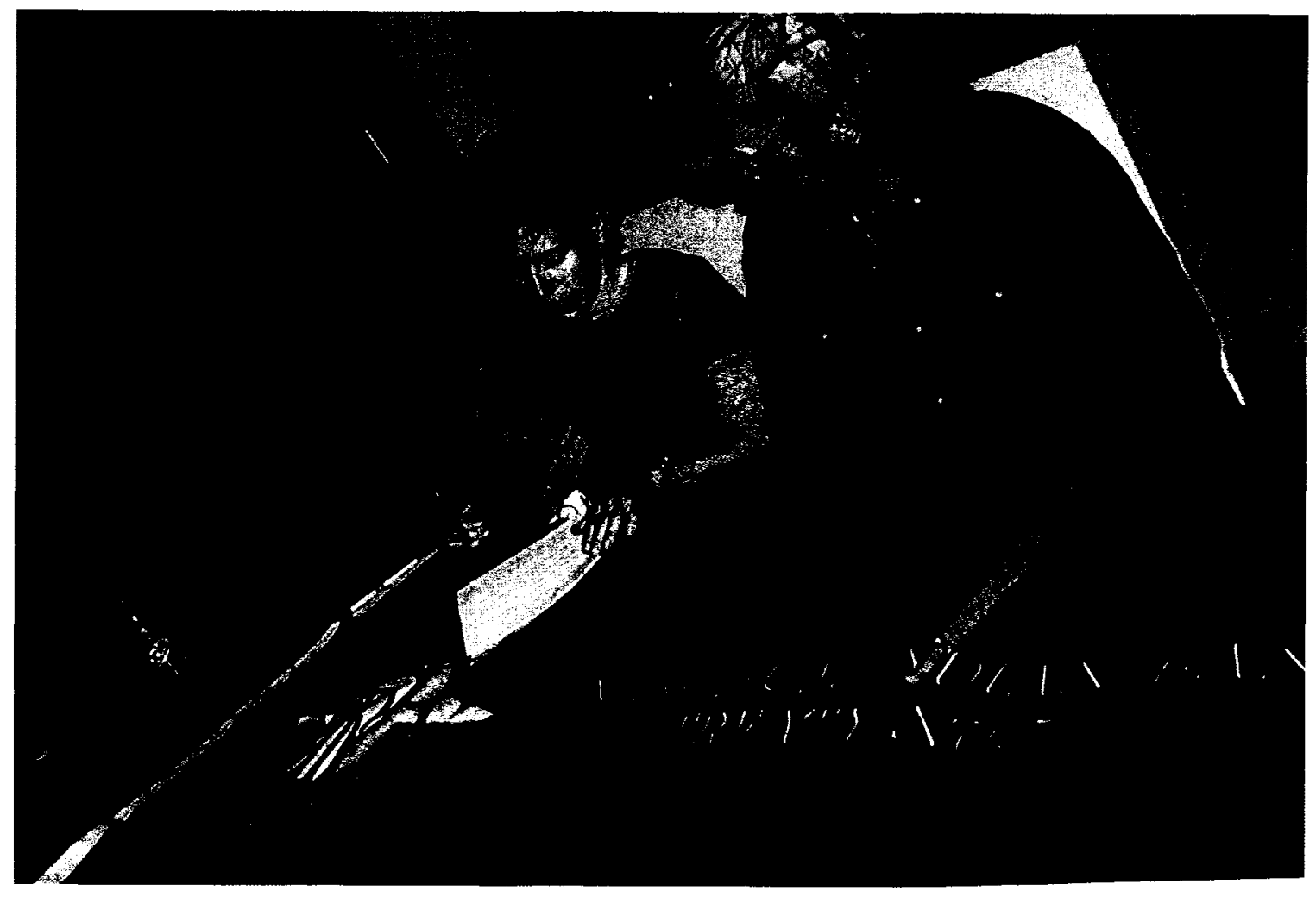

Figure 4.15 - Representatives of the Partnership for Public Lands and Pikangikum First Nation signing the land-use planning agreement. Source: Rendezvous with the Wild. 
some form of government assistance, or as a 'problem' with which the Canadian public must inevitably come to terms. Thus, to view an image showing an environmental group signing a land-use agreement with a group of aboriginal people from the north has the symbolic effect of resolving the 'aboriginal problem.' It also has the effect of narrowing the apparent culture divide that exists between aboriginal peoples in the north and white Canadians in the south. Implicit in this image, however, is that the political agency of Pikangikum attains its legitimacy through the signing of the accord. Pikangikum cannot speak politically, cannot be recognized, unless white agency gives it the nod of approval. But if citationality underlies the intelligibility of contemporary signs, then the signing of the partnership agreement between Pikangikum and the Partnership for Public Lands can also be read alongside an even more powerful set of historical events, the act of treaty signing between the white Dominion government and the aboriginal people who occupied the land the white settlers sought to control. I say this because aboriginal-white relations in Canada, both past and present, have been, and continue to be, predicated in so many instances on the signing of these sorts of agreements, such that the practice is now easily recognized as a symbol of reconciliation between these two 'naturally' opposing cultures. As such, this image poses no real problem for the viewer, which is to say that it is entirely intelligible, because the act of signing such an agreement is something we might fully expect to see carried out between these groups. Indeed so much of the history of aboriginal-white relations in Canada is the history, or the historical absence, of such agreements.

The last observation I wish to make regarding this image is that the signing of the agreement is implicitly framed within a discourse of what Bruce Hodgins has called “canoe irony" (1988). For Hodgins, canoe irony recognizes that "despite the canoe's 
mythological purity as a symbol, it was, in fact, part of the 'idea of progress' which led to the continuing destruction of wilderness and the degradation of the environment" (1988:55). The early surveyors and traders who travelled the pays d'en haut did so by canoe. Nowadays, according to Hodgins, many canoeists are "yuppies," who might very well concern themselves with preserving wilderness spaces for their "two-week vacations," but who are nevertheless more concerned with maintaining their "environmentally destructive urban lifestyles" with nary a concern for finding "new ways for communities in Northern Ontario to have a viable future that is not harmful to the environment and respects the need both for forest conservation and wilderness preservation" (1988:55). Thus the signing of the agreement, in a sense, works to reconcile canoe irony, where wilderness preservation and the need for economic development are sutured through a discourse of conservation that does not fundamentally disrupt the canoeist/aboriginal binary logic that organizes the idea of race in Rendezvous with the Wild. Paradoxically, however, in ameliorating Hodgins' interpretation of canoe irony, the signing of the agreement leaves intact another even more troubling irony, namely that the canoe is an aboriginal artefact that was appropriated by early colonial explorers to facilitate their conquest of North America and has been subsequently inserted into the lexicon of Canadian iconography as a national symbol. It is seems entirely uncanny then that the Rendezvous with the Wild should end with the signing of an agreement that implicitly sanctions the recreational use of canoes by white people and the raced and gendered natures its use implies. 


\section{Chapter 5}

\section{Settling Differences ${ }^{60}$ : Canada's Boreal Forest As Scarcity Narrative}

The beauty of the boreal landscape is at the heart of Canadian identity. It's a commodity every bit as valuable as timber and hydropower and it's vanishing from Canada.

- Don Sullivan, Boreal Forest Network ${ }^{61}$

Societies are most vulnerable at their edges, along the tattered fringes of the known world.

- Anne McClintock, Imperial Leather

The liminal figure helps to maintain societies.

- Edward Said, Culture and Imperialism

\section{Carbon Nation}

In the autumn of 2002, early on in the data collection phase of my dissertation research, I attended a conference at the University of Winnipeg hosted by the Stockholmbased Taiga Rescue Network and its Winnipeg affiliate, the Boreal Forest Network. The conference offered an opportunity for those from around the world interested in boreal forest politics to share their experiences of, and debate issues relating to, the boreal forest. By attending the conference, it had been my hope to learn as much as possible about the politics of the boreal forest and to pick up whatever I could about the salient issues it faced. And indeed, I learned a good deal. I learned, for instance, that less than desirable forms of industrial capital were rapidly denuding the boreal forest and that it

\footnotetext{
${ }^{60}$ This chapter title originally appears as a chapter title in Eva Mackey's The House of Difference: Cultural Politics and National Identity in Canada. (University of Toronto Press, 2000).

${ }^{61}$ Taken from Fen Montaigne's June 2002 National Geographic article "Boreal: The Great Northern Forest."
} 
needed urgent protection. I also learned that the boreal forest together with the Amazonian rainforest are the 'lungs of the earth', that the boreal forest is one of the largest natural aviaries on the planet, and that the Canadian boreal represents a conservation opportunity that Canadians simply cannot afford to squander. But if there was one thing I learned about the boreal forest that weekend in Winnipeg that trumped all others, it was that the boreal forest's greatest contribution to both human and non-human life is its carbon storage capacity. Here I learned that the boreal was a life-giving entity that played a crucially important role in regulating the global climate. Take it away, highgrade it, convert it or destroy it, and the consequences would surely be grave.

Such were the stories being told in Winnipeg about the boreal forest, the very terms by which the boreal forest was made to matter in the context of Canadian and global conservation. But alongside these storylines another set of plots was unfolding in Winnipeg that weekend that said less about the forest than about the role of people in safeguarding its presence. These were the plots of human agency and identity. I learned, for instance, that there was a competition between human agencies, a 'competition to coexist', as one person put it, between industrial capital and life. I also learned that the "name-and-save" model for conservation was no longer applicable to the boreal forest context, but that a much more sustained engagement with all the relevant stakeholders was needed, due in part to its sheer magnitude but also because the name-and-save model has often resulted in acrimony and conflict. Instead, the metaphor that one person used to conceptualize the burgeoning boreal politics that really caught my attention was that of a big tent. What was needed for boreal forest conservation to occur, according to the metaphor, was a big tent within which could be crafted a positive overall vision for the 
boreal forest, a democratic public space from which to pose questions about the kind of nature that is socially desirable for all Canadians.

And if I can add one last item to the list of things I learned in Winnipeg that weekend, it would be that boreal forest conservation must be subsumed not only by a big tent, but also by a very straightforward economic logic: scarcity drives value. Here the basic message being delivered was twofold. First, if the boreal forest could be rendered culturally significant through the language of scarcity, then the voting and consuming publics would be more inclined to value it. And second, while this valuation might begin as an expression of inherent, cultural or political value, ultimately it should be expressed in the universally recognized language of economic value, capital. To this a corollary was added: if the boreal forest is valorized by capital, then this valorization must be redistributive such that those with the most at stake, the communities situated within the boreal, particularly Aboriginal communities, would become its primary beneficiaries.

Needless to say these were all very inspiring themes, particularly given that the positive messaging offered a much-needed corrective to the adversarial politics so characteristic of past episodes in Canadian conservation politics. ${ }^{62}$ Yet, in spite of the lofty ambitions and positive messaging in Winnipeg, and given the legacy of conflict marking Canadian conservationism, I nevertheless harboured a niggling suspicion, a rather naïve one perhaps, that I might find in Winnipeg something resembling the

\footnotetext{
${ }^{62}$ There are numerous examples in Canada where forest conservation has resulted in adversarial relations among stakeholders, litigation and in some cases violence. The famous "war in the woods" over the fate of Clayoquot Sound in British Columbia offers perhaps the most widely circulated example (see for example Braun, 2002; Magnusson and Shaw, 2003) but there are many others. The highly charged debates over logging, recreation and aboriginal rights in the Temagami region in central Ontario in the 1980s and early 1990s offer an historical example (see for example Hodgins and Benidickson, 1989) whereas the Lands for Life land-use planning process in Northern Ontario, which culminated with the signing of the controversial Ontario Forest Accord in 2000, offers a more recent one, the effects of which continue to reverberate in ongoing political struggles in Northern. On Lands for Life see Cartwright, 2003. On some of the residual politics following the Lands for Life process see Chapeski et. al., forthcoming.
} 
familiar political intrigue of previous conservation campaigns. What exactly this might have entailed, I am not entirely sure. Heated exchanges between Manitoba Hydro executives and grassroots environmental organizations, perhaps? Or maybe forest workers and environmentalists rehashing their familiar claims, this time over the north woods? Not surprisingly, very little of this sort of controversy transpired. And, as the conference wore on, I figured that its absence was really no surprise at all, since these were still early days in the boreal forest campaign. The real politics, I assumed, would likely begin in about a year's time when the media savvy environmental groups would dazzle the media viewing public with images of clear cuts and high profile consumer boycotts of unscrupulous big box retailers.

One experience at the conference did, however, leap out at me as being, indeed, very political. It was during a panel session on the boreal forest and climate change. One of the conference participants had just completed a detailed, if rather technical, presentation explaining the intricate relationship between the boreal forest, the burgeoning global carbon market and the Kyoto Protocol. The explicit tenor of the talk was that, while flawed, the Kyoto Protocol could become a key resource in the politics of boreal forest conservation. Following some discussion, and well attuned to the abstract language that had just been used to position the boreal forest within such a technocratic discourse, another panellist very passionately emphasized the need to simplify the language used in climate-forest politics, and said that the political discourse of climate change ought to be re-articulated as one directly related to land-use, land rights and consumption. The auditorium suddenly erupted into a loud, emotive applause and I had found my guarantee that I was in the presence of politics. 
This story is particularly germane to the discussion that follows because it draws into sharp relief a tension between, on one hand, the geographies of colonialism and, on the other, the spaces of ecological modernization (Baldwin, 2004). What I mean by this tension is that so much of contemporary environmental political subjectivity is underwritten by an abiding concern for a nature frequently codified as terrestrial, ecological space, spaces like the boreal forest or the Amazonian rainforest. ${ }^{63}$ Yet all too characteristic of this concern for ecological space is a spatial fetishism that disavows the colonial histories and 'buried [colonial] epistemologies' (Willems-Braun, 1997) through which these spaces attain their presence (Wainwright, 2005). Understanding these two geographies in tension is extremely important in my view because it highlights how global environmental issues like climate mitigation and biodiversity conservation often come into direct conflict with local political struggles, especially those that work against and challenge the colonizing influences of the state and capital.

Such conflict is perhaps of little surprise for an issue like climate change and a space as vast and multifarious as the boreal forest. When articulated through the climate change discourse, the boreal forest is said to contain such vast quantities of terrestrial carbon that devastating global consequences would result if released into the atmosphere. Yet, in constructing the boreal forest through such terms, the "messy" political content of the boreal forest is "bypassed" and invariably subsumed within a teleological narrative of national and global ecologically modern progress (Sandilands, 1999a). For those conference participants, then, many of whom were aboriginal people, sitting in an auditorium listening to yet another white environmentalist speak about their traditional

\footnotetext{
${ }^{63}$ It is important to bear in mind that there can be no singular mode of environmental subjectivity. The identificatory practices at work in conservation issues are very different than those modes of environmental subjectivity that see, for example, the issue of urban pollution as a primary environmental concern.
} 
territories in such abstracted, universalizing terms - the boreal forest, a carbon reservoir, the Kyoto Protocol - must have been a real affront. ${ }^{64}$ Suddenly, through the nifty work of words and climate science, the places they call home, the ways they move and the stories they tell, what Doreen Massey might call their 'power geometry' (Massey, 1999), were instantly repositioned within an abstract calculus that valued carbon above all else. It is really no wonder, then, that the audience responded the way it did when the issue of climate change and the carbon stored in the boreal forest was rearticulated (ironically by another white environmentalist) as an issue of territorial land claims and land-use as opposed to one strictly concerned with carbon-forest management.

Bearing all of this in mind, then, what I would like to do in this chapter is work out how terms like nature, culture, aboriginality, the national economy and scarcity intermingle to render the boreal forest available to the abstract calculus of carbon management. In doing so, I seek to do two things. First, I want to examine how the boreal forest is constructed through the discourse of climate change. What I mean by this is that if climate change represents one of the dominant narratives constituting the discourse of ecological modernity, then how does the boreal forest assume its coherence as a naturalized spatial form through such a narrative? How, in other words, is nature codified as the boreal forest within the climate change problematic? In considering this question, one of my aims is to come to terms with how the narrative of resource scarcity secures the terms 'nature' and 'culture' and, in so doing, authorizes the political project of ecological modernization. This is not entirely unlike what I tried to do in the previous two chapters where I tried to show how the performativity of nature is implicated in other

\footnotetext{
${ }^{64}$ The concept of traditional territory is one that many aboriginal peoples in Canada use to delimit the landbase used historically for livelihood purposes.
} 
dominant narratives organizing boreal forest discourse. But unlike those previous chapters in which the rhetorics of national forestry and Canadian canoe culture lent more readily to critical discussions of imperial visuality and power, in this chapter I seek to do something slightly different. I want to read the highly technical discourse of economics, specifically forest-carbon management, against the debate concerning nature's performativity.

Second, I want to examine how, when cast in the language of climate change and the seemingly anodyne narrative of scarcity, the boreal forest might be reconceptualized in orientalist terms. Here, my concern is with understanding how, if at all, the regulatory schema of climate discourse and carbon scarcity works in a performative fashion to materialize cultural difference in such a way as to consolidate the national subject and to domesticate cultural difference in the elusive attempt to synchronize national experience. Here my interest lies in trying to understand what identities are secured by positioning the boreal forest within the discourse of global climate change? In other words, if the boreal forest attains its metaphysical presence as a natural object through the language of climate change, what identificatory practices are avowed through its presencing? This is, of course, a crucial question but by no means a straightforward one to answer. In the conventional meta-narrative of climate change, at least in the West, the dominant political framing of the climate debate falls somewhere in between liberal and conservative subjectivity, moral-liberal believers (Demeritt, 1998) versus conservative sceptics. Yet such a polarized framing of the climate change debate seems to obscure far more about the identifications that are at stake in climate change discourse than it reveals. Here, the politics of climate change can be viewed not simply as struggles over which mode of capitalist production should predominate globally - 'carboniferous capitalism' or 
capitalism in some ecologically benign modern form, what Steven Bernstein might call 'liberal environmentalism' (2001) - but, consistent with so much of political ecology, it is also a terrain upon which certain forms of cultural identity are enacted, secured and contested. In this sense, the discourse of carbon management affects a "regulation of identificatory practices" (Butler, 1993:3), meaning that bodily normativity is constituted and constrained through the discourse. And, this, I want to argue, is a way of seeing the problems of climate change mitigation and adaptation as not simply technical or economic problems but as a deeply cultural ones as well.

At stake in the issue of climate change, then, is not simply the geopolitics of oil consumption, the culture of auto-mobility, ecologically benign production or the distribution of 'blue' and 'red' states on a map. Indeed, one of the fascinating things about the politics of climate change is that it is about all of these simultaneously. But it is also a concern for the very terms through which the problem of climate change is articulated - culture in its modern, industrial form and nature, in both its universalizing, global form and in its sovereign, territorial form. The discourse of ecological modernization, of course, promises to suture these severed realms through a teleology of ecologically-infused progress. But, as I aim to show towards the end of the chapter, this has not only material implications, but also goes some way in illuminating how ecological modernity might also be about the management of racial difference. Thus, I return to Moore, Kosek and Pandian's assertion that "race and nature are constitutive features of modern power," "integral to the rule of modernity rather than an exception", to ask whether race can be understood as central, or if not central, than as a core dimension to the exercise of ecologically modern power (Moore et al, 2003:15). Here I want to consider how, beyond simply the promise of securing an ecologically modern 
future, the discourse of forest carbon management might also be viewed as effecting a (material and discursive) resettlement of identifications. In other words, if we are to take the performativity of nature seriously, which I believe we should, and if conservation politics offer a fruitful site for considering the production of naturalized identity, which I believe it does, then how, if at all, does nature's performativity square with what some consider to be the most pressing environmental concern for the twenty-first century global climate change?

Answering this question is no easy task not least because the fact of climate change is so irrefutable within mainstream environmentalism that to critique its presuppositions or draw attention to the relations of power that construct the problem might easily be misconstrued as an assault on environmentalism. Worse, one might risk being categorized as an oil industry apologist for whom the problem of climate change is overstated (Lomborg, 2001) or, perhaps even worse, as a red state sympathizer. So, for the record, I want to state very flatly that this could not be further from the truth. In advancing this critique, I am not arguing that the politics of climate change should be abandoned because of its constructed-ness or that climatic transformations that result from anthropogenic carbon dumping are a figment of imaginary science and therefore of no material consequence. Nor am I saying that lurking behind climate change discourse waits a fiendish instrumental rationalism ready to pounce on the economic benefits of carbon trading once they start to accrue. (Although I do maintain that those with economic clout will more than likely end up the primary beneficiaries of carbon trading while assuming as little liability as possible.) Instead, my aim in writing about climate change and the boreal forest in this way is to draw critical attention to the ways in which environmentalism's most cherished categories are constituted. In doing so, I hope to 
create a space within which mainstream environmentalism might contemplate the fabrication of its own biases, innocences and origins and to draw attention to the fact that how specific spatial environments are articulated in political discourse has considerable bearing on how political debate concerning those spaces materializes. Reading climate change politics in this way is important because, in many ways, the fact of climate change enjoys a political status almost beyond critique. But, as so many postcolonial critics have argued, it is precisely where power appears to be entirely absent that its productive work seems to be operating most effectively. If anything, then, the difficulty in situating climate change discourse within performative critique should not preclude such readings, but should instead be a signal that such readings are bound to be productive and fruitful, if not downright discomforting.

Writing about this topic in the way, however, carries with it two notable limitations. First, and probably the most important, is that, as I write, the Canadian federal government has still not taken a decision on how it will count forest carbon in its national reporting under the Kyoto Protocol. The Government of Canada fought hard during early negotiating rounds of the Kyoto Protocol to include forest sinks in the budgetary calculus for national reporting, which is a strong indication that it will use forest sinks in its national account. But since the Canadian government has not yet finalized whether it will even include managed forests for carbon accounting purposes, the relation between forests and climate in Canadian climate policy remains an open question. Not surprisingly, what this means is that very little actual implementation of forest carbon management policy has occurred in Canada. To be sure, there have been a few small pilot projects that have involved the sale of carbon, but in general this is a practice that is still very far from being institutionalized. 
Related to this is that textual representations that position the boreal forest within the climate change discourse remain rather sparse, and are limited for the most part to those that seek to secure the boreal forest in terms of its role in mitigating climate change. In this sense, most of this type of writing about the boreal forest occurs under the assumption that the boreal forest is a continent-sized carbon reservoir that stores enormous amounts of carbon. Moreover these sorts of representations derive mainly from the scientific community, but have certainly found expression in popularized publications issued by the mainstream environmental community. In this sense, while the scientific debate concerning the place of carbon in the boreal forest is well underway, political debate concerning forest carbon management in Canada is still quite nascent. This is especially the case for how forest-carbon management might affect aboriginal communities located in the Canadian north.

\section{Economizing Borealia}

It is not surprising that the boreal forest of the Canadian north is often represented in economic terms. After all, it has been a crucial space in the pre- and postConfederation staples economy (Hayter \& Barnes, 2001), having furnished metropolitan demand with a steady supply of furs, timber products, precious metals and ores, oil and natural gas and hydro-electric power for several centuries. Indeed, long before it was known as the boreal forest, much of it went under the moniker of Rupert's Land, named after Prince Rupert, who was instrumental in securing the Hudson's Bay Company charter in 1670 from Charles II, granting the company permission to exploit the space for the acquisition of furs (Newman, 1985). The Canadian Forest Service-Canadian Geographic map of the boreal forest that I used to organize the discussion in Chapter 3 
illustrates this quite clearly, where at the top of the map it reads, "This forest has shaped our history and economy".

However, as the discourses of climate change and biodiversity take hold, the language used to articulate the economic importance of the boreal forest is shifting. No longer is the boreal forest exclusively constructed as a passive space of resource extraction. Under the shadow of the Kyoto Protocol, its economic importance now trades firmly, or at least discursively, on its capacity to store scarce carbon. Arturo Escobar's notion of modern capital is useful in articulating this shift in more general terms. For him, modern capital is that form of capital that presses deeper into the lifeworld ${ }^{65}$ by capitalizing the conditions of production that are the necessary requirements for ensuring the re-production of capital. That is, for capitalism to be self-sustaining and not collapse under the weight of its 'second contradiction' (O'Connor, 1994), it needs to convert all forms of land and labour into capital, to commodify land and labour as it were, so as to guarantee their deployment in the most efficient manner possible. In the now familiar language of conventional environmental policy, what this means is that environmental services, those services provided by the biophysical that sustain life - water, air, a stable climate system - are commodified (codified in terms of economic value) and their values are internalized into the overall costs of production. Accordingly, the costs of manufacturing wooden building materials, for instance, are no longer simply a matter of harvesting, milling, paying the worker, and transporting the lumber, but also include the costs associated with the protection and conservation of riparian zones, critical habitat and, in some cases, paying higher wages. But with the advent of the Kyoto Protocol, the

\footnotetext{
${ }^{65}$ Although Escobar does not use Habermas' notion of the lifeworld in his own description of modern capital, he does liken this process to Habermas' formulation of the colonization of the lifeworld in and Foucault's notion of biopower.
} 
costs associated with timber production must now also account for the carbon value contained in the forest. Or at least that is what the politics of forest carbon management are about. Indeed, in a report recently published by the Canadian Boreal Initiative, the estimated carbon value of the boreal forest (both stored and sequestrated carbon) for the year 2002 was over US\$ 3.7 trillion (Canadian Boreal Initiative \& The Pembina Institute, 2005). Not a paltry sum.

In this section, then, I want to consider how the narrative of resource scarcity organizes (and regulates) the transactions between culture and nature within the discourse of forest carbon management. However, in keeping with the argument running throughout this dissertation I do not take either nature or culture to pre-exist this transaction. Rather, I argue that nature and culture emerge as discrete entities through the technical practice of environmental economics. In exploring how this is so I want to turn now to what I have called the scarcity narrative.

\section{Scarcity Narrative}

In economics, there is always a need to locate scarcity. This is because the imperative to economize would be non-existent in its absence. Indeed, the very need to economize would be rendered inessential for in the absence of scarcity there would presumably be either abundance or nothing. But since 'nothing' cannot exist in any material sense, the absence of scarcity would perforce have to be a state of material abundance. The articulation of scarcity, therefore, foreshadows the need for its own management because in the condition of unmanaged scarcity lurks the ever present possibility of being without, or of being poor. Here, according to Linda Singer "scarcity is crucial to capitalism both as its justification... and sometimes, at least, as that for which 
capitalism is the remedy" (Singer, 1993 as quoted in Sandilands 1999c:82). In this sense, the discourse of modern economics promises to manage the exchange between scarcity and abundance by ensuring that neither of these terms exceeds the other. Economy, or more properly the discourse of economics, thus becomes a truth regime regulated by the principle of scarcity. Inasmuch as this is true (the truth effects of power withstanding) the scarcity narrative is an always recurring, continuously repeated problem of modernity (Dalby, 2002; Xenos, 1989).

However, echoing pleas registered within the sub-disciplines of economic and cultural geography that the idea of economy must not be immunized against poststructural critique (Barnes, 2003; Castree, 2004; Mitchell, 1998), I contend that neither should scarcity be granted such amnesty, since scarcity plays such a central role in organizing the language of economics. The fetishization of scarcity was, of course, challenged over three decades ago when David Harvey made the argument that scarcity is not a fact of nature, but a socially constituted notion that has as much to do with the cultural needs and wants that organize particular, historically situated modes of production, as it does with the finite presence of the material world (Harvey, 1974). The point of Harvey's critique, however, was not so much that we need to dispense with the idea of scarcity, as it was to challenge the ethical neutrality of those practices (science, economics) that purport to reveal scarcity as natural. For Harvey, the articulation of scarcity as ethically neutral was to expose its instrumental rationalism and locate in scarcity one of the dominant strategies used by capitalists to appropriate resources and commodify their production. However, while I am strongly inclined to agree with Harvey's intervention, my interest in critiquing the notion of scarcity is motivated by a different set of concerns. Whereas Harvey was concerned with installing dialectical 
materialism as a means of rearticulating the population resource problem, my interest is in trying to understand how the assumption of scarcity organizes a hegemonic cultural visuality and how scarcity, in turn, might be construed as a regulatory apparatus governing the production of modern subjectivity. It is, borrowing from Sandilands, an effort to understand how scarcity works as a normative idea (Sandilands, 1999b).

In locating its normativity, I want to suggest that scarcity is not a thing, but is instead perhaps better construed as a narrative. In this sense, scarcity is not an a priori, measurable phenomenon. Instead, borrowing once again from Butler's idea of performativity, I want to argue that scarcity is a performative notion, meaning it is impelled into being through the repetition of iterable norms or previously articulated narrations, whereby a thing's scarcity is rendered as such not by its measurable lack, but instead by being positioned on a ubiquitous narrative trajectory comprised of a unique beginning, middle and end.

But what does such a narrative trajectory look like? Unlike the recovery narrative, the scarcity narrative does not locate its origin in innocence, nor is it precipitated by some mythological fall, or paradise lost. Instead, the scarcity narrative simply opens in what is assumed to be an a priori state of fallen nature in which the omni-present threat of poverty and death are the universal condition. Thomas Hobbes infamously characterized life under such conditions as "solitary, poore, nasty, brutish, and short" (Hobbes, 1660:186). Scarcity is, after all, persistently troped in capitalism as one of nature's commonest, most innate attributes. It is not surprising, then, that natural scarcity is one of the founding postulates of classical political economy, nor that classical political economy sets about to manage scarcity. But if scarcity is one of the founding postulates of capitalism, its justification, according to Linda Singer, then scarcity is not the only 
one. It does not stand alone. This is because the justification for managing scarcity is not more scarcity, but rather its amelioration, its antithesis. Thus, as Nicholas Xenos insists, "abundance is the conceptual twin of scarcity" (1989:35), where abundance is the telos of the scarcity narrative and scarcity, if properly managed, can be transformed into perpetual abundance. In this sense, abundance is the natural outcome of properly managed scarcity. Bernard Fernow's adage "per aspera ad astra, through rough work to civilization" (Fernow, 1903:14) provides a good example of how the work of the forester might be construed as integral to fulfilling the teleology of abundance that is so central to resource capitalism.

Central to the logic of scarcity, then, is the idea of nature. To further clarify the location of nature in the scarcity narrative, I turn to Erich Zimmerman's seminal, if outmoded, work on resource geography (Zimmermann, 1951). In particular, I want to focus on the image Zimmermann uses to visualize the process by which a particular aspect of biophysical materiality is converted into a resource. Zimmermann's image can be read as a scarcity-producing machine (see Figure 5.1, page 210) that extricates 'man' from nature and renders nature 'neutral stuff' that can be appropriated to satisfy the needs and wants of human culture. It is, in this sense, not unlike Ferguson's anti-politics machine (Ferguson, 1990) and McClintock's “conversion technology” (McClintock, 1995), since the social content of whatever stands before it is pushed aside, neutralized and depoliticised, or more properly, in this case, internalized and domesticated. In no uncertain terms, Zimmermann is clear that those things that might become resources are already pre-figured as "neutral stuff" and are of no value to anyone except those who 


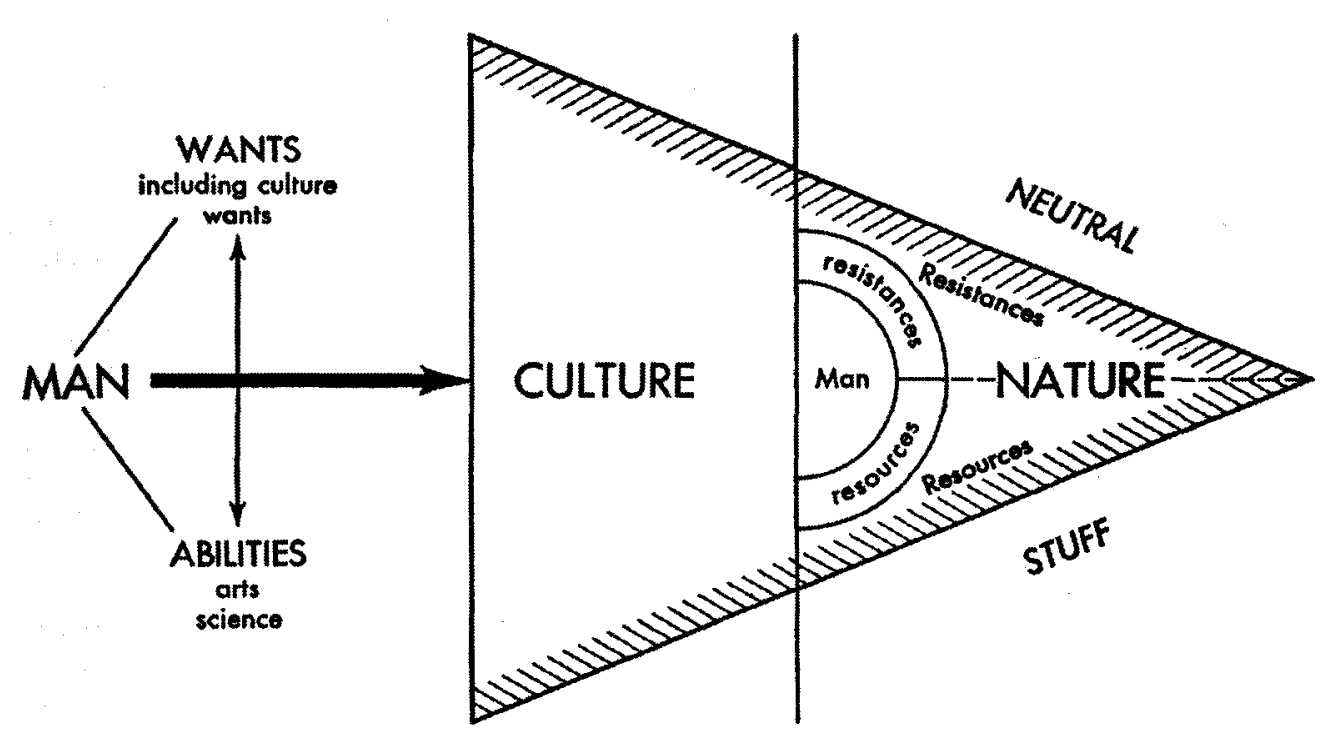

Figure 5.1 - Zimmermann's Meaning and Nature of Resources in World Resources and Industries (1951, p. 13). ${ }^{66}$

${ }^{66}$ I am grateful to Jamie Linton for alerting me to Zimmermann's work. 
might use it to enhance the project of civilization. Similarly, his image already prefigures the removal of Man (sic) from the spaces within which scarce resources are said to exist.

Zimmermann's schema raises a number of critical concerns. First, although Zimmermann's image is meant to convey some inherent, incontestable truth about the availability of resources, in my view, it does precisely the opposite. By situating the appropriation of resources within a context of cultural want, Zimmermann is, paradoxically, making a very strong case for the performativity of resource scarcity, since such resources do not pre-exist the discourses that name them. This is to say that they are not resources, nor are they scarce resources until so named, or as one commentator put it, "resources are not; they become" (Chapeski, 2001:41). Another way of saying the same thing is that Zimmermann is able to render "neutral stuff" intelligible as a resource only by situating it within the already hegemonic cultural narrative of scarcity. In this sense, the act of valuing resources can be understood as repeating a norm of scarcity, such that scarcity is materialized through the repetition of a set of conventions that specify what qualifies as a valuable resource. Of course, one might interject by asking how the norm of scarcity is derived. Does it not locate its original moment in nature? And the answer is, yes, of course, it does. But to ask this question is to forget that the language of scarcity produces its own nature, or rather, that nature is materialized by citing Zimmermann's regulatory schema governing what counts as a resource. Scarcity and its corresponding nature are therefore inextricably of the same phenomenon. To articulate a concern for nature is to anticipate the politics of scarcity. Similarly, to pose the problem of scarcity assumes its a priori presence in nature. 
A second critical concern raised by Zimmermann's schema follows from this, which is that through the performative of scarcity, the conditions of its own contestability and instability emerge with the formation of the abject. Here, on the right side of the image, "Man", by which Zimmermann is clearly referring to 'primitive man', is represented as subsumed within the field of nature, where overcoming the resistance imposed on him (sic) by that (external and universal) nature constitutes his basic life condition. Closely related to this, of course, is the production of the economizing subject, the subject that economizes in order to conserve scarce nature - the resource economist in this case. This is the subject "Man" appearing in the cultured space on the left side of the image. What I find so remarkable (and paradoxical) about this image is that Zimmermann, in his attempt to naturalize the availability of resources, visualized and anticipated in starkly obvious terms one of the core themes in political ecology and anticolonial struggle: local resistance to abstract resource appropriation. In performative terms, the economizing subject is constituted precisely at the moment that the delimitation of the abject occurs. This is important because it suggests that the abject marks the limit of the economizing subject thereby drawing attention to the subject's always incomplete condition. Following Butler, the abject 'is... 'inside' the [economizing] subject as its own founding repudiation" (Butler, 1993:3, my insertion). Accordingly, it is perhaps of little surprise that in Canada resource struggles frequently involve the articulation of aboriginal peoples' political concerns in terms of resource rights because, if Zimmermann's image is to have any practical bearing on real world events, aboriginal peoples are routinely disqualified from the processes by which resources are identified as such. 
A third concern, and perhaps that of greatest consequence, is that for Zimmermann's image to retain its internal coherence, all the various components in it need to be carefully regulated to ensure that they do not exceed their respective locales in the schema. The line separating nature and culture must continue to exist in order for the "Man" on the left to occupy the space of culture and for the "Man" on the right to be the embodiment of that nature. Both the discourses of modernization and ecological modernization depend on it. Similarly, resources must be said to exist in the smooth state of nature, otherwise one's claim to those resources could be deemed illegitimate, since they might be perceived as belonging to someone else. Of course, the glaring irony of Zimmermann's image is that those resources often do belong to someone else. But that does not seem to concern Zimmermann, since those other bodies are, for him, merely extensions of nature, "resources for the production of culture", as Donna Haraway might put it (Haraway, 1992:150). The implication here is that by calling on Zimmermann's regulatory schema to understand some universal truth about resource scarcity, the subject and abject are materialized through precisely this schema. The subject is troped as knowing, managerial and agential - the embodiment of culture. And the abject is troped as temporally displaced, lacking agency and requiring management - the embodiment of nature. A further implication arising from Zimmermann's schema is that the conditions through which both subject and abject bodies might become political, that is, might assert their identities in the 'appropriate' political/public space, are already pre-conditioned by the regulatory schema of resource scarcity that produces those bodies in the first place.

In what follows, I want to explore these ideas in the context of the boreal forest and the discourse of climate change. But before I do, I want to make one last point concerning the language of economics, which is that the discourse of economics is a 
spatializing practice and that the lines Zimmermann draws are the effects of productive power. It spatializes nature and culture by repeating the regulatory norm governing what counts as a resource and then proceeds to manage the relationship between the two terms in order to ensure that neither of these terms exceeds the other and that the supply and demand of the resource in question are held in an appropriate balance. Therefore, not only does the practice of economics, according to conventional accounts, seek to ameliorate natural scarcity through a careful system of rational management (Turner, 1995). A more critical account would have it that the economizing gaze constructs both the nature and the scarcity it seeks to manage. Understood this way, the discourse of economics as culturally meaningful absolutely trades on its propensity to render nature visible through the performativity of scarcity.

\section{Boreal as Scarcity Narrative}

But what does this mean for the politics of the boreal forest? No doubt, there are as many ways of thinking about resource scarcity in the boreal forest as there are commodities taken from it. My interest, however, is in focusing attention on how the burgeoning politics of forest carbon management and the fashionable discourse concerning the payment for environmental services secures the boreal forest by giving it presence as a natural space, but one that is nevertheless central to the Canadian national economy.

To begin, the boreal forest has been routinely articulated within the discourse of modern climate politics as a carbon reservoir (Sierra Club of Canada, 2003). As such, the Intergovernmental Panel on Climate Change has said that it contains approximately twenty-five percent of the world's terrestrial carbon, most of which is fixed in the form of 
peat but also in trees and other organic matter (Bhatti et al, 2003). Explicit within this sort of articulation is that if this stored carbon is released into the atmosphere as a result of fire, excessive industrial activity, flooding or insect infestation, then the terrestrial effects of global climate change could be greatly amplified. Moreover, as many climate models predict, a warming trend resulting from rising temperatures in northern Canada could precipitate a positive feedback whereby the increase in temperature in the boreal region could lead to a greater propensity of forest fires within the boreal forest, which would in turn lead to more carbon being released into the atmosphere (Sierra Club of Canada, 2003). Ensuring that an excessive amount of carbon is not released from the boreal forest due to these or any other large-scale forest disturbances has, thus, become one of the more pressing managerial concerns that environmentalists, conservationists and environmental policy makers face, at least with respect to the issue of forests and their role in the mitigation of climate change.

Closely related to the idea that the boreal forest is a carbon reservoir is that many conservationists now regard the valuation of forest carbon as a potential means of promoting forest conservation insofar as it may enhance forest values other than timber value, such as wilderness and habitat protection, "enlightened" forest management and the harvesting of non-timber forest products (Ross, 2004; Scott, 2000; Sierra Club of Canada, 2003). As such, some have suggested the possibility that carbon reserves be established in order to fix forest carbon while at the same time allowing for other less carbon-intensive forest activities - tourism, hunting/trapping - to occur on the land (Morse et al, 2005). Thus, following Roderick Nash's insight that “wilderness is like any other economic commodity: the scarcer it gets, the more value people put on it" (Nash, 1982 as quoted in Worster 2002:167), a concern for potential carbon scarcity works as a 
justification to secure more wilderness, which is an especially potent argument, particularly given that so much of North American environmentalism has been synonymous in recent decades with a pervasive concern for the erosion of what is prefigured as wilderness space (Cronon, 1996a). Potential carbon scarcity in the boreal forest, thus, now figures as among the primary justifications for reversing the trend of wilderness scarcity by securing wilderness abundance.

It also now figures as one of the primary narrative means for organizing the conditions under which resource conservation may occur in the future, a discursive shift that could benefit not only those who advocate increased wilderness preservation by increasing the volume of wilderness space in Canada, but one that could also augment the state's efforts to regulate forestry practices, since carbon could become another forest value requiring the attention of silvicultural expertise. ${ }^{67}$ The result, one can easily imagine, would be a dramatically altered forestry - longer rotation periods, reduced annual allowable cuts, and potentially increased forest restoration and plantation forestry (Sierra Club of Canada, 2003). Seen through this optic, many have made the argument that, if the Kyoto Protocol is 'properly' implemented in Canada, the boreal forest could be worth more in monetary terms if left 'in tact' as a carbon reservoir than if it were harvested for its timber value (Sierra Club of Canada, 2003). It is worth mentioning here that closely related to this is an argument that has been made within the conservation community, which is that prior to any large-scale land-use allocations in the northern boreal forest, especially those areas that are presently unallocated, the federal or provincial governments must factor into their land-use decisions the current and projected

\footnotetext{
${ }^{67}$ For an interesting look at the place of nature in the re-regulation of forestry practices in the Pacific Northwest see W. Scott Prudham's Knock On Wood: Nature as Commodity in Douglas-Fir Country (Routledge, 2005).
} 
costs of the carbon stored in the forests in question. Doing so, it is argued, will result in a much more accurate valuation of the land-use. This is especially important if the federal government chooses to include forest carbon within the national carbon budget because failing to do so would result in foregone value.

Three possible forms of government action have been identified that would contribute to the revaluation of forest carbon - direct regulation, targeted measures and offset trading (Sierra Club of Canada, 2003). The first, although unlikely to be applied in the forest sector, involves the prohibition of carbon emissions above a certain threshold beyond which sanctions would apply. Most likely this sort of policy response would be directed towards large, industrial-scale, carbon emitters, not forest managers. Targeted measures refer to state-led efforts to increase carbon sequestration and storage through tax incentives and subsidies. In this measure, the state would pay landowners directly to ensure that carbon sequestration occurs within a prescribed area of land under management. A third possible (and very likely) means by which this revaluation of forest carbon could come into effect is through the establishment of a carbon credit or "offset" trading regime. Here, the logic underwriting the development of such a market is that a market for carbon would presumably be a relatively cost-efficient means of reducing carbon emissions across, not simply the forest sector, but the entire national economy. Accordingly, high-volume carbon emitters, such as an energy producer or energy intensive manufacturing facility, would be required to 'offset' their carbon emissions by purchasing carbon credits from either low-volume carbon emitters or land or forest managers who manage their holdings for their carbon value. In effect what both the second and third schemes represent for forest managers is the potential to generate 
revenue from low carbon-intensive forest activities, such as reduced harvesting, increased forest protection or management of non-timber forest values.

These are all, of course, extremely important policy considerations and, if 'properly' implemented, will hopefully generate desirable social and environmental benefits. However, as I have already mentioned, my interest in this chapter is neither to pass judgement on whether forest carbon management policy delivers on its purported benefits, nor is to evaluate the extent to which policies that seek to enhance carbon sequestration or storage might ultimately result in greater protection for the boreal forest. Nor am I interested (not in this discussion anyway) in taking sides in the ongoing political dialogue concerning the implementation of the Kyoto Protocol in Canada and how the boreal forest features within it for, as Braun makes very clear, "to do so would be tacitly to accept the very terms that organized forestry politics...or, more to the point, the political geographies that these terms presume" (Braun, 2002:41). This is not to say, however, that such critical evaluation of forest carbon management is not warranted. Of course, it is, and indeed, for a democratic environmental politics to ensue, such evaluations must be spoken from as many different subject positions as possible. Instead, my interest in examining the discourse of forest carbon management is to examine how the burgeoning technical discourse of forest carbon management and the related concept of payments for environmental services might be understood as repeating the binary logic that works to secure the terms nature and culture that ecological modernization requires in order that it retain its cultural legibility as a pressing political project. And, as a second objective, I want to consider how the production of nature within this performative arrangement may effect a resettlement of identifications. 


\section{Nature's Performativity in Global Climate Discourse}

As a first step, then, in disarticulating the power relations at work in situating the boreal forest within climate change discourse it is important to identity how nature is performed within that discourse. Here, I suggest that there are two distinct yet interrelated natures at work in climate change discourse - global-nature and sovereign-nature. The first, global-nature, is perhaps the easiest to identify, since the discourse of climate change routinely constructs the global climate system - and perhaps even more specifically the global carbon cycle - as a natural phenomenon. This is probably most obvious when considering that the United Nations Framework Convention on Climate Change and the Kyoto Protocol were established to regulate anthropogenic disturbances to the global climate system. In this sense, it is not at all difficult to accept the prevailing logic, which says that by increasing the volume of atmospheric carbon the result will be climatic consequence differentially experienced, yet global in scale. Nor is it difficult to accept that the global nature transformed by the increase of atmospheric carbon stands in direct opposition to industrial modernity (particularly as one is stuck in bumper-tobumper traffic in mid-summer listening to the weather report!). Indeed, it is precisely this difference between the global and local that is so carefully policed by global policy makers, since it is this difference that makes possible their global biopolitical claims (Luke, 1995). ${ }^{68}$ In other words so much of the force of the climate change debate derives from the universality of the problem, something to which all of humanity is subject.

\footnotetext{
${ }^{68}$ The problem with universalizing the consequences of anthropogenic disturbances to global nature is that these consequences will not be evenly distributed, nor will they be evenly felt. In other words, some parts of the globe will be more adversely affected by rising average global temperatures than others and similarly those with greater access to wealth, technology and resources will have a greater capacity to adapt to these changes than will others.
} 
The second, albeit related, nature performed in the climate change discourse is sovereign nature, which I take to mean those instances of nature that cover the entire surface of the planet, but which fall neatly within the purview of specific national (territorial) jurisdictions. Oceans, for example, are not circumscribed by the language of sovereign nature, except those marine ecosystems that fall within national jurisdiction. Neither is the Antarctic. ${ }^{69}$ Canada's boreal forest, on the other hand, is. So too are the Amazon River Basin, the Congo River Basin and the Siberian taiga. Sovereign-natures are forms of nature to which nation-states lay claim and, according to the precepts of sovereignty, over which only those states and their constituents may lay legitimate claim. It is, to borrow from Hardt and Negri, a form of transcendence (Hardt \& Negri, 2000).

Before I continue, however, I should draw what I think is an important distinction between sovereign-nature and national-nature. National-natures are those natures invoked as a means of homogenizing identity across a field of difference and that underwrite nationalized biopolitics and governmentality. ${ }^{70}$ In this sense, national-nature is a means for regulating the sorts of activities that count as national and which, in turn, qualify as representative of national identity. Sovereign-natures, on the other hand, are nationalnatures at work in a different register. They galvanize and mobilize the fantasy of national homogeneity within larger fields of difference. In other words, they are used to reinforce national identification against a field of difference and the attenuation that such fields imply. Within specific national contexts, national-nature and sovereign-nature are

\footnotetext{
${ }^{69}$ This is not to say that oceans and the Antarctic are not circumscribed by other discourses that seek to appropriate those spaces. The discourse of multilateralism serves this purpose very well insofar as it masks political and economic interest behind the apparently moral space that the discourse of multilateral creates. ${ }^{70}$ For more on governmentality and nature see Bruce Braun (2000), "Producing Vertical Territory: Geology and Governmentality in Late Victorian Canada, Ecumene, 7(1), pp. 7-46; Eric Darier, (1999), Discourses of the Environment, Oxford: Blackwell Publishing; and Andrew Baldwin (2003) "The Nature of the Boreal Forest: Governmentality of Forest Nature, Space and Culture, 6(4), pp. 415-428.
} 
the same, but do different work in different discursive settings. National-nature homogenizes and regulates difference within, whereas sovereign-nature is the exercise of identity against a field of difference. One organizes within; the other pushes out.

What this means for boreal forest politics is that the forest itself can be construed as an instance of both sovereign- and national-nature bound to global nature through a discourse of risk management that finds clear expression in the rationalizing-clinical language of economic managerialism. As I tried to show in the previous chapter, as an instance of national-nature, the boreal forest is an important cultural performative for one of Canada's more dominant cultural identifications: Canadian canoe culture. But it is also an important marker of what is unique about Canada vis-à-vis the rest of the world. It is in this respect, as a form of sovereign-nature, that the boreal forest works to secure Canadian national sovereignty, since it is the responsibility of the Canadian state, on behalf of its citizenry, to ensure that its contribution to global nature is not compromised. Global nature, in the form of the universalized global climate system, is, after all, commonly recognized as a global public good which the international community must collectively ensure is not compromised, if not materially, than certainly rhetorically. ${ }^{71}$

There are of course material implications to all of this. Perhaps the most consequential, at least within the discursive frame of ecological modernization, is that boreal forest conservation becomes the impetus for an economic restructuring that has ecologically benign production as its telos. Accordingly, such reforms, at least for the

\footnotetext{
${ }^{71}$ I fully recognize that the ontological spaces of the 'global' and 'global nature' are contested notions and that the associated practice of 'worlding' has come under recent attack by those deploying the methods of postcolonial geography. See for example, Joel Wainwright (2005) "The Geographies of Political Ecology: After Edward Said," Environment and Planning A, 37(6), pp. 1033-1043, and Gustavo Esteva and Madhu Suri Prakash (1998), Grassroots Postmodernism: Remaking the Soil of Cultures, London: Zed, especially Chapter 1.
} 
Canadian "conservation economy,"72 could include clearly delineated property rights for ecological goods and services, comprehensive land-use planning, 'clean' production, dematerialization of the supply chain and so on - the end result of which it is hoped would guarantee a host of environmental benefits. ${ }^{73}$ As some have argued, consistent with the view of the World Resources Institute and Global Forest Watch reports I mentioned in Chapter 1 that represent the boreal forest as a conservation opportunity, Canada is in a unique position to capture the economic and ecological benefits that might accrue under conditions of boreal forest conservation (Chalifour, 2004). In this sense, the boreal forest represents for the Canadian economy a unique comparative advantage globally in terms of the valorization of its conservation value. Nevertheless, it is external nature, or the constitutive outside, in this case represented by the boreal forest, that makes possible the process of restructuring the Canadian national economy along ecological lines and, in so doing, refigures the Canadian national economy into the Canadian moral economy. $^{74}$

\footnotetext{
${ }^{72}$ I take the term 'conservation economy' from a report entitled Securing Canada's Natural Capital: A Vision for Nature Conservation in the 21st Century produced by the National Roundtable on the Environment and the Economy. The National Roundtable provides policy advice to the Government of Canada on topical environmental matters that relate directly to the national or regional economies.

${ }^{73}$ This is by no means intended to be a comprehensive list of possible reforms that might fall within the category of 'conservation economy'. It is simply meant to highlight the sorts of reforms that are commonly associated with ecological modernization. Indeed, as with so many of these foundational categories, 'conservation economy' is highly subject to contest, with possible policy prescriptions ranging from macroscale economic reforms to local scale land tenure arrangements. All of this is to say that what a 'conservation economy' might actually look like in practice is far from certain.

${ }^{74}$ I need to stress here that the boreal forest is not the only representation of external nature that underwrites the processes or ideologies of ecological modernization. Other spaces do as well. A Canadian example can be found in what Timothy Luke has dubbed the shift from "extraction production" to "attraction production" in Clayoquot Sound in the British Columbia following the politicization of the temperate rainforest. Here, the naturalization of Clayoquot Sound has had profound implications for how the local and provincial operate with respect to forests and forest production. For more see Timothy Luke (2003) 'On the Political Economy of Clayoquot Sound: The Uneasy Transition from Extraction to Attractive Models of Development,' in Warren Magnusson and Karena Shaw (eds.) A Political Space: Reading the Global Through the Local, Minneapolis, University of Minnesota Press.
} 
But, like all forms of nature, these natures, or constitutive outsides of the Canadian moral economy - global-nature and sovereign-nature - are never as innocent as they are so frequently made out to be. Indeed, as I have been arguing throughout this dissertation, the power of the idea of nature, in whatever its multiple forms, lies in the fact that its production is concealed. One effect of this is that the social identifications directly implicated in the production of the boreal forest as both a global and sovereign nature are obscured. To the extent, then, that Canadian sovereign-nature in the form of boreal forest carbon is positioned within a discourse of national responsibility for a global, collective nature for which all of humanity is responsible, it is unproblematically deterritorialized and reterritorialized as a commodity in the abstract domain of global capital. Here carbon becomes like any other resource, an abstract commodity that is spatially displaced from its "ecological" and "cultural surrounds" (Braun, 2002:35) and valorized through the abstract logics governing market-based forms of exchange. Yet within this schema, the question of identity is disavowed.

In this respect, the sovereign-nature of the boreal forest (which is also nationalnature exercised in the global register), and more specifically the carbon contained within it, is rendered visible through what Braun has referred to as the "constitutive erasure of indigenous territorialities" from the forest (Braun, 2002:27). In the same way that Zimmermann used his visualizing apparatus to render the natural resources as 'neutral stuff' by segregating so-called primitive man from the space of neutral stuff, modern forest science does precisely the same thing when accounting for the carbon contained in the boreal forest, or in all forests for that matter. The territorial presence of aboriginal people (or settler communities for that matter) in the forest and the livelihoods they obtain from it simply do not enter the forest carbon calculus. Instead, by reiterating the 
fantastic illusion of empty forest space, one that has been endlessly repeated ever since (and even well before) Bernard Fernow's colonial visuality enabled him to visualize only a national forest and not its inhabitants, the practice of carbon accounting in the boreal forest simply assumes away, quite unproblematically, any form of human presence in the forest - aboriginal, recreational, industrial and so on ${ }^{75}$.

Ironically, the cultural purchase of the image of the empty forest is bolstered by accounts of boreal forest-carbon interaction that actually do position people in the forest, specifically those accounts that refer to the active role that industrial forestry activity and other land-uses play in disturbing the carbon balance in the boreal forest (Bhatti et al, 2003). But here, since emphasis is placed on how human presence disturbs the forest's natural balance that might otherwise occur in the absence of disturbing forms of land-use, the illusion of an empty forest still retains its force. This is because, in the carbon calculus, it is assumed that these land-uses occur subsequent to the a priori presence of an untouched forested space. It follows that the baseline used in scientific measurements of forest carbon and forest disturbances is predicated on the total erasure of humans from the forest, a fictionalized image of the forest as it might have existed in a mythic prehistory before the arrival of its human inhabitants.

One very significant consequence of the transformation of carbon into an abstract commodity has to do with ownership rights. If carbon is going retain its position within the global political economy as a commodity, then by definition it must be owned by some legal entity, since one of the core principles of commodity exchange is the fact of ownership and the commensurate right to sell one's ownership rights subject to certain

\footnotetext{
${ }^{75}$ In making this claim it is not my intention to essentialize local aboriginal experience as a singular, common set of uncontested livelihood practices and identifications. Nor am I arguing that by being in the forest, aboriginal people exist in a condition that is closer to nature than for those living in cities.
} 
conditions. Here, the burgeoning discourse of carbon rights is at issue and represents possibly the most pressing issue in forest carbon management and climate change mitigation. Underlying this debate is, of course, the abiding concern as to who owns the rights to forest carbon. In the Canadian context this issue is far from settled with several groups asserting some degree of carbon ownership: provincial and territorial governments (consistent with their constitutional rights over resource management); the federal government (given its jurisdiction over international agreements like the United Framework Convention on Climate Change), forest tenure holders (in most cases largescale forest producers) and aboriginal peoples (through treaty right, aboriginal title right, or constitutional right) (Morse et al, 2005). Although some aver that some form of legislation will likely be required to specify precisely who owns carbon rights and under what conditions those rights may be exercised (Morse et al, 2005), it has also been suggested that a tenure system not unlike that which presently regulates the forestry sector would be used in the carbon sequestration sector. That is, revenues generated from qualifying carbon sequestration efforts would be shared amongst the relevant stakeholders: governments (taxation), aboriginal people (revenue sharing arrangements) and the tenure holder (profits) (Morse et al, 2005).

Needless to say the issues of carbon valuation and ownership will likely have an effect on all those that claim some stake in the boreal forest. My interest, however, has to do with aboriginal peoples and even more importantly with identity. Here the politics of land and resource rights that are so central to aboriginal peoples' political struggles throughout Canada, not just the boreal forest, are displaced or perhaps more accurately must now be re-conceived of in the context of a burgeoning discourse concerning carbon rights. The issue of rights is especially important here because implicit in the legal 
argumentation supporting the practice of carbon sequestration is the idea that the exercise of aboriginal resource rights or land rights is not necessarily incompatible with carbon rights. This means, for instance, that a reserve in the boreal forest established to store carbon could result not only from a transfer of revenue from the purchaser of a carbon credit generated by the carbon reservoir to the owner of that credit, but it could also result in the continuance of aboriginal traditional activities such as hunting, trapping and fishing.

\section{Reinscribing Aboriginality into the Boreal Forest Scarcity Narrative}

The scarcity narrative is a very seductive logic, but it is by no means innocent; it is central to the spatial divisions of modern capitalism, just as it is to the consolidation of state resource control. Yet it is a deeply ambivalent narrative form. By drawing it into critical view I am not suggesting, however, that issues of resource use and management are overstated or that how resources are deployed in fulfilling human needs are not matters of social concern. Of course they are. And it is precisely because they are of such concern that it is imperative that one retains a critical scepticism about the narrative devices deployed in rendering resources culturally meaningful. In this vein, then, to accept unproblematically the fact of scarcity as a necessary pre-condition for doing resource management is to overlook the very possibility that scarcity might be one such narrative device and that through it very powerful political identifications are produced, exercised, legitimated and constrained. In what follows, I want to deconstruct the scarcity narrative, at least insofar as the conjunctive discourse of wilderness and climate change deploy it in rendering the boreal forest an object of political concern. I do so with a view 
to drawing critical attention to the work of power within the climate debate and to elucidate some of the identifications at stake.

If we take Butler's claim concerning performativity to have any validity, then we need to enquire into the types of subjects secured when the scarcity narrative is deployed. Alongside this line of enquiry into performative subjectivity, we also need to ask about that other subject - the abject - that operates as the subject's constitutive outside, its founding exterior. To explore some of these issues, I want to examine how the burgeoning discourse of forest carbon management contains within it a regulatory logic that at once secures a dominant national subject and has the potential to constrain aboriginal bodies within an optic of naturalism and traditionalism. ${ }^{76}$ This is an issue of central importance because at the same time that forest carbon management has the potential to become a key policy tool in climate change mitigation, one that many mainstream environmental organizations look to as an imperfect but nevertheless important instrument (Forsyth, 2003), it also has the potential to repeat older patterns of political conflict in which aboriginal people and environmental groups clash over epistemological and ontological differences. Or as Timothy Forsyth suggests "it is possible that carbon-offset forestry may now be a new epiphenomenon of environmental debate - a new area within which older political debates are replayed, yet from which apparently neutral environmental explanations emerge" (Forsyth, 2003:148-149).

Let me begin, then, by restating an argument I made above, which is that aboriginality is expelled from renditions of carbon scarcity. This is in keeping with Zimmermann's abstract rendering of resource availability, whereby the act of positioning

\footnotetext{
${ }^{76}$ At the outset, I need to place a strong accent on the operative word "could' because, as I have already mentioned, the debate in Canada concerning forest carbon management is still very nascent.
} 
a resource within the scarcity narrative effectively pre-figures the removal of aboriginal people from the space within which that resource is said to exist. This is a practice that Braun has termed "constitutive erasure" (Braun, 2002:27). Here, however, to assume that aboriginal peoples are the constitutive erasure of the carbon scarcity narrative tells only half the colonial equation, because, more in line with Anne McClintock's final manoeuvre in the colonial narrative (1995:25), aboriginality is carefully reinscribed back into the scarcity narrative. That is to say that in the rational pursuit of abundant carbon the telos of the boreal forest scarcity narrative - the figure of aboriginality occupies an important part in ensuring the amelioration of carbon scarcity and the restoration of carbon abundance. Assuming that this is so - and there is at least some textual evidence to suggest that it is - a critical line of questioning here should enquire into the terms through which this reincorporation occurs, or is likely to occur. Furthermore, this line of questioning should enquire into the extent to which this reincorporation reiterates the racialization of aboriginality.

Probably the most important factor to bear in mind as I make this argument is something I mentioned earlier, which is that a discursive shift has occurred within the rhetoric of conservation that positions boreal forest wilderness preservation firmly within the discourse of climate change mitigation. This is critical, in my view, because, in doing so, the political importance of wilderness preservation in Canada shifts from being a politics grounded in the aesthetic value of nature, as I would argue it was during any number of environmental disputes that occurred in Canada in the late 1980s and early 1990s - Temagami, Carmanah Valley, Stein Valley and Clayoqout - to one that bears the full weight of ethical value. Indeed, one of the slogans used by activists to politicize Temagami in their confrontation with logging interests in the late 1980s was a plea for 
"big trees, not big stumps," a slogan strongly suggestive of the aesthetic values that underlay much of the Temagami debate. ${ }^{77}$ In contrast, almost twenty years later, the boreal forest is routinely articulated as the "lungs of the earth," suggesting that the whatever the boreal forest's aesthetic value may have been, boreal wilderness has now been superseded by its ethical value, since the boreal forest is now frequently implicated in scenarios of global survival. This is not to say that the aesthetic of wilderness preservation is not one of the prominent features of boreal forest discourse. To be sure, it absolutely is. But wilderness preservation in the boreal is now considered a normative ideal with global consequences for all planetary life as opposed to being an ideal invoked to territorialize aesthetic value. In this regard, so the argument goes, Canadians bear an ethical responsibility to all of humanity by ensuring that the life-giving capacity of the boreal forest is not compromised. Thoreau's classic quotation "in wildness lies the preservation of the world" thus takes on new meaning in the context of apocalyptic scenarios of climate change, where the aesthetic of which Thoreau so passionately spoke is supplanted by an ethic of urgency.

I am using, admittedly, very sweeping language here, but I use it deliberately to capture the identificatory stakes in the debate over the role that wilderness preservation plays in Canada's contribution to climate change mitigation. One such identification at play in the climate debate in Canada is a culturally pervasive sense of Canadian identity in which being Canadian is about being a responsible global citizen. It is about taking one's international obligations seriously by ensuring that sovereign-nature and global-

\footnotetext{
${ }^{77}$ Readers should bear in mind, however, that the Temagami debate was also driven by concerns voiced by the Tema-Augama Anishnawbe over land-use issues, in particular forestry, on their traditional territory. For a general history see Bruce Hodgins and Jamie Benidickson (1989) The Temagami Experience: Recreational Resources and Aboriginal Rights in the Northern Ontario Wilderness, Toronto: University of Toronto Press.
} 
nature are held in an appropriate balance. These are very powerful ideas, so powerful that their non-innocence bears repeating: the image of the responsible Canadian global citizen is not an innocent category, especially when articulated through a discourse of wilderness preservation cast in ethical as opposed to aesthetic terms.

In making this claim, it is important to bear in mind that the Canadian national subject of responsibility stands in a precarious relation to a second identification: the sanctified image of aboriginality in which aboriginality is celebrated for being the embodiment of an unmediated encounter with nature. This is the long-standing image of aboriginality in its traditional and naturalized form, one that retains considerable cultural appeal within the modern geographic imagination. One reason for its durability is that it serves as an important signifier for authentic experience, a particularly resonate (and durable) sign given the crises of meaning that characterize modernity. The subject of authentic experience appears grounded in local custom and ecology, unsullied by the temptations of modern ideology and, in this sense, provides some assurances to modern subjectivity that real experience can be located outside the otherwise un-real, polluted experience of modernity. This is, of course, also a highly romanticized (and racialized) notion of aboriginality. It is also deeply problematic given that it sits in such an uneasy relation with an equally troubling notion of the modern (national) subject.

Braun offers a very useful schematic for conceptualizing this uneasiness by showing how the identities traditional and modern cannot be understood as independent from one another (see Figure 5.2, page 231). For Braun, what this means is that the plots of modernism absolutely hinge on corresponding images of tradition, because modernism represents, by definition, a temporal trajectory away from a time of tradition located in the distant past. Moreover, by overlaying the nature-culture binary onto the 


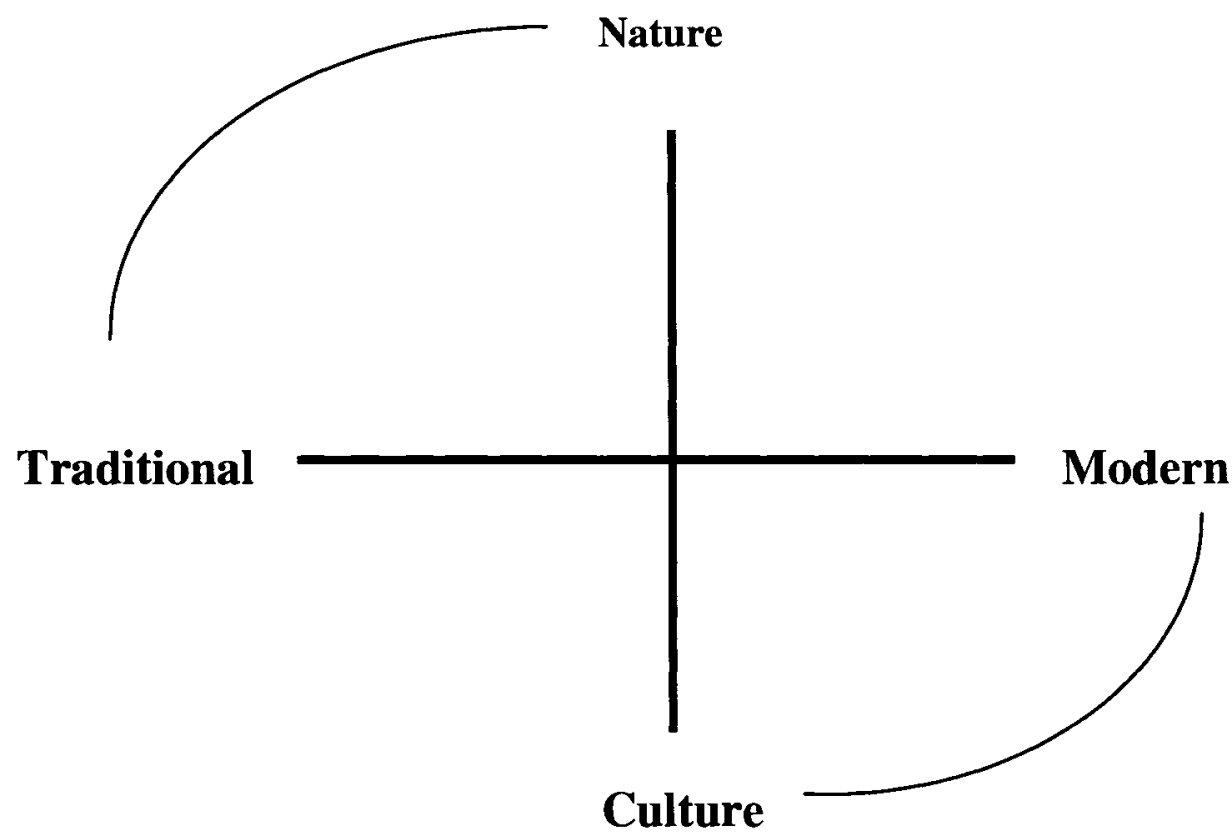

Figure 5.2 - Braun's colonial rhetorics of 'wilderness'. (2000, p.89). 
traditional-modern schema, another layer of meaning comes into view. Here Braun draws attention to how the categories of nature and culture animate and are animated by the traditional-modern coupling, whereby nature is codified as tradition and culture is codified as modern (2002:89).

It is critical to note, however, that neither the modern nor the traditional are reducible to a singular set of meanings, nor do they tell a singular story. Both are imbued with multiple meanings, and can be narrated in myriad ways for multiple purposes. For Braun, anticipating Carolyn Merchant's claim that modernism can be narrated through plots of both progress and decline (Merchant, 2004), the temporal movement of modernism can be narrated in both positive and negative terms. In their positive iteration, ideologies of the modern promise not simply an improvement on the past, but also offer complete extrication from it by liberating humanity from what is perceived to be a mode of life governed by irrationality, atavism, custom and scarcity. The cultivated space of civility is, thus, celebrated for having successfully displaced the non-modern. In this sort of progress narrative, however, the traditional always occupies a subservient, devalued position in relation to the modern, since it represents that which modernity continuously strives to displace. Though curiously, in modernism, the devalued place of tradition can never be completely supplanted for its presence (even if only an invisible presence) must always remain on hand to signify modernity's past and to serve as a cautionary reminder of what modernism could become if not properly maintained. In its negative iteration, on the other hand, modernity is codified as loss or transformation, whereby the loss or transformation of tradition (or nature) are mourned. In this regard, as the forces of modernity press ever deeper into the lifeworld, modernity itself becomes an object of resentment, since it threatens to displace the authentic worlds that individuals and groups 
have so carefully created for themselves. Thus through the narrative of modernity-asdecline, home, nation, city and community, are each thought to sit precariously on the dangerous precipice between life and loss. In such scenarios, however, tradition is reasserted as the antithesis and antidote to modernity's relentless drive and thus comes to occupy a position of value, something worth preserving in the otherwise unseemly chaos of hypermodernity.

In spite of their differences, however, both narratives - modernity-as-progress and modernity-as-loss - retain the traditional as an important placeholder. That is to say, in both, the presence of tradition is absolutely critical. Remove it and both narratives collapse and lose their meaning. Taking this idea a step further, it can be argued that modernism cannot persist in the absence of that placeholder, but instead must actively construct it, since it is through the placeholder of tradition itself that the contours of the modern come into view. Similarly, with the help of Braun's schematic, it becomes possible to see how culture (modernity) cannot exist in the absence of its antithesis (nature/tradition), but instead must actively construct the place of nature so as to retain its own legibility.

The codification of nature-as-tradition and culture-as-modernity is absolutely critical for conceptualizing the uneasiness between the responsible Canadian national subject and the figure of aboriginality, especially when the two are drawn together through a discourse that views the preservation of wilderness as an important instrument in the effort to combat climate change. In one sense, it is not too difficult to conceptualize how seamlessly the figure of aboriginality slips into the position of tradition. Rendezvous with the Wild, the book discussed in the previous chapter, offers numerous representations of aboriginal people occupying this position. Similarly, to visualize the 
responsible Canadian national subject as the embodiment of modern culture is hardly a stretch. But, as mentioned above, it is the narrative (progress or decline) holding these two positions together that is so critical for understanding their relation, for it is through the narrative that meaning is ascribed to the respective terms.

In the wilderness-climate nexus, the dominant narrative is that of scarcity. But scarcity, like modernity, is an ambivalent narrative strategy. In one sense, it can be read as modernity-as-progress whereby the rational management of scarcity promises eternal abundance. But it can just as easily be read as modernity-as-loss insofar as the forces of modernity place increasing pressure on resources thus threatening their scarcity. This ambivalence also marks the discourse of ecological modernization. In one sense, through a reflexive engagement with the present, ecological modernization mourns the passing of a once secure, safe, clean, unpolluted living environment. But, in another sense, the discourse promises the recuperation of this same safe living environment by reforming the institutions of modernity.

What I want to suggest then is that, in the conjunctive moment when the discourses of wilderness and climate change mitigation are conjoined, the figure of aboriginality - the constitutive erasure of scarce resources such as wilderness and carbon - is reinscribed back into the scarcity narrative through a logic of nature/tradition, a move that has the effect of resolving, at least temporarily, this modern crisis of meaning. Borrowing again from Braun, it is precisely at the moment when modernity is troped as loss that the figure of aboriginality-as-natural/traditional is re-appropriated and drawn positively into the narrative of modernity. This is because its apparent location outside the perimeter of the modern can be viewed as resistant to modernity. Thus, to the extent modernity is about the loss of tradition and nature, the experience of loss can be reversed 
by grafting signs of nature and tradition back into the modern field of vision. Similarly, by reinscribing aboriginality into the scarcity narrative (of loss), the possibility of natural abundance in the face of modernity can be maintained. The figure of aboriginality-asnatural/traditional, in this case, is not mourned for being subsumed by modernity, but is, on the contrary, celebrated by the modern national subject for holding "the key to its sustainable future" (Braun, 2002:93).

To explore these themes a bit more closely, I want to look briefly now at two specific policy documents dealing with boreal forest wilderness preservation, aboriginal people and climate change. The first is entitled Remote Tourism Sells, and was published in 2005 by the Wildlands League and Ontario Nature, two well-established Torontobased conservation organizations. ${ }^{78}$ The second is a slightly more obscure document called Aboriginal Issues in Canada's Boreal Forest, and was submitted as a policy input into the recently concluded Boreal Task Force that convened under the auspices of the Government of Canada's National Roundtable on the Environment and the Economy from 2003 to 2005 (Morse et al, 2005). Reading both documents together is important for at least two reasons. First, both represent important contributions to the policy debate concerning the boreal forest of northern Canada. Second, each document assigns aboriginal peoples a place of significance in the political struggle over the conservation of the boreal forest.

\footnotetext{
${ }^{78}$ It should be noted that the Wildlands League is a chapter of the Canadian Parks and Wilderness Society, the conservation group that organized the Boreal Rendezvous discussed in the previous chapter. Ontario Nature is a Toronto-based conservation group formerly known as the Federation of Ontario Naturalists.
} 


\section{Remote Tourism Sells}

The basic argument presented in Remote Tourism Sells (RTS) is that while tourism in remote areas of northern Ontario is becoming increasingly popular among "up-market" vacationers, the overwhelming majority of whom are from the United States, remote tourism is threatened by encroaching commercial forest use, road development and poor land-use planning (Wildlands League \& Ontario Nature, 2005). As such, RTS proposes that remote wilderness tourism offers an important alternative economic development strategy, one that is ecologically sound with measurable benefits for local communities, to the conventional industrial strategy of hydro-electric, forestry and mining development. The authors construct their argument around the results of a 'study,' comprised of a series of interviews with remote tourism operators in northern Ontario, a literature review and discussions with relevant policy experts in the field of remote tourism. The effect of doing so gives the document the flavour of objectivity. The document also contains a set of recommendations aimed at the Ontario Ministry of Natural Resource and First Nations governments on how to ensure that Ontario remains a "world-class wilderness tourism destination" by protecting "wilderness tourism values through appropriate land-use planning and access management." 79

This is a very interesting document about which much can be said. For the purposes of my argument, however, I am concerned less with its veracity, than with how

\footnotetext{
${ }^{79}$ RTS includes a long list of remote tourism values, which included good fishing; sand beaches (often used for shore lunches); wildlife viewing and hunting areas; waterfalls; historical sites (such as old Hudson's Bay Company sites); undeveloped shorelines; remoteness; bear management areas and minnow blocks; eagles' nests; northern lights; all-terrain vehicle (ATV); snowmobile; and portage trails; wild rice patches; other lakes (accessible by portage or other means to supply fishing opportunities); lodges and outposts; boat caches and canoe routes.
} 
it operates as a truth-regime governing future boreal development and how this truth regime constructs aboriginal identity.

At work in the document is a performative spatiality that installs a fictional line separating modernity from the anachronistic space of remote northern Ontario. The positioning of this line is essential for articulating the economic importance of remote tourism because it allows for the easy identification of candidate sites in which remote tourism can be carried out. In RTS one device used in constructing this spatial division is the use of aerial maps of northern Ontario. Early on in the text there appears one such map, depicting the undifferentiated spatial distribution of human population across the region, including both native and non-native settlements: cities, towns and First Nations reserve sites (see Figure 5.3, page 238 ) ${ }^{80}$ This map unequivocally positions humans within the boreal forest space of northern Ontario. Later in the RTS text the same map reappears. But this time it maps the same spatial distribution of settlements against another variable: road-density (see Figure 5.4, page 239). Predictably, the southern half of the map appears much more road-dense than the northern half. This difference, the authors argue, is the threshold demarcating the 'remote', 'unspoiled wilderness' of the north and the fragmented, commercialized, high-graded forests of the south. Here it is suggested that roadless-ness marks the outer extreme of the modern experience. Beyond the boundary, civilization comes to a halt as commercial infrastructure and road development taper to nothing. In the place of nothingness, the boreal forest, the 'frontier' forest par excellence, is materialized.

\footnotetext{
${ }^{80}$ It should be noted that this map is somewhat misleading in this respect because it unproblematically conflates the largest municipality in the region, Thunder Bay (population 121, 986, Statistics Canada 2001 Census Data), with much smaller communities such as Pikangikum (population 1,170 Statistics Canada 1996 Census Data) and Mishkeegogamang (Statistics unavailable).
} 
Figure 2. The three case study areas in Northwestem Ontario

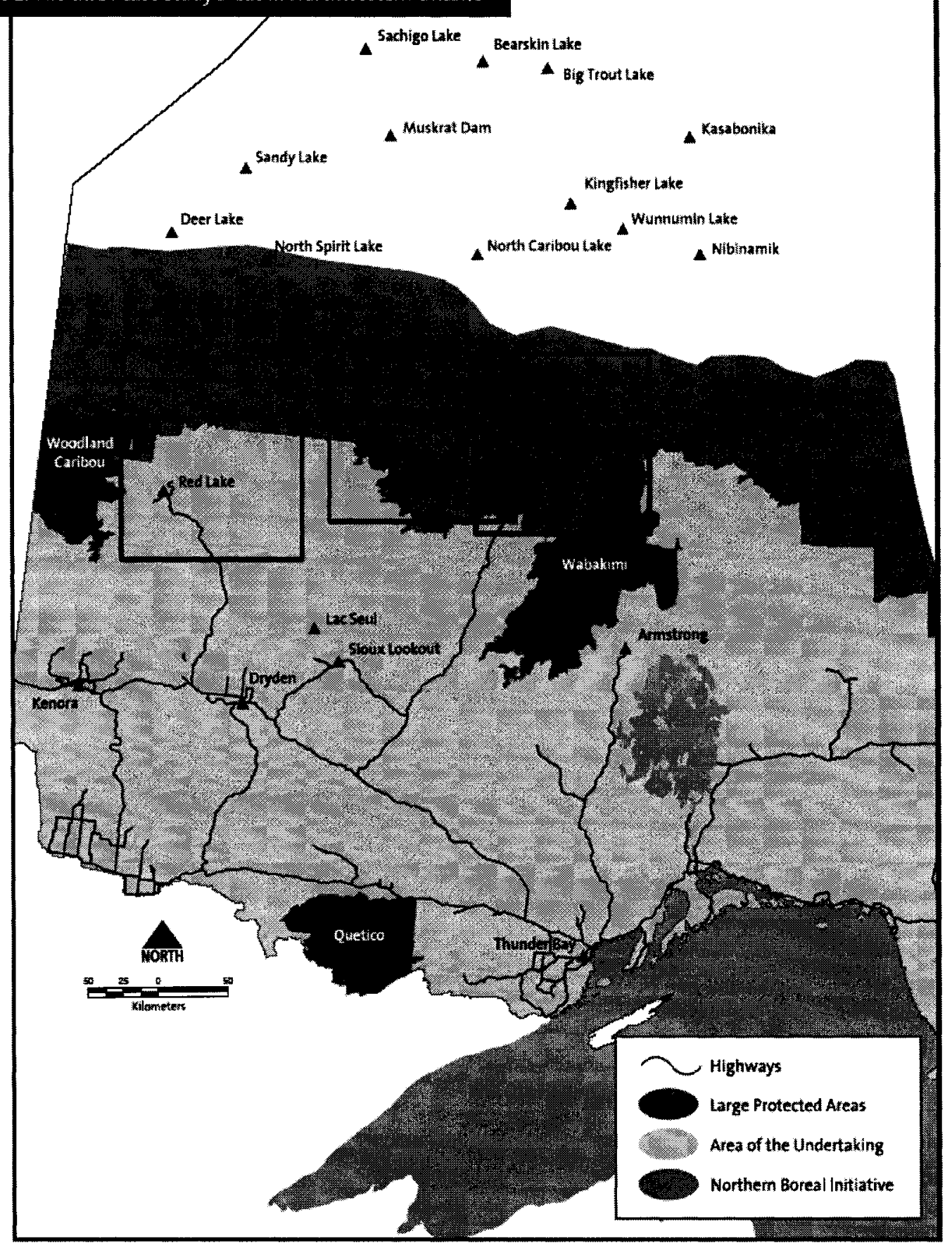

Figure 5.3 - RTS Context Map of Northern Ontario. ${ }^{81}$

\footnotetext{
${ }^{81}$ The Area of the Undertaking refers to a space that was the object of negotiation during the Lands for Life land-use planning process. The Northern Boreal Initiative is a land-use planning exercise currently underway in Ontario.
} 


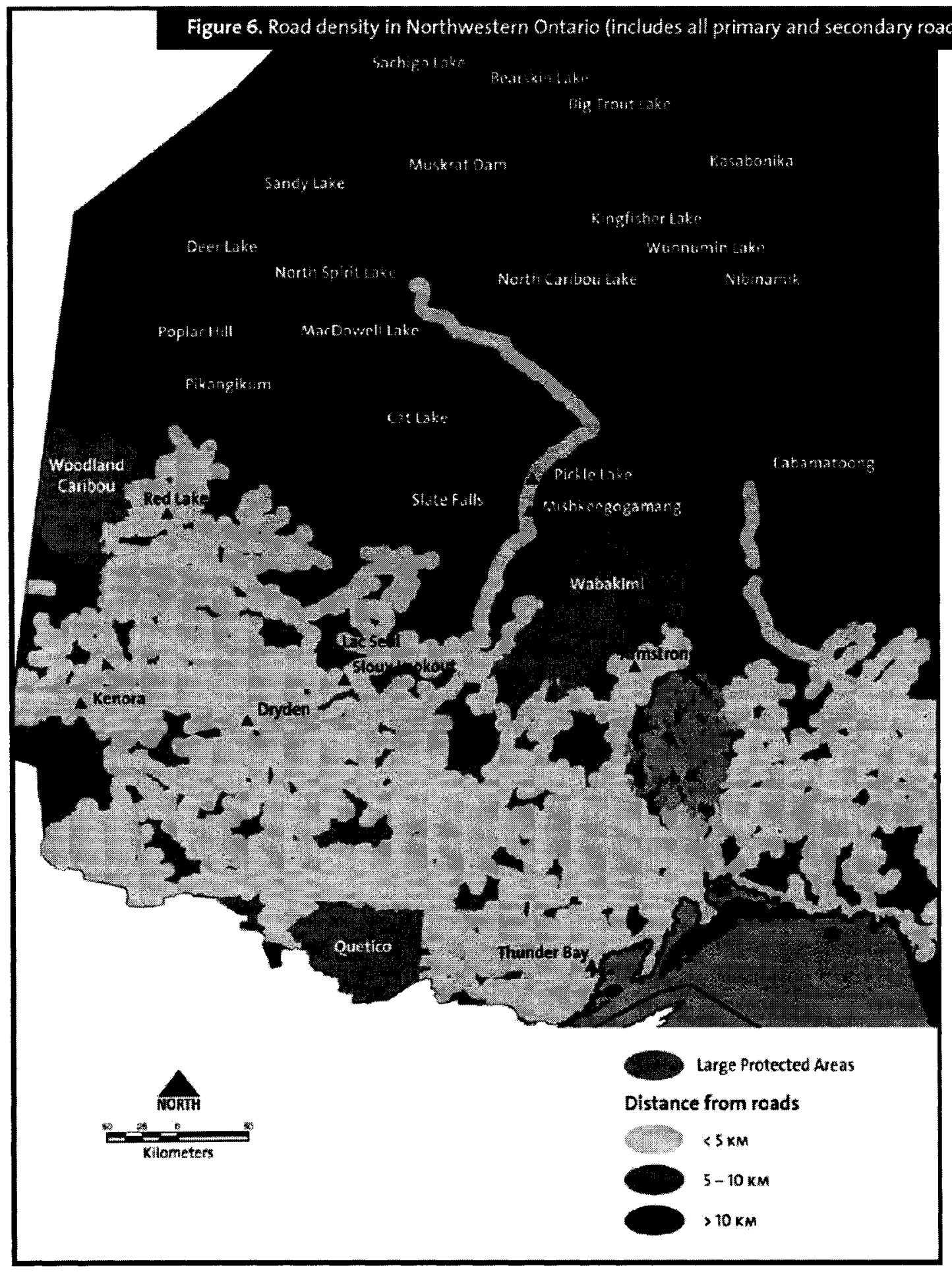

Figure 5.4 - RTS Context Map depicting Road density in Northern Ontario. 
But what about the human presences on these maps? How do they figure within the schema of remote wilderness? The way these maps read, those settlements that lay within the roadless zone are figured as remote communities and that in their remoteness they are somehow 'less spoiled' than those to the south. This is, of course, not explicitly stated in RTS. But when considered alongside other parts of the text that make reference to the complementarity between aboriginal 'traditional' land-uses, such as hunting, fishing and trapping, and remote tourism values, one has to work very hard not to make this inference. This sensibility is furthermore buttressed when considered alongside one of the pervasive rhetorical plot twists running throughout much of the boreal forest campaign rhetoric in which it is now commonplace for boreal forest conservationists to argue for a more enlightened form of conservationism, one that recognizes the place of humans in nature as opposed to one that positions humans on its outskirts. In this regard, many conservationists are now of the view that the historical practice of nature protection (parks, protected areas), which resulted in pockets of nature being established and maintained within a much vaster industrialized landscape, is now outmoded. Instead many now advocate that human development throughout the boreal region must be embedded within vast expanses of wilderness (Federation of Ontario Naturalists et al, 2002). This is a laudable goal, especially when one considers the devastating social and ecological side effects that characterize industrial development. It is also one to which I am at least partially sympathetic, given the mantra of social-nature literature that, in all its various guises, places humans in a direct relation with nature (Braun \& Castree, 1998a; Cronon, 1996b). But, it is nevertheless one that also leaves me feeling rather uneasy for the way in which it imprisons community development and identity within a discourse of 


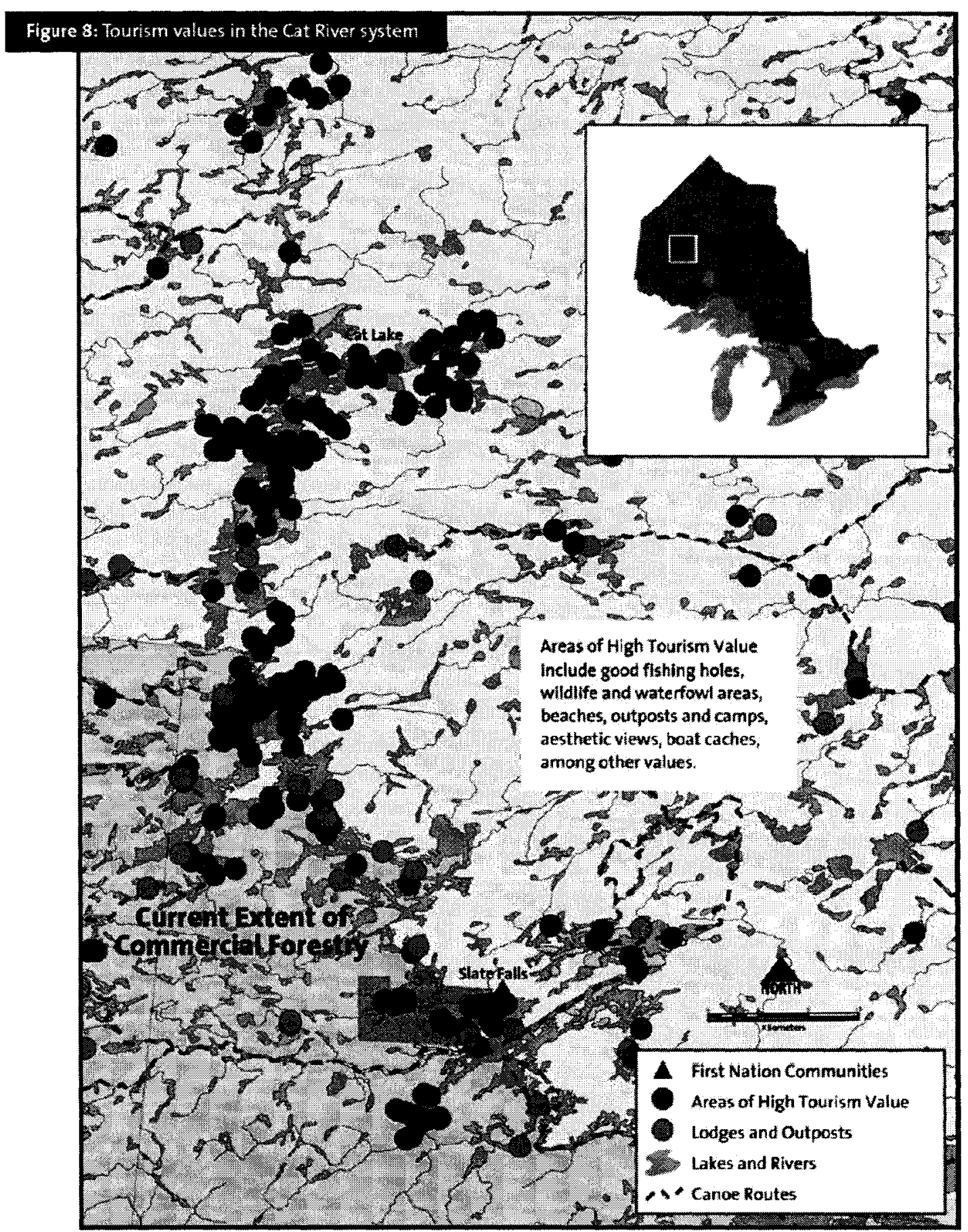

Figure 5.5 - RTS Context depicting Remote Tourism Values in the Cat River System 
remote wilderness that constructs remoteness as distinctly non-modern. I will come back to this momentarily.

A third map draws this sensibility into much sharper relief (see Figure 5.5, page 241). A land area of roughly eight thousand square kilometres in the 'remote' section of the map is shown. On it are hundreds of small dark dots, each depicting a site of high tourism value (for a list of remote tourism values see footnote 78 on page 235 ). Several lightly shaded dots also appear on the map, depicting lodges and outposts. The dots are clustered in the middle of the map. On either end of this cluster, surrounded by numerous dark dots are two small back triangles, one representing Cat Lake First Nation and the other Slate Falls First Nation. From the map it is very easy to generalize that both Cat Lake and Slate Falls, given their status as 'remote' First Nations communities lying within the road-less domain of the non-modern, might be added to the list of remote tourism values. One also gets a sense that development in these locations can only occur, at least so far as enlightened conservationism is concerned, within the carefully circumscribed limits of remoteness.

The place of remote First Nations in the construction of the remote wilderness experience was not lost on Nishnawbe-Aski Nation Deputy Grand Chief Alvin Fiddler, who, later in $R T S$, was quoted as saying "their tourist attraction is our way of life" (p.35). The appearance of this quotation in the text, along with the authors' acknowledgement that where aboriginal tourism is concerned there is "a fine line between spirituality, marketing and exploitation," certainly suggests that the authors are genuinely sympathetic to the political concerns of northern aboriginal peoples. No doubt they are. In a similar gesture, the authors also stress the importance of ensuring that remote 
tourism is not detrimental to local aboriginal communities. But the section in RTS that acknowledges the potential social consequences of remote tourism for aboriginal peoples is very small. Nor does it contain any real argument except to say that economic opportunities exist for aboriginal tourism and that tourism development must respect Aboriginal treaty rights. But on balance these arguments pale in significance when compared to the much more detailed economic argument that makes up the remainder of the text, an argument that champions the benefits of remote tourism for the largely nonaboriginal tourism operators in northern Ontario.

The effect of course is to naturalize remoteness, the cultural significance of which can only be ascertained within the discursive trajectory of modernism. Here an unequal pairing of cultural agencies materializes. In the discourse of remote tourism, it is only the modern tourist (a masculinized figure) who possesses the quality of mobility and is thus able to cross the boundary from the modern to the non-modern and back. The movements of the remote subject (a femininized figure), on the other hand, are constrained within the remote tourism discourse to only those settings that might be of interest to the tourist.

Overall, what I want to emphasize here is how aboriginality is represented in $R T S$. Unequivocally aboriginal culture is represented as traditional. Yet to the extent aboriginal communities are located in a road-less, wilderness region safely outside the boundaries of the modern, aboriginal culture is also codified as natural. I will offer a more detailed explanation as to why this matters later. But for now, I would just point out that representing aboriginal culture in such undifferentiating terms has the effect of essentializing aboriginal experience and constructing aboriginal as a singular category. 


\section{Aboriginal Issues in Canada's Boreal Forest}

A similar codification of aboriginal-as-natural is at work in Aboriginal Issues in Canada's Boreal Forest (AICBF). AICBF was developed as an input to the National Roundtable on the Environment and the Economy's Boreal Task Force. At the outset of the document the authors argue that "reliant on the land they inhabited for basic and spiritual sustenance, Aboriginal peoples have been practitioners of what is now referred to as "sustainable development" for hundreds of years. Traditional practices of hunting, trapping and gathering activities have imparted Aboriginal peoples with expansive knowledge of the level of human extraction and intervention tolerable by natural ecosystems" (Morse et al, 2005:5). This representation of naturalized aboriginality features prominently throughout the remainder of the text, and finds very clear expression in a section of the document on the Kyoto Protocol and aboriginal peoples. Here a case is made for the federal government of Canada to factor the cost of forest carbon into all subsequent land-use decisions in the boreal forest, so as to ensure that economic development decisions reflect the true value of the boreal forest and its contribution to climate change mitigation. Such development, it is furthermore argued, could generate a host of benefits among them a) additional revenues for the provinces and northern communities, including aboriginal communities, b) climate change mitigation, and c) sustainable forest management and forest conservation, including wildlife, tourism and aboriginal traditional land-use values. For the purposes of my argument, however, I want to isolate the last of these, the revenues that might accrue to aboriginal communities, because $A I C B F$ draws explicit attention to this benefit (not surprising given that it appears in a document dedicated to aboriginal peoples issues). Here the main thrust of the argument is that selling carbon credits (assuming that aboriginal communities have the 
right to do so) could enhance sustainable development in remote aboriginal communities, particularly where timber values are marginal, and promote wildlife and forest conservation "which would benefit both traditional use and tourism development for Aboriginal communities" (Morse et al, 2005:83).

There can be no doubt that this is an appealing policy option. It contains remarkable internal coherence and, in principle, offers numerous benefits to the Canadian economy, the practice of forestry, northern communities and aboriginal people. But there is also a great deal about this set of policy proposals that demands careful scrutiny, such as issues of liability and conditions of carbon ownership and transferability, not to mention broader ethical considerations concerning the commodification of carbon. But it is precisely because these policies have the appearance of being so irrefutable that they demand closer criticism. I, therefore, want to suspend judgement on their capacity to deliver long-term economic and environmental benefits, and instead simply wish to insist that the discourse of forest carbon management, at least as it appears in $A I C B F$, reinscribes the figure of aboriginality back into the scarcity narrative as a fully naturalized mode of subjectivity.

\section{Ecological Modernization and Racialization}

To organize a final set of observations for this chapter, I want to return to Said's idea that "the liminal figure helps to maintain societies" (1994:141). The society in question is Canadian national society and the liminal figure I have sought to foreground in this chapter is the aboriginal subject. This is, of course, not the only way of interpreting Said's idea. The liminal subject might just as easily be the colonial surveyor or officer, and the society in question might just as easily be imperial rather than national. 
Either way, the important point about the liminal figure in such cases is that he or she works and lives at the limits of national experience and thus plays a profoundly important role in maintaining collective national identity. This is to say that whatever circumstances the liminal subject might encounter on the frontier of experience are made to constitute the collective national experience. Their fate at the limits of experience becomes the collective fate of all those who occupy the centre. Another very important idea having to do with this figure, however, is that this identity does not pre-exist its construction, but instead must be invented and installed as the liminal figure. Building on Said's initial insights, what I have argued in this chapter is that by constructing aboriginality within the discursive constraints imposed by the closely related narratives of carbon scarcity and wilderness aestheticism, the nostalgic image of aboriginality-as-nature is called upon to manage the relationship between the nation's contradictory desire to retain its origin (wilderness) while pursuing an ecologically modern development trajectory.

In what follows, however, I wish to push these ideas further by suggesting that ecological modernization, in addition to being a politics set to the task of realigning industrial production with the precepts of ecology and atmospheric and climate stability, might also be read as a form of racial management, at least to the extent the process of ecological modernization trades on a lexicon of national imagery that call up the liminal figure of aboriginality. In this sense, I wish to recall Moore, Kosak and Pandian's claim that "race and nature are constitutive features of modern power," "integral to the rule of modernity rather than an exception" (Moore et al, 2003:15) and suggest that perhaps it is possible to understand race as an operative category in the exercise of ecologically modern power. 
How might this be so? First, the reincorporation of the aboriginal other into national discourse amounts to what David Goldberg has referred to as racial historicism (2002:83), the "(re)admission of those deemed not white into a history" (p.97).

Accordingly, racialized aboriginal subjects are thus transformed into historical agents and are invited to participate in history, white national history. Both the recovery narrative addressed in Chapter 4 and the carbon scarcity narrative addressed in this chapter embody a similar reinscription motif, whereby aboriginal peoples are invited to participate in Canadian-national history and are celebrated as important national figures in this regard. But, in both cases, what renders aboriginal reinscription a racializing practice is that the conditions of reinscription are carefully prescribed through a colonial optic of naturalism, tradition and spatial immobility. Such an image of aboriginality can be observed in the familiar tropes of conservation in which aboriginal people are routinely invited to suture economy and environment by assuming the position of land stewards whose responsibility it is to maintain the natural capital of the nation. ${ }^{82}$ And in the context of global capital in which insurance and finance capital are becoming increasingly more attuned to the financial implications of climate change, such a custodial role for aboriginal people in managing forest carbon, amounts to securing the space economies of forest carbon not only for the nation, but for global capital as well. This custodial image thus has the effect of naturalizing aboriginal culture and, in so doing, confines legitimate aboriginal visibility within the fields of national political culture and global capital to precisely those terms. To exceed these terms, to exceed naturalism, is, thus, for the aboriginal to cease being aboriginal.

\footnotetext{
${ }^{82}$ This idea, "securing Canada's Natural Capital" is the title of a 2001 State of the Debate report published by the Canadian National Roundtable on the Environment and the Economy.
} 
But there is a second way in which to understand race as an operative category in the exercise of ecologically modern power. Borrowing again from Moore, Kosek and Pandian, "liberal multiculturalism often disavows the complex histories of racial violence, domesticating social antagonism through a celebration of cultural diversity" (Moore et al, 2003:43). In a similar vein, I wish to argue that these same twin processes of disavowal and domestication occur through the narratives of conservation. The histories of colonial dispossession that mark aboriginal experience in Canada, and their political response to this dispossession, are domesticated, in part, through a celebration of the involvement of naturalized aboriginal peoples in conservationism. Conservation thus becomes not simply a means of safeguarding environmental services in an increasingly vulnerable world, but it also becomes a means by which the aboriginal other is rendered culturally significant to the national project of multiculturalism. In other words, there is a slot for the aboriginal other within the multicultural celebration of the nation, and this slot is located within the narrative of conservation.

A set of critical questions emerge at this point in the argument, concerning the types of cultural difference that are tolerated, and those that are not, within the multicultural project. Which social groups wield the power to draw the line between tolerable and intolerable difference? What forms of political expression are deemed appropriate in the discourse of multicultural conservation? What forms of economic development are aboriginal peoples permitted to pursue when constrained within a discourse of ecological modernity that privileges the scarcity narrative? Together, what these questions suggest is that culture becomes a critical device governing what types of economic activity aboriginal people can engage in. These questions also betray a sensibility within conservation discourse that in addition to conserving nature, certain 
signs of aboriginal culture must also be conserved, in particular those that work to protect national nature. The liminal aboriginal person thus has a (heavily scripted) part to play in conserving the nation. And if I could make one last point, this discourse of cultural conservation can also be read as a discourse of racial preservation, or the preservation of racial difference. Critical here is the idea that culture becomes synonymous with racial difference and displaces biology as the principle discursive means by which racial difference is secured and maintained. In this sense, it then becomes possible to argue that the fate of the nation becomes tied to the preservation of racial difference. 


\section{Chapter 6}

\section{Conclusion: \\ Nature, Space and the Geographies of Non-Fixity}

Through this dissertation I have sought to trace the discursive contours of the boreal forest in order to demonstrate how its appearance as a natural space in Canadian conservation politics is contingent on a hegemonic colonial visuality that erases aboriginality from view. To do so, I have explored three specific narratives - the colonial narrative, the recovery narrative and the scarcity narrative - and have read the histories of forestry, the canoe expedition and climate change through each narrative respectively. But more than this, I have endeavoured to show how contemporary conservation discourses concerning the boreal forest subsequently reincorporate aboriginality back into these discourses through an optic of tradition and naturalism. Such an approach to understanding nature conservation is important, in my view, because it draws much needed attention to the dimensions of race and gender that operate so quietly through discourses on nature.

In making these claims I have taken my cue from a series of debates in human, critical and cultural geography that have been broadly concerned with exposing the social-ness of nature (Braun \& Castree, 1998b; Braun \& Castree, 2001; Castree, 1995; Castree, 2005; Cronon, 1996b). One of the recurring themes in these debates is that despite conventional wisdom, nature is not an ontologically discrete entity, but is a social phenomenon and that political projects carried out in the name of nature are often, if not 
always, euphemistic expressions of cultural identity. This argument, however, is very different from those that claim that nature is simply perceived or consumed according to the epistemological preferences and narrative choices of the viewing subject (Wapner, 2002). Such views take for granted that there is in fact a nature that can be viewed and that such a nature is simply animated by one's epistemological filter. My argument goes further: nature's ontology, durability and spatialization, do not precede their epistemological investment but are produced exactly at the moment of their perception. Needless to say this poses troubling questions for the practice of environmental politics (and, indeed, for the project of modernity) for it dislodges nature from its privileged place in metaphysics and repositions it within the much more complex and messy field of power and cultural politics. Accordingly, environmental politics, or rather more specifically the politics of nature protection, might just as well be read as a cultural politics of identity by another name. Thus, in the three empirical chapters of this dissertation, I have aimed to show how the concept of nature has been indispensable in the historical formation of national discourse in Canada and, in turn, that discourses of Canadian nationalism have been central to, although not always explicitly stated in, the political articulation of the boreal forest as a natural space. As such, I have furthermore argued that the politics of boreal forest conservation in Canada can be understood, at least in part, as expressions of a racialized Canadian national identity that trades on a sharp distinction between a white national subject and a racialized aboriginal subject.

Another recurring theme in these debates concerning the imbrications of nature and culture is that exposing the cultural content of nature is not simply an idle intellectual exercise. Instead these debates emphasize that this is a deeply political act motivated by 
an ethical conviction that nature, in whatever context it may be invoked - environmental, political, theoretical, national or what have you - must not be allowed to stand unchallenged as a realm set apart from the social, since the concept, and its embedded innocence, wields far too much power to fix phenomena in a world that is neither inherently stable, nor preordained. To let nature occupy a fictitious space beyond critique, beyond power, is to overlook the part discursive power plays in securing the conditions by which the world might come to be known through a spatial imaginary that distinguishes between nature and society. Indeed, one of my central concerns in this dissertation has been to demonstrate the need to recognize that how nature comes to occupy space and how nature is materialized, are political acts. In this sense, it is the practices by which nature is made that are so crucial here because such practices betray their own embedded histories, which, in the case of the boreal forest, can be traced to territorial imperatives associated with Canadian imperial expansion. In two of the three empirical sites I have examined in this dissertation, the histories of forest production and modern wilderness canoe travel have been shown to bear a clear relation not only to the forging of the boreal forest space, but also to the space of the Canadian nation and, even more important, the production of the Canadian national subject. Moreover, as I have already mentioned, embedded within each is a colonial visuality that naturalizes aboriginality and civilizes the practices that are implicitly synonymous with white Canadian-ness.

The imperative to "denaturalize" (Castree, 2005) nature thus takes on additional significance in light of another of the central arguments I have made throughout this dissertation, which is that nature is performative. I say this because, as I have shown in 
each of the three empirical studies, nature's geographies are intimately tied up in subjective experience, such that bodies enact the very same natures that regulate them. Thus to dismantle specific expressions of nature by subjecting them to the critical work of deconstruction is not an act of destruction or nihilism as some might contend, but is on the contrary an effort to liberate particular subjective modes - whether modern, indigenous, national, masculine, feminine, raced, rural or urban - from the disciplinary constraints that specific articulations of nature impose upon them. By saying this, however, I am in no way suggesting that we abrogate responsibility for the way in which industrial capital codifies and transforms the biophysical, non-human realm. To the extent that this realm is codified as natural, its deconstruction does not authorize its destruction. Ethics are far more complicated than such a simplistic formulation might allow. What I am arguing, however, is that political projects carried out in the name of nature, coordinated political campaigns like that of the Boreal Rendezvous and the boreal forest conservation movement more generally, must be interrogated for the manner in which they are caught up (in some cases unwittingly) in a politics of identity. Indeed, there is much more at work inside an environmental movement articulated through the language of national belonging and identity than simply the trees it seeks to protect. There is the desire to preserve both that very identity and the specific epistemological systems in which the identifying subject is so deeply enmeshed. Such a view comes out very strongly in a recently published press release issued by the Canadian Boreal Initiative in which Bob Walker, the Vice-President of Sustainability for the Ethical Funds Company Limited, one of Canada's largest financial institutions, ${ }^{83}$ was quoted as saying that "the boreal forest is a Canadian icon. It has shaped our history, our economy, and our

\footnotetext{
${ }^{83}$ Ethical Funds Company Ltd. had an estimated $\$ 1.5$ billion under management in 2005.
} 
culture - it is a part of who we are. We have an obligation to future generations of Canadians to carefully manage all of our activities in the boreal forest - the heart of our nation's identity" (Canadian Boreal Initiative, 2005). For Walker, safeguarding the boreal forest is, indeed, about safeguarding Canadian identity. But the point I would emphasize here is that Canadian identity is not a natural form, nor does it imply a naturalized set of assets or characteristics, nor does it locate its essence in the natural world, and it most certainly cannot be gathered under a singular sign. To make such claims, as Walker and so many others do, is to tread on very dangerous ground.

With these general remarks in mind, I would like now to conclude by considering the implications the three cases I present in this dissertation might have for the interrelated practices of postcolonial geography, poststructural political ecology, and the genealogies and performativities of natural space.

First, what the environmentalization of the boreal forest offers is an immensely productive terrain through which to analyze the geographies of nature's performativity as they are made to appear through discourses of the Canadian nation. I say this not least because the forest fits so snugly within the political boundaries of the Canadian state that it is virtually impossible to think the boreal forest without also thinking Canada. Conversely, it is almost impossible to un-think the boreal forest without also unthinking Canada and Canadian identity. What this suggests is that alongside other geographical scales, such as the city, the nation marks as an important spatial and imaginative scale for considering nature's genealogy. 
But my interest in examining boreal forest politics for what it might tell us about the geographies of nature and nation goes further than merely positioning the nation alongside other scales for thinking nature. I want to propose that, at least in Canada, to the extent nature and nation are so intimately bound, it may be impossible to think nature at all, without also thinking the nation. In other words, while other sites of economic, political and cultural activity may be just as important for contemplating and exposing nature's construction, scales like the city (Swyngedouw, 2004), the suburbs (Keil \& Graham, 1998), the body, the park (Sandilands, 2005), and so on, perhaps the figurative presence of the nation organizes nature's production, albeit to differing degrees, at each of those scales too. This is to say that perhaps the imaginative geographies of nationalnature regulate the production and construction of nature in the ex-urban, on the body and in the city. I say this because nature's performativity is situated within very specific historical economies of experience and practice; the nation is not ahistorical, neither is nature. Both are instead made together through historical practice and continue to be held together in the present through the continued repetition and cultural privileging of such practices. In the Canadian national register, for instance, one of the dominant performative utterances of nature is apparent in William Lewis Morton's definition of the Canadian character, which I raised in the introduction and in Chapter 4 of this dissertation.

...this alternate penetration of the wilderness and the return to civilization is the basic rhythm of Canadian life and forms the basic elements of Canadian character. (1961:4-5)

In Morton's formulation, nature and nation are inseparable from the movements of the national subject. But to really interrogate nature's performativity through the movements 
that Morton so carefully privileges, demands that one ask precisely where and under what sorts of historical circumstances this movement occurs. Answering these questions is what I have tried do in Chapter 3 and Chapter 4, locating the boreal forest's entry into political discourse through such nationalized movements as they appear in the practices of state forestry and canoe travel in the late nineteenth and early twentieth centuries. For Fernow, such a nature appeared as a national forest that could be enlisted to underwrite the economic and moral betterment that accompanied Canadian imperial ambition. For the recreational canoeist, such a nature was a space of purity where bodies could be purged of any undesirable traces of modernity, while still retaining their privileged positions as responsible modern subjects. In both cases, the effect was to render national those very practices that put a detached, un-urban, external national-nature into play. Canoeing thus assumed the status of a national pastime, even though it remained (and continues to remain) something that only few could afford and were inclined to do. Likewise, scientific forestry became a national enterprise and something for which Canada became internationally renowned.

The critical point here though is that these are imaginative geographies that "dramatize the distance" (Said, 1994:75) between city and country, such that each constructs an abstract universalizing nature, external to the urban, which subsequently comes to signify the nation. This leads me to another observation, which is that the finde-siècle urban experience represents another potentially important site for considering the ontological foundation of national discourse at the turn of the last century. After all, it was from the city that the national subject moved. This, in turn, leads to the question: What it was about the Canadian city that led the urban subject to vacate the city in the 
first place? To be sure, I addressed this question, in Chapter 4, when I acknowledged how spaces of privilege, citizenship and responsibility associated with the scouting movement and modern canoe travel had been made to stand apart from the raced and classed spaces of degeneracy, crime, sloth and promiscuity so closely associated with urbanism. But this insight nevertheless suggests that representations of the city might play a potentially important, yet often unstated, part in ordering and regulating the experience of national nature. If anything, then, Ernest Thomson Seton's degrading remarks towards racialized and ethnic subjects in the fin-de-siècle North American city draw attention to how racialized inscriptions of the city work in close proximity to performative natures and are perhaps inscribed directly into those very natures. Similar arguments have been made with respect to risk culture and the genealogies of adventure recreation in contemporary United States (Braun, 2003).

What this might mean for the development of Canadian geography and geographical theory more generally is that Said's notion (and critique) of imaginative geography, and the related practice of postcolonial geography, could be applied with equal force not just to the vast spatial terrains constitutive of empire and the imperial imagination but also to the seemingly more closed, localized spaces of urban experience. Or to put this differently, Seton's contempt for the urban masses suggests that colonial power constructs spatial difference not merely in the assertion of economic, cultural and political domination around the globe, but also through the territorially constrained limits of the metropole as well.

Another lesson learned from my analysis is that nature and space are mutually performative notions. This is may not be such a new idea, especially given Gregory's 
recent use of performativity and space (2004) and his explication on the imbrications of nature and space in colonial discourse and practice. Nor is it especially novel to think these two concepts together. Doing so was certainly a hallmark of Marxist geography in the 1990s, inspired in large measure by Neil Smith (1984) and David Harvey (1996). But curiously in the recent move to rediscover the nature's social inflections in geography (Castree, 2005), nature and space have not been explicitly thought together as mutually performative. To be sure, the performativity of nature has been an emerging theme in cultural geography from at least the late 1990s (Braun, 2003; Braun \& Castree, 1998b). So too the performativity of space has become a dominant area of interest for a number of geography scholars (Gregson \& Rose, 2000; Nash, 2000; Thrift, 2004). Yet within these areas of research little effort has been made to draw these notions together and think them as a unified metaphor. In fact, in some instances these two notions have been deliberately held apart as a matter of heuristic convenience. Braun, for instance, argued that postcolonialism has been primarily concerned with articulating its concern for the concept of space at the expense of addressing the idea of nature as a central concept in the colonial repertoire (1997). His work marvellously dismantles the idea of nature, tracing its ontological legibility through fields of environmental politics, desire and mourning, landscape painting and ecological science. But by focusing so closely on the ontological frame of a single notion - nature - his approach, paradoxically, risks downplaying the ontological production of space. True his work is very much about the political and cultural geographies of nature in (post)colonial British Columbia. But it also implies that the territorialization of nature's geographies is the mechanical byproduct of colonial visions of and political struggles over nature. My contention, 
however, is that space geographies are embedded within the very idea of nature itself, such that nature and space are not separate concepts, but must be thought of as one and the same. Thus to construct nature is to construct a space within which nature might be said to move. Similarly, to construct space is implicitly to assert its underlying nature. What I have tried to show in this dissertation, then, is that nature and space operate together in a singular performative logic. But, as I have also tried to show, this logic is not innocent for, as Jake Kosek insists, it produces and maintains difference (Kosek, 2002). Thus, part of my aim in this dissertation has been to tease out how the idea of nature is implicated in the production of racialized difference.

In more practicable terms, however, the mutual constitution of nature and space finds resonance in contemporary discussions concerning political ecology (Wainwright, 2005) and it is within these discussions that I think my analysis of nature's performativity has something to contribute. Let me explain how. First, if postcolonialism has been concerned with culture, power and spatiality (Gregory, 2001), and if poststructural political ecology has been about exploring strategies of control at work in the political economies of commodity production at the local scale, then Braun's work has been excellent because it draws these two realms together, such that it becomes impossible to speak about the construction of nature and political economy as distinct processes. But Braun's work does more than this. It also foreshadows a concern registered by Joel Wainwright concerning First World political ecology, namely the need to consider the sites of First World political ecology in explicitly ontological terms (Wainwright, 2005). In this sense, while political ecology is becoming more popular as a methodology for interrogating political movements and political power in the global 
north, as Paul Robbins suggests it should be (Robbins, 2002), one also needs to consider the ontological framing of the spaces that are the objects of political ecological concern. Here my analysis makes an important contribution because it draws explicit attention to how narratives of the nation produce the very natures they seek to protect and how such natures are predicated on their exclusions.

This leads me to my final observation and thus brings me back to where this dissertation began, with the idea of spatial fetishism. For Henri Lefebvre, spatial fetishism is strongly indicative of one's desire for a concept of absolute, bounded space. Yet, for him this desire is unavoidably ideological insofar as it hides the workings of material and symbolic history that produce, shape and even destroy space. My interest in interrogating discourses of the boreal forest and through it, discourses on nature, has thus been driven by a similar concern, a nagging sense of dissatisfaction with the implied knowability of the boreal forest as a natural space that accompanies so many of its political renderings. This is to say, a spatial fetishism seems to mark the boreal forest as it is used in such renderings. Its history and conditions of intelligibility have been erased from its sign. So too have the multiple stories that work through it and make it a resolutely peopled phenomenon. Thus one of my primary objectives in writing this dissertation has been to dismantle the boreal forest as a naturalized space and trace how its naturalization has been contingent on the displacement and reincorporation of indigenous alterity. And to this end, I have found the ideas and critical methodologies that have gathered under the sign of social-nature to be immensely productive. The political act of social-naturing offers a very effective means of interrogating spatialfetishism and gestures to a world that is thoroughly marked by its non-fixity. Social- 
naturing, the act of disarticulating nature's naturalness, is, therefore, not simply a means of exposing the identities that work and are silently sustained through the concept of nature, but it is also to de-fetishize space. By exposing the contradiction that nature is often invoked to innocently reflect space, when really it has the effect of securing it in place, social-naturing pries open the fixed space of nature and reveals a world that knows no fixed boundaries. It thus allows for the recognition of the complex geographies of non-fixity and is, in this sense, a minor politics. It breaks down and deconstructs that which is said to be natural. To posit a pure nature is an ontological impulse required for modern morality and ethics to take shape. Yet such purity can never perfectly attain in a boundless world. Social-naturing, on the other hand, disrupts the impulse of moral naturalism by arguing that morality's nature is distilled from social relations and places the subject of nature onto a surface of perpetual undecidability. Perhaps the (dis)placing of nature's subject onto such an uncertain field represents an important way forward in decolonializing the geographic imagination. 


\section{Cited References}

Agnew, John, (1998) Geopolitics: Revisioning World Politics. London: Routledge

Angus, Ian, (1997) A Border Within: National Identity, Cultural Plurality and Wilderness. Montreal and Kingston: McGill-Queen's University Press

Apps, M.J., W.A. Kurz, R.J. Luxmoore, L.O. Nilsson, R.A. Sedjo, R. Schmidt, L.G. Simpson and T.S. Vinson, (1993) "Boreal Forests and Tundra," Water Air Soil Pollution 70: 39-53

Baldwin, Andrew, (2003) "The Nature of the Boreal Forest: Governmentality and Forestnature," Space and Culture 6 (4): 415-428

---, (2004) "An Ethics of Connection: Social-nature in Canada's Boreal Forest," Ethics, Place and Environment 7 (3): 185-194

Barnes, Trevor, (2003) "Introduction: 'Never Mind the Economy. Here's Culture'," in The Handbook of Cultural Geography, eds. K. Anderson, M. Domosh, S. Pile and N. Thrift, pp. 89-96. London: Sage

Barton, Gregory, (2002) Empire Forestry and the Origins of Environmentalism. Cambridge: Cambridge University Press

Bauman, Zygmunt, (1991) Modernity and Ambivalence. Cambridge: Polity Press

Benidickson, Jamie, (1997) Idleness, Water and a Canoe: Reflections on Paddling for Pleasure. Toronto: University of Toronto Press

Berger, Carl, (1966) "The True North Strong and Free," in Nationalism in Canada, ed. P. Russell. Toronto: McGraw-Hill

Berger, Justice Thomas R., (1977) Northern Frontier, Northern Homeland: The Report of the Mackenzie Valley Pipeline Inquiry: Volume One, Ministry of Supply and Services Canada, Ottawa

Bernstein, Steven, (2001) The Compromise of Liberal Environmentalism. New York: Columbia University Press

Bhabha, Homi K., (2004) The Location of Culture. London: Routledge. (Routledge Classics)

Bhatti, J.S., G.C. van Kooten, M.J. Apps, L.D. Laird, I.D. Campbell, C. Campbell, M.R. Turetsky, Z. Yu and E. Banfield, (2003) "Carbon Balance and Climate Change in Boreal Forests," in Towards Sustainable Management of the Boreal Forest, eds. 
P.J. Burton, C. Messier, D.W. Smith and W.L. Adamowicz. Ottawa: National Research Council Press

Blancher, Peter, (2003) Importance of Canada's Boreal Forest to Landbirds, Canadian Boreal Initiative/Boreal Songbird Initiative

Bondar, Roberta, (1999) Passionate Vision: Discovering Canada's National Parks. Vancouver: Douglas and McIntyre

Bordo, Jonathon, (1992-1993) "Jack Pine - Wilderness Sublime or the Erasure of Aboriginal Presence from the Landscape," Journal of Canadian Studies 27 (4): 99-128

Braun, Bruce, (2000) "Producing Vertical Territoriality: Geology and Governmentality in Late Victorian Canada," Ecumene 7 (1): 7-46

---, (2002) The Intemperate Rainforest: Nature, Culture, and Power on Canada's West Coast. Minneapolis: University of Minnesota Press

---, (2003) "'On the Raggedy Edge of Risk": Articulations of Race and Nature," in Race, nature and the Politics of Difference, eds. D. Moore, J. Kosek and A. Pandian. New York: Duke University Press

Braun, Bruce and Noel Castree, eds., (1998a) Remaking Reality: Nature at the Millenium. New York: Routledge

---, (1998b) "The Construction of Nature and the Nature of Construction: Analytical and Political Tools for Building Survivable Futures," in Remaking Reality: Nature at the Millenium, eds. B. Braun and N. Castree. New York: Routledge

---, (2001) Social Nature: Theory, Practice, Politics. Oxford: Blackwell Publishers

Bryant, Dirk, Daniel Nielsen and Laura Tangley, (1997) The Last Frontier Forests: Ecosystems and Economies on the Edge, World Resources Institute, Washington

Burton, P.J., C. Messier, G.F. Weetman, E.E. Prepas, W.L. Adamowicz and R. Tittler, (2003) "The Current State of Boreal Forestry and the Drive for Change," in Towards Sustainable Management of the Boreal Forest, eds. P.J. Burton, C. Messier, D.W. Smith and W.L. Adamowicz. Ottawa: National Research Council of Canada

Butler, Judith, (1990) Gender Trouble: Feminism and the Subversion of Indentity. New York: Routledge

---, (1992) "Contingent Foundations: Feminism and the Question of "Postmodernism"," in Feminists Theorize the Political, eds. J. Butler and J.W. Scott. New York: Routledge 
---, (1993) Bodies That Matter. London: Routledge

Caccia, Charles, (2003) "Caccia Rings Alarm Bell in Reply to the Announcement of the Boreal Forest Conservation Framework." Ottawa: Press Release

Canadian Boreal Initiative, (2003) Industry, First Nations and Conservationists Join Forces in Largest Conservation Vision in Canadian History, Canadian Boreal Initiative Press Release, Ottawa

---, (2005) Unlikely Boreal Conservation Alliance Gaining Momentum: Diverse partners join effort to protect Canada's Boreal forest region, Canadian Boreal Initiative Press Release, Ottawa

Canadian Boreal Initiative and The Pembina Institute, (2005) Counting Canada's Natural Capital: Assessing the Real Value of Canada's Boreal Ecosystems, Canadian Boreal Initiative-The Pembina Institute, Ottawa

Canadian Department of the Interior, (1906) "Atlas of Canada." Toronto: Toronto Lithographing Company Ltd.

---, (1915) "Atlas of Canada." Ottawa: Government of Canada

Canadian Forest Service, (1996) "National Atlas of Canada: The Boreal Forest." Ottawa: Canadian Geographic Enterprises, Canadian Forest Service and Geomatics Canada

Cartwright, John, (2003) "Environmental Groups, Ontario's Lands for Life Process and the Forest Accord," Environmental Politics 12 (2): 115-123

Castree, Noel, (1995) "The Nature of Produced Nature: Materiality and Knowledge Construction in Marxism," Antipode 27 (1): 12-48

---, (2004) "Economy and Culture are Dead! Long Live Economy and Culture!," Progress in Human Geography 28 (2): 204-226

---, (2005) Nature. London: Routledge

Chalifour, Nathalie, (2004) "Encouraging the Transition to Sustainable Forestry in Canada with Ecological Fiscal Reform - Potential and Pitfalls," Journal of Environmental Law and Practice 14

Chapeski, Andrew, (2001) "Northern Homelands, Northern Frontier: Linking Culture and Economic Security in Contemporary Livelihoods in Boreal and Cold Temperate Forest Communities in Northern Canada," in Forest Communities in the Third Millennium: Linking Research, Business, and Policy Toward a Sustainable Nontimber Forest Product Sector, eds. I. Davidson-Hunt, L.C. Duchesne and J.C. Zasada, pp. 31-44. St. Paul: United States Department of Argiculture, Forest Service 
Chapeski, Andrew, Michael O'Flaherty, Alex Peters and Norman Quill, (Forthcoming) "The Whitefeather Forest Initiative: Indigenous Wisdom Guiding a New Community Forestry Opportunity in the Boreal Forest of Canada," in Sharing Indigenous Wisdom, ed. D. Kundin. Keshena: Menominee Nation

Chapin, Mac, (2004) "A Challenge to Conservationists," WorldWatch Magazine, Nov./Dec. November/December 2004

Cronon, William, (1996a) "The Trouble with Wilderness; or, Getting Back to the Wrong Nature," in Uncommon Ground: Rethinking the Human Place in Nature, ed. W. Cronon. London: W.W. Norton

Cronon, Willian, ed. (1996b) Uncommon Ground: Rethinking the Human Place in Nature. London: W.W. Norton

Dalby, Simon, (2002) Environmental Security. Minneapolis: University of Minnesota Press

Darier, Eric, ed. (1999) Discourses of the Environment. Oxford: Blackwell Publishing

Davidson, Peter, (2004) The Idea of North. London: Reaktion

Davis, Sasha, (2005) Pristine Devastation and a Modern Wilderness. Presented at 4th International Critical Geography Group, Mexico City

de Lahontan, Baron, (1684) New Voyages to North America

DeLuca, Kevin and Anne Demo, (2001) "Imagining Nature and Erasing Class and Race," Environmental History 6 (4): 541-560

Demeritt, David, (1998) "Science, Social Constructivism and Nature," in Remaking Reality: Nature at the Millennium, eds. B. Braun and N. Castree, pp. 173-193. London: Routledge

---, (2001) "Scientific Forest Conservation and the Statistical Picturing of Nature's Limits in the Progressive-era United States," Environment and Planning D: Society and Space 19: 431-459

---, (2002) "What is the 'Social Construction of Nature'? A Typology and Sympathetic Critique," Progress in Human Geography 26 (2): 767-790

Derrida, Jacques, (1974) On Grammatology. Baltimore: The John's Hopkins University Press

Desbiens, Caroline, (2001) Power from the North: The Poetics and Politics of Energy in Quebec. Ph.D. thesis. University of British Columbia, Vancouver. 307 pp. 
---, (2004) "Producing North and South: A Political Geography of Hydro Development in Quebec," The Canadian Geographer 48 (2): 101-118

Desjardins, Richard and Robert Monderie, (1999) "L'Erreur Boreale." Montreal: Cinema Libre and Office National de Film Canada

Dorst, Adrian and Cameron Young, (1990) Clayoquot: On the Wild Side. Vancouver: Western Canada Wilderness Committee

Drache, Daniel, ed. (1995) Staples, Markets and Cultural Change: Selected Essays, Harold A. Innis. Montreal and Kingston: McGill-Queen's University Press

Dreyfus, Hubert L. and Paul Rabinow, (1982) Michel Foucault: Beyond Structuralism and Hermeneutics. Chicago: The University of Chicago Press

Duncan, Nancy, ed. (1996) BodySpace: Destabilizing Geographies of Gender and Sexuality. London: Routledge

Elliot, Chris, (1999) Forest Certification: Analysis from a Policy Network Perspective. Ph.D. Dissertation thesis. Swiss Federal Institute of Technology, Lausanne. 1-464 pp.

Escobar, Arturo, (1996) "Constructing Nature: Elements for a Poststructural Political Ecology," in Liberation Ecologies: Environment, Development and Social Movements, eds. R. Peet and M. Watts, pp. 46-68. London: Routledge

---, (1999) "After Nature: Steps to an Anti-Essentialist Political Ecology," Current Anthropology 40 (1): 1-30

Esteva, Gustavo and Madhu Suri Prakash, (1998) Grassroots Postmodernism: Remaking the Soil of Cultures. London: Zed

Federation of Ontario Naturalists, Wildlands League and World Wildlife Fund, (2002) The Boreal Forest: Ontario's Big Widl, Federation of Ontario Naturalists, Wildlands League and World Wildlife Fund, Toronto

Ferguson, James, (1990) The Anti-Politics Machine: "Development," Depoliticization and Bureaucratic Power in Lesotho. Cambridge: Cambridge University Press

Fernow, Bernard E., (1902) The Economics of Forestry: A Reference Book for Students of Political Economy and Professional and Lay Students of Forestry. New York: Thomas Y. Crowell \& Company

---, (1903) Forestry Lectures, School of Mining, Kingston, Ontario

---, (1908) Canada's Interest in Forestry. Montreal: Canadian Club of Montreal1-11 pp.

Forest Stewardship Council, (2000) "Statutes," http://www.fscoax.org/principles.htm. 
Forsyth, Tim, (2003) Critical Political Ecology: The Politics of Environmental Science. New York: Routledge

Foucault, Michel, (1977) Discipline and Punish. New York: Vintage Books

---, (1978) The History of Sexuality: Volume 1: An Introduction. New York: Vintage Books

---, (1980) "Truth and Power," in Power/Knowledge: Selected Interviews and Other Writings 1972-1977, ed. C. Gordon. New York: Pantheon Books

,--- (1984) "Nietzsche, Genealogy, History," in The Foucault Reader, ed. P. Rabinow. New York: Pantheon Books

---, (1994) The Order of Things: An Archaeology of the Human Sciences. New York: Vintage

Francis, Daniel, (1997) National Dreams: Myth, Memory and Canadian History. Vancouver: Arsenal

Franks, C.E.S., (2000) "Review of The Canoe in Canadian Cultures by Bruce Hodgins, John Jennings and Doreen Small," The American Review of Canadian Studies 30 (3): 393

Fulford, Robert, (1992) "Robert Fulford Looks at the Making of A Great Canadian Myth," in The Globe and Mail, pp. C1. Toronto

Gillis, R. Peter and Thomas R. Roach, (1986) Lost Initiatives: Canada's Forest Industries, Forest Policy and Forest Conservation. New York: Greenwood Press

Global Forest Watch, (2002) "Remaining Wildlands in the Northern Forests." Washington, D.C.: Global Forest Watch

Goldberg, David Theo, (2002) "Racial Rule," in Relocating Postcolonialism: A Critical Reader, eds. D.T. Goldberg and A. Quayson. Oxford: Blackwell Publishers

Grace, Sherrill E., (2002) Canada and the Idea of North. Montreal and Kingston: McGillQueen's University Press

Grant, Shelagh D., (1988) Sovereignty or Security: Government Policy in the Canadian North, 1936-1950. Vancouver: University of British Columbia Press

Gregory, Derek, (1994) Geographical Imaginations. Oxford: Blackwell

---, (2001) "(Post)Colonialism and the Production of Nature," in Social Nature: Theory, Practice, Politics, eds. B. Braun and N. Castree, pp. 84-111. Oxford: Blackwell Publishers

---, (2004) The Colonial Present. Oxford: Blackwell Publishing 
Gregson, Nicky and Gillian Rose, (2000) "Taking Butler Elsewhere: Performativities, Spatialities and Subjectivities," Environment and Planning D: Society and Space 18 (4): 433-452

Grove, Richard, (1995) Green Imperialism: Colonial Expansion, Tropical Island Edens and the Origins of Environmentalism, 1600-1860. Cambridge: Cambridge University Press

Habermas, Jurgen, (1987) The Philosophical Discourse of Modernity. Cambridge: MIT Press

Haliburton, Robert Grant, (1869) We are the Northmen of the New World: A Lecture delivered before the Montreal Literary Club, March 31st, 1869, Montreal

Halliday, W.E.D., (1937) "A Forest Classification for Canada," in Forest Service Bulletin 89. Ottawa: Department of Mines and Resources

---, (1939) "Forest Regions of Canada: Their Distribution and Character," Canadian Geographic Journal 14 (4): 229-243

Haraway, Donna, (1991) Simians, Cyborgs and Women: A Reinvention of Nature. London: Routledge

---, (1992) "The Promises of Monsters: A Regenerative Politics for Inappropriate/d Others," in Cultural Studies, eds. L. Grossberg, C. Nelson and P.A. Treichler, pp. 295-337. New York: Routlege

Hardt, Michael and Antonio Negri, (2000) Empire. Cambridge: Harvard University Press

Harris, Cole R., (1997) The Resettlement of British Columbia: essays on colonialism and geographic change. Vancouver: University of British Columbia Press

---, (2002) Making Native Space. Vancouver: University of British Columbia Press

Harvey, David, (1974) "Population, Resources and the Ideology of Science," Economic Geography 50: 256-277

---, (1990) The Condition of Postmodernity. Cambridge: Blackwell

--, (1996) Justice, Nature and the Geography of Difference. Oxford: Blackwell Publishers

Hays, Samuel P., (1959) Conservation and the Gospel of Efficiency: The Progressive Conservation Movement 1890-1920. Cambridge: Harvard University Press

Hayter, Roger and Trevor J. Barnes, (2001) "Canada's Resource Economy," The Canadian Geographer 45 (1): 36-41 
Henry, J. David, (2002) Canada's Boreal Forest. Washington: Smithsonian Institution Press

Hobbes, Thomas, (1660) Leviathan. London: Penguin Classics

Hodgins, Bruce, (1988) "Canoe Irony," in Canexus: The Canoe in Canadian Culture, eds. J. Raffan and B. Horwood, pp. 45-57. Toronto: Betegeuse Books

Hodgins, Bruce and Jamie Benidickson, (1989) The Temagami Experience: Recreational Resources and Aboriginal Rights in the Northern Ontario Wilderness. Toronto: University of Toronto Press

Hodgins, Bruce W. and Margaret Hobbs, eds., (1985) Nastawgan: The Canadian North by Canoe and Snowshoe. Toronto: Betelgeuse

Howlett, Michael and Jeremy Rayner, (2001) "The Business and Government Nexus: Principle Elements and Dynamics of the Canadian Forest Policy Regime," in Canadian Forest Policy: Adapting to Change, ed. M. Howlett. Toronto: University of Toronto Press

Hulan, Renee, (2002) Northern Experience and the Myths of Canadian Culture. Montreal-Kingston: McGill-Queen's University Press

Hunter, Andrew, (2002) "Mapping Tom," in Tom Thomson, eds. D. Reid and C.C. Hill. Toronto-Ottawa: Art Gallery of Ontario, National Gallery of Canada and Douglas and McIntyre

Intergovernmental Panel on Climate Change, (2000) Land Use, Land-Use Change and Forestry. Cambridge: Cambridge University Press

Jaimet, Kate, (2003) "MP Finds Fault with Deal to Save Old Forest," in The Vancouver Sun, pp. A8. Vancouver

Jasen, Patricia, (1995) Wild Things: Nature, Culture, and Tourism in Ontario 1790-1914. Toronto: University of Toronto Press

Jennings, John, Bruce W. Hodgins and Doreen Small, eds., (1999) The Canoe in Canadian Cultures. Toronto: Natural Heritage/Natural History

Keil, Roger and John Graham, (1998) "Reasserting Nature: Constructing Urban Environments After Fordism," in Remaking Reality, eds. B. Braun and N. Castree, pp. 100-125. London: Routledge

Kobayashi, Audrey and Linda Peake, (2000) "Racism out of Place: Thoughts on Whiteness and an Antiracist Geography in the New Millennium," Annals of the Association of American Geographers 90 (2): 392-403 
Kosek, Jake, (2002) The Political Life of Forests in Northern New Mexico. Ph.D. thesis. University of California, Berkeley, Berkeley. 349 pp.

---, (2004) "Purity and Pollution: Racial Degradation and Environmental Anxieties," in Liberation Ecologies: Environment, Development and Social Movements, eds. R. Peet and M. Watts, pp. 125-154. London: Routledge

Kuehls, Thom, (1996) Beyond Sovereign Territory. Minneapolis: University of Minnesota Press

Labatt, Lori and Bruce Littlejohn, eds., (1992) Islands of Hope. Toronto: Firefly

Lee, Peter, (2004) Boreal Canada: State of the Ecosystem, State of Industry, Emerging Issues, and Projections: Report to the National Roundtable on the Environment and the Economy, Global Forest Watch Canada, Edmonton

Lefebvre, Henri, (1991) The Production of Space. Oxford: Blackwell Publishing

Lehtinen, Ari Aukusti, Jacob Donner-Amnell and Bjørnar Sæther, eds., (2004) Politics of Forests: Northern Forest-Industrial Regimes in the Age of Globalization. Burlington: Ashgate

Lomborg, Bjorn, (2001) The Skeptical Environmentalist: Measuring the Real State of the World. Cambridge: Cambridge University Press

Loo, Tina, (2001) "Making a Modern Wilderness: Conserving Wildlife in TwentiethCentury Canada," The Canadian Historical Review 82 (1): 92-121

Luke, Timothy, (1995) "On environmentality: geo-power and eco-knowledge in the discourses of contemporary environmentalism," Cultural Critique Fall: 57-81

---, (2003) "On the Political Economy of Clayoquot Sound: The Uneasy Transition from Extraction to Attractive Models of Development," in A Political Space: Reading the Global Through Clayoquot Sound, eds. W. Magnusson and K. Shaw. Minneapolis: University of Minnesota Press

Lynch, Wayne, (2001) The Great Northern Kingdom: Life in the Boreal Forest. Markham: Fitzhenry and Whiteside

Mackey, Eva, (2002) The House of Difference: Cultural Politics and National Identity in Canada. Toronto: University of Toronto Press

Magnusson, Warren and Karena Shaw, eds., (2003) A Political Space: Reading the Global Through Clayoquot Sound. Minneapolis: University of Minnesota Press

Manning, Erin, (2003) Ephemeral Territories: Representing Nation, Home and Identity in Canada. Minneapolis: University of Minnesota Press 
Massey, Doreen, (1999) Power Geometries and the Politics of Space-time. Heidelberg:

Department of Geography, University of Heidelberg

McClintock, Anne, (1995) Imperial Leather: Race, Gender and Sexuality in the Colonial Contest. New York: Routledge

Merchant, Carolyn, (1996) "Reinventing Eden: Western Culture as a Recovery Narrative," in Uncommon Ground: Rethinking the Human Place in Nature, ed. W. Cronon. London: W. W. Norton and Company

---, (2004) Reinventing Eden: The Fate of Nature in Western Culture. London: Routlege

Miller, Chad, (1992) "Wooden Politics: Bernard Fernow and the Quest for a National Forest Policy 1876-1898," in The Origin of the National Forests, ed. H.K. Steen. Durham: Forest History Society

Mitchell, Timothy, (1998) "Fixing the Economy:," Cultural Studies 12 (1): 82-101

Montaigne, Fen, (2002) "The Great Northern Forest," National Geographic Magazine, 201(6). June

Moore, Donald, Jake Kosek and Anand Pandian, eds., (2003) Race, Nature and the Politics of Difference. New York: Duke University Press

Morantz, Alan, (2002) Where is Here?: Canada's Maps and the Stories They Tell. Toronto: Penguin

Morse, Bradford, Jamie Benidickson, Stewart Elgie, Ryan Flewelling, Melanie Mallet and Kenny Loon, (2005) Aboriginal Issues in Canada's Boreal Forest, National Roundtable on the Environment and the Economy, Ottawa

Morton, William, (1961) The Canadian Identity. Madison: University of Wisconsin Press

Nash, Catherine, (2000) "Performativity in Practice: Some Recent Work in Cultural Geography," Progress in Human Geography 24 (4): 653-664

Nash, Roderick, ed. (1970) The Call of the Wild: 1900-1916. New York: George Braziller

---, (1982) Wilderness and the American Mind. New Haven: Yale University Press

National Aboriginal Forestry Association, (2005) "Boreal News \& Aboriginal Views." Ottawa: National Aboriginal Forestry Association

National Roundtable on the Environment and the Economy, (2003) Securing Canada's Natural Capital: A Vision for Nature Conservation in the 21st Century, National Roundtable on the Environment and the Economy, Ottawa 
---, (2005) Boreal Futures: Governance, Conservation and Development in Canada's Boreal, National Roundtable on the Environment and the Economy, Ottawa

Nelles, H. Vivian, (1974) The Politics of Development: Forests, Mines and Hydroelectric Power in Ontario, 1849-1941. Toronto: Macmillan of Canada

Nelson, Richard K., (2005) "Where the Wolf Stood," Trust Magazine, August, http://www.pewtrusts.com.

Neumann, Roderick, (1998) Imposing Wilderness: Struggles Over Livelihood and Nature Preservation in Africa. Berkeley: University of California Press

Newman, Peter C., (1985) Company of Adventurers. New York: Viking

NRTEE, (2003) Securing Canada's Natural Capital: A Vision for Conservation in the 21st Century, National Roundtable on the Environment and the Economy, Ottawa

O'Connor, James, (1994) "Is Sustainable Capitalism Possible?," in Is Capitalism Sustainable? Political Economy and the Politics of Ecology, ed. M. O'Connor, pp. 152-175. London: The Guilford Press

Olwig, Kenneth Robert, (1993) "Sexual Cosmology: Nation and Landscape at the Conceptual Interstices of Nature and Culture; Or What Does Nature Really Mean?," in Landscape: Politics and Perspectives, ed. B. Bender, pp. 307-343. Berg: Oxford

Peet, Richard and Michael Watts, eds., (1996a) Liberation Ecologies: Environment, Development and Social Movements. London: Routledge

---, (1996b) "Liberation Ecology: Development, Sustainability, and Environment in an Age of Market Triumphalism," in Liberation Ecologies: Environment, Development and Social Movements, eds. R. Peet and M. Watts. London: Routeldge

---, eds., (2004) Liberation Ecologies: Environment, Development and Social Movements (2nd Edition). London: Routledge

Poster, Mark, (1989) Critical Theory and Poststructuralism. Ithaca: Cornell University Press

Pratt, Mary Louis, (1992) Imperial Eyes: Travel Writing and Transculturation. London: Routledge

Prudham, W. Scott, (2005) Knock On Wood: Nature as Commodity in Douglas-Fir Country. London: Routledge

Raffan, James, (1990) Summer North of Sixty: By Paddle and Portage Over the Barren Lands. Toronto: Key Porter Books 
---, ed. (2004) Rendezvous with the Wild: The Boreal Forest. Erin: Boston Mills Press

Raffan, James and Bert Horwood, eds., (1988) Canexus: The Canoe in Canadian Culture. Toronto: Betelgeuse Books

Rayburn, Alan, (2001) Naming Canada: Stories About Canadian Place Names. Toronto: University of Toronto Press

Robbins, Paul, (2002) "Letter to the Editor: Obstacles to a First World Political Ecology? Looking near without looking up," Environment and Planning A 34 (8): 15091513

Robinson, Eric and Henry Bird Quinney, (1985) The Infested Blanket: Canada's Constitution - Genocide of Indian Nations. Winnipeg: Queenston House Publishing

Rodgers, Andrew Denny, (1951) Bernard Edward Fernow: The Story of North American Forestry. Durham: Forest History Society

Ross, Nicola, (2004) "Carbon Sinks, Forest Rises," Alternatives Journal 30 (3): 8-12

Said, Edward, (1979) Orientalism. New York: Vintage Books

---, (1994) Culture and Imperialism. New York: Vintage Books

Sandberg, L. Anders, Nicolas Houde and Patrick Lavoie, (2004) "Beyond L'Erreur boréale: The forest industry, environmentalism and image production in Québec, Canada," in The Politics of Forests: Northern Forest Industry Regimes in the Age of Globalization, eds. A.A. Lehtinen, B. Sæter and J. Donner-Amnell. Aldershot: Ashgate

Sandilands, Catriona, (1999a) "Domestic Politics: Multiculturalism, Wilderness and the Desire for Canada," Space and Culture 4 (5): 169-186

---, (1999b) "Sex at the Limits," in Discourses of the Environment, ed. E. Darier. Oxford: Blackwell Publishers

,--- (2003) "Between the Local and the Global: Clayoquot Sound and Simulacral Politics," in A Political Space: Reading the Global Through Clayoquot Sound, eds. W. Magnusson and K. Shaw. Minneapolis: University of Minnesota Press

,--- (2005) "Where the Mountain Men Meet the Lesbian Rangers: Gender, Nation and Nature in the Rocky Mountain National Parks," in This Elusive Land: Women and the Canadian Environment, eds. M. Hessing, R. Raglon and C. Sandilands. Vancouver: University of British Columbia Press

Sandlos, John, (2001) "From the Outside Looking In: Aesthetics, Politics and Wildlife Conservation," Environmental History 6 (1): 6-31 
Savage, Candace, (2004) "The Singing Forest: Why Billions of Birds Need Canada's Boreal Forest," Canadian Geographic, 124(1)

Sawyer, Suzana and Arun Agrawal, (2000) "Environmental Orientalisms," Cultural Critique 45 (7): 77-108

Scott, Dayna Nadine, (2000) "Carbon Sinks and the Preservation of Old-Growth Forests under the Kyoto Protocol," Journal of Environmental Law and Practice 10: 105145

Seltzer, Mark, (1992) Bodies and Machines. London: Routledge

Seton, Ernest Thompson, (1921) The Book of Woodcraft and Indian Lore. Garden City: Page

Shapiro, Michael, (1999) "Triumphalist Geographies," in Spaces of Culture: City, Nation, World, eds. M. Featherstone and S. Lash, pp. 159-174. London: Sage Piblications

Shields, Rob, (1991) Places on the Margin: Alternative Geographies of Modernity. London: Routledge

Sierra Club of Canada, (2003) Forests, Climate Change and Carbon Reservoirs: Opportunities for Forest Conservation, Sierra Club of Canada, Ottawa

Singer, Linda, (1993) Erotic Welfare: Sexual Theory and Politics in the Age of the Epidemic. New York: Routledge

Skelton, Isabelle, (1921) "The Name Canada," Canadian Magazine for Politics, Science, Art and Literature: $312-314$

Smith, Neil, (1984) Uneven Development: Nature, Capital and the Production of Space. Oxford: Blackwell

---, (1998) "Nature at the Millenium: Production and Re-enchantment," in Remaking Reality: Nature at the Millenium, eds. B. Braun and N. Castree. London: Routledge

---, (2003) American Empire: Roosevelt's Geographer and the Prelude to Globalization. Berkeley: University of California Press

Spivak, Gayatri Chakravorty, (1974) "Translators Preference," in On Grammatology, ed. J. Derrida. London: Johns Hopkins University Press

---, (1993) Outside in the Teaching Machine. New York: Routledge

Suzuki, David, (2003) "Canada's Amazon: A Boreal Forest Journey," in The Nature of Things. Toronto: Canadian Broadcasting Corporation 
Swyngedouw, Erik, (2004) Social Power and the Urbanization of Water: Flows of Power. Oxford: Oxford University Press

Taiga Rescue Network, (2002) "Stewart Elgie in the Hot Seat," Taiga-News: Newsletter on Boreal Issue: Taiga Rescue Network Summer 2002 (40)

Taylor, Charles, (1984) "Foucault on Freedom and Truth," Political Theory 12 (2): 152183

Taylor, Nicholas and Mira Spivak, (1999) Competing Realities: The Boreal Forest at Risk, Government of Canada: Standing Senate Committee on Agriculture and Forestry, Ottawa

Thrift, Nigel, (2004) "Performance and Performativity: A Geography of Unknown Lands," in A Companion to Cultural Geography, eds. J. Duncan, R. Schein and N. Johnson, pp. 121-136. Oxford: Blackwell

Thrift, Nigel and Steve Pile, eds., (1995) Mapping the Subject: Geographies of Cultural Transformation. London: Routledge

Turner, R. Kerry, (1995) "Environmental Economics and Management," in Environmental Science for Environmental Management, ed. T. O'Riordan. Harlow: Longman Scientific and Technical

Turner, Victor, (1969) The Ritual Process: Structure and Anti-structure. Ithaca: Cornell University Press

von Mirbach, Martin, (2004) "Setting the Standard," Alternatives, 30(3)

Wainwright, Joel, (2005) "The Geographies of Political Ecology: After Edward Said," Environment and Planning A 37 (6): 1033-1043

Walling, H.F., (1875) "Tackabury's Atlas of the Dominion of Canada." Montreal: G.N.Tackabury

Wapner, Paul, (2002) "The Sovereignty of Nature? Environmental Protection in a Postmodern Age," International Studies Quarterly 46 (2): 167-187

West, Douglas A., (1991) "Re-searching the North in Canada: A Introduction to the Canadian Northern Discourse," Journal of Canadian Studies 26 (2): 108-199

Wildlands League and Ontario Nature, (2005) Remote Tourism Sells: A Report on Resource-based Tourism in Northwestern Ontario, Wildlands League and Ontario Nature, Toronto

Willems-Braun, Bruce, (1997) "Buried Epistemologies: The Politics of Nature in (Post)colonial British Columbia," Annals of the Association of American Geographers 87 (1): 3-31 
Worster, Donald, (2002) "Wild, Tame and Free: Comparing Canadian and U.S. Views of Nature," in Parallel Destinies: Canadian and American Relations West of the Rockies, eds. J.M. Findlay and K.S. Coates. Montreal and Kingston: McGillQueen's University Press

Xenos, Nicholas, (1989) Scarcity and Modernity. London: Routledge

Zimmermann, Erich, (1951) World Resources and Industries: A Functional Appraisal of the Availability of Agricultural and Industrial Materials. New York: Harper \& Brothers. (Revised) 